Cultivating Dynamic
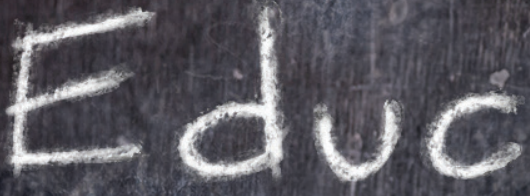

a

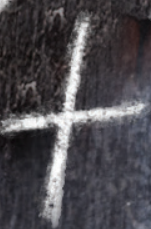

o

Case Studies in Teacher Behavior Change in Africa and Asia

Edited by Sarah Pouezevara

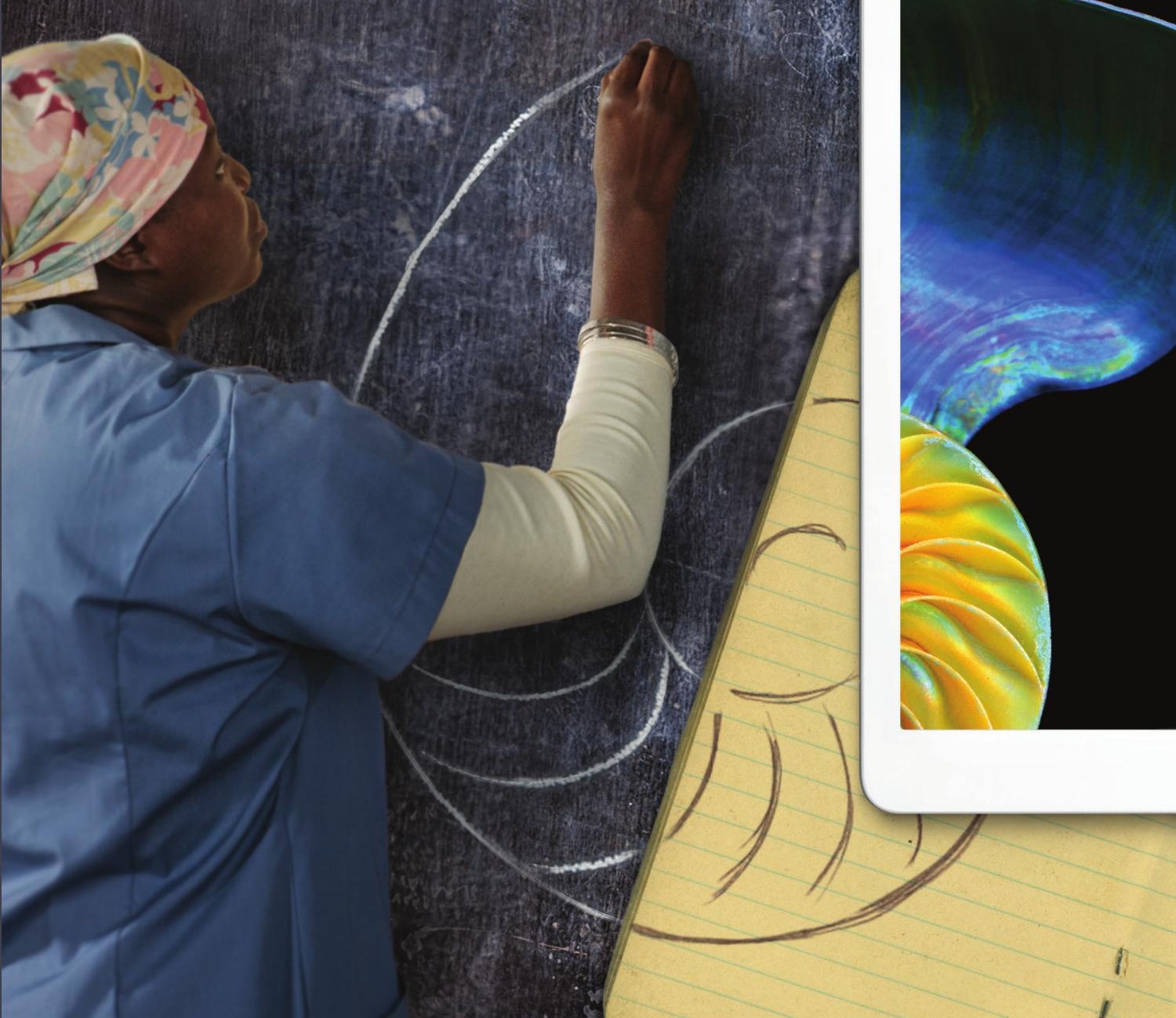





\title{
Cultivating Dynamic Educators: Case Studies in Teacher Behavior Change in Africa and Asia
}

\author{
Edited by
}

Sarah Pouezevara 
(c) 2018 Research Triangle Institute. RTI International is a registered trademark and a trade name of Research Triangle Institute. The RTI logo is a registered trademark of Research Triangle Institute.

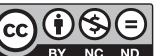

This work is distributed under the terms of a Creative Commons Attribution-NonCommercial-NoDerivatives 4.0 license (CC BY-NC-ND), a copy of which is available at https://creativecommons.org/licenses/by-nc-nd/4.0 /legalcode.

Library of Congress Control Number: 2018959618

ISBN 978-1-934831-22-9

(refers to print version)

RTI Press publication No. BK-0022-1809

https://doi.org/10.3768/rtipress.2018.bk.0022.1809

www.rti.org/rtipress

Cover design: Dayle Johnson
The RTI Press mission is to disseminate information about RTI research, analytic tools, and technical expertise to a national and international audience. RTI Press publications are peer-reviewed by at least two independent substantive experts and one or more Press editors.

RTI International is an independent, nonprofit research institute dedicated to improving the human condition. We combine scientific rigor and technical expertise in social and laboratory sciences, engineering, and international development to deliver solutions to the critical needs of clients worldwide.

This publication is part of the RTI Press Book series.

RTI International

3040 East Cornwallis Road, PO Box 12194

Research Triangle Park, NC 27709-2194, USA

rtipress@rti.org

www.rti.org 


\section{Contents}

Acknowledgments

1. Understanding and Influencing Teacher Behavior Change:

Editorial Introduction

Sarah Pouezevara

2. Changing Teacher Educators' Conceptions and Practices Around Literacy Instruction: Lessons from Teacher Educators' Professional Development Experiences in Ethiopia

Dawit Mekonnen, Marion Fesmire, Adrienne Barnes, Stephen Backman, and Flavia Ramos-Mattoussi

3. School Leadership and Early Grade Reading: Examining the Evidence in Zambia

Mitchell Rakusin and Guy Bostock

4. Making Sense of Teacher In-Service Training in the Philippines

Nancy Clark-Chiarelli and Bonita Cabiles

5. Short Message Service (SMS)-Based Remote Support and Teacher Retention of Training Gains in Malawi

Timothy S. Slade, Scott Kipp, Stirling Cummings, and Kondwani Nyirongo

6. Relationships Between Coach Support and Teachers' Adoption of New Instructional Practices: Findings from the Nigeria Reading and Access Research Activity (RARA)

Karon Harden, Alison Pflepsen, and Simon King

7. Using Activity Theory to Understand Teacher Peer Learning

in Indonesia

Sarah Pouezevara, Feiny Sentosa, and Tifa Asrianti

8. Teacher Motivation and Behavior Change: Results of the Teacher Motivation Diagnostic Tool in Northern India

Molly Hamm-Rodríguez, Emily Richardson, and Jarret Guajardo

9. Once More Up the Mountain: The Promise of High-Quality Teaching

Depends on Behavior Change

Lee E. Nordstrum

About the Contributors

Index 



\section{Acknowledgments}

This volume was made possible through a professional development award from RTI International; the book's editor and chapter authors also wish to recognize, with deep gratitude, the editorial and production support of Erin Newton (RTI) in compiling this volume. Also notably, portions of the editorial introduction were completed as part of the requirements for the Graduate Certificate in Adult Education at Portland State University, awarded to the editor in July 2017 under the same professional development award. The editor gratefully acknowledges the support of Dr. Andrew Job (Portland State University), Dr. Benjamin Piper (RTI), Dr. Matthew Jukes (RTI), and Jennae Bulat (RTI) for comments on early drafts. 



\title{
Understanding and Influencing Teacher Behavior Change: Editorial Introduction
}

\author{
Sarah Pouezevara
}

\section{Introduction}

\section{Problem Statement}

Across the world, governments are embarking on ambitious reforms to improve education systems, often through international donor funding and incentives for education reform at local, subnational, and national levels. Examples of reforms include

- instituting or enforcing policies to implement programs that use mother tongues as the language of instruction in early primary school (e.g., Ethiopia, Uganda, the Philippines);

- expanding government provision of free basic education (e.g., from 10 to 12 years in the Philippines); or

- introducing a thematic structure to the curriculum or revising the methodology for reading instruction to include explicit, systematic instruction in the components of reading (e.g., Indonesia, Tanzania, Morocco, Ethiopia).

Such changes in curriculum and teaching practices require teachers to make significant shifts in their assumptions regarding how children learn and to revise their day-to-day classroom pedagogical methods. It therefore follows that a significant proportion of donor or national reform project funds and human resources are dedicated to in-service teacher professional training on the new content and methods. 
The release of the 2016 Sustainable Development Goals (SDGs), ${ }^{1}$ and specifically Goal 4, to "ensure inclusive and equitable quality education and promote lifelong learning opportunities for all" aims to "substantially increase the supply of qualified teachers, including through international cooperation for teacher training in developing countries, especially least developed countries and small island developing States" (United Nations, n.d.). ${ }^{2}$ Although the mechanisms to engender teacher change differ by context, Bold and colleagues (2017) reported that for teachers to improve learning, they must master the curriculum and learn to apply it to the particularities of the children in their classrooms.

That said, finding, recruiting, deploying, and retaining teachers with basic mastery of the curriculum can be a challenge in many places. Teachers may be recruited with fewer than 12 years of basic education, and teacher preparation programs may be of modest duration and quality (see, for example, the Ethiopia chapter of this volume, in which the authors point out that teachers are recruited from the pool of individuals who received the lowest marks on a grade 10 exit exam and were therefore considered unqualified for higher education). Furthermore, finding the resources to keep teachers' knowledge and skills current can be even more complex. This challenge is especially present in rapidly changing contexts with diverse populations, evolving labor markets that change the skills students need to succeed beyond school, and more competing employment options for would-be teachers.

The scale at which donor programs are attempting to influence instructional behaviors is increasing. For example, the United States Agency for International Development's (USAID’s) 2010-2015 Education Strategy Progress Report noted that its programs were training 450,000 teachers annually, on average (USAID, n.d.). Although the authors could not find a baseline figure of the number of teachers reached through training, the same report stated that the number of basic education programs increased from 48 in 2011 to 123 in 2015; thus, it is logical to assume that teacher-training activities also increased substantially. Based on the

1 The SDGs, spearheaded by the United Nations, are part of a continued attempt to frame a concerted effort at reducing poverty, improving the condition of the planet, and promoting global prosperity over the next 15 years. The SDGs consist of 17 goals and 169 targets that governments, institutions, and individuals can use as a guide to measure the impact of their country-level policies and programs.

2 Consistent with the SDGs, we use the term "developing country" throughout this book. We recognize, however, that each context is unique, and the primary shared characteristic across the case studies and other referenced literature is that the countries engage in international financial cooperation to achieve ambitious education reform goals. 
national or large-scale reforms in Malawi, Ethiopia, Tanzania, and Uganda, among others, in which RTI International has been involved, the authors can attest to the technical, managerial, and logistical challenges that any mode of training presents, given the sheer number of teachers to support and, more importantly, classroom practices to affect. In Kenya, for example, more than 100,000 grades 1-3 teachers and head teachers had been trained under the Tusome literacy program by the end of its third year. In a given month, as many as 16,000 instructional coaching visits may take place (Piper, Oyanga, Mejia, \& Pouezevara, 2017).

The challenge of how best to train teachers is not new. For as long as there have been programs to support education systems, teacher training has been a necessary component. However, the low levels of student achievement shown by any number of national, regional, or international standardized tests suggest that more-or different-professional development opportunities are needed. Moreover, although effective teacher training and support strategies exist, they are usually found at a small scale. Thus, one must ask an important question in meeting today's demand for more and better-quality teaching in most low-resource contexts: How can changes in teacher behavior be facilitated effectively, at scale, using existing systems?

Although this book only scratches the surface of this important question, the authors describe a range of efforts to understand what works in improving teaching behaviors in developing countries as well as why, and in some cases, at what costs. The chapter authors in this book explore approaches to professional development across a teacher's career span, from pre-service to ongoing professional development and informal learning communities. In doing so, they suggest an approach to "more" and "different" teacher professional development that ensures lifelong and career-wide continuous professional improvement for educators.

\section{About This Book}

The diversity of the contexts included in this book is substantial-from fiercely independent Ethiopia, to the religious and geographic complexities of Nigeria, the diverging paths of neighboring Zambia and Malawi, the rapid growth of Kenya and the roaring economic growth of India, and the geographically vast island nations of the Philippines and Indonesia. As much as the geographies of these countries are different, so are their histories, their cultures, and the way their education systems have evolved from the colonial period, to post-colonial euphoria, to modern civil service structures. 
Yet there are also similarities, which include the difficulties of recruiting and retaining high-quality teachers in rural areas and coping with the language of instruction used at particular levels of the system. The chapter authors describe efforts, as well as technical support from international and local nongovernmental organizations, by international donors and by national and regional governments to achieve the ambitious targets outlined in the SDGs and national educational policies. The authors also portray the methods, and often the challenges, of measuring the effectiveness of specific activities designed to influence teacher behavior change. Finally, they illustrate the influence of context as well as the need for collaboration across the education system to support and motivate teacher learning and prepare them for the challenges they face in the classroom.

The desire to compile a book covering so many different aspects of teacher professional development came about because RTI, as a research institute, is deeply committed to continuous improvement and application of evidencebased approaches. Furthermore, as a nonprofit organization, RTI continually reinvests earnings into improvement. This investment includes substantial resources for internally funded research and product development. Between 2013 and 2016, its International Education Division benefited from such internal funding to systematically review methods and approaches to instructional coaching and other forms of professional development of the teachers in RTI's programs.

At the same time, several staff received individual awards to pursue research, coursework, and product development in areas of individual interest. The topics under investigation through these mechanisms covered adult learning theory and practice, instructional coaching, school leadership, and technology in education in developing countries. Each study clearly fit within a larger, systemic view of these various entry points to supporting teacher change, but none emerged as the only or best way to support teachers.

As such, it seemed valuable to present all of the case studies under one cover, to be considered together, rather than each in separate publications. In this way, planners can refer to one reference document covering a variety of options at once as a "road map" of sorts to the unique considerations, advantages, and challenges of each modality. Moreover, presenting the case studies together emphasizes their interrelatedness and interdependencies and may encourage planners to consider more integrated approaches. 
Because of the way the book originated, the case studies are derived largely, but not exclusively, from work carried out by RTI. In striving to understand what works, it was important for the authors to look outside their own sphere of activity and learn what others were doing as well. A request for contributions to the book was made in various settings, including an interinstitutional affinity group that emerged around instructional coaching after the 2016 Comparative and International Education Society conference and among the Teacher Motivation Working Group convened by Save the Children, USA, which also includes a range of academic and nonprofit researchers and practitioners. In some cases, the editor also reached out directly to individuals who were implementing specific teacher behavior-change approaches that would fill a gap in the areas that RTI was actively researching.

Ultimately, the chapters selected for this volume were those that could be completed within the publication schedule and that would provide insight into various points of teachers' careers. Most of the chapter authors discuss programs designed to influence teacher behaviors specific to reading instruction in early primary school, consistent with USAID's strategy. However, the intent was not to compile a book about reading instruction, and we believe that the methods and approaches described are applicable to other subject areas as well.

This volume is certainly not a comprehensive compendium of all of the influences on a teacher's knowledge and behaviors. A full picture might also include how teachers' own primary education experiences influence their teaching practice; how classroom infrastructure and resources-including teachers' guides-influence teaching behavior (Piper, Sitabkhan, Mejía, \& Betts, 2018); and what the impacts are of a range of other policy mechanisms and incentives, including the professional career ladder for teachers. Another volume could be written on the influences of cultural norms across different societies and the way they affect mindsets, risk-taking, power relations, and self-efficacy of teachers. Lee Nordstrom tackles this issue to some extent in the concluding chapter (Chapter 9).

This introductory chapter provides an overview of the methods used in and collective findings from the cases described in the following chapters. It also offers some alternative theoretical directions for further exploration of lifelong learning focused on continuous improvement and development of professional expertise. A concluding chapter summarizes the theoretical perspectives on behavior change and how these chapters fit into a behavioral model. 


\section{Researching Teacher Behavior Change \\ Understanding How to Influence Change}

The title of this chapter orients the work toward both process

("understanding”) and outcomes ("influencing”). Most of the chapter authors discuss examples of continuous monitoring and evaluation or research taking place in the context of program implementation. These programs-almost all USAID-funded-have had predetermined outcomes, targets, and participants. The ability to conduct rigorous, controlled research in these circumstances requires significant lead time and cooperation from the implementing program. RTI and others have engaged in this type of research in the past; in fact, the Nigeria chapter is based on the secondary analysis of a data set from a controlled pilot experience. However, such opportunities are rare; more common is learning what is working over the course of the program and adjusting along the way. The line between research and evaluation becomes blurred in these cases, and our ability to say with certainty what works and what doesn't in one context-much less what can be generalized or replicated in another context-is mired in the complexity of human behavior, generally, and the limits of program implementation, specifically.

Therefore, the collection of case studies is also valuable to the extent that each chapter describes processes in which practitioners have engaged to critically evaluate program approaches. A variety of different approaches is described, and some findings are more conclusive than others. Nonetheless, currently so little evidence of any kind is available outside of gray literature (such as project reports) about teacher behavior change in developing countries - and about how to evaluate what works - that we hope this book contributes to filling that gap. The types of research approaches found in this volume are described next.

\section{Survey Research and Descriptive Studies}

The example from India describes the background, implementation, and results of a survey instrument that can be used to gather information about the sources of teachers' motivation. This tool can help implementers understand the context before or during implementation of any teacher support program. With this information, they are more prepared to be responsive to the realities of the teaching context, or its use could be incorporated into research or evaluation to help explain findings. The 
Philippines chapter describes the elements of a teacher-training model that is part of a reading program that is showing positive results, but the researchers were unable to conclusively isolate the effect of the training model on the overall outcomes because of the program's many overlapping components. This situation is similar to that of the Indonesia case study, in which the peer-learning component is just one aspect of a program that is showing overall positive results. Thus, the goal is less about proving that the model has had an impact so it can be adopted elsewhere and more about understanding what about the model works in that context so that other programs can make an informed choice about adapting it.

In Ethiopia, the authors used questionnaires, focus groups, and interviews to examine the contributions of materials and training to teachers' practices and to understand what factors positively or negatively affected implementation. While the methods and instruments could certainly be replicable in another country, the pre-service training program was tailored to the Ethiopian context. The goal was as much formative evaluation designed to adjust and improve along the way as it was to draw conclusions about the approach at the end.

\section{Experimental Studies}

The program described in the Zambia chapter stands out as one of the most rigorous and deliberate research designs investigated. Although the population of interest was involved in an international cooperation program, the study did not depend upon implementation of the program, was funded separately, and was designed to answer specific questions empirically. The Indonesia case study was also designed and funded independently of the program but targeted a specific population of interest. That population consisted of the beneficiaries of a USAID-funded program to support teacher learning through peer communities of practice. Unlike Zambia, the research questions in Indonesia were very much linked to understanding how and why the communities functioned as they did. The judgment that the communities functioned well and contributed to overall learning outcomes was an a priori assumption based on program implementation.

In Malawi, the team implementing the USAID Early Grade Reading Activity, in the course of regular program implementation, decided to evaluate the effectiveness of a training workshop using pre- and post-tests. At the suggestion of a team that had received RTI research funding, they built on this opportunity to test a model of follow-up training support using telephone 
text messaging. Although they set up different groups to act as control and implementation, the context was such that maintaining strict implementation fidelity and eliminating all other influences on the groups proved difficult. Was this research or evaluation of the feasibility of a specific product or service, or perhaps a bit of both? Ultimately, although the effort in detecting effects from the text messaging campaign was not successful, the chapter provides details about the costs and implementation considerations for such an effort, which makes it an important contribution to the field.

\section{Secondary Analysis of Data}

The Nigeria chapter represents an attempt to glean more information from an existing data set. In this case, the data came from a pilot program that gathered a considerable amount of information at baseline, during program implementation, and at endline to measure the impact of the approach to train teachers on a new reading instruction method using instructional coaching. The authors attempted to use that information to answer additional questions about the influence of coach characteristics.

All of the cases described in this book drew on background literature to inform the approach, but the goal was not necessarily to conduct original research designed to fill a gap in the empirical literature. The goal of any program like the ones described in this volume always is to deliver the best possible services during implementation in a particular context and learn lessons that can be considered for other contexts in the future. For this reason, although some of the chapter authors' findings were somewhat inconclusive relative to the research questions, publishing them is still valuable because every such effort brings us incrementally closer to understanding some aspect of teacher behavior change as well as understanding our own processes of learning what works and why.

\section{Influencing Professional Development: What Have We Found?}

Although the editor and chapter authors recognize that the level of precision with which we can say "what works" is limited in these complex environments, nonetheless, lessons can be learned through the work presented in this volume. The concluding chapter summarizes some of these key takeaways. In addition, and by way of framing the purpose of this volume, we return to the notion of the larger picture of the teaching career span. One lesson we hope that this volume communicates is that teacher behavior change is subject to multiple and competing influences and there are no easy, single solutions. 
Figure 1-1. Career-wide influences on teachers' career preparation and learning

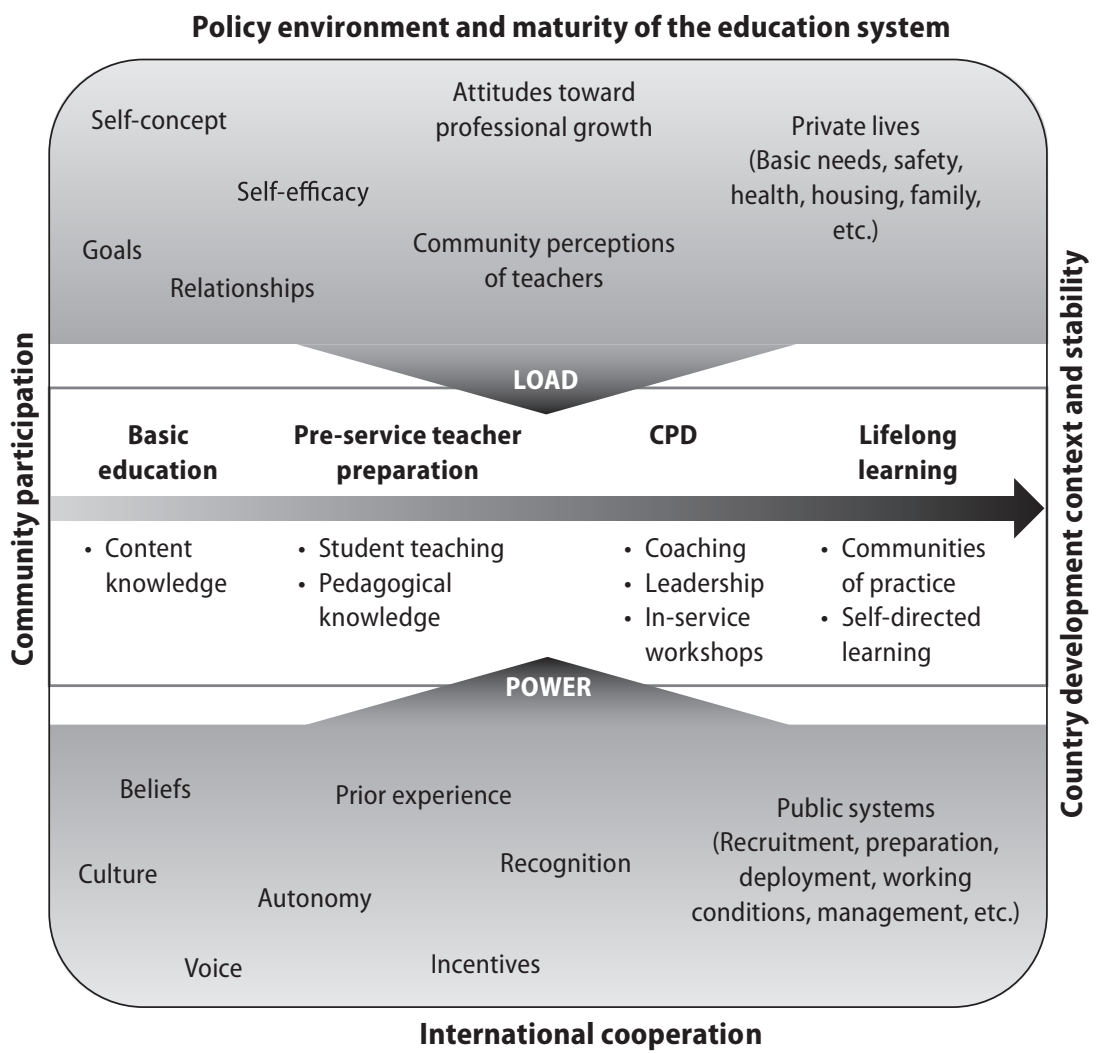

$\mathrm{CPD}=$ continuing professional development.

Figure 1-1 illustrates some of the influences surrounding teachers as they move through their career. Yet what many of the chapters in this volume emphasize is that education-sector programs need to work at the level of those surrounding influences for lasting change and that every intervention needs to be combined with some type of follow-up, in essence extending its influence among all teaching-career stages. The following section explains in more detail, with reference to the Figure 1-1 diagram.

\section{Learning over the Course of the Teaching Career}

Teacher behavior change is a process (Guskey, 1986, 2002), and successful programs target particular behaviors at specific times with particular 
interventions. A career-wide view of learning recognizes that influences on teaching behavior originate indirectly when the teacher is a student. They continue more directly during formal pre-service teacher preparation and certification-if the individual has been required to complete one. The format, duration, and quality of such programs vary considerably from country to country, but in many places, to address shortages, contractual or community-sourced teachers may be recruited even if they have no prior teacher education. This situation tends to occur most in rural areas (Kruijer, 2010; Nordstrum, 2015).

Next, a teacher may benefit from in-service professional development programs, instructional coaching, and school-based support. Evidence of the positive impact of instructional coaching in developing and developed countries alike is increasing (Kraft, Blazar, \& Hogan, 2018; Piper \& Zuilkowski, 2015). Yet less often recognized are the range of system-wide support structures that are required for improved teacher performance until retirement. A career-wide view of professional development takes the position that even well-designed short-term "minimum pedagogical training" (as per the SDG 4) is rarely enough to fully arm teachers. They need skills to teach better, to adapt to changes in curriculum, to change pedagogical methods in the face of shifting student demographics, and to adapt to pupils' language and learning needs. Finally, they must be able to learn and integrate ever-new technologies in ever-improving pedagogical methods. This is why we refer to cultivating dynamic - as opposed to static-educators in the title of this volume.

The chapters in this volume cover many, though not all, of these stages. The Ethiopia chapter was selected as one example of a program designed to improve pre-service education for reading instruction. This chapter focuses on the instructional change of teacher educators, who are tasked with influencing the teaching behaviors of future teachers. The authors concluded that student teachers are not the only ones who need ongoing follow-up to ensure concepts are applied in the classroom: The teacher educators need ongoing support, too. Therefore, we are reminded that pre-service training is necessary, but not sufficient, for developing expertise in complex areas of teaching.

Several chapters of the book cover different modalities of ongoing support (i.e., post-certification training), including instructional coaching and workshops. The Philippines and Malawi chapters describe approaches to teacher-training workshops designed to impart new knowledge and skills related to changes in the curriculum. In both cases, the authors have 
emphasized the need to ensure that these workshops do not stand alone as isolated inputs but rather are deliberately associated with other elements of the program, including follow-up support for implementing training concepts and aligning with the teaching materials. Thus, we come to understand that workshops are an important forum for meeting other teachers and practicing new concepts, but that without follow-up at the school level, teachers may revert to their habitual methods.

The Zambia and Nigeria chapters also bolster the notion that follow-up support at the school level is critical. By using survey research and mining existing data, the authors of these two chapters tried to learn how the characteristics of instructional coaches (in Nigeria) and school leadership practices (in Zambia) influenced student outcomes, as mediated by teaching. The Nigeria study provides evidence that coaching works-the more frequently teachers are visited by a coach, the more their behavior changes. This chapter also brings us back to the notion that pre-service teacher preparation is an important source of influence on teachers and instructional coaches and that, as concluded in the Ethiopia chapter, considerable efforts should go into the recruitment, training, and support of instructional coaches if they are to influence teachers' behavior change.

The authors of the Zambia chapter noted that school leadership is a means to an end, to the extent that school leaders shape school culture, expectations, and relationships, including support for peer-to-peer collaborative learning. This was a key finding from the Indonesia chapter as well, which looked at how peer-learning networks functioned as a form of ongoing, school-based support. This study found that peer-learning networks could not operate without two other elements: strong incentives and an enabling environment created by school leaders and the larger policies of district and central governments.

In many chapters, though developed independently, the authors come up with related conclusions around the way in which teacher communities of practice emerge to support ongoing learning and skills application. The Ethiopia, Zambia, Philippines, and Indonesia chapter authors addressed this point explicitly, either as part of the underlying program design or in their conclusions. Still other chapter authors highlighted the social aspect of behavior change indirectly, for example, describing the way in which teachers voluntarily exchanged text messages in Malawi and, as a result, created their own informal communities of learning. Finally, the content of the India 
teacher motivation survey was precisely designed to gain insights into the larger social and contextual motivations that influence teachers before any professional development activities even begin.

The social nature of teaching and learning how to teach is related to a second underlying theme relevant to this volume: Teachers, as individuals, are also adult learners with their own unique needs and barriers to participation in professional development.

\section{The Teachers as Adult Learners}

Recognizing teachers as adults is the foundation of Knowles and Associates' (1984) concept of andragogy, which emphasizes ways in which learning in adulthood differs from learning in childhood. For example, Knowles and colleagues posited that learning must be relevant and immediately applicable for adults, who learn by processing new knowledge in comparison to previous knowledge and experience. In other words, whereas learning for children involves building their knowledge base, learning for adults requires transforming it. Such learning is done best in contexts in which adults are highly involved in the learning process and learning is task- and problemoriented rather than instructor-led and content-oriented. Social cognitivist learning theory also posits that human learning happens in a social environment involving reciprocity among learning, the person, and the environment (Merriam, Caffarella, \& Baumgartner, 2007).

Consistent with the theory of andragogy (Knowles \& Associates, 1984), teachers and teachers in training involved in the Indonesia, Philippines, and Ethiopia case studies preferred training programs that matched the contexts of their classrooms (i.e., were highly relevant) and provided information that was immediately applicable. Less appreciated were highly theoretical, instructor-led workshops that were disconnected from daily practice. The Philippines case study, drawing on Knowles and Associates, highlights how the content of training must be embedded in the reality of day-to-day practice. The authors called this "coherence" and extended the concept to emphasize that other stakeholders and other grade-level teachers also need to be well versed in the content, methods, and materials promoted through the education system and training opportunities.

A similar sentiment was expressed by teachers in Indonesia: Highly social, school cluster-based meetings supported cross-grade coherence by ensuring there were "no gaps" in student experiences because all teachers were well versed 
in the same pedagogies and content. In fact, the Basa Pilipinas program in the Philippines promoted coherence through a community-of-practice model, using Learning Action Cells in a way that was similar to how the PRIORITAS (Prioritizing Reform, Innovation, and Opportunities for Reaching Indonesia's Teachers, Administrators, and Students) program in Indonesia made use of gugus, or cluster teacher working groups. Through these local communities of practice, school leaders could disseminate new teaching innovations and engage teachers in reflection, action planning, materials design, and sharing of their own lessons (other countries and programs described in this book also have made use of school clusters and community-of-practice models in various ways, but they are not specifically highlighted in these case studies).

Whether organized formally or informally, between schools or using within-school networks, teacher professional development in these chapters involved some measure of collaboration and interaction. This engagement was designed to encourage teachers to transform their existing methods incrementally through cycles of practice, reflection, and feedback. According to andragogy and socially situated learning theories, in learning through observation and practice, the goal is not static imitation of expert behavior. Instead, it is a shift in cognition and behaviors that recognizes teachers' knowledge and experience and reshapes it through externally regulated tools. In this way, the learned behavior becomes locally relevant, feasible, and self-regulated (Feryok, 2009; Junor Clarke \& Fournillier, 2012). Nir \& Bogler (2008) concur that training programs that happen "on the job" are both relevant and immediately applicable and can bridge "the constantly expanding gap between teachers' previous studies and the developments taking place in the educational realm" (p. 383). Several studies in this book support the notion that these methods are particularly suitable for teacher professional development. This finding further emphasizes the need for a career-wide view of professional development planning.

Another important perspective on understanding adults as learners comes from acknowledging the many other influences in teachers' lives that affect their willingness and motivation to engage in learning opportunities or apply concepts from them. Two theories are particularly relevant here: Maslow's (1943) hierarchy of needs and McClusky's (1963) Theory of Margin. Both of these theories imply that certain basic needs must be fulfilled before an individual has the capacity (i.e., motivation, time, or cognitive resources) to 
take on new tasks such as professional learning. The hierarchy of needs outlined by Maslow begins with basic physiological needs (such as shelter, or salary in the case of teachers) and moves upward in complexity to security, social, esteem, and self-actualization needs. Maslow's theory emphasizes the need to meet adult learners at the stage they are in and to organize learning opportunities from a humanist perspective that helps foster personal growth in any of the stages.

McClusky (1963) added to this concept of a prioritization of needs by introducing the idea of the "margin", which is a ratio between "load"- the magnitude of life's demands (e.g., family, work, goals) - and the "power" one has to deal with those demands (e.g., resources, allies, knowledge). When one's "load" increases without a consequent increase in power, then limited "margin" is available to engage in new tasks, including professional learning. Therefore, either load must decrease or power must increase, as implied by the arrows in Figure 1-1. As summarized in the India chapter: "Teachers who live and work in low-income contexts often have heavy loads with limited power, leaving low capacity to take on new tasks" (p. 254). Some aspects of an individual's power load are also gathered through the Teacher Motivation Diagnostic Tool described in the India chapter. The Indonesia and Zambia chapters illustrate ways in which teachers' load can be decreased and power increased through school leadership policies and practices. This type of underpinning enables them to participate in learning opportunities.

\section{Summary and Future Directions}

The global objective of the SDGs is imperative for accelerating and improving teacher training in developing countries; the SDG 4 target, which is the most relevant to our focus on teacher change, is to "by 2030, substantially increase the supply of qualified teachers, including through international cooperation for teacher training in developing countries, especially least developed countries and small island developing States." The indicator associated with this goal sets the bar relatively low in terms of "lifelong learning," stated as the "proportion of teachers ... who have received at least the minimum organized teacher training (e.g. pedagogical training) pre-service or in-service required for teaching at the relevant level in a given country" (United Nations, n.d.). 
Given the complexity of teacher change, while this target is desirable in and of itself, we argue that it is unlikely on its own to be enough to significantly improve teaching and learning in developing countries, given its emphasis on "training." Instead, we propose taking a closer look at the notion of lifelong learning and suggest framing teacher behavior change as a much broader process of professional development that combines career-wide formal, informal, externally driven, and self-directed forms of learning.

\section{Self-Directed, Lifelong Learning}

In this book, in examining methods for influencing teacher behavior change, we conceptualize teachers as learners and, as such, explore whether the concept of lifelong learning cited in the SDG 4, if applied more explicitly to teachers' continuous professional development, could help amplify efforts to improve teaching in particular by encouraging more self-directed and peer learning. Lifelong learning is a somewhat ambiguous concept (Abiy, Kabeta, \& Mekonnen Mihiretie, 2014; Molla, 2010; Walters, Yang, \& Roslander, 2014) that means one thing in academic sectors but often quite another in international development literature. In the latter, it is often synonymous with "adult education" or is even more narrowly understood as adult literacy. The World Bank (2003), for example, defined a comprehensive program of lifelong learning as something that encompasses "all levels: early childhood development, primary, secondary, tertiary, and adult continuing education within the context of the overall development framework of each country" (p. iv), and characterized it as "a constant retooling and renewal of skills and knowledge required for effective participation in the ever-changing macroeconomic and labor market contexts" (p. 18).

Although few projects explicitly promote self-directed learning, Orr et al. (2013), in a systematic review of cost-effective strategies for teacher training, found that "three strategies of workshops, in-class support and independent study, used in combination, appear to be the most effective strategies" (p. 45). A more deliberate look at specific country-level education-sector and teacherdevelopment policies, where available, may identify whether the notion of self-directed lifelong learning can be used to support the expansion of informal professional learning as a norm.

An example of how continuous, self-directed learning can be applied to teachers comes from an Indonesia government task force that developed a teacher certification instrument that included teacher self-appraisal and peer 
appraisal as processes required by teachers to upgrade their certification. The policy for continuing professional development (CPD) states:

Continuing Professional Development activities may include selfdevelopment through: participation in training programs or peer events; preparation of scientific papers on the basis of relevant educational research or writing text-books, additional reading materials or teacher instruction guidance; the development of innovative creations such as applicable technologies, art work; the development or modification of teaching aids; and participation in the development of guidance books, test questions, etc. The key to CPD is a proactive attitude, with the majority of the development activities taking place at the school (30\%) and the school cluster (60\%) levels. School-based activities can include self study, including online study, observations, and peer discussion and mentoring. Cluster-based activities may include group discussions, experience sharing and visits to other schools. (Ministry of Education and Culture [Indonesia], 2013, p. 117)

These development activities, over time, connect with each other to contribute to professional learning across a career-level developmental trajectory. The same policy document outlines targets that classify teachers from "novice" level to "senior," by way of "junior" and "experienced" levels that are defined by specific improvement targets. However, as found in the course of interviews in Indonesia (see Chapter 7), it turned out that expectations for lifelong learning and methods of self-directed learning were not explicitly part of the pre-service program at one institution. It seems that these strategies and learning targets, if made more explicit, if supported through the system, and if recognized by tangible professional rewards, would contribute significantly to a culture of lifelong learning for teachers.

The idea of lifelong learning also finds resonance in the Ethiopia chapter, as the authors have emphasized "learning to learn" during pre-service. Yet at the policy level, in contrast to Indonesia, Ethiopia's Education Sector Development Plan for 2010-2015 (Federal Ministry of Education, Ethiopia, 2015) and a National Adult Education Strategy (Federal Ministry of Education, Ethiopia, 2008) remained silent on the theme of lifelong learning. The goal for adult education as described in these policy documents is related to alternative formal and nonformal opportunities to improve functional literacy and life skills (Abiy et al., 2014; Molla, 2010). 
Molla's analysis of the sector concluded that "lifelong learning as an educational organising principle is not in place ... the formal and the non-formal educational settings are not linked meaningfully and continuing learning possibilities for adults is not ensured" (pp. 19-20). Abiy et al. (2014) also noted that in Ethiopia, higher education is associated with certification and credentials, and so informal learning unassociated with these credentials may not be valued. They expressed the need for institutional reform that embeds "principles and practices of LLL [lifelong learning] both in curriculum development, and in teaching and learning practices" (p. 657).

We therefore encourage readers to consider whether more emphasis can and should be placed on preparing teachers to be more self-directed and, when possible, to build incentives and expectations for this into the teaching career span.

\section{Occupational Learning and Building Expertise}

Because most teacher behavior change (with the exception of pre-service training) involves on-the-job behaviors, certain lessons related to lifelong and career-wide learning can also be culled from occupational learning theories. For example, Herzberg's (1966) two-factor model, that of motivating and hygiene factors, is cited in the India chapter with respect to teacher motivation in terms of "job satisfaction." Motivating factors are largely intrinsic, such as recognition and personal growth, whereas hygiene factors are mostly extrinsic, such as job security and salary. Herzberg's (1966) key point is that a given set of hygiene factors may not increase satisfaction, but their absence will increase dissatisfaction (demotivation).

Motivation and hygiene factors were explored in the Teacher Motivation Diagnostic Tool used in India, but some of the other chapters and contexts allude to these factors as well and usefully remind us that change is about not just reinforcing the desirable but also eliminating or minimizing the undesirable. The Zambia chapter explores the ways in which school leadership affected teaching and learning by influencing the conditions in which teachers were working. In this way, teacher behavior change can be influenced both indirectly, through supportive conditions and leadership expectations rather than direct training, and directly, when instructional leadership practices are the norm. 
Also, as described in the Indonesia chapter, government and school-level policy and support provided a sense of security and removed barriers to participation in peer-learning activities, which allowed motivating factors to flourish. For example, when teachers had the resources they needed to support students, teaching improved and students expressed demand and satisfaction. These, in turn, fulfilled the teachers' sense of self-efficacy and motivation to participate in organized professional development. That is, they wanted to continue to better support the students and achieve their professional vocation as teachers. Indeed, in defining themselves as professionals and believing in their responsibilities, they gained the intrinsic motivation needed to be self-directed (as opposed to accepting a definition of "improvement" that was externally defined and imposed).

A related theoretical domain is that of building expertise, which examines how experts in a certain domain differ from novices and what steps they undertook to get to that stage. A thorough summary of all of the research in this field is beyond the scope of this introductory chapter; however, several important distinguishing features of expertise, as described by Hatano and Oura's (2003) review, are worth noting: (1) the acquisition of expertise is accompanied by changes in attitudes, values, and confidence; (2) the process of gaining expertise is assisted by other people; (3) expertise is distributed among people; and (4) expertise occurs in socioculturally significant contexts.

In particular, due to rapid shifts in technology, globalization, and demographic patterns, effective functioning today in most professional domains requires not just content and skills expertise but also adaptive expertise (World Bank, 2003). Originally coined by Hatano and Inagaki (1986), the term adaptive expertise refers to the ability to flexibly apply expertise to solving problems in innovative ways, even in different contexts. The contrast is routine expertise, in which experts are characterized by their ability to complete tasks accurately and efficiently (Hatano \& Oura, 2003).

At present, given the magnitude of change needed in many countries' education contexts, focusing on development of routine expertise may already be enough to change student-level outcomes. However, maintaining expectations of higher-order adaptive expertise may be the key to sustainable teacher behavior change. The foundations for adaptive expertise are laid in early teacher-training opportunities that allow space for experimentation, failure, reflection, and refinement through feedback and scaffolding from other experts (Anthony, Hunter, \& Hunter, 2015). All of the chapters in this 
volume in some way allude to these features of expertise development, but more explicit attention to this domain of professional development may also be an area for further exploration.

In this book, we use the term teacher behavior change to describe the process by which new skills or attitudes presented during professional development activities result in changed instructional processes. Reaching all teachers with a carefully designed program that combines face-to-face teacher professional development with the feedback and support required for instructional change necessitates careful planning but, more importantly, an a priori view of how teacher behavior change can be undertaken in contexts of complex reform at large scale.

The cases described in this book, as well as other evidence available from developing countries, suggest that teacher behavior change is possible, that it is more likely to occur when multiple training and support designs are used, and that it succeeds best when interventions focus on reinforcing behaviors and skills that are required for successful implementation of the desired changes. Moreover, what these cases also show is that truly fostering sustained teacher behavior change is beyond the scope of any one project; it requires consistent and orchestrated support at all levels of the education system.

\section{References}

Abiy, D. S., Kabeta, G. G., \& Mekonnen Mihiretie, D. (2014). Developing a lifelong learning system in Ethiopia: Contextual considerations and propositions. International Review of Education, 60(5), 639-660. https://doi.org/10.1007/s11159-014-9435-z

Anthony, G., Hunter, J., \& Hunter, R. (2015). Prospective teachers development of adaptive expertise. Teaching and Teacher Education, 49, 108-117. https://doi.org/10.1016/j.tate.2015.03.010

Bold, T., Filmer, D., Martin, G., Molina, E., Rockmore, C., Stacy, B., ... Wane, W. (2017). What do teachers know and do? Does it matter? Evidence from primary schools in Africa (Policy Research Working Paper 7956). Washington, DC: The World Bank Group. https://doi.org/10.1596/ 1813-9450-7956

Federal Ministry of Education, Ethiopia. (2008). National adult education strategy. Addis Ababa, Ethiopia: Author. Retrieved from http://www.moe.gov.et/documents/20182/42694/National+Adult+Educatio n+Strategy.pdf/f56b2d3f-1c68-4174-b3e8-f449316709eb?version=1.0 
Federal Ministry of Education, Ethiopia. (2015). Education sector development programme V (ESDP V): Programme action plan. Addis Ababa, Ethiopia: Author. Retrieved from http://www.cmpethiopia.org/ content/download/2267/9609/file/ESDP\%20V\%20FINAL.pdf

Feryok, A. (2009). Activity theory, imitation and their role in teacher development. Language Teaching Research, 13(3), 279-299. https://doi.org/10.1177/1362168809104699

Guskey, T. R. (1986). Staff development and the process of teacher change. Educational Researcher, 15(5), 5-12.

Guskey, T. R. (2002). Professional development and teacher change. Teachers and Teaching, 8(3), 381-391. https://doi.org/10.1080/135406002100000512

Hatano, G., \& Inagaki, K. (1986). Two courses of expertise. In H. Stevenson, J. Azuma, \& K. Hakuta (Eds.), Child development and education in Japan (pp. 262-272). New York, NY: W. H. Freeman \& Co.

Hatano, G., \& Oura, Y. (2003). Commentary: Reconceptualizing school learning using insight from expertise research. Educational Researcher, 32(8), 26-29. https://doi.org/10.3102/0013189X032008026

Herzberg, F. I. (1966). Work and the nature of man. Cleveland, OH: World Publishing.

Junor Clarke, P. A., \& Fournillier, J. P. (2012). Action research, pedagogy, and activity theory: Tools facilitating two instructors' interpretations of the professional development of four pre-service teachers. Teaching and Teacher Education, 28(5), 649-660. https://doi.org/10.1016/j.tate. 2012.01.013

Knowles, M., \& Associates. (1984). Andragogy in action: Applying modern principles of adult learning. San Francisco, CA: Jossey-Bass.

Kraft, M. A., Blazar, D., \& Hogan, D. (2018). The effect of teacher coaching on instruction and achievement: A meta-analysis of the causal evidence. Review of Educational Research, 88(4). https://doi.org/10.3102/003465 4318759268

Kruijer, H. (2010). Learning how to teach: The upgrading of unqualified primary teachers in sub-Saharan Africa. Brussels, Belgium: International Education.

Maslow, A. H. (1943). A theory of human motivation. Psychological Review, 50(4), 370-396. https://doi.org/10.1037/h0054346 
McClusky, H. Y. (1963). The course of the adult life span. In W. C. Hallenbeck (Ed.), Psychology of adults (pp. 10-19). Chicago, IL: Adult Education Association of the USA.

Merriam, S. B., Caffarella, R. S., \& Baumgartner, L. M. (2007). Learning in adulthood: A comprehensive guide (3rd ed.). San Francisco, CA: Jossey-Bass.

Ministry of Education and Culture, Indonesia. (2013). Overview of the education sector in Indonesia: Achievements and challenges. Jakarta, Indonesia: Author.

Molla, T. (2010). Widening access to lifelong learning for adults in Ethiopia: Opportunities with recognition of prior learning. Widening Participation and Lifelong Learning: The Journal of the Institute for Access Studies and the European Access Network, 12(2), 7-22.

Nir, A. E., \& Bogler, R. (2008). The antecedents of teacher satisfaction with professional development programs. Teaching and Teacher Education, 24(2), 377-386. https://doi.org/10.1016/j.tate.2007.03.002

Nordstrum, L. (2015). Effective teaching and education policy in sub-Saharan Africa: A conceptual study of effective teaching and review of educational policies in 11 sub-Saharan African countries. Prepared for the USAID Bureau for Africa under the Education Data for Decision Making (EdData II) project, Data for Education Research and Programming in Africa, Task Order No. AID-OAA-12-BC-00004 (RTI Task 19). Research Triangle Park, NC: RTI International. Retrieved from http://pdf.usaid.gov/pdf_docs/PBAAF487.pdf

Orr, D., Westbrook, J., Pryor, J., Durrani, N., Sebba, J., \& Adu-Yeboah, C. (2013). What are the impacts and cost-effectiveness of strategies to improve performance of untrained and under-trained teachers in the classroom in developing countries? London, United Kingdom: EPPI-Centre, Social Science Research Centre, Institute of Education, University of London. Retrieved from http://sro.sussex.ac.uk/43901/1/Undertrained_ teachers_2013_Orr.pdf

Piper, B., Oyanga, A., Mejia, J., \& Pouezevara, S. (2017). Implementing large-scale instructional technology in Kenya: Changing instructional practice and developing accountability in a national education system. International Journal of Education and Development Using Information and Communication Technology, 13(3), 57-79. Retrieved from http://ijedict. dec.uwi.edu/include/getdoc.php?id=7416\&article=2353\&mode=pdf 
Piper, B., Sitabkhan, Y., Mejía, J., \& Betts, K. (2018). Effectiveness of teachers' guides in the Global South: Scripting, learning outcomes, and classroom utilization (RTI Press Publication No. OP-0053-1805). Research Triangle Park, NC: RTI Press. https://doi.org/10.3768/rtipress.2018.op.0053.1805

Piper, B., \& Zuilkowski, S. S. (2015). Teacher coaching in Kenya: Examining instructional support in public and nonformal schools. Teaching and Teacher Education, 47, 173-183. https://doi.org/10.1016/j.tate.2015.01.001

United Nations. (n.d.). Sustainable Development Goal 4: Ensure inclusive and equitable quality education and promote lifelong learning opportunities for all. Progress of goal 4 in 2017. Retrieved from https://sustainabledevelopment.un.org/sdg4

United States Agency for International Development (USAID). (n.d.). 20112015 USAID Education Strategy progress report. Washington, DC: Author. Retrieved from https://www.usaid.gov/sites/default/files/ documents/1865/2011-2015_ProgressReport_r13_Final_WEB.pdf

Walters, S., Yang, J., \& Roslander, P. (2014). Key issues and policy considerations in promoting lifelong learning in selected African countries: Ethiopia, Kenya, Namibia, Rwanda and Tanzania (UIL Publication Series on Lifelong Learning Policies and Strategies: No. 1). Hamburg, Germany: UNESCO Institute for Lifelong Learning. Retrieved from http://unesdoc. unesco.org/images/0023/002311/231157e.pdf

World Bank. (2003). Lifelong learning and the knowledge economy: Summary of the Global Conference on Lifelong Learning, Stuttgart, Germany, October 9-10, 2002. Washington, DC: World Bank. Retrieved from http://siteresources.worldbank.org/EDUCATION/Resources/2782001099079877269/547664-1099079984605/lifelong_KE.pdf 


\title{
Changing Teacher Educators' Conceptions and Practices Around Literacy Instruction: Lessons from Teacher Educators' Professional Development Experiences in Ethiopia
}

\author{
Dawit Mekonnen, Marion Fesmire, Adrienne Barnes, \\ Stephen Backman, and Flavia Ramos-Mattoussi
}

\section{Introduction}

\section{Problem Statement}

Both research and anecdotal evidence in the past decade have highlighted that primary school teachers in sub-Saharan countries typically are not adequately prepared to teach the contents of the school curriculum (e.g., Bold et al., 2017). International donors who are engaged in developing countries tend to support and fund educational reforms that focus mainly on improving the skills of in-service teachers, even where program descriptions include support for improving teacher education programs at the pre-service level. As identified in the United Nations Sustainable Development Goals ${ }^{1}$ covering the period 2015-2030, a supply of well-trained teachers is one way to improve equity and quality of education (UNESCO, 2015).

The Sustainable Development Goal for education advocates for international support for pre-service teacher education by aiming to "substantially increase the supply of qualified teachers, including through international cooperation for teacher training in developing countries" (p. 15). As a result, governments and donors have begun to support teacher education institutions to improve teacher preparation and the equity and

\footnotetext{
Sustainable Development Goal 4: "Ensure inclusive and equitable education and promote life-long learning opportunities for all," including " $4 . c$ by 2030 increase by $\mathrm{x} \%$ the supply of qualified teachers, including through international cooperation for teacher training in developing countries, especially LDCs and SIDS.” The United Nations Association of Greater Philadelphia has prepared a two-page downloadable PDF of Goal 4 with all its targets and indicators, available from http://una-gp.org/clancyt/files/goals/goal4.pdf
} 
quality of primary education. How best to do this is the subject of ongoing research, including this case study from Ethiopia.

The purpose of this case study was to examine the contribution of the pre-service interventions within the Reading for Ethiopia's Achievement Developed Technical Assistance (READ-TA) program, funded by the United States Agency for International Development (USAID) from October 2012 through December 2017. Of particular interest were revisions of the mother tongue pre-service teacher education program and the related professional development for teacher educators and student teachers (we use the term teacher educators to refer to the lecturers and instructors at the colleges of teacher education and the term student teachers to refer to the students at colleges of teacher education, also referred to in Ethiopia as "teacher-trainees" and "wouldbe-teachers"). The professional development activities included engagement of these educators in module development, adaptation of the modules and related materials into seven mother tongues, ${ }^{2}$ and training on the module contents.

The objectives of this chapter are to describe the extent to which teacher educators' involvement across multiple initiatives promoted changes in conceptions of literacy instruction; depth of understanding of literacy content; and student-centered, participatory teaching and learning pedagogy. (For this chapter, the term literacy encompasses reading, writing, speaking, and listening.) To document changes in conceptions, knowledge, and skills, we collected data throughout the life of the project to gather teacher educators' reflections on learning processes, changes in teaching practices, and student teachers' readiness to teach the new primary curriculum.

We addressed the following research questions:

- What was the impact of professional development on teacher educators' beliefs and practices?

- What was the impact of teacher educators' new practices on the student teachers' preparation to teach in the primary school?

- What were the barriers to implementation and sustainability of the revised mother tongue teacher education program?

\footnotetext{
2 As of early 2018, more than 20 local languages were being used as languages of instruction in Ethiopia. READ-TA targeted seven of the most widely spoken languages of instruction. The pre-service teacher education program prepares student teachers to teach in the mother tongue used as the language of instruction in grades 1-8 in each of the nine regions of the country.
} 


\section{Background and Context of Primary Education in Ethiopia}

Primary education in Ethiopia consists of eight years divided into two cycles: first cycle (grades 1-4) and second cycle (grades 5-8). Mother tongues commonly are used as a language of instruction in at least the first cycle of primary education. For example, during the READ-TA project, the regions of Tigray and Oromia ${ }^{3}$ were using the regional mother tongue (Tigrinya and Afaan Oromo, respectively) as the language of instruction for grades 1-8. Other regions (i.e., Southern Nations, Nationalities, and Peoples Region [SNNPR]) introduced English as the language of instruction beginning in grade 5. In Amhara, Amharic was being used as the language of instruction to teach all subjects in primary grades except science and mathematics.

The results of Early Grade Reading Assessments administered in 2010 (Piper, 2010) and 2014 (RTI, 2014) were not very promising; many children were not able to read at grade level in their mother tongue. The READ-TA program supported the Ethiopian Ministry of Education in its efforts to develop a nationwide reading and writing program, particularly focused on the skills of children in grades 1-8 in the seven selected major mother tongues and in English. The overall goal of the READ-TA program was to boost the quality of literacy instruction and learning in the target languages and consequently to improve the reading outcomes of 15 million Ethiopian children.

The READ-TA program approach was a context-specific model of developing, implementing, and piloting educational reforms aimed at improving literacy instruction in Ethiopia in the target languages of instruction: Af Somali, Afaan Oromo, Amharic, Hadiyyisa, Sidaamu Afoo, Tigrinya, and Wolayttatto. Supports included the development of new primary curriculum and instructional materials, such as teacher guides and student textbooks for grades 1-8 in the target mother tongues. Another major goal of the READ-TA program support was to develop and revise the pre-service mother tongue teacher education program at colleges of teacher education. This chapter focuses primarily on the outcomes of this initiative,

\footnotetext{
3 Ethiopia has two chartered cities (Addis Ababa and Dire Dawa) plus nine national region states: Afar; Amhara; Benishangul-Gumuz; Gambela; Harari; Oromia; Somali; Southern Nations, Nationalities, and Peoples' Region (SNNPR); and Tigray.
} 
which was the scope of work assigned to Florida State University (FSU) under the READ-TA project.

\section{Pre-service Teacher Education in Ethiopia}

The Learning Systems Institute at FSU was a partner to RTI International on the READ-TA program. At the beginning of the project, FSU conducted a baseline assessment of pre-service teacher education programs at colleges of teacher education in Ethiopia (RTI \& FSU, 2013). The baseline report submitted to the Ethiopian Ministry of Education provided the background for the next phases of the project related to reforms in the pre-service teacher education program.

The FSU team was responsible for revising the pre-service Mother Tongue Language Program syllabi, course modules, and training for mother tongue teacher educators. Also, from 2013 to 2017, a team of specialists from FSU and their Ethiopian counterparts collaborated with the Ministry of Education, Regional State Education Bureaus, Zonal Education Bureaus, and colleges of teacher education to reform the Mother Tongue Language Program for pre-service teachers (which included both language and literacy skills instruction).

\section{Student Teachers}

At the end of grade 10, all students complete a national secondary school exit exam administered by the Ministry of Education. Students who score well are promoted to grade 11 to attend preparatory classes for tertiary education. Those students who perform poorly but manage to pass with the lowest scores are not permitted to proceed to grade 11 but rather are offered alternative educational routes, including primary pre-service teacher education. Colleges of teacher education enroll student teachers who have completed grade 10 of general education and provide a three-year training to teach primary school grades $1-8$. The colleges mostly use the regional or local language as the language of instruction to prepare primary school teachers. Thus, across all regions, the student teachers enrolled in the three-year Mother Tongue Language Program at colleges of teacher education tend to exhibit basic literacy skills but may not be ready for higher education. They receive training using only the local language. Preparing knowledgeable and skilled mother tongue teachers for literacy instruction in this diverse language context was one of the challenges that the READ-TA program addressed with the government of Ethiopia. 


\section{Teacher Educators}

In the Ethiopian context, most teacher educators hold an advanced degree (a Master of Arts or Science) in one of the education subjects, such as English, math, biology, or language, or in a field such as psychology or curriculum. The teacher educators who participated in the development, implementation, and training of the new course modules had not completed a program of study specifically related to literacy theory or pedagogy. Some teacher educators had experience in teaching at the primary or secondary school level, but most had not been prepared to teach early grade literacy. Only a few of them had completed individual courses related to reading instruction.

Although teacher educators brought many years of experience teaching courses at colleges of teacher education on reading and writing that focused on scanning, skimming, contextualization, and intensive and extensive reading, the newly developed primary curriculum included many new concepts and skills, such as the five components of reading (National Institute of Child Health and Human Development, 2000) and a gradual-release model (“I do, We do, You do"; Fisher \& Frey, 2008; Rosenshine \& Stevens, 1986). Teacher educators had no exposure to these new concepts before the READ-TA project started, and the teacher education courses were not aligned with the new primary school curriculum. As a result, the FSU focus was to impart practical information about literacy instruction as well as to introduce the pedagogy used in the new primary curriculum.

\section{Process of Module Development}

FSU supported the development of seven mother tongue course modules directly related to literacy instruction. Each of the seven modules was meant to be covered in a single-semester class (two to four credit hours) and to address a range of literacy theories and pedagogies. Student teachers typically enrolled in one to four of the newly developed modules ${ }^{4}$ as part of their six-course semester load.

\footnotetext{
4 The modules were produced under the USAID READ-TA project (2012-2017), Cooperative Agreement No. AID-663-A-12-00013. They are available to the public from USAID's Development Experience Clearinghouse website, https://dec.usaid.gov. See RTI and FSU (2015a-2015b, 2016a-2016f, 2017a-2017b).
} 
- MT [Mother Tongue] 201: Cognitive Development and Literacy Skills (Module 1). Introduces the theoretical framework for how children learn to read, write, speak, and listen. The five components of reading (and writing) are introduced and discussed thoroughly.

- MT 222: Teaching Reading and Writing in Primary Schools (Module 2). Provides opportunities for student teachers to learn how to teach skills and strategies in reading and writing, with due emphasis on the primary school mother tongue curriculum.

- MT 224: Methods of Teaching Speaking and Listening in Primary Schools (Module 3). Focuses on how children acquire a first and second language, and various instructional and assessment techniques for oral language (speaking and listening).

- MT 322: Assessing Literacy Skills and Differentiated Instruction (Module 4). Builds on the previous courses. The major objective of the course is to develop student teachers' ability to assess students' reading and writing skills and to use the assessment information to design instruction that meets the needs of diverse learners.

- MT 212: Introduction to Language and Linguistics of the Mother Tongue (Module 5). Teaches the student teachers about the characteristics of language and the structures of their mother tongue that affect literacy instruction.

- MT 223: Children's Literature in the Mother Tongue (Module 6). Allows student teachers to explore the different types of children's literature and to practice activities that support children's understanding of what they are reading. The module develops student teachers' competence in using children's literature to build the literacy skills of primary school students.

- MT 221: Developing Reading Skills in the Mother Tongue (Module 7). Supports student teachers' improvement in the skills needed to read, comprehend, synthesize, and process complex information found in the mother tongue course work.

These seven modules were fully developed, adapted to the seven mother tongues, and implemented at colleges of teacher education across all regions of Ethiopia. Each module was taken through multiple development steps with the support of stakeholders including teacher educators, the Ministry of Education, and regional and zonal staff representing the seven mother 
tongues and five of the country's nine regions: Tigray, Oromia, Amhara, Somali, and SNNPR. Below were the steps taken for materials development.

1. English module development. A draft in English for each module was developed by the FSU team based on the national teacher education syllabi and primary mother tongue curriculum. The draft was then presented to the various stakeholders for review and revision. The course outline, objectives, contents, and proposed activities were further developed during a workshop for each module.

2. Adaptation to the mother tongues. A group of four to five representatives adapted the English version of the module to the mother tongues. The groups worked together for up to three weeks to ensure that proper adaptation (not translation) took place. During adaptation, teacher educators integrated activities and examples from the primary school mother tongue student textbooks and teacher guides developed under a separate component of the project.

3. English and mother tongue module validation and post-validation revision. Each module was validated by regional stakeholders listed previously. Their comments were reviewed, and each module was revised based on relevant and appropriate recommendations. Selected teacher educators led the validation workshops and completed revisions.

4. Module training (co-trainer and participant). More than 250 teacher educators received three- or four-day trainings on module contents. The trainings were provided by FSU reading specialists and mother tongue co-trainers, in both English and the mother tongue, with participants grouped by language. FSU reading specialists and mother tongue co-trainers modeled how to teach the module contents using various instructional techniques.

5. Pilot implementation and monitoring and evaluation. Modules were implemented at all colleges of teacher education by the trained teacher educators. The FSU team selected and trained teacher educators who monitored and evaluated the fidelity of implementation of the draft modules. During the monitoring, teacher educators were observed during a class session. A focus group discussion was conducted with selected student teachers who had attended the class, and an oral questionnaire was completed with the teacher educators. In addition, monitoring and evaluation included 
assessment of proper use of an information and communication technology package (which included one projector, one document camera, and multiple tablets for teacher educators in the mother tongue program). Monitoring and evaluation reports were submitted to READ-TA and to the Ministry of Education on the implementation of each module in all seven mother tongues (Barnes, Zuilkowski, Mekonnen, \& Ramos-Mattoussi, 2018).

6. Module revision. Based on the feedback from the monitoring and evaluation, the English module and each mother tongue module were revised by the representatives noted previously.

\section{Literature Review}

Research on the specifics of how teachers are educated (e.g., the content, pedagogy, and materials used in teacher education programs) is quite scarce, meaning that the topic may be undervalued (Brody \& Hadar, 2011; Edmond \& Hayler, 2013; Korthagen, Loughran, \& Russell, 2006; Lanier \& Little, 1986). Until recently little has been written about how student teachers experience their training programs. However, new theories and instructional methods have driven greater examination of the teacher preparation phase that occurs in colleges of education and the importance of understanding student teacher and teacher educator needs (Guskey, 2002; Guskey \& Yoon, 2009; Lunenberg, Korthagen, \& Swennen, 2007).

These new directions have influenced global interest (Ali, 2017; Hökkä, Vähäsantanen, \& Mahlakaarto, 2017) in how theory is linked to practice, and the subsequent impacts on student teachers (Guskey, 2002; Korthagen et al., 2006; Moats \& Foorman, 2003). As an example, in the United States, Clark, Jones, Reutzel, and Andreasen (2013) indicated that beginning teachers who completed a literacy teacher education program needed continuous support from teacher educators and additional training to competently meet the diverse needs of students in schools. Their findings and those of others (e.g., French, 1997; Joyce \& Showers, 2002; Nkambule \& Muheridzi, 2017) underscore the importance of conceptualizing teachers' learning as an ongoing process that must be supported by induction and continuous school-based and external teacher support systems.

It is important to recognize variations in both the timeline necessary for teacher change and the assimilation of knowledge and skills related to new practices. Veteran educators who have long-held beliefs may experience 
cognitive dissonance. That is, these educators may perceive themselves as experts in the field, and yet their lack of knowledge of new practices places them in the uncomfortable position of being novices (Brody \& Hadar, 2011; Van der Klink, Kools, Avissar, White, \& Sakata, 2017). For some educators who are aware of the new practices, acceptance and implementation may be an easier process (Gulamhussein, 2013). While building on prior research on teachers' professional development, the analyses carried out for this chapter also contribute to the existing research by specifically examining how the teacher educators involved in READ-TA gained the knowledge and pedagogical skills to learn and teach research-based literacy instruction.

\section{Professional Development of Teacher Educators}

Although evidence has shown an impact of in-service teacher professional development on classroom teaching behaviors, much less is known about how pre-service teacher educators learn the skills of their profession (e.g., Vanassche \& Kelchtermans, 2014). Therefore, this literature review includes research on preparation of both classroom teachers and teacher educators.

It remains unclear how teacher educators effectively respond to the demands of their profession and continue their professional development (Ferguson, 2006; Koster, Brekelmans, Korthagen, \& Wubbels, 2005), what impact professional development has on the practices of teacher educators (Van der Klink et al., 2017; Vanassche \& Kelchtermans, 2014), and to what extent professional development affects change in beliefs and practices. As noted at the beginning of this literature review, even though they are perceived to be the foundation of the educational system, teacher educators have not received attention from researchers (Brody \& Hadar, 2011). Recent research has focused on the use of self-study (Hwang, 2014), teacher educators as researchers in their own contexts, and engagement in learning communities (Korthagen et al., 2006; McIntyre \& Hagger, 1992). However, Brody and Hadar (2011) noted that there is no adequate account of how teacher educators learn using these processes and underlined the need for more research on teacher educators' professional development.

High-quality professional development is designed to produce systemic change in the practices and beliefs of teachers (Amado, Dalelo, Adomßent, \& Fisher, 2017; Blazer, 2005; DeMonte, 2013; Guskey, 2002). Teachers participate in professional development to gain new knowledge and skills, enhancing their teaching practices with goals of professional growth and advancement. 
They are seeking practical ideas that inform primary teaching (Fullan \& Miles, 1992). However, many professional development programs fail to effect change on teachers' or teacher educators' practices and student teachers' learning, or they are perceived as "irrelevant" (Guskey, 2002; Kennedy, 2005; Lieberman \& Mace, 2008). Short-term trainings not supported with follow-up capacity development and learning typically fail to bring the desired change in teachers' practices (Darling-Hammond, Wei, Andree, Richardson, \& Orphanos, 2009).

While initial behavioral, attitude, and commitment changes may be observed, long-term change is often minimal (Guskey, 2002; Jones \& Hayes, 1980; Ottley et al., 2015). However, when teachers observe positive outcomes as a result of their behavioral change, they are likely to continue those practices. One suggestion for improving implementation and sustainability is to involve teachers in planning sessions and to conduct initial surveys to align development with needs identified by educators (Guskey, 2002). The professional development activities for teacher educators in this study were created based on identified gaps in the educators' literacy knowledge and skills. As a result of the change in the primary school curriculum, new literacy content knowledge and instructional practices were included in the pre-service teacher education program. Findings from teacher education research helped identify what practices should be implemented to build content knowledge in literacy instruction (Hwang, 2014).

\section{Modeling and Simulations}

The extent to which a teacher can translate theory into classroom practices has been found to be a key factor in student learning (Blazer, 2005; Bold et al., 2017; Gulamhussein, 2013), despite assumptions that teaching individuals to become teachers does not require specific preparation (Zeichner, 2005). Emerging evidence indicates that teachers must be able to translate their content and pedagogical knowledge into classroom practice by using individual and group activities and providing specific feedback (Bold et al., 2017; Koster et al., 2005). Very few published studies have addressed how to prepare teacher educators effectively for these functions or what influence teacher educators' knowledge, skills, and practices have on student teachers' understanding and classroom practices (Lunenberg et al., 2007).

One body of knowledge supports the notion that teacher educators should model new techniques and provide time for student teachers to practice using 
these techniques (Lindvall, Helenius, \& Wiberg, 2018; Lunenberg et al., 2007): Modeling helps student teachers see the link between theory and pedagogy, connect their personal learning experiences with course content, and understand how to implement these practices. Immersion in real-world simulations using materials and specific concepts can powerfully affect student teacher learning (Darling-Hammond, 2006), and teacher educators should provide a continuum of practical activities and settings, ranging from the pre-service classroom to the primary school (Lampert, 2006, as cited in Ball \& Forzani, 2009).

Korthagen and colleagues (2006) suggested that observations in primary classrooms, combined with conversations and student teachers' reflections, increase understanding of the link between pre-service course content and what happens in primary classrooms. However, what has been learned does not always work in "real life" classrooms (Hökkä et al., 2017). There are indications that, in the first year of teaching, changes in attitudes occur as a result of teaching practices in the school or the teacher's own experience in primary school: "Teachers tend to teach as they were taught, not as they have been taught to teach" (Blume, 1971, as cited in Lunenberg et al., 2007, p. 588).

\section{Self-Reflection and Collaboration to Build Sustainability}

In discussing how teacher educators can promote their own professional development and support student teachers' learning, Zeichner (2005) recommended that teacher educators should model self-reflective practices and develop similar habits among student teachers. Teachers and teacher educators accumulate educational experiences throughout their life (Hwang, 2014), and self-reflection helps them think about and evaluate the effectiveness of their practices (Schön, 1987). The self-reflection process facilitates knowledge enhancement, understanding of subject matter, the ability to learn and use research-based practices (Hwang, 2014), and critical reflection (Hökkä et al., 2017). As a result, linkages between practice and theory are strengthened (Korthagen et al., 2006).

Educators can also combine their knowledge, skills, and resources to develop collective identities and shared understandings (Hökkä et al., 2017), referred to as communities of learners (Lave \& Wenger, 1991). The groups share common concerns and sets of problems and/or topics through ongoing interactions (Hadar \& Brody, 2010; Wenger, McDermott, \& Snyder, 2002). Educators may observe one another's teaching, provide feedback, and 
work together to reflect on their practices, resulting in suggestions for enhancement and improvement (Hadar \& Brody, 2010; Lunenberg et al., 2007). McLaughin and Talbert (2001) identified three main outcomes from collaboration: improvement in teaching practices, opportunities for personal and professional development, and a decrease in isolation.

\section{Institutional Structure and Resource Availability}

Educators' roles and tasks are embedded in the local institutional context (Hwang, 2014), which can support or impede implementation of new practices. The structure determines the available resources, working conditions, organizational structure, cultural expectations, teacher educator workload, and the student teacher population (Hwang, 2014; Vanassche \& Kelchtermans, 2014). Many of these barriers to resource availability need to be addressed at the systemic level (national, regional, local) (Bold et al., 2017).

In sum, most of the literacy content and instructional practices introduced during the READ-TA project were new to most of the teacher educators. Moreover, in addition to learning the new mother tongue content and practices themselves, the teacher educators had to change their beliefs and instructional practices in terms of preparing school teachers. In our review of the literature, we found no conclusive evidence of large-scale professional development opportunities that had an effect on teacher educators' knowledge and practice. Some studies demonstrated gains in educators' knowledge and beliefs, while others reported a lack of impact (as cited in Ottley et al., 2015: LeMoine, 2008; Neuman \& Cunningham, 2009; Whitebook \& Ryan, 2011). The success of professional development activities also has been documented as varying among teacher educators as a function of educators' prior knowledge and ability to implement new practices. An educator's openness to change, motivation, self-efficacy, and self-confidence are good predictors of implementation (Ottley et al., 2015).

Changing beliefs is not an easy process; change takes time and can create anxiety and resistance to implementation (Guskey, 2002). Even when provided evidence that new practices work, teachers may still be reluctant to change until something happens to help them believe these practices will work. In addition, positive learning outcomes may be a prerequisite to significant changes in an educator's attitudes and beliefs (Guskey, 2002). It is also important to build partnerships among colleges, schools, and student teachers (Korthagen et al., 2006). 


\section{Methodology}

\section{Approach of the Case Study}

The findings in this case study were drawn from data generated through monitoring and evaluation of teacher educators' and student teachers' use of new course materials, surveys, focus groups, anecdotal notes, and individual interviews. The objectives were to examine the impact of professional development on teacher educators' beliefs and practices, to assess the impact of these new practices on student teacher learning, and to identify barriers to implementation and sustainability of the newly revised pre-service teacher education curriculum.

\section{Data Collection}

The FSU team designed a set of data collection tools for each of the seven modules, including a classroom observation checklist, focus group discussion guides, a teacher educator survey, and a semi-structured interview guide (these data collection tools were prepared to address USAID's project goals and expectations; neither were the tools, and the related research questions, devised with a publication in mind nor was the study designed to address theory from the literature, per se). These data collection tools were piloted and revised to ensure clarity and accuracy in collection of the data.

The purpose of the monitoring and evaluation tools was to assess the fidelity of implementation for the field-tested modules and to identify any potential challenges with the content, activities, instructional approaches, and institutional resources. In recognition that English was not their first language, the teacher educators were given time to review the instruments and to provide suggestions (wording, revision of questions, etc.). Across module implementation, 78 classes were observed. Professional development evaluations, semi-structured interview questions, and additional focus group discussion guides were compiled for use during training sessions and materials development workshops.

\section{Classroom Observations}

Classroom observations were conducted by the FSU team and selected teacher educators. The observation checklists addressed how the contents of the modules were taught: instructional methods, activities, projects, questioning strategies, etc. The purpose was to gain insight into the actual implementation, including challenges and module content in need of improvement. 


\section{Focus Group Discussions}

After each classroom observation, a group of student teachers participated in a focus group session. Student teachers discussed what they had learned, the effectiveness of activities, strengths and weaknesses of the module, and any additional concerns. Each focus group consisted of 10-12 student teachers (equally representing males and females) randomly selected to participate. In classrooms that included student teachers with disabilities, at least one such student teacher was selected for the focus group. Focus group discussions were also held with teacher educators at various times throughout module development and various training sessions.

\section{Teacher Educator Surveys}

Each teacher educator who was observed teaching completed a survey. First, each teacher educator was provided a copy of the survey questions in English and given time to read the survey and ask for clarifications. Then the teacher educator completed the survey. The purpose of this activity was to gather the teacher educators' perspectives on the module, what they felt worked and didn't work, and suggestions for revision.

\section{Professional Development Evaluations}

During each training session before module piloting took place, teacher educators were asked to complete a survey evaluating the quality and content of the training session.

\section{Semi-Structured Interviews With Selected Teacher Educators}

Semi-structured interviews were conducted in a one-on-one setting with 12 teacher educators representing the seven mother tongues. These teacher educators were selected based on their participation in a majority of the professional development and module development opportunities. The purpose of these interviews was to understand the teacher educators' views on the effectiveness of the different professional experiences provided throughout the life of the project and to elicit rich descriptions of how teacher educators reconceptualized literacy concepts and practices. Each teacher educator was given a copy of the questions to read and was encouraged to ask for clarification as needed. Interview questions probed content knowledge, reflections on experiences, and synthesis of new conceptual knowledge. In addition, the interview questions explored the teacher educators' perceptions of student teachers' learning and the student teachers' ability to apply new skills during microteaching, practicum, fieldwork, etc. 
Table 2-1. Summary of participants

\begin{tabular}{|c|c|c|c|}
\hline \multirow[b]{2}{*}{ Data collector } & \multicolumn{2}{|c|}{$\begin{array}{l}\text { Participants in project monitoring and } \\
\text { evaluation classroom activities }\end{array}$} & \multirow[b]{2}{*}{$\begin{array}{l}\text { Teacher educators } \\
\text { selected for final } \\
\text { semi-structured } \\
\text { interviews }\end{array}$} \\
\hline & $\begin{array}{l}\text { Teacher educators } \\
\text { involved in classroom } \\
\text { observation and } \\
\text { survey }\end{array}$ & $\begin{array}{l}\text { Number of } \\
\text { student teachers } \\
\text { in focus groups }\end{array}$ & \\
\hline FSU team & 15 & 168 (14 groups) & 12 \\
\hline $\begin{array}{l}\text { Monitoring and evaluation } \\
\text { data collectors }\end{array}$ & 63 & 756 (63 groups) & 0 \\
\hline
\end{tabular}

FSU = Florida State University.

\section{Participants}

Participants in this case study included more than 350 stakeholders, teacher educators, and student teachers. Table 2-1 presents the participants who contributed the data included in this case study. These data points provided the richest information regarding the impact of the READ-TA project on teacher educators, student teachers, and systemic change. All teacher educators and student teachers gave oral permission to participate in the research activities.

\section{Data Analysis}

Data were collected and analyzed using a multifaceted approach. Monitoring and evaluation data for the modules were recorded using Qualtrics, a quantitative data analytic software. Interviews and focus group discussions were completed in both English and the mother tongue. When the data were collected in the mother tongue, the data collectors provided a summary in English for analysis. The data were then conceptually clustered in a matrix. Triangulation was achieved by comparing responses and identifying similarities and differences across the multiple data collection tools. These tools were used in all five regions and seven mother tongues.

\section{Findings and Discussion}

\section{Research Question 1: What Was the Impact of Professional Development on Teacher Educators' Beliefs and Practices?}

Before implementation of the READ-TA project, teacher educators commonly held a very simplified view of the teaching and learning of literacy skills. The teacher educators' new conceptualization of literacy, 
however, included reading, writing, speaking, listening, and technology skills. Teacher educators discussed their changes in conception of their roles, beliefs, and practices. They stated that before the READ-TA project was implemented, their major instructional method was lecturing, and they derived the content from books that were not closely related to the primary school curriculum. The course content they taught focused primarily on theory. They reported that they had gained an understanding of what primary school teachers were expected to teach and recognized the importance of integrating the primary curriculum into the mother tongue courses at colleges of teacher education.

Teacher educators also were able to identify the new concepts that they were teaching. For example, they said that the first module introduced theories about how children learn to read, the five components of reading and writing, and the gradual-release model. Teacher educators stated that they had broadened their understanding of literacy beyond just reading and writing, and they recognized that teaching literacy skills is not a simple task. One teacher educator mentioned that before the READ-TA program, he used to think teaching reading meant reading aloud in front of the students or having students read silently and then asking comprehension questions. He explained that his view of reading had evolved to include learning to read and reading to learn. Teacher educators stressed that their primary task was developing the knowledge, skills, and strategies student teachers need to teach primary students.

To achieve this goal, many teacher educators recognized the importance of increasing their own content knowledge and applying what they learned to classroom pedagogy. New practices included connecting course content in colleges of teacher education with the recently developed primary school curriculum, preparing for instruction, developing and locating supporting materials, modeling research-based pedagogy, and modifying the vocabulary used in teaching materials to facilitate student teachers' understanding. Comments that teacher educators made regarding roles and tasks included (1) "[being] prepared for [and knowing] what to teach" and (2) "know[ing the] science of teaching primary school methods that are appropriate."

\section{Module Development and Training}

During 2014-2017, teacher educators actively participated in the READ-TA activities discussed in the introduction to this chapter, and they were able to cite many benefits. During module development and adaptation, for example, teacher educators emphasized the impact of their exposure to new research-based 
practices and content-area vocabulary and said they had developed a deeper understanding of ideas, concepts, theories, and pedagogy. Teacher educators stated that, because of their experience under the READ-TA program, they (1) recognized the value of external cross-checking of materials; (2) appreciated individual differences in understanding materials, concepts, and theories; and (3) learned how to provide constructive feedback. They also recognized the value of editing and revising materials, as revision involved many discussions about the content and the mother tongue, which further deepened their understanding.

The respondents said they came to conceptualize adaptation as localizing the information to the sociocultural context rather than just translating the words from English to the mother tongue. Adaptation of words and phrases such as literacy, think aloud, differentiating instruction, and voice required an understanding of each term's meaning in both English and the mother tongue. Teacher educators engaged in many discussions (both among themselves and with the FSU team) to thoroughly understand new concepts and determine how to convey those concepts in the mother tongue. A recurring theme among teacher educators' statements was that they felt the process of module development was as intense as a graduate studies program.

Selected teacher educators involved in module development were co-trainers in their specific mother tongue for large-group module training. Taking a co-trainer role required a thorough understanding of the module concepts and the ability to clarify misunderstandings by the participants. Co-trainers learned how to conduct training, provide positive feedback, and manage teaching and learning activities with large groups. Training allowed for pedagogical practice, helped narrow knowledge gaps, and supported the transfer of knowledge and practices to classroom instruction in colleges of teacher education.

\section{Instructional Methods}

Teacher educators recognized effective pedagogical skills such as using explicit instruction, practicing literacy skills and strategy instruction through microteaching, and engaging in practicum and fieldwork. They also recognized the importance of modeling and giving student teachers time to practice using the primary mother tongue curriculum. They reported that they now must demonstrate how to teach primary school students, which they previously thought was too routine and below the academic sphere of a teacher educator.

The teacher educators confirmed that effective teaching methods and activities depended upon the needs of the student teachers, the content being 
taught, and available instructional materials. Teacher educators reported that the most common instructional methods used in the colleges of teacher education were

- question-and-answer (Q\&A) sessions and interactive lectures;

- working in pairs and in groups;

- direct/explicit instruction (gradual-release model);

- microteaching;

- practicum and fieldwork;

- individual and task-based work;

- audiovisual activities; and

- experience sharing and reflection.

While field visits were cited as a valuable component in pre-service teacher education, they appeared to have been uncommon (except in the case of practicum) due to the lack of transportation to primary schools located far from the colleges of teacher education. Figure 2-1 shows the general types of classroom practices that were observed during monitoring and evaluation.

\section{Self-Assessment}

Teacher educators assessed their own progress and performance through answering questions: "What new things did I learn?" "Where am I?" and "What do I need to know?" One teacher educator discussed his personal method of identifying areas for learning and setting learning goals before attending workshops. Teacher educators also assessed student teachers' progress in identifying knowledge gaps to inform instruction, and some teacher educators reported that they had begun to differentiate instruction in their own classrooms.

\section{Collaboration}

Teacher educators maintained that collaborative learning through discussions among team members during module development and adaptation helped them address misunderstandings about pedagogy and content, thereby supporting the development of communities of learners. Several teacher educators described how collaboration (including classroom observations and feedback) facilitated changes in beliefs and practices. 


\section{Figure 2-1. Teaching practices in Mother Tongue 201 classrooms in colleges of teacher education}

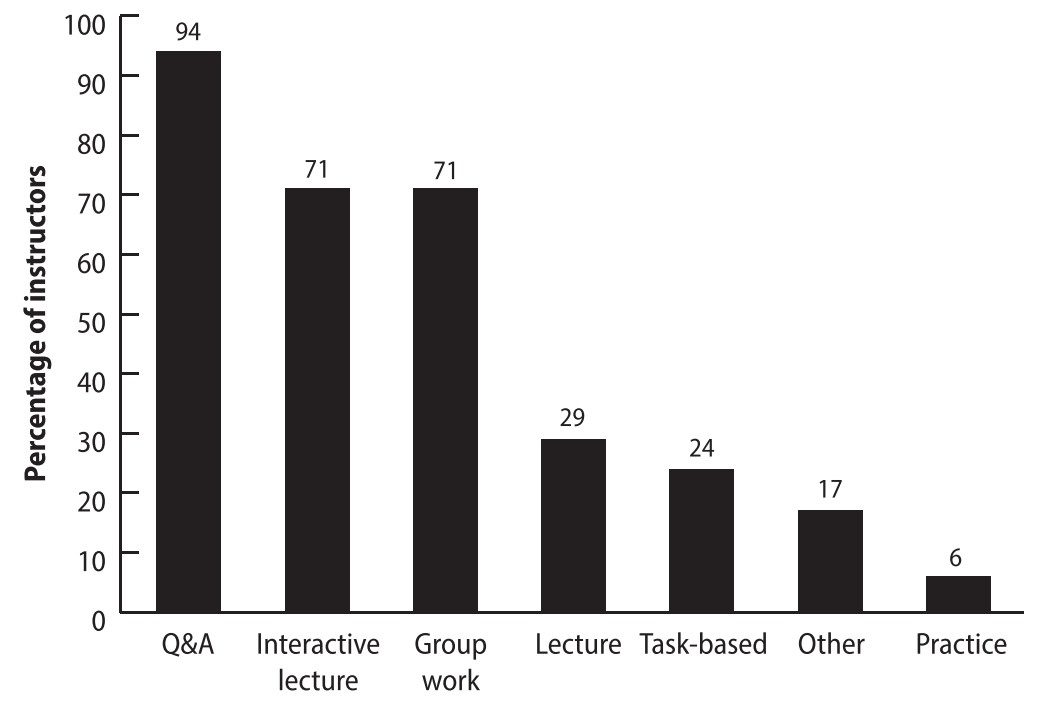

$\mathrm{Q} \& \mathrm{~A}=$ question and answer.

Collaborative interactions emerged at both the college level and across regional and language barriers to support the exchange of ideas on the contents and activities of the modules as well as classroom practices among teacher educators. Due to inconsistent Internet connections and lack of access to social media, teacher educators most frequently used mobile phones and text messaging to communicate. Additionally, these collaborations resulted in the mentoring and, in some cases, training of new instructors on content and pedagogy and fostered feelings of shared responsibility and a willingness to learn from others. As a result, feelings of isolation decreased considerably for teacher educators in the Mother Tongue Language Program and at the colleges of teacher education.

Participation in the READ-TA project and in the communities of learners supported major shifts in teacher educators' conceptualization of reading and reading comprehension as well as their beliefs regarding the nature of reading in the mother tongue. Specifically, they moved from the idea that reading is a natural process requiring little effort from students and teachers to an understanding that reading is a developmental process that requires learning necessary skills and strategies that build comprehension. Building 
communities of learners and collaborating across regional and language boundaries was identified by many teacher educators as the most influential aspect of the project.

\section{Research Question 2: What Was the Impact of Teacher Educators' New Practices on the Student Teachers' Preparation to Teach in the Primary School? \\ Teacher Educators' Perceptions}

Comments teacher educators made regarding what student teachers should know and be able to do included (1) "[be] well equipped with subject matter," (2) "make learners think for the future-visionaries," and (3) "make learners know and use [skills] in life. If [they] don't, [they] aren't learning." Some teacher educators also emphasized the importance of guiding student teachers through the process of translating learning theory into classroom practice. Teacher educators indicated that they had moved from a theoretical focus to using participatory, student-centered teaching and learning activities. Identified instructional methods included the use of presentations, discussions, and microteaching in the teacher education classroom. This process not only supported student teachers' preparation for fieldwork but also provided opportunities for teacher educators to give constructive feedback and for the student teachers to reflect on their teaching practices. Other practices used were group work, explicit instruction and the gradualrelease model, and support to student teachers with disabilities. Important activities for building student teacher capacity included projects requiring application of learning, field experiences, and primary school visits.

Teacher educators reported that practice teaching in primary classrooms allowed for practical, hands-on, and realistic experiences in which misconceptions could be remediated. Teacher educators who observed the student teachers in primary classrooms stated that student teachers were confident and competent in their instruction, particularly in teaching reading fluency and comprehension strategies. The teacher educators believed that most student teachers who received the new training were prepared to teach despite some gaps in specific skills and strategies, inadequate support from primary teachers, and lack of primary materials. While these successes are a solid foundation for change, a need for additional support for student teachers remains.

In primary classrooms where the new materials were available, student teachers were observed using the new methods. However, in some instances, student teachers were placed in primary school classrooms where veteran 
teachers continued to use the traditional methods and expected the student teachers to do the same. And yet, in classrooms in which the new primary materials were not available, some student teachers persisted in using the new methods and were able to sensitize other primary teachers on the new pedagogy. However, introducing new approaches did not always go smoothly. The teacher educators reported that dissonance had sometimes arisen between student teachers completing their practicum and their mentors. It remains to be seen whether these beginning teachers will continue to use the new practices or acculturate themselves to the traditional approach found in many primary schools.

There was a shared belief among teacher educators that the new Mother Tongue Language Program had resulted in improvement of student teacher quality and capacity for teaching (as compared with graduates from the past few years). Teacher educators described the impact on student teachers in terms of not only the student teachers' understanding of the new literacy concepts but also their reports of positive learning outcomes. Student teachers gained an understanding of the new primary school curriculum and felt successful during practicum. One teacher educator mentioned receiving a call from one of his former student teachers who wished to communicate gratitude for preparedness and competency in teaching the primary school curriculum. This teacher educator commented on the "very happy moment" when his efforts were recognized and resulted in the new teacher being able to effectively apply what had been learned to teach in the primary classroom.

\section{Student Teachers' Perceptions}

According to the student teachers, differences existed between the new courses and other courses in the program. The new courses prepared student teachers to teach primary students and informed them about what those students would need to learn and how to use differentiated instruction. They noted that the new course content used many new terms associated with literacy and other topics, requiring student teachers to learn and understand vocabulary and specific content knowledge related to literacy instruction. Student teachers appreciated the new pedagogy, which incorporated studentcentered, participatory teaching and learning activities such as group discussions and explicit instruction. In the final round of site visits to colleges of teacher education, the FSU team heard student teachers begin referencing the information and communication technology package provided by the READ-TA program. Student teachers stated that the use of technology in the 
Mother Tongue Language Program classes allowed the teacher educator to share resources with them via the projector and improved the learning experience.

Some student teachers had difficulty articulating their level of confidence in teaching children based on what they were presently learning. However, other student teachers stated that they could teach, use explicit instruction, and make learning enjoyable for children. Second-year student teachers had received some exposure to the primary school setting through observations during practicum. The student teachers who completed observations explained how the new course content prepared them for teaching in a primary school classroom. For instance, they commented that learning lesson planning was important for understanding what the teacher was doing, particularly when engaging students in cooperative learning activities.

Overall, student teachers recognized how information was connected across the new modules and generally agreed that the information would be important in their primary teaching career. Due to a lack of prior knowledge, the student teachers perceived modules' content as complex and relied on the teacher educators' support. However, most student teachers found the modules useful, practical, and highly relevant to instruction in the primary schools.

\section{Research Question 3: What Were the Barriers to Implementation and Sustainability of the Revised Mother Tongue Teacher Education Program? Institutional Obstacles}

Barriers were identified at four institutional levels: government, college, teacher education classroom, and primary school. At the government and college levels, teacher educators cited class size, lack of necessary resources (technology, materials, and time), inadequate payment for professional development activities (they received per diem but not a professional fee), and a lack of opportunities for certification and advanced degrees. At the teacher education level, it was reported that some teacher educators did not develop a deep understanding of the new methodology and technology and did not have a personal commitment to learning about and implementing the new program.

\section{Limited Resources}

The need for resources was an ongoing issue throughout the project, especially access to teaching resources such as printed course modules for the 
student teachers. Teacher educators had to adapt to this situation by requiring group work and sharing of the modules. The data revealed great variations in terms of resource allocation. At colleges of teacher education in some regions, there was only one printed module for every four to five student teachers, while at other colleges of teacher education, there was one module for each student teacher. This shortage added to the difficulties of small-group work and occasionally resulted in one or two student teachers completing the group activities while others passively waited for the activity to be completed. Several colleges of teacher education used their own resources to print copies of the modules for each student teacher; however, many had not yet received the final print-ready versions of the modules, which had been produced and distributed by the Ministry of Education and Regional State Education Bureaus.

Other resources that should have been available at the colleges of teacher education were the primary mother tongue curriculum and supplementary readers. Materials such as letter cards (or Fidel cards for languages with non-alphabetic scripts-two of the languages used in Ethiopia, Amharic and Tigrinya, are written with a version of the Ge'ez script known as "Fidel" and are also referred to as Saba-based languages), reference books, and journal articles would have further supported learning. A general need for basic classroom supplies such as whiteboards, chart stands, and markers existed at all colleges of teacher education. Hard copies of grades 1-4 materials were randomly available or personally procured by teacher educators, and hard copies of grades 5-8 materials were unavailable in either the colleges of teacher education or primary classrooms. Soft copies of grades 1-8 materials were uploaded to tablets supplied to most of the teacher educators; however, limited machine memory reduced the number of modules and materials that could be digitally stored.

\section{Technology}

Access to technology resources also proved to be challenging. The READ-TA program provided tablets for most teacher educators as well as one projector and one document camera for each college of teacher education in the five target regions. The projector and document camera were housed in a classroom designated as the sole mother tongue technology classroom at each college of teacher education. However, multiple classes were often scheduled during the same time period, and, while instructors had presentation slides, videos, and other resources that they could show to the class, most of the 
colleges of teacher education had insufficient technology. Another factor related to the limitations of technology was the lack of and inconsistent availability of Internet access and utilities. Power outages and intermittent electricity were common features of colleges of teacher education in every region. Internet access was available at many colleges of teacher education but not in the classrooms. Student teachers requested more direct support: They wanted to become tomorrow's teachers who are able to teach "the right way."

\section{Time}

At the teacher education classroom level, the depth and breadth of the modules exposed the student teachers' lack of prior knowledge, resulting in classroom discussions that exceeded the allotted class time. In addition, many teacher educators were engaged in other READ-TA and Ministry of Education activities as well as other assignments that interfered with and reduced their instructional time. Student teachers said the modules were far too much to cover in a semester and added that certain areas need not be repeated from previous modules-although they also commented that multiple exposures were necessary for understanding new concepts.

\section{Course Scheduling}

Student teachers made recommendations regarding the sequence of courses in the Mother Tongue Language Program to facilitate understanding of the content and to distribute the course load across the program. Their comments indicated that the current schedule did not allow enough time to thoroughly learn the content of most modules. However, monitoring and evaluation observations revealed that many teacher educators lacked efficient time management and pedagogical strategies.

\section{Fieldwork}

Teacher educators also discussed challenges associated with student teachers' field experiences in primary schools. In some cases, colleges of teacher education were located very far from primary schools, and the colleges of teacher education did not provide transportation for field experiences outside of the formal teaching practicum. Also, student teachers often found that the primary schools to which they were assigned lacked books and mother tongue materials.

\section{Collaboration}

Once teacher educators engaged in communities of learners, they began scheduling time for collaborative meetings. Some deans and department 
heads at the colleges of teacher education provided support in terms of collaboration time and space, while other deans and department heads declined supporting collaborative efforts by the teacher educators.

\section{Misalignment of Practicum and Courses}

The teaching practicum and the course assignments for the new mother tongue modules were not well-aligned, resulting in disparities between course and practicum requirements. Completing primary school-based projects or activities not related to the teaching practicum proved difficult for many student teachers given the distance from their colleges of teacher education and the need to coordinate the work with primary school staff. While some student teachers were able to complete the module projects or activities when they were at primary schools, others had to complete the projects via nonschool-based activities. Often, projects and activities were skipped due to time constraints. It appears very unlikely that student teachers will carry out fieldwork while completing teacher education courses unless the practicums are revised to better match the field assignments in the new modules.

\section{External Funding}

Lack of funding was said to inhibit motivated instructors from completing advanced degree programs. Teacher educators recognized that information in their field was constantly changing, requiring continuous follow-up and learning. Teacher educators desired access to more information (research and textbooks) and wanted to build their depth of knowledge in active learning, brainstorming, gap lecture (question and answer), pedagogy, primary materials, assessment, and technology use.

\section{Limitations}

The findings reported herein were identified through the various data collected from teacher educators and student teachers. These items were selected by the FSU team based on evaluation tools found in the research, used in other programs, and adapted to the Ethiopian context. The data were collected by both the FSU team and selected mother tongue teacher educators. As a result, responses may have been affected by social desirability. The multiple data tools helped to triangulate the findings and identify changes in beliefs and practices. The current conclusions provide initial insights into the areas examined. It is recommended that follow-up activities be completed to determine what changes have been sustained since the completion of the project in December 2017. 


\section{Conclusions}

\section{Changing Teaching Practices of Teacher Educators}

The major questions for this study included (1) What was the impact of professional development on teacher educators' beliefs and practices?

(2) What was the impact of teacher educators' new practices on student teachers' preparation to teach in primary classrooms? and (3) What were the barriers to implementation?

The READ-TA project supported professional development focused on systematic change in beliefs and practices of teacher educators. The findings of the study revealed that most teacher educators had moved somewhat from teaching theory to integrating effective teaching practices, including linking their instruction to the primary curriculum. Previous studies on teacher educators' professional development also have reported changes in teacher educators' beliefs and practices regarding literacy when the instructional design considered two basic principles and practices of adult education: considering their background knowledge and giving them immediate opportunities to apply innovative ideas and practices (Hadar \& Brody, 2016; Ottley et al., 2015).

Although shifts in teacher educators' literacy conceptions and practices were observed, the extent of the changes varied among teacher educators, and the change in literacy practices remained a work in progress. It is worth noting that teacher educators required repeated and continuous exposure to learn new literacy concepts and practices, and some teacher educators continued to raise questions of clarity on literacy concepts discussed in the first module in later workshops. Teacher educators' level of competence also appeared to influence the fidelity of the modules' implementation, supporting the findings of other researchers (Hwang, 2014; Korthagen et al., 2006).

Hökkä and colleagues (2017) found that learning communities provided a social context, which can be a natural and fruitful method of professional development for teacher educators. Learning communities evolved gradually from groups of teacher educators assigned to work on the module development and take part in trainings. At the beginning of the READ-TA initiative, teacher educators reported that they did not ask questions or appreciate the views of others, as they believed that their conceptions and knowledge of literacy were correct. However, over time, teacher educators reported that they developed skills they needed for collaborating and learning together among not only teacher educators who spoke the same mother tongue but also those 
who spoke other mother tongues. This collaboration and change required a safe learning environment in which teacher educators were reminded that they could ask FSU specialists questions and should respect the views of their colleagues. This collaboration transcended discussion and sharing of ideas in workshop venues and transferred to collaboration within colleges of teacher education and to the training of others.

At the teacher education level, both employing reflective practices and engaging in discussions with other teacher educators improved implementation of new practices and student learning. Teacher educators used reflection to examine (1) implementation of research-based concepts and practices and (2) the impact on student teachers' learning. Some teacher educators also engaged in communities of learners, either informally or formally. They reported positive effects on personal identity, professional development, and the work environment. These findings confirm those of previous studies that continuously engaging in asking questions and using evidence from practice can lead to considerable changes in teacher educators' beliefs and behaviors (Harootunian \& Yargar, 1980; Korthagen et al., 2006).

Teacher educators noticed changes in the practices of student teachers, which appeared in turn to strengthen the new practices of teacher educators, supporting Guskey's (2002) findings that observing improvement in students' behaviors reinforced changes in teacher educators' practices. Teacher educators also reported that student teachers appeared to be competent to teach the new primary school curriculum. However, as Hökkä and colleagues (2017) pointed out, the effects of pre-service teacher education programs on student teachers may not outlast the beginning years of teaching unless teachers are supported by sound professional development opportunities.

Barriers to new programs have been identified at many structural levels by other researchers (e.g., Hwang, 2014; Vanassche \& Kelchtermans, 2014). This study identified similar concerns related to institutional structure at multiple levels (national, regional, and local), such as resource availability, lack of instructional time, teacher educator course overload, and student teachers' lack of prior knowledge. These repeatedly observed and reported resource scarcities could present a major barrier to implementation fidelity and sustainability of the revised Mother Tongue Language Program courses.

The data collection tools used in this case study were not originally designed with a research publication in mind; however, the information gleaned from the data collected consistently revealed themes relevant to multi-language literacy projects. Throughout the project and the research 
process, FSU reading specialists spent time reflecting, noting, and discussing lessons learned and brainstorming ways to build success into future activities.

\section{Recommendations}

Based upon the Ethiopian context and experiences, the following major themes are presented as future recommendations for stakeholders, policy makers, and education program implementers.

\section{Promote Ongoing Professional Development}

Unless program-sponsored training workshops are supported by continuous professional development opportunities, introductory workshops, and access to resources and research, teacher educators will not have adequate professional preparation on the topic of training. A professional development training manual for new hires is also highly recommended, as teacher educators require a high-quality introduction to and repeated trainings on content and pedagogy. One-time training of each module for teacher educators had variable impact on knowledge development, even when participatory teaching and learning activities were implemented. Some teacher educators fully understood the major literacy concepts by the third or fourth training session, whereas others continued to exhibit misunderstandings about basic concepts even after four module training sessions (occurring at six-month intervals). In short, initial trainings must be paired with in-depth analyses of the content, followed by refresher workshops occurring at regularly scheduled intervals and activities to increase teacher educators' knowledge. An accountability component could motivate teacher educators to stay involved in training sessions and take responsibility for their own professional development.

\section{Prepare for "Unlearning and Relearning"}

Teacher educators need time to uncover their misconceptions, or "unlearning and relearning" (Cochran-Smith, 2003). Reflective skills develop slowly and through repeated exposure, and deep reflection can take place only when a person has a deep understanding of the concept. The teacher educators required months, if not years, to discover their misunderstandings-and doing so is a continual process. After having learned how much they did not know previously, these teacher educators reasoned that a much better version of the adapted materials would be possible if they were provided a final opportunity to review and revise all the modules. 


\section{Train the Trainers}

Successful implementation of capacity development and materials preparation requires that teacher educators' prerequisite knowledge, beliefs, and skills be examined. Development workshops and initial trainings should build on prior knowledge for a core set of teacher educators, who could then be tasked with roles in major materials development (i.e., course modules) and teacher education-level training. Capacity building is more effective when a core team of individuals acquires content and pedagogical proficiency and then can train others. Findings from the study indicate that importing ready-made materials would have devalued the process of designing and developing course modules as a critical aspect of capacity development. Group work and discussions contributed to a more thorough understanding of literacy concepts and ideas, as well as pedagogical methods such as the gradual-release model.

\section{Observe and Support}

It is imperative for project technical teams to conduct field observations and provide continuous support throughout implementation. Firsthand information gleaned from observations can help the technical team understand contextual challenges and gather insights helpful for developing training materials and modules. In addition to field observations, teacher educators need continuous follow-up support and professional development opportunities conducted in both the mother tongue and English. Project implementers should consider exploring ways to engage stakeholders in development, execution, and ongoing support. A gradual-release model for these steps would allow skilled local trainers to slowly take responsibility for training and support as their knowledge grew.

\section{Communities of Learners}

Continuous professional development in the form of planned, recurring workshops and seminars at the teacher education level is suggested. This training could be similar to the English Language Improvement Centers and the Higher Diploma Program at colleges of teacher education (see Gebru, 2016, for details on these two programs). Teacher education-level institutionalization of formal professional learning communities would allow teacher educators to discuss and share ideas, engage in academic dialogue, become reflective practitioners, and continue their professional development. 
Collaboration among the colleges of teacher education, the mother tongue pre-service program, and primary schools will be necessary to ensure that cooperating teachers support student teachers in applying the knowledge and practices that they gain in their pre-service education program. Collaboration across regions and languages should continue to ensure alignment across all teacher education mother tongue programs. Entities such as the Ministry of Education, Regional State Education Bureaus, and Zonal Education Bureaus could observe the implementation of completed modules and facilitate the revision of the remaining six mother tongue course modules that were not part of this project. Meetings, trainings, and seminars are all methods that these entities could use to provide ongoing support.

\section{Work to Institutionalize Changes}

Our evidence showed that the early changes in teacher educators' practices might not last unless they receive sustained support from all institutional levels while these innovative ideas and practices are institutionalized in colleges of teacher education. Collaborative time and activities should be allocated by the teacher education administration as part of the teacher educators' staff responsibilities. Professional learning communities could provide a means for teacher educators to receive support and build sustainability. Observations and evaluations would allow teacher educators to receive administrative and peer feedback. Highly skilled veteran teacher educators, with support from the Ministry of Education and Regional State Education Bureaus, could lead an initial orientation, continuous professional development trainings, and mentoring. In addition, teacher educators need more resources to support classroom instruction (i.e., modules, information and communication technology, supplementary materials, research, and reference books).

\section{Conduct Further Research on Teacher Educators and Implementation of New Practices}

Finally, although we examined the literature about teacher educators' knowledge, practices, and professional development needs, even after our analysis, we found gaps and several questions that remained to be answered. Future research should examine the factors most likely to result in implementation of new practices, to build capacity, and to ensure sustainability. This type of research will require modified thoughts about what roles teacher educators play within an education system and how those 
roles affect professional development opportunities for teacher educators, teachers, and student teachers. All actors within an education system must recognize that in-depth change can take many years to implement. The focus should be on change that improves the practices of teacher educators and the student teachers they teach, including observations of new teacher educators and primary teachers to ensure they can implement the improved teaching practices they have learned.

\section{Align Pre-service Teacher Education with Country-Based Policies} The READ-TA project provided technical assistance to design and develop the pre-service teacher-training mother tongue curriculum and materials in alignment with the primary curriculum and to train over 200 teacher educators on the new mother tongue language curriculum. Engaging the teacher educators in the development of these pre-service teacher-training modules, and providing them with training, support, and reading resources in the target languages, helped motivate them to adopt changes to their ways of teaching that resulted in positive outcomes, as reported by the teacher educators and student teachers. Teacher educators recognized the importance of connecting teacher education course content (modules) with the recently developed primary school curriculum. Many of the project interventions, including culturally and linguistically appropriate textbooks, along with pre- and in-service teacher training, were associated with positive impacts on student learning elsewhere (Popova, Evans, \& Arancibia, 2016).

\section{Policy Implications of Pre-service Teacher Education Reforms in Ethiopia}

All the previous recommendations are pertinent to the context of the case study. However, ensuring long-term benefits of current reforms for the teaching life cycle will require continuous investment in the sector and the Ethiopian government's commitment to support proposed policies and goals set for the 2016-2020 education sector plan.

In its situation analysis, the next five-year Education Sector Development Program, for 2016-2020, identified structural education challenges, particularly "that children in primary first cycle were not developing the basic skills required to learn effectively in later years" (Federal Ministry of Education, Ethiopia, 2015, p. 17). Moreover, "the low quality of outcomes and persistent high dropout and repetition rates reflect low quality of educational inputs, i.e. skilled teachers, relevant teaching and learning materials, etc." (Federal Ministry of Education, Ethiopia, 2015, p. 19). The low educational 
attainment in the country has serious implications for national development and economic growth.

The technical assistance that the READ-TA program provided to the government of Ethiopia during 2012-2017 aligned with both national education strategic plans (Federal Ministry of Education, Ethiopia, 2010, 2015).

Under the 2010-2015 strategic plan, the technical assistance corresponded to the priority of "Quality of Primary and Secondary Education" (p. 19), as follows:

1. Component: Teachers' and leaders' development. Target outcomes:

(1) Qualifications of teachers significantly improved; and

(2) Teaching processes rendered more effective through improved pre-service teacher training, in-service training and professional support. (p. 22)

2. Component: Curriculum, textbooks and assessment. Target outcome: (1) Revised school curriculum made responsive to international economic and social realities, national democracy and gender equity. (p. 22)

Under the 2016-2020 strategic plan, the project's technical assistance aligned with the key plan goal "General Education: Quality”:

1. Component 1: Teachers' and leaders' development; subcomponent 2: Teachers' training and professional development. (pp. 55-60)

2. Component 2: Curriculum, teaching and learning materials; subcomponent 1 , curriculum development; and subcomponent 2 , teaching and learning materials. (pp. 63-65)

The two Education Sector Development Program plans also defined challenges related to the quality of education and set goals for investment in the sector. For instance, remaining challenges with relevance to the pre-service teacher education sector include (Federal Ministry of Education, Ethiopia, 2015):

- Regions with multiple languages of instruction and consequent implications for the quality and equity of education offered across the regions. (p. 58)

- Lack of pedagogical skills among teachers is the largest barrier to effective implementation of the revised curriculum... . The professional competencies of teacher educators are supported through the higher diploma program; however, this program does not yet equip teacher 
educators with the skills required to provide training on modern teaching methods or other key pedagogical skills. (pp. 57-58)

- There exists no standardized method or national guideline for evaluation of teacher competency on completion of teacher training. Region-specific approaches are applied, and this has an impact on the consistency of knowledge and skills among new teachers graduating from colleges of teacher education and universities. (p. 57)

To address these challenges, the Ministry of Education developed specific lines of action in its Education Sector Development Program for 2016-2020, including the following:

- The government will ... provide support to [improve] qualification processes and standards (pre-service training), enriching continuous professional development (CPD) and strengthening supervision processes (inservice training). (p. 57)

- During pre-service training, teachers will be prepared to teach in the language of instruction demanded by their expected deployment. Teachers of mother-tongue language subjects will be recruited from the local area to assure full mother-tongue proficiency. (p. 58)

- [Information and communication technology] will also be fully integrated in teachers' training courses and supported with practice so that teachers are better equipped to use technology and to teach and assist their students with technology. (p. 58)

- Pre-service training: Candidate selection processes for colleges of teacher education will be improved and minimum entry requirements established. (p. 57)

- The current gender imbalance among teacher trainees will be addressed with the objective of achieving, as soon as possible, a 50 percent share of women teacher trainees in new annual intakes to colleges of teacher education; and in ensuring retention of all teacher trainees. (p. 57)

- A strengthened evaluation process - and additional quality assurance-will inform improvements to teacher training in colleges of teacher education and universities supplying trained teachers. (p. 57)

- In addition to assuring the quality of service delivery through licensing teachers, colleges of teacher education will be accredited to certify that the standards for teacher education are met. (p. 73) 
- Strengthening all colleges of teacher education to train pre-primary teachers for certificate and diploma courses so that they can deploy adequate qualified teachers. (p. 79)

By the end of the READ-TA project in December 2017, not all the above recommendations had been implemented. The implementation of the above plans set out by the Ministry of Education to strengthen pre-service teacher education at both teacher education and university levels by setting the standards for accreditation, preparing teachers to teach in the language of instruction, and providing them with the resources to succeed (i.e., instructional materials, skilled teacher educators, assessment tools, etc.) is still in progress. For instance, an increase in the number of female student teachers at colleges of teacher education was evident in the last year of the project, as was increased support for integration of information and communication technology into the pre-service program at colleges of teacher education.

Although we have not directly investigated the impact of the pre-service teacher professional development on the primary school teachers recently graduated from the teacher education three-year program, we may speculate that the overall READ-TA activities may have contributed to the attainment of the strategic plan's goals to improve general education quality, which are expected to improve children's literacy skills and boost achievement and economic productivity.

\section{Acknowledgments}

The authors would like to acknowledge RTI International, especially the staff of the Reading for Ethiopia's Achievement Developed Technical Assistance (READ-TA) project, for support during the project activities that led to the preparation of this chapter. The READ-TA project (2012-2017) was funded by the United States Agency for International Development (USAID) under Cooperative Agreement No. AID-663-A-12-00013.

\section{References}

Ali, T. (2017). Raising teachers' voices: An in-depth qualitative inquiry into teachers' working conditions and professional development needs in Khyber Pakhtunkhwa, a province of Pakistan. Teacher Development, 22(1), 78-104. https://doi.org/10.1080/13664530.2017.1308432 
Amado, A., Dalelo, A., Adomßent, M., \& Fisher, D. (2017). Engaging teacher educators with the sustainability agenda: A case study of a pilot professional development program from Ethiopia. International Journal of Sustainability in Higher Education, 18(5), 715-737. https://doi.org/10.1108/ ijshe-02-2016-0029

Ball, D. L., \& Forzani, F. M. (2009). The work of teaching and the challenge of teacher education. Journal of Teacher Education, 60(5), 497-511. https:// doi.org/10.1177/0022487109348479

Barnes, A., Zuilkowski, S. S., Mekonnen, D., \& Ramos-Mattoussi, F. (2018). Improving teacher training in Ethiopia: Shifting the content and approach of pre-service teacher education. Teaching and Teacher Education, 70, 1-11. https://doi.org/10.1016/j.tate.2017.11.004

Blazer, C. (2005). Literature review on professional development for teachers. Miami, FL: Dade County Public Schools. Retrieved from http://citeseerx. ist.psu.edu/viewdoc/download?doi=10.1.1.558.9262\&rep=rep1\&type=pdf

Bold, T., Filmer, D., Martin, G., Molina, E., Rockmore, C., Stacy, B., ... Wane, W. (2017). What do teachers know and do? Does it matter? Evidence from primary schools in Africa (Policy Research Working Paper 7956). Washington, DC: The World Bank Group. https://doi.org/10.1596/ 1813-9450-7956

Brody, D., \& Hadar, L. (2011). "I speak prose and I now know it." Personal development trajectories among teacher educators in a professional development community. Teaching and Teacher Education, 27(8), 1223-1234. https://doi.org/10.1016/j.tate.2011.07.002

Clark, S. K., Jones, C. D., Reutzel, D. R., \& Andreasen, L. 2013. An examination of the influences of a teacher preparation program on beginning teachers' reading instruction. Literacy Research and Instruction, 52(2), 87-105. https://doi.org/10.1080/19388071. 2012.754520

Cochran-Smith, M. (2003). Learning and unlearning: The education of teacher educators. Teaching and Teacher Education, 19, 5-28. https://doi. org/10.1016/s0742-051x(02)00091-4

Darling-Hammond, L. (2006). Constructing 21st-century teacher education. Journal of Teacher Education, 57(3), 300-314. https://doi.org/10.1177/ 0022487105285962 
Darling-Hammond, L., Wei, R. C., Andree, A., Richardson, N., \& Orphanos, S. (2009). Professional learning in the learning profession: A status report on teacher development in the US and abroad. Technical report. Washington, DC: National Staff Development Council and the School Redesign Network at Stanford University. Retrieved from http://learningforward. org/docs/default-source/pdf/nsdcstudytechnicalreport2009.pdf? sfvrsn=0\&plus;

DeMonte, J. (2013). High-quality professional development for teachers. Washington, DC: Center for American Progress. Retrieved from https://cdn.americanprogress.org/wp-content/uploads/2013/07/DeMonte Learning4Teachers-1.pdf

Edmond, N., \& Hayler, M. (2013). On either side of the teacher: Perspectives on professionalism in education. Journal of Education for Teaching, 39(2), 209-221. Retrieved from https://www.tandfonline.com/doi/full/10.1080/02 607476.2013 .765193

Federal Ministry of Education, Ethiopia. (2010). Education sector development program IV (ESDP IV), 2010/2011-2014/2015, 2003 EC-2007 EC): Program action plan. Addis Ababa, Ethiopia: Federal Ministry of Education.

Retrieved from https://www.globalpartnership.org/content/ ethiopia-education-sector-development-program-iv-2010-2015

Federal Ministry of Education, Ethiopia. (2015). Education sector development programme V (ESDP V), 2008-2012 EC, 2015/16-2019/20 GC: Programme action plan. Addis Ababa, Ethiopia: Author. Retrieved from https://www.globalpartnership.org/content/ education-sector-plan-2016-2020-ethiopia

Ferguson, R. F. (2006). Five challenges to effective teacher professional development: School leaders can improve instruction by addressing these issues. Journal of Staff Development, 27(4), 48-52.

Fisher, D., \& Frey, N. (2008). Better learning through structured teaching: A framework for the gradual release of responsibility. Alexandria, VA: ASCD.

French, V. W. (1997). Teachers must be learners, too: Professional development and national teaching standards. NASSP Bulletin, 81(585), 38-44. https://doi.org/10.1177/019263659708158507

Fullan, M. G., \& Miles, M. B. (1992). Getting reform right: What works and what doesn't. Phi Delta Kappan, 73(10), 745-752. 
Gebru, D. A. (2016). Effectiveness of higher diploma program for early career academics in Ethiopia. Studies in Higher Education, 41(10), 1741-1753.

Gulamhussein, A. (2013). Teaching the teachers: Effective professional development in an era of high stakes accountability. Alexandria, VA: Center for Public Education. Retrieved from http://www.centerforpubliceducation. org/system/files/Professional\%20Development.pdf

Guskey, T. R. (2002). Professional development and teacher change. Teachers and Teaching, 8(3), 381-391. https://doi.org/10.1080/135406002100000512

Guskey, R. R., \& Yoon, K. S. (2009). What works in professional development? Phi Delta Kappan, 90(7), 495-500. https://doi.org/10.1177/003172170909000709

Hadar, L., \& Brody, D. (2010). From isolation to symphonic harmony: Building a professional development community among teacher educators. Teaching and Teacher Education, 26(8), 1641-1651. https://oi.org/10.1016/ j.tate.2010.06.015

Hadar, L., \& Brody, D. (2016). Talk about student learning: Promoting professional growth among teacher educators. Teaching and Teacher Education, 59, 101-114.

Harootunian, B., \& Yargar, G. P. (1980, April). Teachers' conceptions of their own success. Paper presented at the Annual Meeting of the American Educational Research Association, Boston, MA.

Hökkä, P., Vähäsantanen, K., \& Mahlakaarto, S. (2017). Teacher educators' collective professional agency and identity: Transforming marginality to strength. Teaching and Teacher Education, 63, 36-46. https://doi. org/10.1016/j.tate.2016.12.001

Hwang, H. (2014). The influence of the ecological contexts of teacher education on South Korean teacher educators' professional development. Teaching and Teacher Education, 43, 1-14. https://doi.org/10.1016/j. tate.2014.05.003

Jones, L. L., \& Hayes, A. (1980). How valid are surveys of teacher needs? Educational Leadership, 37(5), 390-392. Retrieved from http://www.ascd. org/ASCD/pdf/journals/ed_lead/el_198002_jones.pdf

Joyce, B., \& Showers, B. (2002). Designing training and peer coaching: Our needs for learning. In B. R. Joyce (Ed.), Student achievement through staff development (3rd ed., pp. 69-94). Alexandria, VA: Association for Supervision and Curriculum Development. 
Kennedy, A. (2005). Models of continuing professional development: A framework for analysis. Journal of In-service Education, 31(2), 235-250. https://doi.org/10.1080/13674580500200277

Korthagen, F., Loughran, J., \& Russell, T. (2006). Developing fundamental principles for teacher education programs and practices.Teaching and Teacher Education, 22(8), 1020-1041. https://doi.org/10.1016/j. tate.2006.04.022

Koster, B., Brekelmans, M., Korthagen, F., \& Wubbels, T. (2005). Quality requirements for teacher educators. Teaching and Teacher Education, 21(2), 157-176. https://doi.org/10.1016/j.tate.2004.12.004

Lanier, J., \& Little, J. (1986). Research in teacher education. In M. C. Wittrock (Ed.), Handbook of research on teaching (pp. 527-569). New York, NY: Macmillan.

Lave, J., \& Wenger, E. (1991). Situated learning: Legitimate peripheral participation. Cambridge, United Kingdom: Cambridge University Press.

Lieberman, A., \& Mace, D. H. P. (2008). Teacher learning: The key to educational reform. Journal of Teacher Education, 59(3), 226-234. https:// doi.org/10.1177/0022487108317020

Lindvall, J., Helenius, O., \& Wiberg, M. (2018). Critical features of professional development programs: Comparing content focus and impact of two large-scale programs. Teaching and Teacher Education, 70, 121-131. https://doi.org/10.1016/j.tate.2017.11.013

Lunenberg, M., Korthagen, F., \& Swennen, A. (2007). The teacher educator as a role model. Teaching and Teacher Education, 23(5), 586-601. https://doi. org/10.1016/j.tate.2006.11.001

McIntyre, D., \& Hagger, H. (1992). Professional development through the Oxford Internship model. British Journal of Educational Studies, 40(3), 264-283.

McLaughin, M. W., \& Talbert, J. E. (2001). Professional communities and the work of high school teaching. Chicago, IL: University of Chicago Press.

Moats, L. C., \& Foorman, B. R. (2003). Measuring teachers' content knowledge of language and reading. Annuals of Dyslexia, 53(1), 23-45. https://doi.org/10.1007/s11881-003-0003-7 
National Institute of Child Health and Human Development (NICHD). (2000). Report of the National Reading Panel. Teaching children to read: An evidence-based assessment of the scientific research literature on reading and its implications for reading instruction. Reports of the subgroups (US National Institutes of Health Publication No. 00-4754).

Washington, DC: US Government Printing Office. Retrieved from https:// www.nichd.nih.gov/publications/pubs/nrp/documents/report.pdf

Nkambule, T., \& Mukeredzi, T. G. (2017). Pre-service teachers' professional learning experiences during rural teaching practice in Acornhoe, Mpumalanga Province. South African Journal of Education, 37(3), 1-9. https://doi.org/10.15700/saje.v37n3a1371

Ottley, J. R., Piasta, S. B., Mauck, S. A., O’Connell, Q., Weber-Mayrer, M., \& Justice, L. M. (2015). The nature and extent of change in early childhood educators' language and literacy knowledge and beliefs. Teaching and Teacher Education, 52, 47-55. https://doi.org/10.1016/j.tate.2015.08.005

Piper, B. (2010). Ethiopia Early Grade Reading Assessment data analytic report: Language and early learning. Prepared for USAID under the Education Data for Decision Making (EdData II) project, Task Order Nos. EHC-E-07-04-00004-00 and AID-663-BC-10-00001 (RTI Tasks 7 and 9). Research Triangle Park, NC: RTI International. Main report retrieved from http://pdf.usaid.gov/pdf_docs/PNADY834.pdf; regional findings annex retrieved from http://pdf.usaid.gov/pdf_docs/PNADY835. pdf

Popova, A., Evans, D. K., \& Arancibia, V. (2016). Training teachers on the job: What works and how to measure it (Policy Research Working Paper No. 7834). Washington, DC: World Bank. Retrieved from https:// openknowledge.worldbank.org/handle/10986/25150

Rosenshine, B., \& Stevens, R. (1986). Teaching functions. In M. C. Wittrock (Ed.), Handbook of research on teaching (3rd ed., pp. 376-391). New York, NY: Macmillan.

RTI International. (2014). Ethiopia 2014 Early Grade Reading Assessment: Report of findings. Prepared for USAID/Ethiopia under READ-TA, Cooperative Agreement No. AID-663-A-12-00013. Research Triangle Park, NC: RTI International. Retrieved from http://pdf.usaid.gov/pdf_ docs/PA00MHT3.pdf 
RTI International \& Florida State University. (2013). Baseline assessment of pre-service teacher education programs at colleges of teacher education in Ethiopia. Prepared for USAID/Ethiopia under the Reading for Ethiopia's Achievement Developed Technical Assistance (READ-TA) project, Cooperative Agreement No. AID-663-A-12-00013. Research Triangle Park, NC: Authors. Retrieved from http://pdf.usaid.gov/pdf_docs/PA00MHTB.pdf RTI International \& Florida State University. (2015a). Module 1: MT 201, Latin. Cognitive development and literacy skills. Prepared for USAID under READ-TA, Cooperative Agreement No. AID-663-A-12-00013. Research Triangle Park, NC: Authors. Retrieved from http://pdf.usaid.gov/pdf_docs/ pa00mmcv.pdf

RTI International \& Florida State University. (2015b). Module 1: MT 201, Saba. Cognitive development and literacy skills. Prepared for USAID/ Ethiopia under READ-TA, Cooperative Agreement No. AID663-A-12-00013. Research Triangle Park, NC: Authors. Retrieved from http://pdf.usaid.gov/pdf_docs/PA00MMCW.pdf

RTI International \& Florida State University. (2016a). Module 2: TMT 222, Latin. Teaching reading and writing in primary school. Prepared for USAID/Ethiopia under READ-TA, Cooperative Agreement No. AID663-A-12-00013. Research Triangle Park, NC: Authors. Retrieved from http://pdf.usaid.gov/pdf_docs/pa00mn74.pdf

RTI International \& Florida State University. (2016b). Module 2: TMT 222, Saba. Teaching reading and writing in primary school. Prepared for USAID/Ethiopia under READ-TA, Cooperative Agreement No. AID663-A-12-00013. Research Triangle Park, NC: Authors. Retrieved from http://pdf.usaid.gov/pdf_docs/pa00mn75.pdf

RTI International \& Florida State University. (2016c). Module 3: TMT 224. Teaching speaking and listening in primary school. Prepared for USAID/ Ethiopia under READ-TA, Cooperative Agreement No. AID663-A-12-00013. Research Triangle Park, NC: Authors. Retrieved from http://pdf.usaid.gov/pdf_docs/pa00mmcz.pdf

RTI International \& Florida State University. (2016d). Module 5: MT 212, Introduction to language and linguistics. Prepared for USAID/Ethiopia under READ-TA, Cooperative Agreement No. AID-663-A-12-00013. Research Triangle Park, NC: Authors. Retrieved from https://pdf.usaid. gov/pdf_docs/PA00N38Z.pdf 
RTI International \& Florida State University. (2016e). Module 6: MT223, Children's literature in mother tongue. Prepared for USAID/Ethiopia under READ-TA, Cooperative Agreement No. AID-663-A-12-00013. Research Triangle Park, NC: Authors. Retrieved from http://pdf.usaid.gov/pdf_docs/ pa00mtm9.pdf

RTI International \& Florida State University. (2016f). Module 7: MT221 Developing reading skills in mother tongue. Prepared for USAID/Ethiopia under READ-TA, Cooperative Agreement No. AID-663-A-12-00013. Research Triangle Park, NC: Authors. Retrieved from http://pdf.usaid.gov/ pdf_docs/pa00mtmb.pdf

Schön, D. A. (1987). Educating the reflective practitioner: Toward a new design for teaching and learning in the professions. San Francisco, CA: Josey-Bass.

United Nations Educational, Cultural and Scientific Organization (UNESCO). (2015). Unpacking Sustainable Development Goal 4 Education 2030 guide. Paris, France: UNESCO. Retrieved from http://unesdoc. unesco.org/images/0024/002463/246300E.pdf

Van der Klink, M., Kools, Q., Avissar, G., White, S., \& Sakata, T. (2017). Professional development of teacher educators: What do they do? Findings from an explorative international study. Professional Development in Education, 43(2), 163-178. https://doi.org/10.1080/19415257.2015.1114506

Vanassche, E., \& Kelchtermans, G. (2014). Teacher educators' professionalism in practice: Positioning theory and personal interpretative framework. Teaching and Teacher Education, 44, 117-127. https://doi.org/10.1016/j. tate.2014.08.006

Wenger, E., McDermott, R., \& Snyder, W. M. (2002). Cultivating communities of practice: A guide to managing knowledge. Cambridge, MA: Harvard Business School Press.

Zeichner, K. (2005). Becoming a teacher educator: A personal perspective. Teaching and Teacher Education, 21(2), 117-124. https://doi.org/10.1016/ j.tate.2004.12.001 



\title{
School Leadership and Early Grade Reading: Examining the Evidence in Zambia
}

\author{
Mitchell Rakusin and Guy Bostock
}

\section{Introduction}

This chapter attempts to address persistent questions relating to school leadership and its impact on instructional change and early grade learning outcomes, particularly in developing countries. We explore how school leadership affects school reform and learning outcomes in developing countries whose organizational context and school culture contrast with the American and European education systems, in which most of the substantive research and literature on school leadership reside.

\section{Purpose and Relevance of Studying Leadership Effects from Zambia}

The purpose of the study covered in this chapter was to generate insight on which leadership styles, practices, and behaviors were characteristic of high- and low-performing schools in Zambia that were attempting to reform their curricula and instruction in early grade teaching and learning. The appeal from a policy perspective is that in a low-income, resourceconstrained education system like that in Zambia, one of the few things that the ministry can control is its ability to identify highly talented school leaders and place them into schools that have the greatest need.

Unlike the other chapters in this book, for Zambia we were not studying direct school leadership effects on teacher behavior and instructional change. For this study, we have attempted to identify leadership behaviors associated with some high-performing schools in Zambia and likewise those behaviors absent from or weakly associated with low-performing schools, particularly in the context of early grade reading improvement programs and instructional change. However, we assumed-because there is a sufficient body of research behind it-that teachers are always the direct mediators of learning. Nonetheless, creating the conditions for them to implement professional development principles is a necessary motivating condition, 
according to a range of theories explored in other chapters of this volume (see, in particular, the India chapter on teacher motivation theories). The importance of "instructional leadership," in particular, in the literature is relevant to this volume because instructional leadership is a form of professional development, loosely related to school-based coaching.

This study is pertinent because many developing countries have taken on significant education, school, and instructional reforms that focus on improving learning outcomes. Due to historic improvements in education access and enrollment indicators (World Bank, 2017), international donors such as the United States Agency for International Development (USAID), the World Bank, and the United Kingdom's Department for International Development have begun to shift resources from policy goals of improving access to those of improving teaching, learning, and outcomes.

In the decade leading up to 2017, early grade literacy and numeracy assumed policy priority in many developing countries, particularly with assistance from USAID. Thus, an increasing number of USAID-supported programs targeted interventions to improve the quality of early grade teaching, early grade learning materials, and early grade classroom conditions.

Nearly every donor-funded early grade learning improvement program includes some form of school leadership intervention. Most-if not allprograms include targeted and specific capacity-building programs aimed at school leaders and local education officials to strengthen education systems and instructional leadership and support early grade instructional reforms. These programs posit that school and education leadership is a fundamental part of the school improvement and learning outcome equation. Their theory of change is based on the premise that school leaders will have direct or indirect effects on the quality of teaching, as well as school and classroom conditions, which will have a direct impact on learning gains.

\section{Education Leadership in the Context of the Zambia Primary Literacy Program and the USAID/Zambia Read to Succeed Project}

Heads of school in Zambia are referred to as head teachers. They are, in effect, the most senior teachers, and they are assigned administrative and leadership responsibilities in addition to their teaching workload. While many head teachers in larger schools eliminate their teaching workload altogether, it is common to find head teachers who do both: manage schools and teach 
classes. Most head teachers are appointed based on some combination of experience and merit. There is no professional certification or minimum academic achievement prerequisite for becoming a head teacher.

In the Zambian education system, the head teachers are responsible for "managing effectively" and "ensuring" that their school (Ministry of General Education, 2018; Zambian Teachers' Forum, n.d.):

- provides academic programs for delivery of high-quality education;

- delivers administrative support services in the interest of effective and efficient operations;

- implements policies to guide administrative compliance;

- prepares departmental budgets for acquisition and management of monetary resources;

- monitors and evaluates programs to facilitate appropriate interventions;

- develops individual and departmental work plans to monitor and evaluate performance;

- manages human, financial, and material resources for achievement of set objectives;

- maintains up-to-date and accurate records to ensure the quality and accountability of school data;

- regularly inspects infrastructure, focusing on conducive learning and teaching environments; and

- supervises the teaching and administrative staff to attain the objectives of the school and departments.

This job description details the functional requirements of the head teacher. Leadership attributes, however, are conspicuously absent. There is no explicit requirement to engage in leadership practices outside the narrow confines of administrative management. Nevertheless, providing an academic program to ensure education quality, monitoring and evaluating academic programs, and supervising teachers all imply a modicum of educational leadership capacity to execute the head teacher role effectively.

Understanding effective leadership in the context of instructional reform is particularly relevant to Zambia's national early grade reading improvement efforts. In 2012, the Zambia Ministry of General Education adopted a new 
curriculum and approach for early grade reading instruction called the Primary Literacy Program (PLP). The USAID/Zambia-supported Read to Succeed (RTS) project, which operated from March 2012 to April 2017 (RTI International was a partner of lead implementer Creative Associates International), was designed to strengthen the capacity and skills of teachers and the Ministry of General Education to implement the PLP curriculum effectively in 1,200 schools, targeting the most disadvantaged schools, teachers, and students.

The RTS project took a "whole school, whole teacher, whole child" approach, which views schools as centers of learning, care, and support and addresses five key elements common to school-effectiveness models: learning, teaching, management and accountability, parental and community participation, and responsiveness to children's needs. Central to the RTS theory of change was the role of education leadership and management. The purpose of the RTS project was to transform the role of the head teacher and the zonal and district education support teams into one that leads and supports instructional reform efforts implemented by teachers in grades 1 to 3 as well as to provide guidance and counseling services to the most vulnerable learners. From 2012 to 2016, the RTS project supported over 1,200 schools across 18 districts, providing training and materials to teachers, head teachers, and school-community stakeholders.

Each intervention required by the PLP and supported by the RTS project reflected a significant change in traditional work practices by teachers and head teachers. The types of changes in the school and classroom included changes to time on task for reading and writing; curricular changes to reading instructional strategies and lesson execution; use of new textbooks and student books by teachers and students; dedicated time for peer-to-peer learning in teacher group meetings; and time spent by head teachers monitoring, observing, and reporting on teaching and learning in the classroom.

To enhance the capacity of head teachers' instructional leadership to support and sustain instructional changes and learning outcomes, the RTS project introduced specific tools and strategies that included the Zambia School Gateway, learner performance improvement plans, semi-structured teacher group meetings, and parental and community engagement activities. These interventions were buttressed by intensive in-service training and professional development of school head teachers, early grade teachers, and even leaders of parent-teacher associations. 
The Zambia School Gateway allowed head teachers to systematically monitor and report on teachers' instructional practices and pupils' literacy progress. The Gateway required head teachers to observe grade 2 teachers twice per year and report on specific instructional practices through a classroom observation protocol that covered seven dimensions of teaching and learning. Head teachers were also required to assess grade 2 pupils twice per year (at the beginning and end of school years) to report on pupils' literacy progress in four areas: phonics, vocabulary, reading comprehension, and writing.

The results of the teacher observations and student assessments were consolidated centrally in a database, and literacy progress reports were produced for every school that showed their performance over time and in comparison to the average scores and results from schools in their respective zones and districts. Similar reports were produced at zonal and district levels, with the intent to help officials identify and prioritize support to schools and areas that were in greatest need. This approach drew on the large body of research suggesting that systematic coaching of teachers through observations, monitoring, reporting, and feedback on teacher and student performance lead to gains in learning outcomes (Piper \& Zuilkowski, 2015; Steinberg \& Sartain, 2015).

The RTS project also introduced the concept of and supported the implementation of learner performance improvement plans (LPIPs). LPIPs were developed by a school leadership team consisting of school leaders, teachers, and community stakeholders in a participatory process in which they conducted a situational analysis and identified specific school-level activities and interventions that would positively influence reading achievement. The concept of the LPIP follows in the footsteps of the comprehensive school reform models for school improvement, in terms of fostering collaborative leadership practices and whole-school development approaches (Camburn, Rowan, \& Taylor, 2003; Datnow, 2005).

The RTS-introduced innovations to school leadership attempted to transform the role of the head teacher from that of administrator to instructional leader. Through the Zambia School Gateway, head teachers were recast as mentors and coaches, not merely teacher evaluators. They not only reported on results but also were trained on how to provide constructive feedback to teachers.

The LPIP process stimulated collaborative leadership practices, prioritized focus on learning outcomes, and emphasized the role of data for monitoring 
and evaluating. This process required head teachers to take on shared instructional leadership responsibilities that were theretofore uncommon in the Zambia context. In addition, schools supported by the RTS project were encouraged to activate teacher group meetings. Head teachers and senior teachers were to facilitate weekly meetings of teachers to share their experiences. Teacher group meetings were conceptualized in a fashion similar to the peer-learning communities and other peer-to-peer learning opportunities that Fullan (2005) suggested are critical to fostering a shared knowledge and understanding of the educational reform.

These interventions tracked closely with the findings of a recent study on leadership effectiveness in Zambia (James, Anthony, Warner, Rhodwell, \& Banguna, 2014). In this study by researchers from the University of Pittsburgh and Creative Associates International, elements of effective school leadership were identified among high-performing schools in Zambia. In schools that had higher-performing students (as measured by a group-administered literacy assessment), head teachers characterized themselves as open to new ideas (willingness to innovate) and applying an authoritative approach to leadership. They played important roles in school management and planning and set goals for teachers and learners through school and LPIPs. Lastly, they were found to be more supportive of teachers through frequent monitoring via lesson plan reviews, observations, and post-observation discussions. These findings further revealed that high-performing head teachers had some predisposition to practices characterized in a few of the instructional, transformative, and collaborative leadership dimensions discussed in the literature review that follows. The research described in this chapter complements these findings by looking at whether differences in school leadership behaviors and leadership effectiveness influence school and learner performance.

\section{Literature Review}

We turn now to the literature to develop a framework for assessing school leadership in the context of instructional change. The research base on school leadership is extensive, dating back to the 1960s, although-as noted previously-very little has been undertaken in developing countries. The literature review was guided by the following questions:

- Is there evidence of the impact of leadership effectiveness on learning outcomes?

- If so, what are the models and attributes of effective school leadership? 
- What are the most appropriate approaches to assessing and measuring leadership qualities and practices in the context of instructional reform?

- Is there existing evidence of effective school leadership practices in low-income countries?

\section{Influence of Leadership on Learning Outcomes}

There are three competing viewpoints in the literature on the impact of educational leadership. The first viewpoint is based on qualitative assessments that examined high-performing and low-performing schools and found significant leadership effects that helped explain the schools' exceptional or dismal performance (Gezi, 1990; Mortimore, 1993; Scheurich, 1998). These "outlier design" studies examined the role and qualities of school principals and leadership practices that distinguished them from their peers. This type of research has presented persuasive arguments and anecdotal evidence relating to the unique qualities and practices of the school leader and their effects not only on student learning but also on an array of school conditions (Leithwood, Harris, \& Hopkins, 2008). Per Leithwood and colleagues, however, most of these studies have lacked external validity or broader generalizability (Leithwood et al., 2008; Leithwood, Seashore Louis, Anderson, \& Wahlstrom, 2004).

The second viewpoint reflects the findings that school leadership has small but significant effects on learning outcomes. These findings have come from reviews of large-scale quantitative studies to identify empirical evidence as to whether and to what extent leadership influences learning outcomes (Hallinger \& Heck, 1996, 2010; Hallinger \& Leithwood, 1998; Leithwood et al., 2004; Robinson, Lloyd, \& Rowe, 2008; Witziers, Bosker, \& Krüger, 2003). Hallinger \& Heck $(1996,2010)$ found that leadership had no direct effect on learning outcomes but did have an impact when mediating or indirect effects were accounted for. Other studies have pointed to the impact of leadership when accounting for mediating or indirect effects (Leithwood et al., 2004, 2008; Marzano, Waters, \& McNulty, 2005), which in turn had more direct impact on learning outcomes. Leithwood et al. (2008) concluded from their comprehensive review of the literature that leadership was "second only to classroom instruction among all school-related factors that contribute to what students learn at school." They explained:

While leadership explains only $5-7 \%$ of the difference in pupil learning and achievement across schools (not to be confused with the typically very large differences among pupils within schools), this difference is 
actually about one-quarter of the total difference across schools (12-20\%) explained by all school-level variables, after controlling for pupil intake and background factors. (Leithwood et al., 2008, p. 28)

The third point of view is that effective school leadership is highly contextualized based on how leadership is defined, operationalized, and subjected to the environmental conditions in which leadership is exercised (Hallinger \& Heck, 1996, 2010; Fullan, 2001; Leithwood et al., 2004, 2008; Robinson, Lloyd, \& Rowe, 2008). In applying this viewpoint, there is no one-size-fits-all approach to effective school leadership. This refrain reflects what Leithwood, Harris, and Hopkins (2008) cited from their meta-analysis as the relative effect of contextualized leadership types and styles (Marzano et al., 2005; Pont, Nusche, \& Moorman, 2008; Robinson et al., 2008). It also echoes the explanation from Witziers, Bosker, and Krüger (2003) for the contradicting evidence, which was that leadership has been conceptualized and operationalized in different ways. Namely, different leadership styles are appropriate for different contexts, and leadership behaviors must be tailored to specific school needs and organizational environments.

\section{Models of Effective School Leadership}

The education leadership research presents various models that have set out to test the efficacy of leadership.

\section{Direct Effects Model}

The direct effects model posits that school leadership has a direct impact on learning outcomes. However, large-scale studies examining this relationship have consistently found small, negligible, but significant leadership effects on learning outcomes (Hallinger, Bickman, \& Davis, 1996; Hallinger \& Heck 1996, 2010; Witziers et al., 2003). Hallinger and Heck (2010) concluded that the direct effects model "approach is a 'dry hole' for exploring leadership effects on learning in schools" (p. 102).

\section{Indirect Effects Models}

The prevailing view and stronger evidence support a conclusion that school leadership has a more indirect than direct impact on learning outcomes (Hallinger \& Heck, 1996, 2010; Marzano et al., 2005). This notion that leadership affects student learning indirectly means that school leaders' impact on student learning is mediated by the quality of classroom instruction and interactions with school and societal conditions 
(or antecedents) that exist outside the school and classroom. In this regard, several models have emerged that showcase an array of mediating and antecedent (existing) variables:

- antecedent with direct effects model (Hallinger \& Heck, 1996)

- mediated effects model (Marzano et al., 2005)

- antecedent with mediated effects model (Hallinger \& Heck, 1996)

Through these models, researchers have attempted to unpack and define the following key relationships:

- leadership inputs (predictor $[x]$ variables) such as school leadership attributes, styles and qualities, behaviors and practices

- learning outcomes (response [y] variables) such as test scores, dropout rates, and other measures of school effectiveness

- outcome drivers or mediating effects that have a more direct influence on student learning, such as the instructional climate, opportunity to learn, teacher motivation, instructional practices, curricular implementation, and classroom and school conditions

- environmental and contextual conditions (antecedent $[z]$ variables) in which the school operates, such as socioeconomic status, gender, school type, district and state effects, resources

\section{Education Leadership Archetypes: Instructional, Transformational, and Collaborative}

Many studies have attempted to understand the relative efficacy of different leadership types. Following their lead, we have incorporated several of these archetypes (and their related terminology) as variables within our own modeling exercise; as a reference, here we elaborate on their development in the literature.

Leadership practices that are designed to induce specific mediating effects tend to take on a leadership-by-adjective typology. For example, leadership practices that focus nearly all efforts on teaching and learning are referred to as instructional leadership. Leadership that aims to influence teacher motivation and commitment, engagement, and relationships between school actors and clients is regarded as transformational leadership (Leithwood \& Jantzi, 2005; Robinson et al., 2008). Leadership that is shared by different 
persons or positions within the school is often referred to as distributed (also shared or collaborative) leadership.

These three archetypes are not mutually exclusive, as Table 3-1 illustrates. Their associated behaviors, responsibilities, and practices often overlap. These leadership theories are complemented by other leadership styles and behaviors outlined by Bush and Glover (2014), such as managerial leadership, moral and authentic leadership, teacher leadership, system leadership, or contingent leadership. Table 3-1 outlines the three broad leadership archetypes that are found most consistently in the literature.

Table 3-1. Three leadership archetypes and their dimensions and characteristic behaviors

\begin{tabular}{ll}
\hline Archetype & Description \\
\hline Instructional leadership & Building a vision by establishing clear learning goals and \\
(Bush \& Glover, 2014; & garnering school-wide-and even community-wide- \\
Stronge, Richard, \& Catano, & commitment to these goals \\
2008) & Sharing leadership and collaborating in leading by creating \\
& opportunities for teachers to work together and share \\
& teaching practices with one another; tapping the expertise of \\
& teachers to participate in the school improvement process \\
& Leading a learning community by becoming role models for \\
& learning while seeking tools and ideas that foster school \\
& improvement (Lashway, 2002) \\
& Sharing knowledge and intellectual stimulation, and \\
encouraging continuous and ongoing professional & development of all school staff (Marzano et al., 2005) \\
& Gathering and using data for school effectiveness and \\
continuous improvement (Fullan, 2005) & Monitoring curriculum and instruction by visiting classrooms \\
to help teachers improve in areas of weakness, accomplished \\
through observations and mentoring and feedback
\end{tabular}

\section{Transformational} leadership

(Bush \& Glover, 2014;

Leithwood \& Jantzi, 2005)
Setting directions by building school vision, establishing goals and priorities, setting high performance expectations

Developing people through intellectual stimulation, individual support, and modeling of desirable professional practices

Redesigning the organization by fostering collaborative school culture, making decisions collaboratively, creating productive community relationships, and incentivizing behaviors through results-based management tools

\section{Distributed, collaborative, or shared leadership}

(Bush \& Glover, 2014; Hallinger \& Heck, 2010)
Distributing leadership responsibilities and functions to multiple school actors

Broadening the participatory process for school improvement planning and implementation

Focusing strategic school-wide actions directed toward school improvement that are shared among the principal, teachers, administrators, and others 
One widely cited study on this topic, conducted by Robinson et al. (2008), examined the relative impact of different types of leadership on students' academic and nonacademic outcomes. Robinson and colleagues conducted two meta-analyses: one that compared instructional leadership and transformational leadership styles, and a second that compared effects of five general leadership dimensions. They found that the average effect of instructional leadership on student outcomes was three to four times that of transformational leadership. They then constructed five leadership dimensions or practices from the survey items:

1. establishing goals and expectations

2. resourcing strategically

3. planning, coordinating, and evaluating teaching and the curriculum

4. promoting and participating in teaching and learning development

5. ensuring an orderly and supportive environment

The notion of integrated leadership emerged from Marks and Printy's (2003) observation that when "principals who are transformational leaders accept their instructional role and exercise it in collaboration with teachers, they practice an integrated form of leadership" (p. 376). In their article on principal leadership and school performance, they hypothesized that, while transformational leadership is necessary for reform-oriented school improvement, without shared instructional leadership practices, transformational leadership alone will not achieve high-quality teaching and learning and outcomes. This notion of integrated leadership was also found to have strong effects in schools operating in challenging circumstances (Harris, 2002).

\section{Formulating the Assessment Framework and Filling the Research Gaps}

The conclusion that we drew from this body of research was that effective leadership is not based on a singular construct. For the purposes of this study, we chose to test our hypothesis for this chapter (see the Methodology section) using adaptations of two models: (1) direct effects model and (2) antecedent with direct and mediated effects model (or whole model test). We examined three leadership archetypes: instructional, transformational, and integrated. In addition, we explored leadership effects on outcome measures-both learning outcomes and mediating conditions such as time on task, teacher motivation, and parental engagement-which may offer insight on how school leadership affects educational reforms, particularly in the context of early grade learning. 
Lastly, as noted previously, because the literature on school leadership effects in developing-country environments is very thin, this study aims to illuminate both the effects of school leadership and its measures in that context.

\section{Methodology}

\section{Research Questions and Study Hypotheses}

Our investigation was driven by several research questions relevant to advancing the field of educational leadership research in low-income country contexts:

1. What are the salient leadership behaviors that relate to gains in early grade reading outcomes?

2. Which leadership characteristics relate most to schools adopting and sustaining early grade reading improvement practices?

3. What challenges might we expect to confront in measuring leadership effectiveness with acceptable levels of reliability and validity?

Note that we were not attempting to evaluate the efficacy of the RTS project described in the Introduction section, the RTS-introduced interventions, or the PLP overall. We drew our data from a cohort of schools that had been supported by the RTS project as they were undergoing significant change with the goal of improving early grade reading outcomes. Our research thus focused on how differences in school leadership behaviors and effectiveness influenced school and learner performance in relation to the reforms, innovations, and outcomes they were attempting to achieve.

\section{Hypothesis}

Our hypothesis posited that leadership behaviors would have a positive, significant relationship with RTS-supported high-performing schools and early grade learning outcomes. We further hypothesized that attributes relating to instructional leadership would have a greater impact on early grade learning outcomes than would transformational leadership behaviors. We tested this hypothesis through two models: a direct effects model and a whole model test of direct and indirect effects on learning outcomes.

\section{Direct Effects Test}

We tested this model through both a qualitative assessment and a large-scale survey. Our version of the model focused on the direct relationship between 
Figure 3-1. Direct effects model of leadership versus school performance

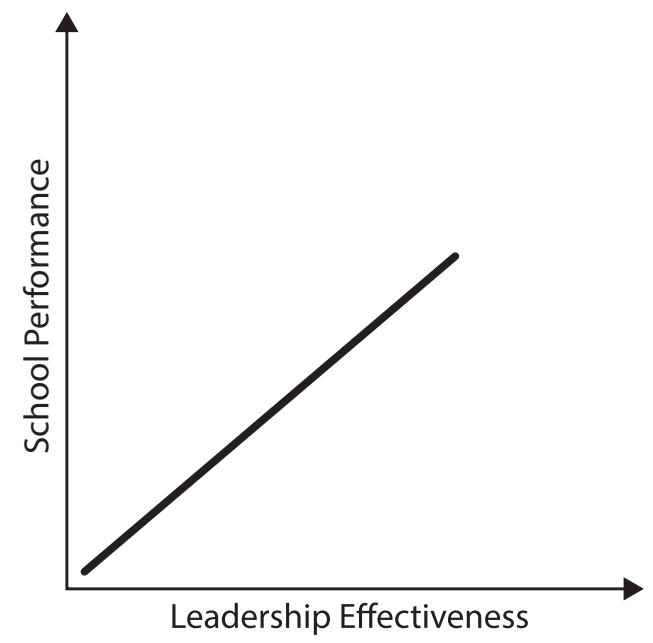

leadership behaviors and RTS-supported high-performing schools. This model is described in Figure 3-1, which is analogous to the "heroic principal" direct effects model of leadership described by Hallinger and Heck (2010). The difference between this test and the "dry hole" direct effects model was that the outcome variable of school performance combined pupils' reading gains with measures of schools' adherence to RTS-introduced interventions and other RTS monitoring and evaluation indicators.

\section{Whole Model Test}

We based the whole model (direct and indirect effects) test incorporating antecedent variables on mediated (indirect) condition variables, as shown in Figure 3-2. The whole model tested the approach to studying leadership effects reflected in the meta-analyses conducted by Hallinger and Heck (1996, 2010), Leithwood et al. (2004), and Marks and Printy (2003). The intent was to identify the strength and relationship for each of the connected variables shown in Figure 3-2 through path analyses. The connected lines trace the relationships of the antecedent (existing) conditions with school leadership practices and effectiveness; the direct and indirect effects of the leadership variables on mediating conditions; and the direct and indirect effects of these variables on learning outcomes. 
Figure 3-2. Whole model effects: Antecedents with direct and mediated (indirect) effects

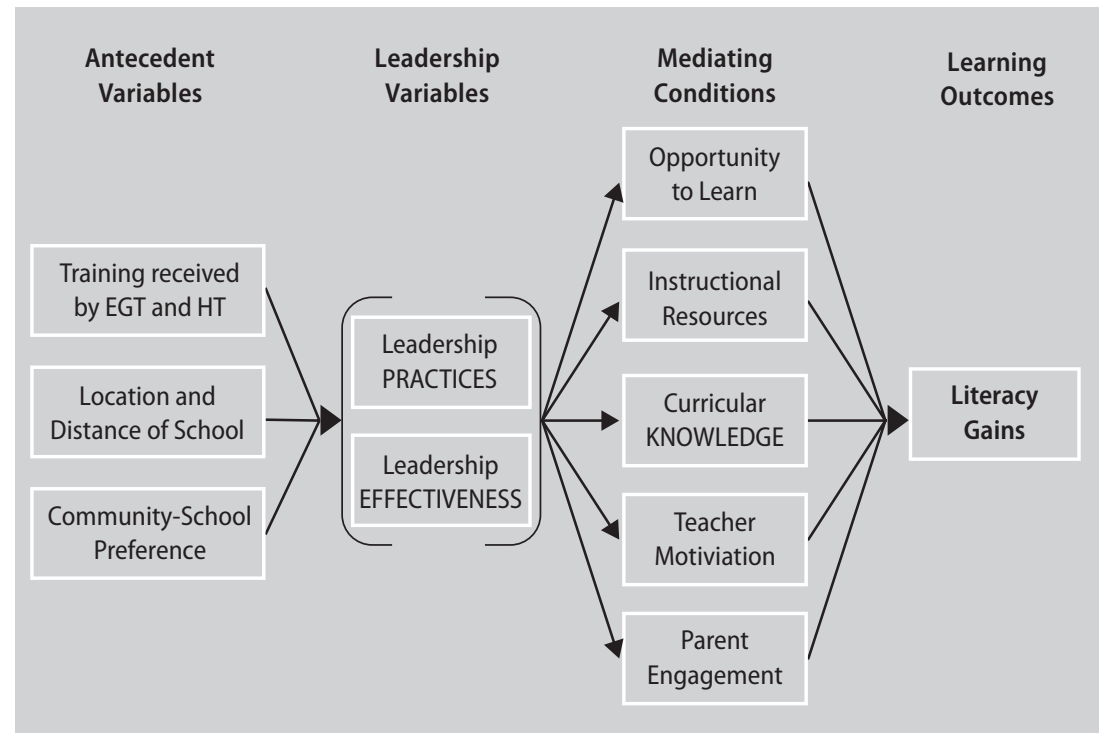

$\mathrm{EGT}=$ early grade teacher; $\mathrm{HT}=$ head teacher.

\section{Mixed-Methods Research Design: Pilot Qualitative Assessment Followed by a Large-Scale Survey}

The study collected data in two discrete stages: an initial pilot qualitative assessment based on the direct effects model was administered in November 2015 in 28 schools followed by a large-scale survey of head teachers and early grade teachers in June 2016 (320 schools).

\section{Pilot Qualitative Assessment}

The purpose of the qualitative assessment was to identify anecdotal evidence as to whether and which school leadership characteristics were more pronounced in high-performing schools versus low-performing schools. Because we employed an outlier research design, we expected the leadership characteristics to be more pronounced and therefore more likely to showcase anecdotal evidence of leaderships' direct effects on school performance. The qualitative assessment process also offered an opportunity to test the efficacy of the leadership questionnaire survey in terms of its internal consistency, reliability, and validity. 
The qualitative assessment consisted of three data collection tools: (1) open-ended interview questions to the head teacher; (2) a pilot leadership effectiveness survey made up of Likert-scale items administered to both head teacher and teachers; and (3) a test of the respondents' knowledge of early reading curriculum and instructional practices (curricular knowledge).

The open-ended interviews attempted to explore the head teachers' perspectives on the following thematic areas in relation to their implementation of RTS-introduced innovations:

- best practices, accomplishments, and innovative actions

- challenges and constraints

- key leadership practices

The pilot leadership effectiveness survey required respondents to rate the effectiveness of their school's head teacher on a scale of 1 to 4 (ineffective to highly effective). The questionnaire was inspired by the Vanderbilt Assessment for Leadership in Education, which surveys school principals and teachers on the core components of the principal's responsibility and the core processes that principals should undertake to satisfy their leadership function (Condon \& Clifford, 2012). The head teachers and selected early grade reading teachers were invited to complete the questionnaire independently and in privacy. Every leadership behavior statement was introduced by the statement, "During this school year, how effective has the school's leadership been at ..." Each behavior statement was then followed by a Likert scale of five response options: Ineffective, A little bit effective, Effective, Highly effective, Don't know/refuse.

The curricular knowledge test involved eight multiple choice questions requiring the respondent to choose the best answer relating to early grade reading curricular and instructional best practices in the Zambia PLP context.

\section{Large-Scale Survey}

The research team undertook a follow-on large-scale survey of 320 schools in June 2016. The two purposes of the large-scale survey were to produce a more rigorous test than the qualitative assessment had produced (see Figure 3-1) and to test for whole model (direct and indirect) effects (see Figure 3-2). The large-scale survey incorporated a revised leadership effectiveness survey, a revised curricular knowledge test, and an additional leadership practices survey. The surveys were administered to all respondents (head teachers and selected early grade teachers). 
Table 3-2. Details of leadership practices subdimension variables

\begin{tabular}{|c|c|c|c|}
\hline $\begin{array}{l}\text { Leadership practices } \\
\text { dimension }\end{array}$ & Items & $\begin{array}{l}\text { Leadership practices subdimension } \\
\text { variables }\end{array}$ & $\alpha$ \\
\hline \multirow[t]{2}{*}{$\begin{array}{l}\text { Vision and goal } \\
\text { setting }\end{array}$} & \multirow[t]{2}{*}{$\begin{array}{l}45.3,50.2,53,57.1 \\
57.3,58.1,58.3,58.4\end{array}$} & $\begin{array}{l}\text { Subdimension } 1 \text { : Goal setting and } \\
\text { action planning }\end{array}$ & \multirow[t]{2}{*}{0.83} \\
\hline & & Subdimension 2: Vision and beliefs & \\
\hline \multirow[t]{3}{*}{$\begin{array}{l}\text { Coaching, feedback, } \\
\text { and accountability }\end{array}$} & \multirow{3}{*}{$\begin{array}{l}43.3,49,50.1,50.3 \\
50.4,50.5,51.3,56.2 \\
58.2,58.5,59.5,59.6\end{array}$} & $\begin{array}{l}\text { Subdimension 1: Teacher } \\
\text { performance feedback }\end{array}$ & \multirow[t]{3}{*}{0.82} \\
\hline & & $\begin{array}{l}\text { Subdimension 2: Learner } \\
\text { performance monitoring }\end{array}$ & \\
\hline & & $\begin{array}{l}\text { Subdimension 3: Personal } \\
\text { accountability }\end{array}$ & \\
\hline \multirow{2}{*}{$\begin{array}{l}\text { Collaborative learning } \\
\text { and continuous } \\
\text { professional } \\
\text { development }\end{array}$} & \multirow[t]{2}{*}{$\begin{array}{l}42.1,42.3,43.1,46.3 \\
51.4,54\end{array}$} & $\begin{array}{l}\text { Subdimension 1: Individual teacher } \\
\text { support }\end{array}$ & \multirow[t]{2}{*}{0.74} \\
\hline & & $\begin{array}{l}\text { Subdimension 2: Collaborative } \\
\text { learning }\end{array}$ & \\
\hline
\end{tabular}

\section{Measures of Leadership Practices and Effectiveness}

The study generated two types of leadership variables: leadership practices and leadership effectiveness.

\section{Leadership Practices Variables}

The items that addressed leadership practices asked respondents whether specific leadership practices or actions had occurred at least once since the beginning of that calendar year (January 2016). The responses were coded as binary (yes/no), and the items were grouped into three broad leadership dimensions:

(1) vision and goal setting; (2) coaching, feedback, and accountability; and (3) collaborative learning and continuous professional development. Overall, each of the leadership dimension variables exhibited an acceptable Cronbach's alpha $(\alpha)(>0.7)$ with no more than two to three subdimensions, as shown in Table 3-2, based on a principal components analysis of the variables' items. ${ }^{1}$

\section{Leadership Effectiveness Variables}

We constructed the leadership effectiveness variables using a two-step process. The first step was to create a composite leadership effectiveness

\footnotetext{
1 The principal components analysis was used to determine the common underlying factors or subdimensions associated with each of the items. This process allowed us to identify the most important and consistent items for each leadership dimension. The composite items for each leadership practices dimension were finalized iteratively to maximize Cronbach's alpha and minimize the number of factors (or subdimension variables).
} 
variable from all 17 survey effectiveness rating items. Through a principal components analysis, we identified the following three factors (or dimensions) as having strong internal associations: (1) instructional leadership, (2) transformational leadership, and (3) integrated leadership. We then fine-tuned each factor as a standalone effectiveness dimension variable, testing for internal consistency and reliability. The Cronbach's alpha values for each of the effectiveness variables, which were greater than 0.70 , indicated that they were internally consistent even when disaggregated by respondent.

\section{Differences in Leadership Effectiveness Survey from Pilot to Large-Scale}

Following the pilot qualitative assessment, the research team adjusted the leadership assessment instruments for the large-scale survey in three important ways.

The first was by including a leadership practices questionnaire, which asked head teachers and teachers whether certain leadership actions had been undertaken (yes/no practices questions). The practices questionnaire required respondents to indicate whether a certain behavior, practice, or responsibility had been exercised or implemented since the beginning of the school year.

The second difference was by pitching both the effectiveness and practices questionnaires as an assessment of the school's leadership in general, not of the head teacher specifically. The intent was to shift the focus from a single individual to the collective leadership of the school. The aim in both cases was to de-personalize the respondent answers to reduce inherent bias that could in turn reduce the quality of the measures. To test and validate the revised questionnaire items before the large-scale administration, the team conducted a series of cognitive interviews with selected head teachers and teachers (cognitive interviewing is a technique used to systematically understand how target audiences understand, mentally process, and respond to questionnaire items; see Willis, 2004).

Finally, the updated survey included a revised PLP curricular knowledge test that drew from the RTS reading team's technical input, such that it reflected the particularities of the PLP curriculum and the knowledge acquired through the RTS-supported training. In short, the research team attempted to create an improved test that would be able to discriminate 
between individuals with strong and weak knowledge of the PLP curricular requirements.

\section{School Performance and Learning Outcome Measures School Performance Measures for Testing Direct Effects}

To assess school leadership's direct effects on school performance, the team aimed to develop a school performance variable beyond the measures of student performance alone. The intent was to develop a robust indicator of school performance in the context of sustained educational reforms, reflecting the innovations introduced through the RTS project. To do so, the research team first had to determine the criteria to identify and select high- and low-performing schools for the pilot qualitative assessment. The team drew on existing RTS data sets to assign schools a rating per their performance on the following variables: changes in Early Grade Reading Assessment (EGRA) scores, submission of Zambia School Gateway reports, designation as guidance and counseling centers of excellence, and project staff monitoring and evaluation observations.

A brief note on the variables used to construct the school performance rating:

- The EGRA is a standardized oral assessment of a student's reading skills, including oral reading fluency (ORF), reported as the number of correct words per minute a student can read. The EGRA has become established as an internationally accepted protocol for measuring foundational literacy skills (Dubeck \& Gove, 2015). It has been used in many countries to produce indicators of literacy and fluency (see Gove \& Wetterberg, 2011, for example), including in Zambia for the RTS baseline, midline, and endline impact evaluation surveys (Rhodwell, 2013, 2015, 2017).

- As described in the Introduction, the Zambia School Gateway was a system by which head teachers reported twice yearly on student and teacher performance.

- The "guidance and counseling center of excellence" designation was a recognition of excellence bestowed upon high-performing schools. They served as model schools for implementing innovative reforms in relation to guidance and counseling services provided to their students. One component of the RTS project was to support schools to adopt and 
implement guidance and counseling services to improve student health outcomes.

- Lastly, the RTS project monitoring and evaluation team maintained a database of school statistics including dropouts, participation in RTS-supported activities, and responsiveness to PLP requirements (teachers participate in training, materials are used in the classroom, etc.).

Table 3-3 details the school performance rating construct that was assigned to all 1,200 plus RTS-supported schools. Schools could be scored as high as 4 points (if they scored positively for all four possible 1-point criteria) or as low as -3 points (if they scored negatively for all three possible -1-point criteria). This indexed school performance score attempted to balance field observations with characteristics of schools' fidelity to RTS-introduced innovations.

Table 3-3. School performance rating criteria

\begin{tabular}{|c|c|c|}
\hline Criterion & Score $=1$ point & Score $=-1$ point \\
\hline $\begin{array}{l}\text { Change in EGRA } \\
\text { score from baseline } \\
\text { to midline }\end{array}$ & $\begin{array}{l}\text { If a school's midline ORF average was } \\
\text { greater than five correct words per } \\
\text { minute (the national average) and } \\
\text { improved over its baseline score } \\
(n=53)\end{array}$ & $\begin{array}{l}\text { If a school's midline ORF } \\
\text { average was one correct } \\
\text { word per minute or } \\
\text { worsened over its baseline } \\
\text { score }(n=22)\end{array}$ \\
\hline $\begin{array}{l}\text { Zambia School } \\
\text { Gateway returns }\end{array}$ & $\begin{array}{l}\text { If a school successfully submitted } \\
\text { teacher and learner performance data } \\
\text { for each cycle beginning in Term 1, } \\
2014 \text {, through Term 1, } 2015 \text { (all six } \\
\text { submissions) ( } n=318 \text { ) }\end{array}$ & $\begin{array}{l}\text { If a school submitted teacher } \\
\text { and learner performance } \\
\text { data for no more than two or } \\
\text { fewer cycles out of six } \\
\text { expected submissions } \\
(n=269)\end{array}$ \\
\hline $\begin{array}{l}\text { Designation as } \\
\text { guidance and } \\
\text { counseling center } \\
\text { of excellence }\end{array}$ & $\begin{array}{l}\text { Based on school list provided by } \\
\text { guidance and counseling team, school } \\
\text { was accorded } 1 \text { point for designation } \\
(n=107)\end{array}$ & $\begin{array}{l}\text { No criterion given to } \\
\text { negatively score school's } \\
\text { performance in relation to } \\
\text { guidance and counseling } \\
\text { implementation }(n=0)\end{array}$ \\
\hline $\begin{array}{l}\text { Field monitoring } \\
\text { and evaluation } \\
\text { observations }\end{array}$ & $\begin{array}{l}\text { The RTS project monitoring and } \\
\text { evaluation team observed schools and } \\
\text { collected monitoring and evaluation } \\
\text { records for its statistical database; } \\
\text { schools identified as high performers } \\
\text { were given } 1 \text { point ( } n=256 \text { ) }\end{array}$ & $\begin{array}{l}\text { Schools identified as low } \\
\text { performers were given }-1 \\
\text { point }(n=92)\end{array}$ \\
\hline
\end{tabular}

EGRA = Early Grade Reading Assessment; ORF = oral reading fluency; RTS = Ready to Succeed. 
On an 8-point scale, the 1,204 RTS-supported schools received the following scores:

- super $=4$ points ( 2 schools, 0.2 percent $)$

- excellent $=3$ points ( 33 schools, 2.7 percent)

- good $=2$ points (111 schools, 9.2 percent)

- notable $=1$ point (297 schools, 24.7 percent)

- neutral $=0$ points (496 schools, 41.2 percent)

- poor $=-1$ point $(255$ schools, 21.2 percent $)$

- very poor $=-2$ points ( 9 schools, 0.7 percent)

- extremely poor $=-3$ points ( 1 school, 0.1 percent)

\section{Learning Outcome Measures for the Whole Model Test: Changes in ORF for Grade 2 and Grade 3 Learners from Baseline to Midline to Endline}

The learning outcome measures were the changes in ORF, as measured by the number of correct words per minute, from baseline to endline and from midline to endline for grade 2 and grade 3 students. The EGRA was administered in 197 schools (approximately 4,000 learners) in 2013 for the baseline, 200 schools (4,000 learners) in 2015 for the midline, and 200 schools (4,000 learners) in 2017 for the endline of the RTS project. The EGRA results-and in particular, the changes in ORF scores-were among the key indicators for evaluating the RTS project's impact on literacy learning outcomes. The Cronbach's alpha for the EGRA ORF subtask was 0.97 , and the overall mean ORF scores for grade 2 and grade 3 were 7.4 correct words per minute and 12.5 correct words per minute respectively. However, an analysis of the endline EGRA ORF scores showed that significant differences were attributed to the language in which the students took the test.

Table 3-4 displays the summary statistics for the learning outcome variables. The values in the second column reflect the total number of schools that participated in the leadership survey and from which data were available from the baseline, midline, and endline EGRAs. The smaller the number of schools surveyed, the greater the standard error, and the larger the confidence intervals. The relatively large standard deviations and upper and lower 95 percent confidence means attest to the lack of precision due to the small sample size. The maximum and minimum scores intimate that outliers may have skewed the results of the analyses. 
Table 3-4. Changes in raw (unstandardized) ORF scores: Summary statistics of the EGRA learning outcome variables

\begin{tabular}{|c|c|c|c|c|c|c|c|}
\hline \multirow[b]{2}{*}{ ORF variable } & \multirow{2}{*}{$\begin{array}{l}\text { No. of } \\
\text { schools } \\
\text { surveyed }\end{array}$} & \multirow{2}{*}{$\begin{array}{l}\text { Mean } \\
\text { delta }\end{array}$} & \multicolumn{2}{|c|}{$\begin{array}{l}\mathbf{9 5 \%} \\
\text { confidence } \\
\text { interval }\end{array}$} & \multirow{2}{*}{$\begin{array}{l}\text { Standard } \\
\text { deviation }\end{array}$} & \multirow[b]{2}{*}{ Maximum } & \multirow[b]{2}{*}{ Minimun } \\
\hline & & & Upper & Lower & & & \\
\hline $\begin{array}{l}\text { Grade } 2 \text { baseline- } \\
\text { to-endline change }\end{array}$ & 38 & 6.2 & 7.9 & 4.5 & 5.21 & 23.9 & 0.0 \\
\hline $\begin{array}{l}\text { Grade } 2 \text { midline- } \\
\text { to-endline change }\end{array}$ & 41 & -0.86 & 0.78 & -2.5 & 5.20 & 8.6 & -15.8 \\
\hline $\begin{array}{l}\text { Grade } 3 \text { baseline- } \\
\text { to-endline change }\end{array}$ & 36 & 11.9 & 14.1 & 9.7 & 6.60 & 28.4 & -2.8 \\
\hline $\begin{array}{l}\text { Grade } 3 \text { midline- } \\
\text { to-endline change }\end{array}$ & 41 & 2.4 & 4.4 & 0.41 & 6.30 & 17.5 & -9.6 \\
\hline
\end{tabular}

$\mathrm{EGRA}=$ Early Grade Reading Assessment; ORF = oral reading fluency.

\section{Antecedent and Mediating-Condition Variables (Whole Model)}

To test the indirect effects model, the research team constructed variables for antecedents, mediating conditions, and learning outcomes.

\section{Antecedent Variables}

Often the strongest predictor of learning outcomes is socioeconomic status of students and the community (Dubeck \& Gove, 2015; Hallinger \& Heck, 1996, 2010). The RTS project, however, did not survey students or include questions related to their socioeconomic status. Instead, proxy variables were the school's location and distance from the district center. Typically in Zambia, the greater the distance from the district center, in a rural or remote location, the greater the likelihood that the school is located in a less-developed community of lower socioeconomic status. The location variable consisted of the school's designation as urban, rural, or remote. The distance variable was based on kilometers from the district center. There was a moderate correlation $(r=.49$, $\alpha=0.65$ ) between school location and distance from the district center.

A third antecedent variable related to the level of training received by the head teachers and early grade teachers. The RTS project team trained early grade teachers and head teachers on several PLP-related curricular topics, as well as on guidance and counseling, the Zambia School Gateway, and LPIPs, among others. Training was delivered at school, zonal, and district levels. The training variable was based on the total number of workshops the respondent reported having attended. The community-school preference variable was derived from 
two questions asking the respondents to indicate whether they would prefer to work at this school or another and, when they retired, whether they planned to live in their existing school community or if they would live elsewhere.

The last variable designated whether the school also served as a zonal school. A zonal school in Zambia is one that serves a cluster of schools in peer-to-peer continuous professional development. Zonal head teachers, along with school in-service coordinators and zonal in-service coordinators, play a crucial role in supporting, coaching, and mentoring head teachers and teachers respectively. All antecedent variables' raw scores were transformed into standardized $z$-scores for comparative purposes.

\section{Mediating-Condition Variables}

The mediating-condition variables were crafted based on a principal components analysis of similar items relating to four broad dimensions of mediating conditions: (1) opportunity to learn $(\alpha=.54),(2)$ instructional resources $(\alpha=.66)$, (3) teacher motivation $(\alpha=.65)$, and (4) parental engagement $(\alpha=.83)$. As with the leadership variables, we finalized the composite items for each mediating-condition dimension iteratively to maximize Cronbach's alpha and minimize the number of factors (or subdimension variables). Cronbach's alpha indicated that all but the parental engagement variable had relatively weak internal consistency or reliability. The results therefore should be treated with caution.

Note these variables were derived from the respondent questionnaires and were not directly observed phenomena. The "opportunity to learn" item asked respondents whether school leadership established remediation opportunities for struggling learners. Instructional resources items focused on whether head teachers encouraged the use of local materials, requested or allocated additional reading resources, or established reading corners and libraries. Teacher motivation questions explored whether school leadership praised, recognized, awarded, or otherwise motivated teachers for high performance in relation to learners' literacy performance. Parental engagement items examined whether school leaders mobilized support from the parent-teacher association and community stakeholders or provided school performance feedback to these stakeholders.

\section{Curricular Knowledge}

Information on the respondents' knowledge of the PLP curriculum was also generated from a PLP curricular knowledge test. The results of the 
PLP knowledge test yielded a very low Cronbach's alpha $(\alpha=0.46)$, which indicates that the test suffered from a lack of reliability and validity. Any significant relationship this variable had with the antecedent, leadership, mediating-condition, or outcome variables in the whole model test must therefore be treated with the utmost caution. For practical purposes, we listed the knowledge variable as a mediating condition, but in reality, it might have had a two-way influence on leadership performance and other mediating-condition variables. For this analysis, we assumed (with a stretch of imagination) that it maintained a one-way relationship within the model.

\section{Sampling Plans}

\section{Sample of Schools for the Pilot Qualitative Assessment}

The school selection criteria are detailed in Table 3-3. For the pilot qualitative assessment to test the direct effects model, the research team purposefully selected schools at each pole of the performance spectrumthose that scored super, excellent, very poor, and extremely poor-as well as from a cross-section of districts and locations (urban, rural, and remote). In lower-performing districts such as Mulobezi District, the only "good" school was selected for the pilot. In addition, several "poor" and "good" schools were selected in Sesheki District in lieu of "excellent" and "very poor," of which there were none. The research team surveyed the two "super" schools as well as the only "extremely poor" school in the population. Table 3-5 details the sample of schools surveyed, by location and performance category.

\section{Sample of School Head Teachers and Early Grade Teachers for Follow-on Large-Scale Survey}

The large-scale survey was administered to 412 early grade teachers and 314 head teachers drawn from 320 schools. The schools were randomly selected, clustered by districts and zones, and proportional to the number of schools in the districts and zones. This sample size was powerful enough to yield statistically significant results for each respondent type.

Table 3-6 shows the count of schools sampled, by performance category, for the large-scale survey. Due to the very few schools at each pole of the performance spectrum (super, excellent, and very poor), the school performance variables were collapsed into three categories: high-performing schools (>fair), neutral, and low-performing schools (<neutral). 
Table 3-5. Number of schools, head teachers, and early grade teachers sampled for the qualitative pilot study

\begin{tabular}{lccc}
\hline $\begin{array}{l}\text { Types of schools, by location and } \\
\text { performance }\end{array}$ & $\begin{array}{l}\text { Number of } \\
\text { schools }\end{array}$ & $\begin{array}{l}\text { Number of } \\
\text { head teachers }\end{array}$ & $\begin{array}{l}\text { Number of early } \\
\text { grade teachers }\end{array}$ \\
\hline Remote & $\mathbf{1 2}$ & $\mathbf{1 2}$ & $\mathbf{2 3}$ \\
\hline Super & 2 & 2 & 4 \\
\hline Excellent & 5 & 5 & 12 \\
\hline Good & 2 & 2 & 5 \\
\hline Poor & 1 & 1 & 0 \\
\hline Very Poor & 2 & 2 & 2 \\
\hline Rural & $\mathbf{1 4}$ & $\mathbf{1 4}$ & $\mathbf{3 6}$ \\
\hline Excellent & 7 & 7 & 20 \\
\hline Good & 2 & 2 & 4 \\
\hline Poor & 1 & 1 & 2 \\
\hline Very Poor & 3 & 3 & 3 \\
\hline Extremely Poor & 1 & 1 & 7 \\
\hline Urban & $\mathbf{2}$ & $\mathbf{2}$ & $\mathbf{5}$ \\
\hline Excellent & 2 & 2 & 5 \\
\hline Grand total & $\mathbf{2 8}$ & $\mathbf{2 8}$ & $\mathbf{6 4}$ \\
\hline
\end{tabular}

Table 3-6. Count of schools surveyed by performance category (large-scale survey)

\begin{tabular}{lcll}
\hline Performance rating & Count & Proportion & Performance category \\
\hline Very poor & 3 & 0.00938 & Low-performing \\
Poor & 77 & 0.24063 & $n=80$ \\
\hline Neutral & 119 & 0.37188 & Neutral \\
Fair & 85 & 0.26563 & $n=204$ \\
\hline Good & 29 & 0.09063 & High-performing \\
Excellent & 6 & 0.01875 & $n=36$ \\
Super & 1 & 0.00313 & \\
\hline Total & $\mathbf{3 2 0}$ & $\mathbf{1 . 0 0 0 0 0}$ & $\mathbf{3 2 0}$ \\
\hline
\end{tabular}

\section{Findings}

Findings from the Pilot Qualitative Assessment to Test the Direct Effects Model

The open-ended interview questions in the pilot qualitative assessment for head teachers explored the head teachers' perspectives in relation to RTSintroduced innovations to early grade learning and leadership. The questions 
focused on head teachers' best practices, accomplishments, innovative actions, challenges and constraints, and key leadership practices. The results from the open-ended interviews revealed a greater leadership effect than did the questionnaire responses that rated effectiveness.

Responses associated with vision and goal setting, school improvement, and guidance and counseling were noted in high-performing schools and absent entirely in low-performing schools. However, the major difference between high- and low-performing schools was not so much the type of responses as the volume or quantity of responses. Head teachers in highperforming schools could describe on average 6.4 unique leadership behaviors that characterized their work practices. In contrast, head teachers in lowperforming schools on average could cite closer to 4.6 leadership practices. This result fits with anecdotal observations by the researchers who conducted the interviews that the head teachers of high-performing schools generally offered a wider repertoire of leadership strategies than their peers at lowperforming schools.

The findings from the leadership effectiveness questionnaire administered in the pilot study were less informative. The pattern one would expect to find was related to the direct effects model described in Figure 3-1. The results in Figure 3-3, however, show a trend that clearly does not fit the model. In terms of leadership effectiveness, the worst-performing schools tended to rank their head teachers as equal in effectiveness to the better-performing schools. The very best schools had measurably greater effectiveness rankings, but the number of super schools was too small to make generalizable and statistically conclusive assertions. Figure 3-3 also shows the lack of relationship between the PLP knowledge test and the total leadership score. Note the scores are presented as standardized $z$-scores for comparative purposes.

\section{Findings from the Large-Scale Survey to Test the Direct Effects Model}

\section{Correlation Between Leadership Practices and Leadership Effectiveness}

The first question we posed when examining the data was whether there was a relationship between practices and effectiveness by leadership dimension. To put it bluntly, we wanted to examine whether respondents practiced what they preached. That is, did their leadership effectiveness ratings align with their actual leadership practices? Figure 3-4 shows a weak but significant relationship between overall effectiveness versus practices $\left(R^{2}=0.15\right)$, even when controlling for respondent (head teachers = black dots; early grade teachers $=$ gray dots). Head teachers tended to overvalue practices, as 
Figure 3-3. Leadership effectiveness ratings and curricular knowledge: z-scores, by school performance category, from pilot qualitative assessment

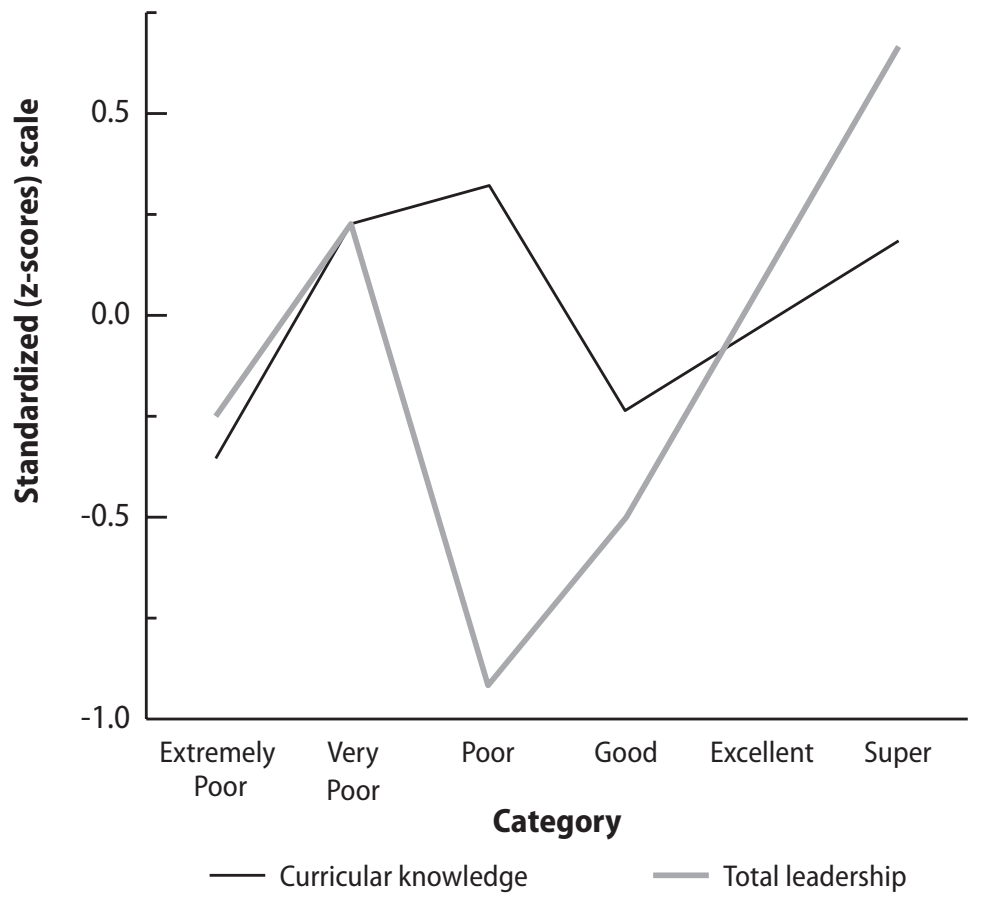

Note: Scores are presented as standardized z-scores for comparative purposes.

indicated by the concentration of black dots above the fit line. Early grade teachers tended to undervalue practices in relation to effectiveness; most gray dots fall below the fit line.

As previously discussed, we isolated three distinct leadership practices variables (vision and goal setting; coaching, feedback, and accountability; and collaborative learning and continuous professional development) and three distinct leadership effectiveness variables (instructional, transformational, integrated). The pairwise correlation coefficients between the variables exhibited a strong positive relationship when compared intra alia (that is, average $r$ for practices vs. practices variables and effectiveness vs. effectiveness variables $=.73$ ) but weak relationships when compared inter alia (that is, average $r$ for practices vs. effectiveness variables $=.32$ ). The weak correlations between practices and effectiveness suggest a disconnect between school 
Figure 3-4. Correlations between leadership practices and leadership effectiveness

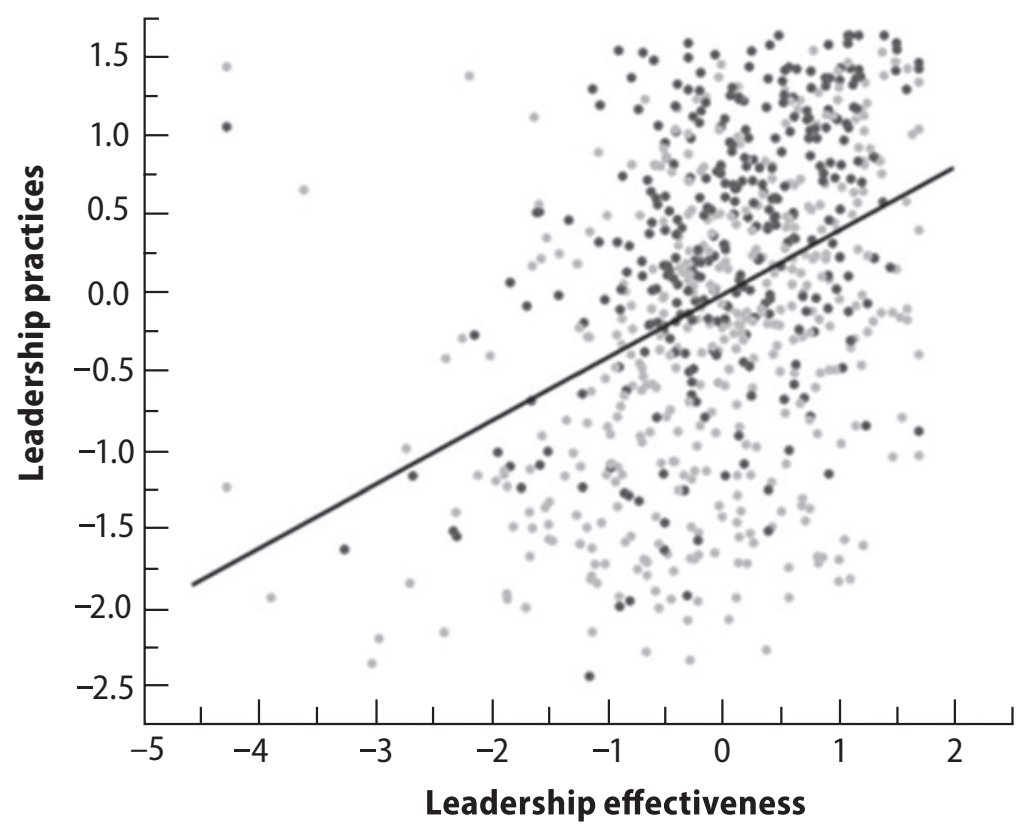

- Early grade teacher - Head teacher — Leadership practices fit line

leaders' actual practices and the respondents' perceptions of school leaders' effectiveness.

The next question was whether head teachers and teachers viewed their leadership's practices and effectiveness similarly or differently. Figure 3-5 reveals that, in terms of practices, head teachers responded significantly more positively to a greater number of leadership behaviors than did their teacher counterparts $\left(\mathrm{R}^{2}=0.11, p<.0001\right)$. However, Figure 3-6 shows a negligible difference in teachers' and head teachers' evaluations of school leadership's effectiveness $\left(\mathrm{R}^{2}=0.0004, p=.0627\right)$. Note the scores are presented as standardized $z$-scores.

\section{Relationship Between Leadership Variables and School Performance Categories}

Next, we examined the relationships between the leadership variables and the school performance categories to test the direct effects model. Figures 3-7 and 
Figure 3-5. Leadership practices, by early grade teachers and head teachers

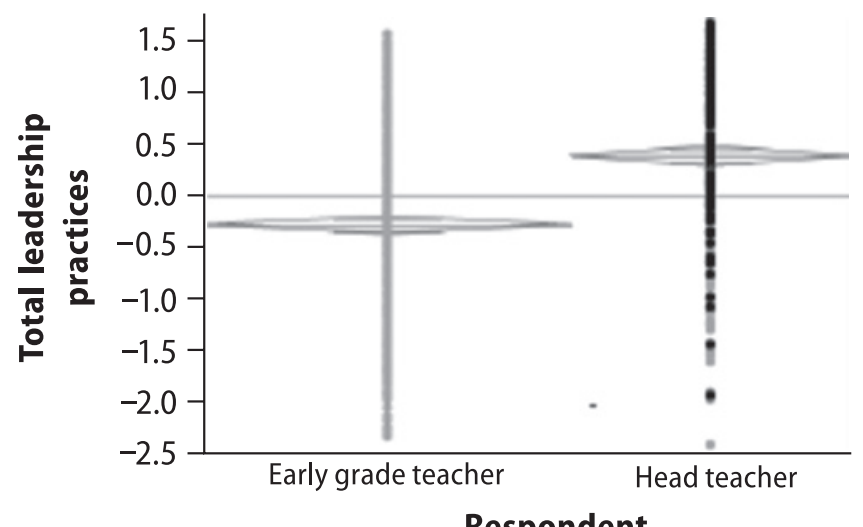

Figure 3-6. Leadership effectiveness, by early grade teachers and head teachers

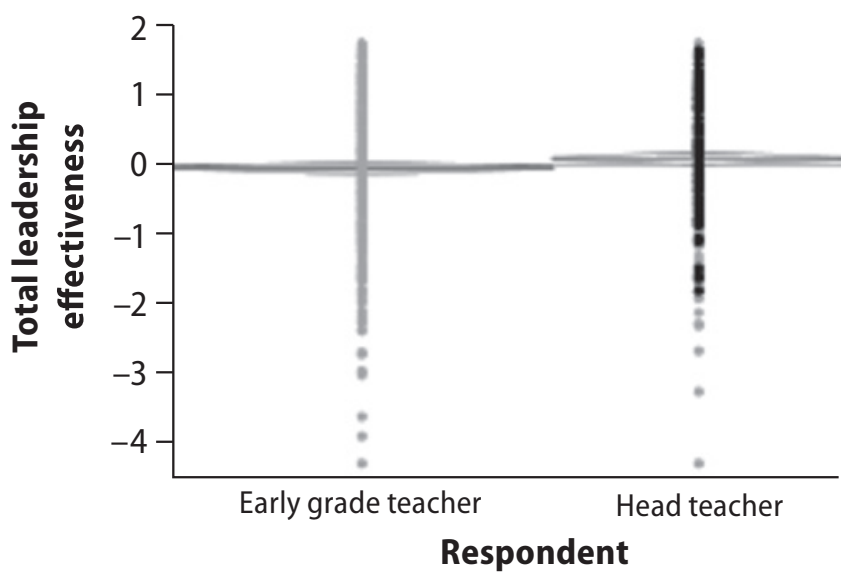

3-8 illustrate the pattern for leadership practices and effectiveness in terms of the average standardized $z$-scores for low-, middle- (neutral), and highperforming schools. Notably, the effectiveness scores followed the hypothesized pattern, whereas the practices scores, particularly for early grade teacher respondents, presented an inverse relationship with school performance. 


\section{Figure 3-7. Leadership practices versus school performance}

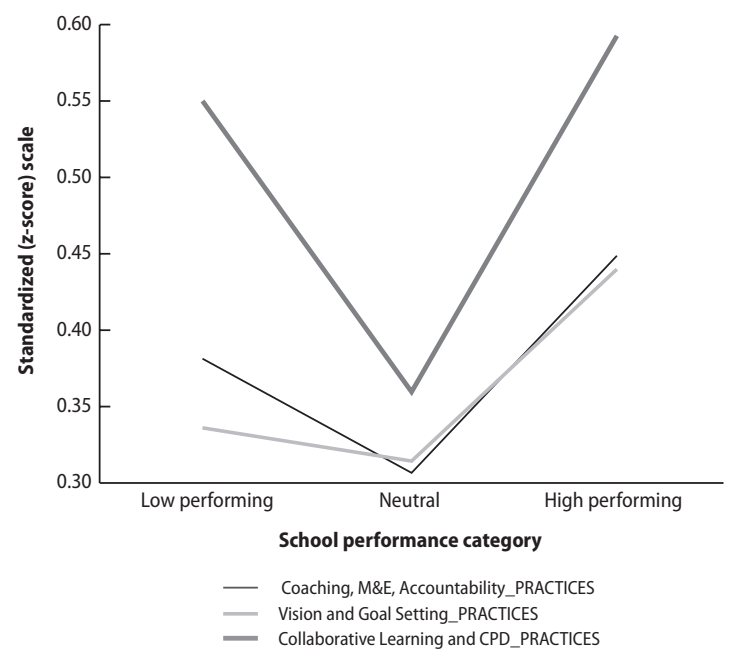

$\mathrm{CPD}=$ continuous professional development $\mathrm{M \& E}=$ monitoring and evaluation.

As shown in Figure 3-7, overall leadership practices had an inverse or negative relationship with school performance. Notably, the negative relationship between collaborative learning practices-which involved teacher group meetings, teachers' participation in professional development, and individualized teacher support-and school performance was statistically significant ( $p=.04$ ). All the more revealing is how the patterns changed when we filtered by category of respondent: Whereas early grade teacher respondents exhibited a consistent inverse trend from low- to highperforming schools, head teachers displayed a V-shaped pattern, which indicates that low- and high-performing schools exhibited similar leadership practices, but neutral schools exhibited lower leadership practices scores.

On the other hand, Figure 3-8 reveals that the effectiveness variables trended according to the hypothesized relationship, in which leadership effectiveness associated positively and directly with school performance. Notably, overall integrated leadership effectiveness-which related to four leadership practice areas (promoting PLP, organizing teacher group meetings, providing feedback, and monitoring teacher preparation) - was significantly associated with positive school performance $\left(p=.01, \mathrm{R}^{2}=0.012\right)$. Transformational leadership effectiveness exhibited a more muted relationship with school performance, in contrast to instructional and 
Figure 3-8. Leadership effectiveness versus school performance

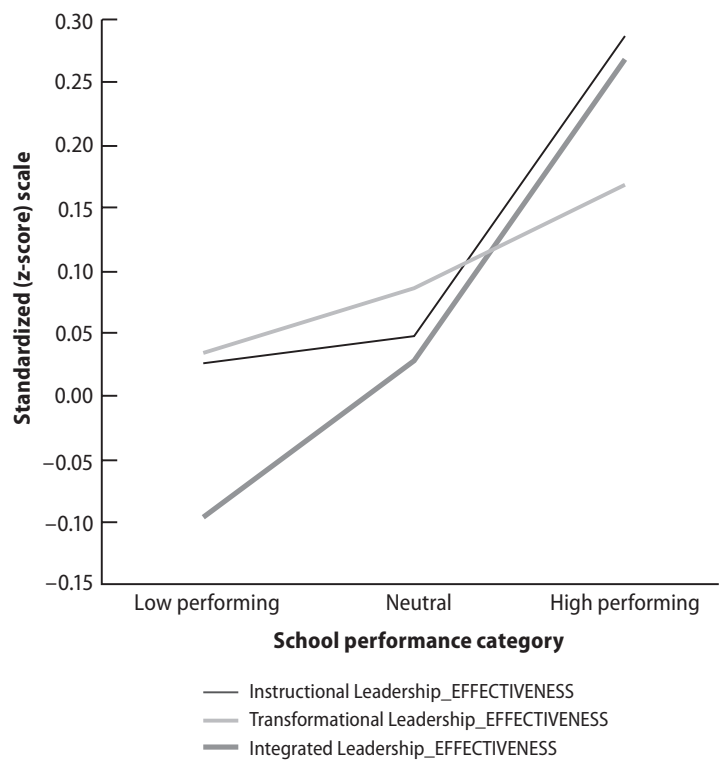

integrated leadership effectiveness ratings. This was especially so when we filtered by head teacher respondents.

\section{Whole Model Tests of Direct and Indirect Effects on Learning Gains Whole Model Test Methodology}

To test the whole model effects from among the antecedent, leadership, mediating-condition, and learning outcome variables, we estimated the strength and direction of the variable relationships using a path analysis, which is a method employed to determine whether "a multivariate set of nonexperimental data fits well with a particular causal model" (Wuensch, 2016, p. 1). Figure 3-2 offers a starting point in developing a model. To conduct the whole model test, we analyzed the relationship of the variables through the following steps:

- Step 1. Run pairwise correlation coefficients across all variables.

- Step 2. Regress leadership variables on antecedent variables.

- Step 3. Regress mediating-condition variables on leadership and antecedent variables. 
- Step 4. Regress learning outcome variables on mediating-condition, leadership, and antecedent variables.

- Step 5. Produce the model(s), calculating the total model effect based on path coefficients (standardized estimate $[\beta]$ generated from the regression analyses) of connecting variables.

\section{Whole Model Test of Changes (delta, $\delta$ ) in Grade 2 and Grade 3 ORF}

Path analyses were developed for each outcome variable but are not included here for space considerations. Instead, Table 3-7 summarizes the total model effect and significance for each change $(\Delta)$ in ORF for grade 2 and grade 3. The standardized beta coefficient indicates the direction and magnitude of the relationship of the model variables on the learning outcome. Negative (-) figures indicate a negative relationship; the larger the number, the greater the effect on the learning outcome. The grade 3 baseline-endline ORF has a beta of -1.29 , indicating that every 1.0 standardized deviation increase in the overall model value resulted in a (negative) -1.29 standardized deviation decrease in grade 3 baseline-endline changes. $R^{2}$ is an indicator of the strength of the relationship. The larger the $\mathrm{R}^{2}$, the greater the model accounted for changes in ORF. The grade 3 baseline-endline ORF had an $\mathrm{R}^{2}$ of .53, indicating that the model explained approximately 53 percent of the deviation in observed ORF scores.

Lastly, the $p$ value is an indicator of the significance of the relationship. The higher the $p$ value, the higher the likelihood that the relationship had more to do with random chance. The grade 3 baseline-endline ORF had a $p$ value of .0008 , indicating that the chances of this relationship occurring strictly by chance were approximately 0.08 percent, well below the 5 percent threshold.

Table 3-7. Summary of findings of whole model tests for each learning outcome

\begin{tabular}{llll}
\hline Learning outcome measure & $\begin{array}{l}\text { Standardized } \\
\text { beta coefficient }\end{array}$ & $\mathbf{R}^{\mathbf{2}}$ & $\begin{array}{l}\text { Significance } \\
\text { ( } \boldsymbol{p} \text { value) }\end{array}$ \\
\hline Grade $2 \Delta$ baseline-endline ORF & -0.72 & 0.34 & .0479 \\
\hline Grade $2 \Delta$ midline-endline ORF & -0.17 & 0.27 & .0421 \\
\hline Grade $3 \Delta$ baseline-endline ORF & -1.29 & 0.53 & .0008 \\
\hline Grade 3 $\Delta$ midline-endline ORF & 0.32 & 0.20 & .0381 \\
\hline
\end{tabular}

$\Delta=$ change; ORF = oral reading fluency. 


\section{Meta-Analysis of School Leadership Models: Whole Model Effects on Changes in EGRA ORF}

Table 3-8 displays the results of the whole model tests together in aggregate, providing the total frequency and average effects (standardized beta coefficient) for each variable that was directly associated with EGRA ORF changes. The most frequent and positively associated leadership variables were vision and goal setting (0.53), followed by instructional leadership (0.16) and integrated leadership (0.09). The negatively associated leadership variables were collaborative learning $(-0.34)$ and transformative leadership $(-0.34)$, followed by coaching and feedback $(-0.29)$.

\section{Discussion}

\section{Discussion and Limitations of Pilot Qualitative Assessment Findings}

The findings from the interviews reflect responses to open-ended questions from only 14 out of 28 schools. As such, the number of schools was too small to make statistically valid conclusions regarding their effect size or goodness of fit for the entire population. Nevertheless, the findings offered important

Table 3-8. Meta-analysis of direct effect variables from the whole model tests

\begin{tabular}{lll}
\hline Predictor variables & $\begin{array}{l}\text { Frequency of } \\
\text { inclusion in models }\end{array}$ & $\begin{array}{l}\text { Average of standard } \\
\text { beta (coefficient) }\end{array}$ \\
\hline Antecedent & 1 & -0.59 \\
\hline Distance & 1 & -0.46 \\
\hline Location & & \\
\hline Leadership effectiveness & 2 & 0.16 \\
\hline Instructional leadership & 3 & 0.09 \\
\hline Integrated leadership & 2 & -0.34 \\
\hline Transformative leadership & & \\
\hline Leadership practices & 1 & -0.29 \\
\hline Coaching, feedback, and accountability & 3 & -0.34 \\
\hline Collaborative learning & 2 & 0.53 \\
\hline Vision and goal setting & & \\
\hline Mediating conditions & 1 & -0.35 \\
\hline Instructional resources & 1 & -0.41 \\
\hline Knowledge & 1 & -0.24 \\
\hline Opportunity to learn & 2 & -0.05 \\
\hline Parental engagement & &
\end{tabular}


anecdotal information on the types of leadership practices that were found uniquely in high-performing schools.

It is notable that guidance and counseling, school improvement, and vision and goal setting were completely absent from the open-ended responses of the low-performing schools. It is also worth noting that high-performing schools mentioned community engagement twice as often as low-performing schools. These findings make sense in the context of the RTS project: high-performing criteria included, among other factors, whether they had been selected as a guidance and counseling center of excellence and whether they had consistently submitted learner and teacher performance data to the Zambia School Gateway.

Schools that were guidance and counseling centers of excellence were more likely to be identified as high-performing schools, to have implemented and benefited from the complex guidance and counseling intervention, and to have mentioned it in the interview than those schools that were not. Similarly, schools that had consistently submitted their performance data to the Zambia School Gateway were more likely to have been identified as high performers, to have used the data for setting targets and planning for learner performance improvements, to have benefited from those exercises, and to have mentioned them in the interview.

\section{Discussion and Limitations of Direct Effects Test from Large-Scale Survey}

The direct effects test offered some evidence of school leadership effectiveness and revealed major challenges in measuring school leadership indicators. The leadership effectiveness measures had a stronger positive relationship to school performance when administered to a much larger sample size. Moreover, the internal consistency and reliability of these effectiveness variables, as well as the consistency in responses between head teachers and early grade teachers, strengthened the findings that 'integrated' and 'instructional' leadership behaviors were more effective than transformational practices. On the other hand, the leadership practices variables manifested a negative or inverse relationship with school performance variables. The conflicting results are indicative of the broader challenge in obtaining accurate measures of school leadership.

We found evidence of the disconnect between actual leadership practices and perceived leadership effectiveness. The difference was more discernable in view of the contrasting responses provided by head teachers and early grade teachers in relation to leadership practices. Obtaining an accurate 
representation of leadership practices from teacher respondents was possibly confounded by their incomplete knowledge of all that went on in the school and community. It was also quite possible that the culture in Zambia made it more difficult for teachers and head teachers to rate their leadership in highly critical ways. This possible conclusion could explain the findings from the large-scale survey in which the highest-performing schools had the lowest practices scores. These findings are instructive because they shed light on the likely weak relationship that persists between head teachers and teachers when it comes to instructional change and support.

In addition to respondent bias, two key limitations of the direct effects test affected the quality of the research design.

1. Limited-outcome (response variable) measures. The school performance indicator was a composite, unweighted, and coarse measure of school performance that attempted to present a combination of fidelity to innovation on the one hand and learning achievement on the other. However, the scale skewed positively for all schools due to the greater number of positive variables in the construct. It also did not allow all schools to have an equal chance of rating very high or very low because not all schools participated in the EGRA or were candidates for centers of excellence.

2. Lack of antecedent and mediating factors. The direct effects model did not account for important mediating or antecedent factors, such as socioeconomic status or observed teacher instructional practice.

\section{Discussion and Limitations of Whole Model Test from Large-Scale Survey}

Based on whole model meta-analysis (of all ORF measures), the following practices and effectiveness behaviors had the greatest positive relationships with change in EGRA performance: vision and goalsetting leadership practices $(\beta=0.52)$; instructional leadership effectiveness $(\beta=0.16)$; integrated leadership effectiveness $(\beta=0.09)$. However, the greatest takeaway from the whole model tests was the overall negative effect of the models, except for the change in grade 3 midline-to-endline ORF scores. Moreover, the negative direct effects relating to coaching, feedback, and accountability, collaborative learning, and transformative leadership effectiveness ran counter to expectations because these variables reflected practices and behaviors deemed desirable by head teachers. Moreover, all the mediating conditions that were shown to have had direct effects on learning outcomes 
were negative on average, belying the importance of these conditions on learning outcomes. The results were consistent with past studies, indicating a "dry hole" in which the relationships between leadership and learning outcomes are positively and significantly associated.

Some limitations of this study should raise caution about conclusions based on the findings. First and most obvious, the EGRA schools represented only a subsample of the schools that participated in the larger leadership survey. A difference-in-means test indicated that non-EGRA schools were more likely to be rural and urban, whereas EGRA schools were more likely to be rural and remote, which was the only statistically significant difference among any of the model antecedent variables. Nevertheless, because the EGRA sample selected was a predetermined set of schools, and not necessarily randomly selected from the larger leadership survey population, the results should be treated with caution and the analyses should be corrected for greater error.

A second limitation was the reliance on changes in the ORF scores. Considering how low the ORF scores were overall, and how few schools comprised the sample, the models could have been highly sensitive to outliers. Outliers were not removed from this analysis, and, therefore, the findings were not subjected to a more robust sensitivity analysis. Correcting for outliers might significantly adjust the findings. Another outcome measure from the EGRA, such as correct letter sounds per minute, would yield far fewer zero scores and therefore would offer a greater range of learner performance. Although understanding of letter sounds is considered foundational for reading, in studies such as these, the correct-letter-soundsper-minute score should not replace the ORF score, which (along with scores on accompanying comprehension questions) has become an accepted standard for measuring literacy (Dubeck \& Gove, 2015).

Lastly, the path analyses did not attenuate the estimates to correct for reliability. Attenuation is the process of factoring predictor variables' reliability (Cronbach's alpha) in relation to their estimated effect $(\beta)$ on the response variable (Marzano et al., 2005). Attenuation would have reduced the estimates by a factor of alpha, and therefore likely would have reduced the overall test effects.

\section{Positive Leadership Practices and Effectiveness Behaviors}

Although the overall results were inconsistent, the findings from each of the tests point to a few important themes that emerged throughout. Table 3-9 


\section{Table 3-9. Positive leadership practices}

\begin{tabular}{|c|c|}
\hline $\begin{array}{l}\text { Clearly communicated to teachers high } \\
\text { standards for teaching reading } \\
\text { Set personal targets for learner performance } \\
\text { Used previous year's data on teacher and }\end{array}$ & $\begin{array}{l}\text { Developed learner performance } \\
\text { improvement action plans in consultation } \\
\text { and with input from teachers and } \\
\text { community stakeholders }\end{array}$ \\
\hline learner performance to set goals and targets & \multirow{2}{*}{$\begin{array}{l}\text { Solicited input from teachers during } \\
\text { teacher group meetings on key challenges } \\
\text { relating to PLP }\end{array}$} \\
\hline & \\
\hline & $\begin{array}{l}\text { Developed learner performance } \\
\text { improvement strategies with teachers }\end{array}$ \\
\hline $\begin{array}{l}\text { Used current-year data on teacher and learner } \\
\text { performance to prioritize action items in the } \\
\text { learner performance improvement plan }\end{array}$ & $\begin{array}{l}\text { improvement strategies with teachers } \\
\text { Shared vision of what the school should be } \\
\text { like with teachers and learners }\end{array}$ \\
\hline $\begin{array}{l}\text { Shared learner improvement progress reports } \\
\text { with teachers and community stakeholders }\end{array}$ & $\begin{array}{l}\text { Explicitly communicated strong beliefs or } \\
\text { ideals related to early grade reading to } \\
\text { teachers and learners }\end{array}$ \\
\hline
\end{tabular}

PLP $=$ Primary Literacy Program.

\section{Table 3-10. Positive leadership effectiveness behaviors}

\begin{tabular}{|c|c|}
\hline Promoted the PLP in the school & $\begin{array}{l}\text { Took decisive action on important issues } \\
\text { related to PLP implementation }\end{array}$ \\
\hline $\begin{array}{l}\text { Convinced parents and teachers about the } \\
\text { benefits of the PLP }\end{array}$ & \multirow{2}{*}{$\begin{array}{l}\text { Used input from teachers and stakeholders } \\
\text { to solve problems or identify solutions } \\
\text { related to PLP implementation }\end{array}$} \\
\hline $\begin{array}{l}\text { Shared knowledge of best practices for the } \\
\text { teaching of early grade literacy }\end{array}$ & \\
\hline & Ensured that teacher groups met regularly \\
\hline & $\begin{array}{l}\text { Personally provided helpful feedback to } \\
\text { teachers after classroom observations }\end{array}$ \\
\hline $\begin{array}{l}\text { Openly shared literacy performance progre } \\
\text { with school-community stakeholders }\end{array}$ & \multirow{2}{*}{$\begin{array}{l}\text { Monitored teacher preparation and } \\
\text { implementation of individual work plans, } \\
\text { weekly forecasts, schemes of work, and } \\
\text { lesson plans }\end{array}$} \\
\hline $\begin{array}{l}\text { Evaluated the impact of the school } \\
\text { improvement plan by using information on } \\
\text { the learners' performance in reading }\end{array}$ & \\
\hline
\end{tabular}

PLP $=$ Primary Literacy Program.

identifies the positive leadership practices that consistently emerged from the findings. Likewise, Table 3-10 identifies the positive leadership effectiveness behaviors that were associated with high performance.

\section{Conclusions}

The specific practices and behaviors (see Tables 3-9 and 3-10) reveal key themes that highlight school leaders' effective roles in supporting early grade learning. The first theme is a shift from general school improvement planning to a more focused approach and then to learner performance improvement planning. This final stage of the shift relied on a clear vision and goals for 
teaching and learning, as well as timely data on grade 2 literacy progress reports and early grade reading instructional practices.

The second theme relates to the head teachers' role in promoting the new curriculum of the PLP. Head teachers in higher-performing schools tended to take on a more active role in communicating expectations and supporting teachers' implementation of the PLP curriculum. To do so, they mentored and fostered collaborative (peer-to-peer) learning opportunities. From a policy standpoint, curriculum reform efforts would benefit if the specific behaviors and desired qualities of head teachers were to be incorporated into any training they received that was intended to support instructional reform. Another approach would be to emphasize these behaviors and attributes in head teachers' job descriptions.

Head teachers have extensive responsibilities in supporting, managing, and overseeing the curricular change process. They must ensure appropriate time on task; provide pedagogic support to early grade teachers through monitoring, feedback, and coaching; lead school improvement planning; facilitate teachers' continuous professional development; lead teacher group meetings and peer-learning circles; motivate teachers through nonmonetary recognition and award schemes; engage the parents and communities for home- and school-based support; and respond to the litany of administrative demands put upon them by the district and ministry.

Many head teachers also have a teaching role, particularly at smaller, rural, and remote schools. And many others are required to play a leadership role as a zonal head teacher, in which they are assigned to support other schools in their zone. In fact, our findings showed that zonal schools and schools whose head teachers had a higher classroom-teaching load had negative associations with leadership practices and learner performance. This correlation suggests that many head teachers were stretched too thin to effectively execute head teacher, classroom teacher, and/or zonal head teacher functions.

Lastly, the schools in Zambia operate in a highly centralized environment in which head teachers are given little autonomy or wherewithal to make school-based decisions on key management issues such as teacher hiring and firing, use of school discretionary funds, or procurement of learning materials. The narrowly defined administrative role of the head teachers, combined with the limited school-level decision-making responsibilities, conspires to curtail the impact that even the most dynamic school leader might have on school effectiveness. These environmental and organizational 
constraints are among the many key differences between school leadership in much of the West and school leadership in low-income, developing-country contexts (others being professionalization, pay, prestige, etc.).

Based on the findings from this study, the policy and program design considerations that affected leadership effectiveness and school performance included (1) limited degree of decentralized authority of head teachers in Zambia, which affected their influence on school effectiveness; (2) the working relationship between head teachers and teachers; (3) head teachers' teaching and mentoring workload; and (4) lack of attention to school climate. Taken together, these themes are emblematic of the broader school culture change required for sustained reform and offer areas for further examination in the field of educational leadership in developing-country contexts.

\section{Acknowledgments}

This chapter was made possible through a professional development award from RTI International, and in the context of the generous support of the American people through the United States Agency for International Development (USAID) under the Read to Succeed project implemented by Creative Associates International and RTI. The contents of this chapter are the responsibility of the authors and do not necessarily reflect the views of USAID or the US government. The writers warmly acknowledge the help that we received during the research fieldwork from the USAID Read to Succeed project team, as well as the openhearted participation from the hundreds of head teachers and teachers all over Zambia who took part in the survey.

\section{References}

Bush, T., \& Glover, D. (2014). School leadership models: What do we know? School Leadership \& Management, 34(5), 553-571. https://doi.org/10.1080/ 13632434.2014.928680

Camburn, E., Rowan, B., \& Taylor, J. E. (2003). Distributed leadership in schools: The case of elementary schools adopting comprehensive school reform models. Educational Evaluation and Policy Analysis, 25(4), 347-373. https://doi.org/10.3102/01623737025004347 
Condon, C., \& Clifford, M. (2012). Measuring principal performance: How rigorous are commonly used principal performance assessment instruments? (A Quality School Leadership Issue Brief). Naperville, IL: American Institutes for Research. Retrieved from https://ioeducation.com/ wp-content/uploads/AIR-Measuring_Principal_Performance.pdf

Datnow, A. (2005). The sustainability of comprehensive school reform models in changing district and state contexts. Educational Administration Quarterly, 41(1), 121-153. https://doi.org/10.1177/ $0013161 X 04269578$

Dubeck, M. M., \& Gove, A. (2015). The Early Grade Reading Assessment (EGRA): Its theoretical foundation, purpose, and limitations. International Journal of Educational Development, 40, 315-322. https://doi.org/10.1016/ j.ijedudev.2014.11.004

Fullan, M. (2001). Leadership in a culture of change. San Francisco, CA: Jossey-Bass.

Fullan, M. (2005). Leadership and sustainability: System thinkers in action. Thousand Oaks, CA: Corwin Press.

Gezi, K. (1990). The role of leadership in inner-city schools. Educational Research Quarterly, 12(4), 4-11.

Gove, A., \& Wetterberg, A. (Eds.). (2011). The Early Grade Reading Assessment: Applications and interventions to improve basic literacy. Research Triangle Park, NC: RTI Press. https://doi.org/10.3768/ rtipress.2011.bk.0007.1109

Hallinger, P., Bickman, L., \& Davis, K. (1996). School context, principal leadership, and student reading achievement. The Elementary School Journal, 96(5), 527-549. https://doi.org/10.1086/461843

Hallinger, P., \& Heck, R. H. (1996). Reassessing the principal's role in school effectiveness: A review of empirical research, 1980-1995. Educational Administration Quarterly, 32(1), 5-44. https://doi.org/10.1177/ 0013161X96032001002

Hallinger, P., \& Heck, R. H. (2010). Collaborative leadership and school improvement: Understanding the impact on school capacity and student learning. School Leadership \& Management, 30(2), 95-110. https://doi.org/10.1080/13632431003663214 
Hallinger, P., \& Leithwood, K. (1998). Unseen forces: The impact of social culture on school leadership. Peabody Journal of Education, 73(2), 126-151. https://doi.org/10.1207/s15327930pje7302_6

Harris, A. (2002). Effective leadership in schools facing challenging contexts. School Leadership \& Management, 22(1), 15-26. https://doi.org/10.1080/ $13632430220143024 \mathrm{a}$

James, J. W., Anthony, A., Warner, H., Rhodwell, C., \& Banguna, B. (2014). The influence of head teachers on improving reading in Zambian primary schools: Final report. Prepared for USAID under the Zambia Read to Succeed Project, Contract No. AID-611-C-12-00003. Washington, DC: University of Pittsburgh and Creative Associates International, Inc. Retrieved from http://pdf.usaid.gov/pdf_docs/ PA00M447.pdf

Lashway, L. (2002). Developing instructional leaders. Eugene, OR: ERIC Clearinghouse on Educational Management. Retrieved from https://eric.ed.gov/?id=ED466023

Leithwood, K., Harris, A., \& Hopkins, D. (2008). Seven strong claims about successful school leadership. School Leadership \& Management, 28(1), 27-42. https://doi.org/10.1080/13632430701800060

Leithwood, K., \& Jantzi, D. (2005). A review of transformational school leadership research 1996-2005. Leadership and Policy in Schools, 4(3), 177-199. https://doi.org/10.1080/15700760500244769

Leithwood, K., Seashore Louis, K., Anderson, S., \& Wahlstrom, K. (2004). Review of research: How leadership influences student learning. Minneapolis, MN: Center for Applied Research and Educational Improvement, University of Minnesota; Toronto: Ontario Institute for Studies in Education, University of Toronto; and New York NY: The Wallace Foundation. Retrieved from http://www.wallacefoundation.org/knowledge-center/ Documents/How-Leadership-Influences-Student-Learning.pdf

Marks, H. M., \& Printy, S. M. (2003). Principal leadership and school performance: An integration of transformational and instructional leadership. Educational Administration Quarterly, 39(3), 370-397. https://doi.org/10.1177/0013161X03253412

Marzano, R. J., Waters, T., \& McNulty, B. A. (2005). School leadership that works: From research to results. Alexandria, VA: ASCD. 
Ministry of General Education, Republic of Zambia. (2018). Ministry of General Education. Retrieved from http://www.moge.gov.zm/

Mortimore, P. (1993). School effectiveness and the management of effective learning and teaching. School Effectiveness and School Improvement, 4(4), 290-310. https://doi.org/10.1080/0924345930040404

Piper, B., \& Zuilkowski, S. S. (2015). Teacher coaching in Kenya: Examining instructional support in public and nonformal schools. Teaching and Teacher Education, 47, 173-183. https://doi.org/10.1016/j.tate.2015.01.001

Pont, B., Nusche, D., \& Moorman, H. (2008). Improving school leadership: Vol. 1. Policy and practice. Paris, France: OECD publishing. Retrieved from https://www.oecd.org/edu/school/44374889.pdf

Rhodwell, C. (2013). Read to Succeed: Baseline survey report. Prepared for USAID/Zambia under Contract No. AID-611-C-12-00003. Washington, DC: Creative Associates International, Inc. Retrieved from http://pdf. usaid.gov/pdf_docs/PBAAE456.pdf

Rhodwell, C. (2015). Read to Succeed: Midline survey report. Prepared for USAID/Zambia under Contract No. AID-611-C-12-00003. Washington, DC: Creative Associates International, Inc. Retrieved from http://pdf.usaid.gov/pdf_docs/PA00M441.pdf

Rhodwell, C. (2017). Read to Succeed: Endline survey report. Prepared for USAID/Zambia under Contract No. AID-611-C-12-00003. Washington, DC: Creative Associates International, Inc. Retrieved from http://pdf.usaid.gov/pdf_docs/PA00MW9V.pdf

Robinson, V. M., Lloyd, C. A., \& Rowe, K. J. (2008). The impact of leadership on student outcomes: An analysis of the differential effects of leadership types. Educational Administration Quarterly, 44(5), 635-674. https://doi.org/10.1177/0013161X08321509

Scheurich, J. J. (1998). Highly successful and loving, public elementary schools populated mainly by low-SES children of color: Core beliefs and cultural characteristics. Urban Education, 33(4), 451-491. https://doi.org/10.1177/0042085998033004001

Steinberg, M. P., \& Sartain, L. (2015). Does teacher evaluation improve school performance? Experimental evidence from Chicago's Excellence in Teaching project. Education Finance and Policy, 10(4), 535-572. https://doi.org/10.1162/EDFP_a_00173 
Stronge, J. H., Richard, H. B., \& Catano, N. (2008). Qualities of effective principals. Alexandria, VA: ASCD.

Willis, G. B. (2004). Cognitive interviewing: A tool for improving questionnaire design. Thousand Oaks, CA: Sage.

Witziers, B., Bosker, R. J., \& Krüger, M. L. (2003). Educational leadership and student achievement: The elusive search for an association. Educational Administration Quarterly, 39(3), 398-425. https://doi.org/10.1177/ $0013161 X 03253411$

World Bank. (2017, January). World development report 2018: Realizing the promise of education (Concept Note). Retrieved from http://pubdocs. worldbank.org/en/580361486043888162/WDR2018-Concept-Paper.pdf

Wuensch, K. L. (2016). An introduction to path analysis [Statistical instruction]. Retrieved from http://core.ecu.edu/psyc/wuenschk/MV/SEM/ Path.pdf

Zambian Teachers' Forum. (n.d.). Zambian Teachers' Forum. Retrieved from www.teachersforum.org.zm [site no longer works] 


\title{
Making Sense of Teacher In-Service Training in the Philippines
}

\author{
Nancy Clark-Chiarelli and Bonita Cabiles
}

\section{Introduction}

About the Research

In this chapter we discuss teacher professional development and teacher change in the context of the Basa Pilipinas (Read Philippines) program (referred to as Basa in this chapter). Basa is funded by the United States Agency for International Development (USAID) and implemented by Education Development Center, Inc. (EDC). Data presented in this paper were drawn primarily from the program's research component aimed at measuring teacher improvement. The research, therefore, is framed within the context of the whole project and is discussed here with reference to the program's interventions.

Two key questions that drove this work were:

- After two years of the Basa intervention, do students at the end of grade 2 demonstrate improved oral reading and comprehension skills in Filipino?

- Have teachers' instructional practices in teaching students to read in Filipino improved?

Knowledge is limited about what specific elements of professional development result in improved outcomes for students in middle- and low-income countries (Popova, Evans, \& Arancibia, 2016). However, professional development is also a key component of most education reform programs (see the editorial introduction, Chapter 1, for discussion of the magnitude of this investment by USAID), which suggests two things: methods used to train teachers up to now have been insufficient, and we need current and future investments for training to work. This chapter aims to describe a specific model of teacher professional development and link it to 
observed changes in teaching behaviors. The insights derived from careful examination of the model, described in the final section, may therefore provide a starting point for designing other future initiatives aimed at improving student literacy.

\section{The Basa Approach to Professional Development}

Basa is a five-year (2013-2018) early reading project, with the goal to improve the reading skills of one million students in the primary grades in three languages: the mother tongue of the region, Filipino, and English. To that end, Basa supports the Philippines Department of Education's (DepEd's) national reading program and is helping it implement transformative literacy practices in selected divisions of two regions of the country-Ilokos and Cebu-by training teachers in grades $1-3$, facilitating post-training support, and providing teacher and pupil materials. High-quality professional development plays a pivotal role in Basa's strategy for improving the reading ability of Filipino children.

The Basa approach to professional development uses face-to-face training sessions in conjunction with ongoing support and the opportunity for teachers to engage in interactive activities and reflection, as facilitated by a skilled trainer. The teachers can share their own ideas and experiences in plenary sessions and in small groups, an approach that underscores the recognition that professional development is not "one size fits all." To help maintain consistent quality, the Basa staff selects and trains a core cadre of master trainers. These master trainers are paired with DepEd-selected trainers, who are typically deputy superintendents, principals, or lead teachers. This teamteaching approach not only reinforces quality control and fidelity of implementation but also builds sustainability within the ranks of DepEd.

Face-to-face training consists of two three-day sessions, one session in April or May before the beginning of the school year and one in October during a school break (in the Philippines, the public school calendar typically begins in early June and ends in late March, with a short semester break in October and end-of-year break during April-May). All teachers in the selected divisions participate. Trainings focus on developing teachers' pedagogical content knowledge and are supported by materials for teachers and students that scaffold teachers' application of new learning in the classroom. These learning materials include detailed teacher guides as well as student readers in the four languages. Following the April/May face-to-face training, ongoing support is provided at the school and/or cluster level through peer-learning groups called Learning Action Cells. The principal 
and other school leaders convene the Learning Action Cells at least once a month-in some cases much more frequently. At least one hour of each Learning Action Cell is devoted to language and literacy.

\section{Conceptual Theory of Change}

Underlying the hypothesis that teachers are a key mediator in influencing pupil achievement is a conceptual theory of change. Figure 4-1 articulates this process associated with improvement in literacy instruction and the ultimate goal of positive changes in pupils' literacy achievement.

Moving from left to right, this diagram identifies the inputs and processes that support pupil literacy achievement. Undergirding classroom instruction are inputs controlled at the macro level of the school system, be it at the national, regional, or district level. These inputs, over which teachers usually have little control, include (1) educational policy, leadership, and supervision; (2) standards and benchmarks; (3) curriculum; and (4) opportunities for professional development. The mediator between these macro-level policies and structures (inputs) and pupil literacy achievement (outputs) is ultimately the actual instruction that teachers deliver and pupils receive (processes). Teachers enact curricular and instructional goals and objectives in the classroom daily, and the quality of this enactment is associated with pupil gains.

A similar model was described by Desimone (2011), in which she posited a change theory including the following steps: (1) professional development experience for teachers; (2) professional development-related increases in knowledge and skills and influences on attitudes and/or beliefs;

Figure 4-1. Theory of change: Teachers' enactment of curricular and instructional goals and objectives as mediators of pupil literacy achievement

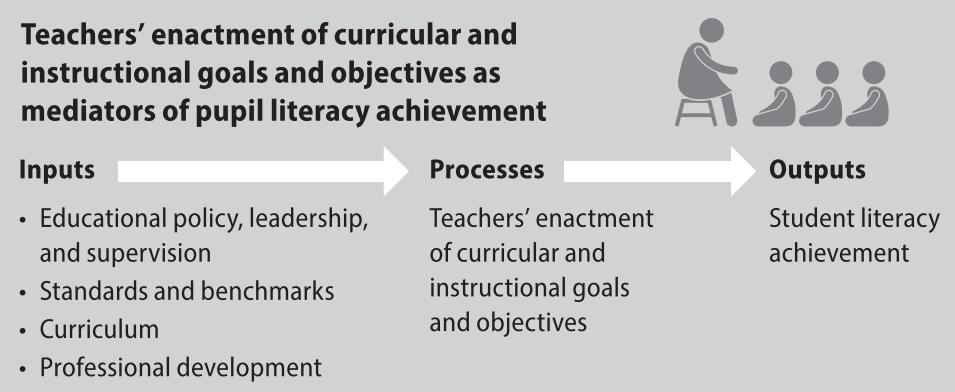

Outputs

Student literacy achievement 
(3) improvement in content and pedagogy of instruction; and (4) gains in pupil learning.

To build teachers' capacity to adopt new teaching practices, new models for what effective literacy instruction "looks like" are essential. Although effective teaching practices are readily identifiable and can be taught explicitly to teachers, all teachers need guidance on how to enact new instructional strategies in their own classrooms. The response to this challenge quite sensibly has been to provide in-service professional development for teachers that supports the implementation of best practices in their classrooms-essentially allow for a transfer of theory to practice (Davis \& Varma, 2008).

\section{Literature Review}

\section{Teacher Effectiveness and Student Achievement}

Research has shown that teachers can have a substantial impact on pupil learning (a point further emphasized in the concluding chapter of this volume). For example, one recent meta-analysis of over 2,000 research studies of teacher quality found that, after controlling for pupil characteristics, the effect size of teacher quality on pupil achievement averaged 0.50 standard deviations (SD), which is equivalent to half of a school year of learning gain (Hattie, 2009). Although individual pupil background is usually found to explain much of the variance in pupil scores, some studies have shown that high-quality instruction throughout the primary grades can substantially offset the disadvantages associated with poverty (Darling-Hammond, 2000). Indeed, a study by Rowe (2003) found that teacher effects are more influential than other factors such as gender and background characteristics on pupils' cognitive, affective, and behavioral outcomes, and teacher quality can be influenced by strategic teacher professional development.

Moreover, there is evidence that the effects of teacher quality on pupil performance are cumulative. Pupils who are assigned to several ineffective teachers in a row have significantly lower achievement and educational gains than those who are assigned to several highly effective teachers in sequence (Sanders \& Rivers, 1996). By highlighting the key role that teachers can play in pupils' academic success, there is increasing consensus based on research that building teacher capacity to improve outcomes for pupils is a promising strategy for promoting education in developing countries. 


\section{What Works in Literacy Professional Development?}

Research from high-income countries suggests that professional development in reading for primary-grade teachers must be structured around the key components and dimensions of literacy and its effective instruction. This position may mark a major departure from traditional methods of professional development, in which general pedagogical topics are addressed with the assumption that teachers will apply them to whatever subject they are teaching (e.g., the topic of using graphic organizers across the curriculum). Research has shown that the building of teachers' pedagogical content knowledge, in which both content and pedagogy are blended, produces more effective professional development (Hammerness, DarlingHammond, Grossman, Rust, \& Shulman, 2007).

In middle- and low-income countries, professional development focusing on pedagogical content knowledge is particularly important because many teachers are poorly trained and thus have limited skills and knowledge (Popova et al., 2016). In Nigeria, only 0.1 percent of teachers were found to demonstrate sufficient knowledge in science, 0.4 percent in English, and 7.8 percent in mathematics (Education Data, Research and Evaluation in Nigeria [EDOREN], 2014). Other challenges for in-service teacher training in Nigeria, identified by EDOREN (2014) were that trainings were neither at an inappropriate level nor not clearly related to a teacher's experience in the classroom.

The importance of an explicit link between training and classroom lessons has been underscored in research from high-income countries (Desimone \& Garet, 2015). Moreover, Popova et al. (2016) found that in-service teacher training that included supplemental materials, follow-up visits, and a focus on a specific subject resulted in greater student gains in low- and middleincome countries. Similar findings came from the 2013 Teaching and Learning International Survey of 35 middle- and low-income countries; the survey results indicated that professional development linked to a teacher's curriculum was more effective (Organisation for Economic Co-operation and Development, 2017).

Additionally, EDOREN (2014) found that the cascade model—which is widely used and assumes that a cadre of trained teachers can then provide the in-service training to their colleagues-was often ineffective due to a lack of detailed understanding on the part of the teacher trainers. Finally, although teachers often left the training with some factual knowledge, because it was 
largely superficial, they were unable to apply effective teaching techniques in their daily instruction. To address these challenges, EDOREN (2014) recommended using teacher-training guides to improve the cascade approach to training as well as support teachers in building a deeper understanding of content knowledge and pedagogy.

\section{Key Features of Literacy Professional Development}

While there is a dearth of comprehensive frameworks for effective professional development, Desimone and colleagues identified five key features that can be articulated in terms of literacy (Desimone, 2011; Desimone \& Garet, 2015; Desimone, Porter, Garet, Yoon, \& Birman, 2002).

1. Content focus. Effective professional development focuses training on developing knowledge about literacy and how to effectively teach students how to read. In other words, it focuses on pedagogical content knowledge.

2. Active learning. Effective professional development engages teachers in activities that foster discussion, analysis, critical thinking, and reflection on their own teaching. This approach contrasts with more traditional models of training in which lecture is the primary, or only, feature of the training.

3. Coherence. Effective professional development is not decontextualized. It is responsive to the curriculum and needs associated with particular teachers, schools, and communities.

4. Duration. Effective professional development goes well beyond one-shot workshops and incorporates a sustained plan for delivering face-to-face training and ongoing support. Desimone \& Garet (2015) suggested that training requires a minimum of 20 hours to be considered of high quality.

5. Collective participation. Effective professional development builds a shared approach to literacy instruction among teachers within a grade level and across grades. The training is then sustained through school-based structures such as communities of practice.

These five features of high-quality professional development were incorporated into the Basa professional development program. The next section describes the features of that program and presents the tools and strategies employed to measure changes in teachers' instructional practice 
and students' achievement in literacy. While Basa includes students in grades $1-3$, we focus specifically on teacher and student outcomes in Filipino for grade 2 . Grade 1 students were not assessed, and grade 3 students did not take part in the program until 2015. Therefore, by design, the data collection on teacher performance and pupils' achievement was more robust for grade 2.

\section{Methodology \\ Evaluation Design}

As shown by the theory of change depicted in Figure 4-1, positive changes in teacher practice are reasoned to be associated with positive outcomes in young readers. Although no causal link can be made between the two based on the available Basa data, we hypothesized an association or correlation based on the literature. As an explanation for our rationale, the evaluation protocols were designed to measure improvement in teachers' instructional practices in reading over the course of the Basa intervention. They also measured changes in grade 2 pupil achievement associated with the Basa intervention, focusing on the effects of two years of the intervention.

To study teacher practice, we used a longitudinal design in which the same grade 2 teachers were observed annually; we used a cross-sectional design to examine changes in pupil achievement in reading. In school year (SY) 20132014, before the full implementation of the project, the Basa project team collected the first round of data on teachers' classroom practices and on grade 2 pupil reading achievement in Filipino-using the Early Grade Reading Assessment (EGRA). This cohort of grade 2 students would serve as a comparison cohort for the Basa intervention. Data were collected from 40 schools in both regions. In SY 2015-2016, data again were collected on teachers' classroom practices and on pupil achievement in grade 2 using the EGRA. Although the original sample consisted of 40 teachers, only 28 teachers were tracked longitudinally due to attrition. The pupil sample included 2,127 learners from classrooms in the same schools as the teacher sample.

\section{Instruments}

To measure improvement in teacher practice, the Standard Classroom Observation Protocol for Education-Literacy (SCOPE-Literacy), developed by EDC to measure the quality of classroom instruction across grades and subjects, was administered. The observation protocol has subsequently been 
adapted to capture the quality of instructional practices with specific focus on literacy. The SCOPE-Literacy tool has two major sections-classroom structure and language literacy instruction - and a total of 13 items describing specific literacy-related instructional practices. Based on the observation of a classroom lesson on literacy, each item is scored on a scale from 1 to 5 (EDC, 2016, p. 65):

- (Rating 1) Deficient. There is minimal or no evidence of the practice.

- (Rating 2) Inadequate. There is limited evidence of the practice.

- (Rating 3) Basic. There is some evidence of the practice.

- (Rating 4) Strong. There is ample evidence of the practice.

- (Rating 5) Exemplary. There is compelling evidence of the practice.

The EGRA in Filipino was used to assess pupil achievement, as noted previously, and included subtests that measured initial sound identification, letter sounds, familiar words, nonsense words, oral passage reading, prosody, reading comprehension, listening comprehension, and dictation. The EGRA also measured both accuracy and automaticity/fluency for those subtests, as appropriate.

\section{Findings}

As noted in the introduction to this chapter, two key questions underlay the research:

1. After two years of the Basa intervention, do students at the end of grade 2 demonstrate improved oral reading and comprehension skills in Filipino?

2. Have teachers' instructional practices in teaching students to read in Filipino improved?

Results are based on two-tailed $t$-tests using a pooled SD.

\section{Research Question 1: After Two Years of the Basa Intervention, Do Students at the End of Grade 2 Demonstrate Improved Oral Reading and Comprehension Skills in Filipino?}

After two years of Basa intervention, the assessed grade 2 pupils were performing significantly better in reading Filipino than pupils performed before the intervention on four out of eight of the EGRA subtests $(p<.001)$ 
(EDC, 2016). The average percent correct for pupils after two years of Basa was 41.8 versus 28.1 before Basa (Table 4-1). An analysis of effect size, which is used to measure the magnitude of change, was also conducted.

The largest effect sizes occurred on the dictation (0.52 SD) and reading comprehension ( $0.43 \mathrm{SD})$ subtests. There were also moderate effects for initial sound identification (0.42 SD) and letter sounds (0.32 SD) as well as prosody (0.33 SD). The effect size declined for listening comprehension $(-0.42 \mathrm{SD})$.

Table 4-1. Filipino grade 2 EGRA results, by subtest and school year

\begin{tabular}{|c|c|c|c|c|}
\hline $\begin{array}{l}\text { Filipino EGRA subtests } \\
(d f=2,125)\end{array}$ & $\begin{array}{l}\text { SY 2013-2014) } \\
(n=469)\end{array}$ & $\begin{array}{l}\text { SY 2015-2016 } \\
(n=1,658)\end{array}$ & Gain & $\begin{array}{l}\text { Effect } \\
\text { size (SD) }\end{array}$ \\
\hline $\begin{array}{l}\text { Initial sound identification } \\
\text { (percent correct) }\end{array}$ & $57.6 \%$ & $72.1 \%$ & $14.5 \%$ ( $\pm 3.6 \%)$ & $0.42^{* *}$ \\
\hline $\begin{array}{l}\text { Letter sounds } \\
\text { (percent correct) }\end{array}$ & $19.1 \%$ & $24.1 \%$ & $5.0 \%( \pm 1.5 \%)$ & $0.32^{* *}$ \\
\hline $\begin{array}{l}\text { Letters correct } \\
\text { (per minute) }\end{array}$ & 19.2 & 24.3 & $5.1( \pm 1.5)$ & $0.31^{* *}$ \\
\hline $\begin{array}{l}\text { Familiar words } \\
\text { (percent correct) }\end{array}$ & $68.4 \%$ & $65.9 \%$ & $-2.5 \%( \pm 3.3)$ & $-0.08^{* *}$ \\
\hline $\begin{array}{l}\text { Familiar words correct } \\
\text { (per minute) }\end{array}$ & 37.5 & 35.3 & $-2.2( \pm 2.0)$ & $-0.11^{* *}$ \\
\hline $\begin{array}{l}\text { Nonsense words } \\
\text { (percent correct) }\end{array}$ & $46.2 \%$ & $46.8 \%$ & $0.6 \%( \pm 2.6 \%)$ & $0.02^{* *}$ \\
\hline $\begin{array}{l}\text { Nonsense words correct } \\
\text { (per minute) }\end{array}$ & 23.2 & 23.6 & $0.40( \pm 1.4)$ & $\begin{array}{l}0.02 \\
\text { (n.s.) }\end{array}$ \\
\hline $\begin{array}{l}\text { Oral passage reading } \\
\text { (percent correct) }\end{array}$ & $56.1 \%$ & $58.7 \%$ & $2.6 \%( \pm 3.0 \%)$ & $\begin{array}{l}0.09 \\
\text { (n.s.) }\end{array}$ \\
\hline $\begin{array}{l}\text { Words correct in a text, or oral } \\
\text { reading fluency (per minute) }\end{array}$ & 37.0 & 39.4 & $2.4( \pm 2.1)$ & $0.11^{* *}$ \\
\hline Prosody score & 2.1 & 2.4 & $0.3( \pm 0.1)$ & $0.33^{* *}$ \\
\hline $\begin{array}{l}\text { Reading comprehension: } \\
\text { timed (percent correct) }\end{array}$ & $28.1 \%$ & $41.8 \%$ & $13.7 \%( \pm 2.9 \%)$ & $0.43^{* *}$ \\
\hline $\begin{array}{l}\text { Listening comprehension } \\
\text { (percent correct) }\end{array}$ & $49.1 \%$ & $34.7 \%$ & $-14.4 \%( \pm 3.7 \%)$ & $-0.49^{* *}$ \\
\hline $\begin{array}{l}\text { Dictation composite } \\
\text { (percent correct) }\end{array}$ & $45.6 \%$ & $59.7 \%$ & $14.1 \%( \pm 2.8 \%)$ & $0.52^{* *}$ \\
\hline \multicolumn{5}{|c|}{$\begin{array}{l}d f=\text { degrees of freedom; EGRA = Early Grade Reading Assessment; } n . s .=\text { not statistically significant; } \\
\text { SD = standard deviation; } S Y=\text { school year. }\end{array}$} \\
\hline \multicolumn{5}{|c|}{$*^{*}=p<.01$} \\
\hline Source: $\operatorname{EDC}(2016$, p. 19). & & & & \\
\hline
\end{tabular}


Figure 4-2. Filipino oral reading fluency (cwpm), by school year

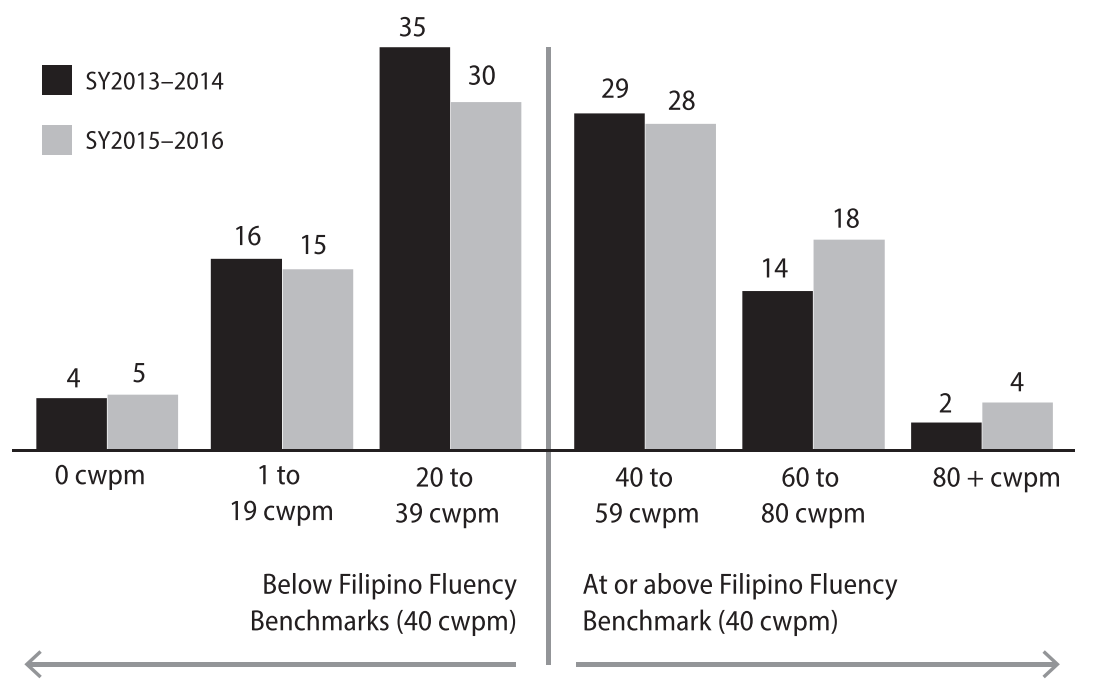

cwpm $=$ correct words per minute.

Source: EDC (2016, p. 30).

No statistically significant changes were noted in familiar word reading, nonsense word reading, or oral passage reading. It should be noted that students in SY 2013-2014 did better than students in SY 2015-2016, and this finding was statistically significant. Of particular interest, analyses showed statistically significant improvement in student performance in two key EGRA measures: oral reading fluency and reading comprehension. Given that an understanding of what one reads is the ultimate goal of reading, this was a very encouraging finding.

Figure 4-2 displays the distribution of fluency scores by school year. An estimated 50 percent of students in SY 2015-2016 were reading at or above the grade 2 proposed proficiency level of 40 correct words per minute (cwpm) (in conjunction with DepEd, the Basa project team set benchmarks in 2015 for fluency and comprehension in Filipino, English, and the mother tongue), compared with 45 percent in SY 2013-2014 before the Basa intervention began.

To measure comprehension, students were asked questions about the text after reading a grade-level Filipino passage. From SY 2013-2014 to SY 2015-2016, the students showed a statistically significant $(p<.001)$ increase in the number of reading comprehension questions they could 
Figure 4-3. Grade 2 reading comprehension results on the Filipino EGRA, by school year

SY 2013-2014

SY 2015-2016
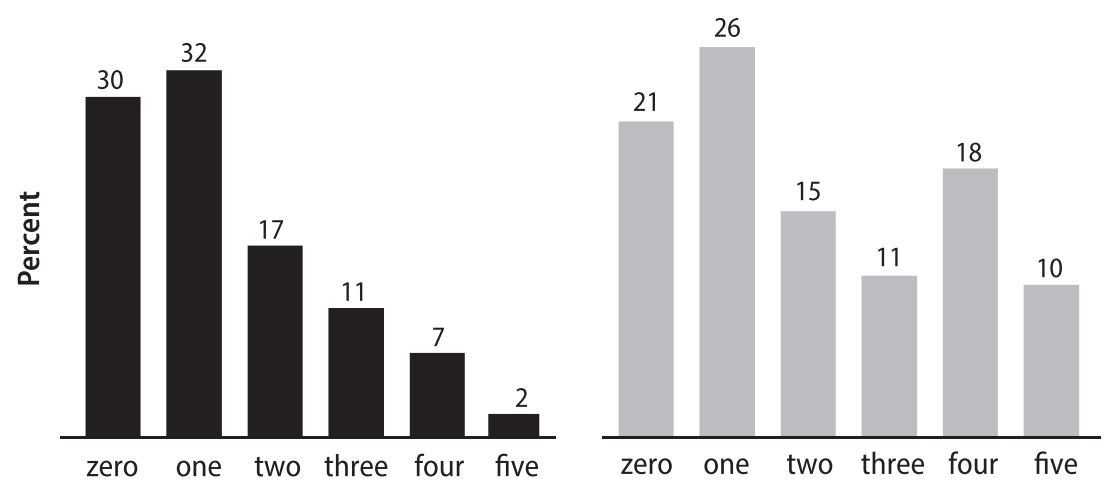

EGRA = Early Grade Reading Assessment; $S Y=$ school year.

Note: $y$-axis $=$ percentage of pupils; $x$-axis $=$ number of questions answered correctly.

Source: EDC (2016, p. 32).

answer correctly. For SY 2013-2014, the total number of reading comprehension questions answered correctly ranged from 0 to 5 , with a mean of 1.4 (28.1 percent), while SY 2015-2016 students answered on average 2.1 questions correctly (41.8 percent).

Figure 4-3 shows the distribution of the percentage of students who correctly answered each possible number of reading comprehension questions. Fewer students in SY 2015-2016 were unable to answer any questions correctly than students before the Basa intervention in SY 20132014. More than a quarter (28 percent) of SY 2015-2016 students answered four or more comprehension questions correctly, compared with 9 percent of SY 2013-2014 students. Additionally, the percentage of grade 2 learners who were unable to answer a single reading comprehension question correctly decreased: while 30 percent of SY 2013-2014 students were unable to answer a single reading comprehension question, only 21 percent of SY 2015-2016 students were unable to do so.

Research Question 2: Have Teachers' Instructional Practices in Teaching Students to Read in Filipino Improved?

Mean scores from the SCOPE-Literacy instrument are presented in Table 4-2. 
Table 4-2. Ratings of classroom instruction, by items and school year

\begin{tabular}{|c|c|c|c|}
\hline SCOPE-Literacy items $(d f=27)$ & $\begin{array}{l}\text { SY 2013-2014 } \\
\text { Mean rating }\end{array}$ & $\begin{array}{l}\text { SY 2015-2016 } \\
\text { Mean rating }\end{array}$ & Effect size \\
\hline \multicolumn{4}{|l|}{ Classroom structure } \\
\hline Positive learning environment & 2.4 & 2.8 & 0.43 (n.s.) \\
\hline Effective grouping strategies & 1.6 & 1.7 & 0.13 (n.s.) \\
\hline Participation of all learners & 2.2 & 2.6 & 0.51 (n.s.) \\
\hline Opportunities for reflection & 1.2 & 2.0 & $1.32^{* *}$ \\
\hline Classroom materials & 2.6 & 3.6 & $1.37^{* *}$ \\
\hline $\begin{array}{l}\text { Management of reading/writing } \\
\text { instruction }\end{array}$ & 2.4 & 3.1 & $0.84^{* *}$ \\
\hline \multicolumn{4}{|l|}{ Language and literacy instruction } \\
\hline $\begin{array}{l}\text { Opportunities for oral language } \\
\text { development }\end{array}$ & 1.5 & 2.1 & $0.86^{*}$ \\
\hline $\begin{array}{l}\text { Opportunities for meaningful } \\
\text { reading }\end{array}$ & 1.8 & 1.6 & -0.15 (n.s.) \\
\hline $\begin{array}{l}\text { Opportunities for learning to decode } \\
\text { and spell words }\end{array}$ & 1.6 & 1.7 & 0.08 (n.s.) \\
\hline $\begin{array}{l}\text { Opportunities for developing } \\
\text { reading fluency }\end{array}$ & 1.0 & 1.7 & $1.17^{*}$ \\
\hline $\begin{array}{l}\text { Opportunities for developing } \\
\text { vocabulary }\end{array}$ & 1.7 & 2.1 & 0.37 (n.s.) \\
\hline $\begin{array}{l}\text { Opportunities for developing } \\
\text { comprehension }\end{array}$ & 1.4 & 2.0 & 0.67 (n.s.) \\
\hline Writing instruction & 1.4 & 1.1 & $-0.48^{*}$ \\
\hline
\end{tabular}

$d f=$ degrees of freedom; n.s. $=$ not statistically significant; $S Y=$ school year.

${ }^{*}=p<.05 ;{ }^{* *}=p<.01$.

Source: Authors.

Figure 4-4 depicts the overall trends observed in teachers' practices in classroom structure and language literacy instruction from SY 2013-2014, before Basa began, to SY 2015-2016, after two years of the Basa intervention.

The largest gains were seen in the classroom structure rating, in which three items were statistically significant at the $p<.01$ level. Improvements from 2013 to 2015 suggested that teachers were starting to apply new teaching practices. It should be noted that a "basic" rating of 3 (see the Methodology section as well as Table 4-2) is quite positive in the context of introducing new literacy instruction techniques in the Philippines. More specific detail on items from the classroom structure subscale and language and literacy instruction subscale is discussed below. 
Figure 4-4. Graphic depiction of changes in average SCOPE-Literacy rating scores from SY 2013-2014 to SY 2015-2016 $(n=28)$

\section{Deficient Inadequate Basic Strong}
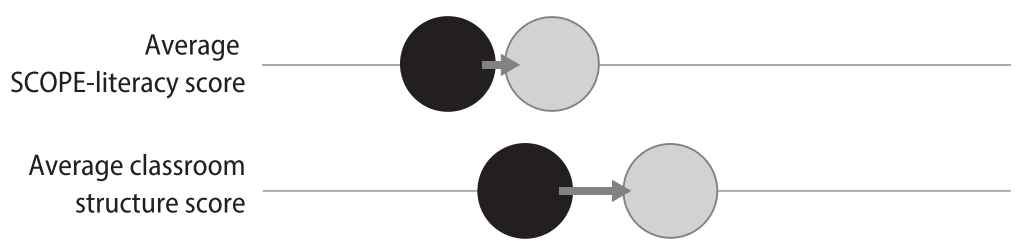

Average language

and literacy

instruction score

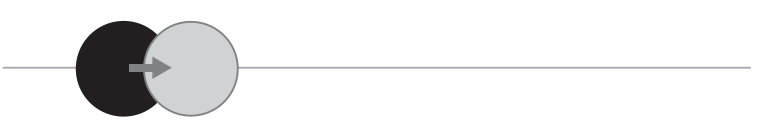

Avg. = average; $S Y=$ school year.

Source: EDC (2016, p. 65).

\section{Classroom Structure Results}

In the classroom structure domain of the SCOPE-Literacy instrument, teachers showed the largest improvements in the classroom materials, opportunities for [student] reflection, and management of reading/writing instruction items $(p<.01)$ (Figure 4-5). Figure 4-5 shows the difference in the average rating from SY 2013-2014 to SY 2015-2016; more precisely, in SY 2015-2016, more than half (62 percent) of observed teachers scored "strong" on the classroom materials items and nearly a third (30 percent) on the management of reading/writing instruction items. This result is important given that the Basa project team has introduced a large number of new reading materials for teachers to manage in the classroom. Ensuring access to the materials is key for student learning, as is management of reading and writing instruction in the classroom.

Teachers did not score as highly in the areas of effective grouping strategies and opportunities for reflection-both items require more advanced classroom management skills. Teachers are encouraged to effectively group students to provide differentiated learning opportunities as well as opportunities for reflection that can deepen students' understanding of text.

\section{Language and Literacy Instruction Results}

The language and literacy instruction domain of the SCOPE-Literacy instrument includes seven items (see Table 4-2). While baseline scores were 
Figure 4-5. Change in average classroom structure scores for the SCOPELiteracy instrument from SY 2013-2014 to SY 2015-2016 $(n=28)$

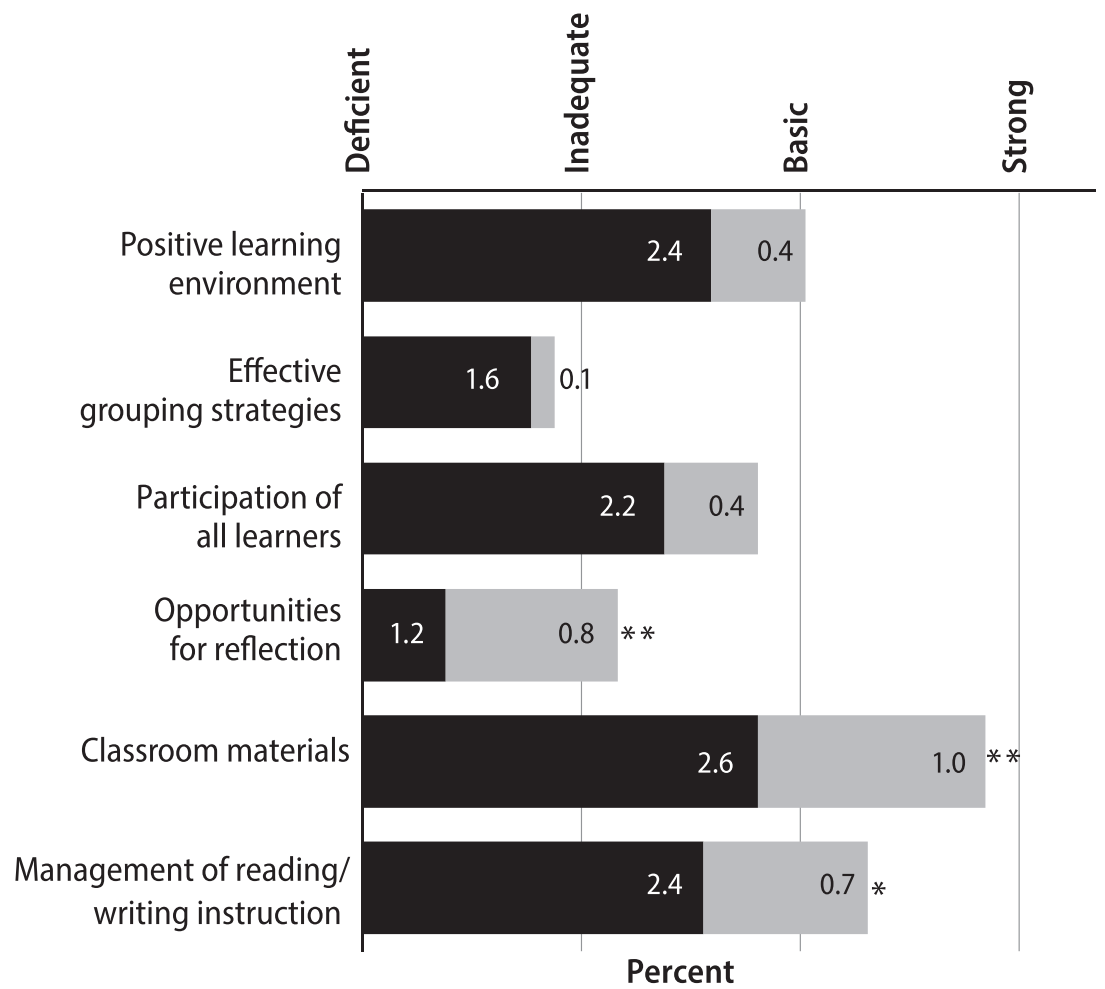

Before Basa (SY 2013-2014)

Gain after two years of Basa (SY 2015-2016)

SY $=$ school year. ${ }^{*}=p<.05 ;{ }^{*}=p<.01$.

Source: EDC (2016, p. 66).

lower overall in the domain of language and literacy instruction (Figure 4-6), teachers showed improvement in five out of seven observed practices. Teachers significantly improved literacy instruction in the areas of oral language development, developing reading fluency, and developing comprehension $(p<.05)$. The improvement on opportunities for developing reading fluency items was particularly striking because almost no evidence of this practice appeared in the first observation. Oral language development is also a key new skill for teachers in the multilingual context of the Philippines where bridging opportunities from one language to another needs to be intentionally planned by teachers. 
Figure 4-6. Change in average language and literacy instruction scores for the SCOPE-Literacy instrument from SY 2013-2014 to SY 2015-2016 $(n=28)$

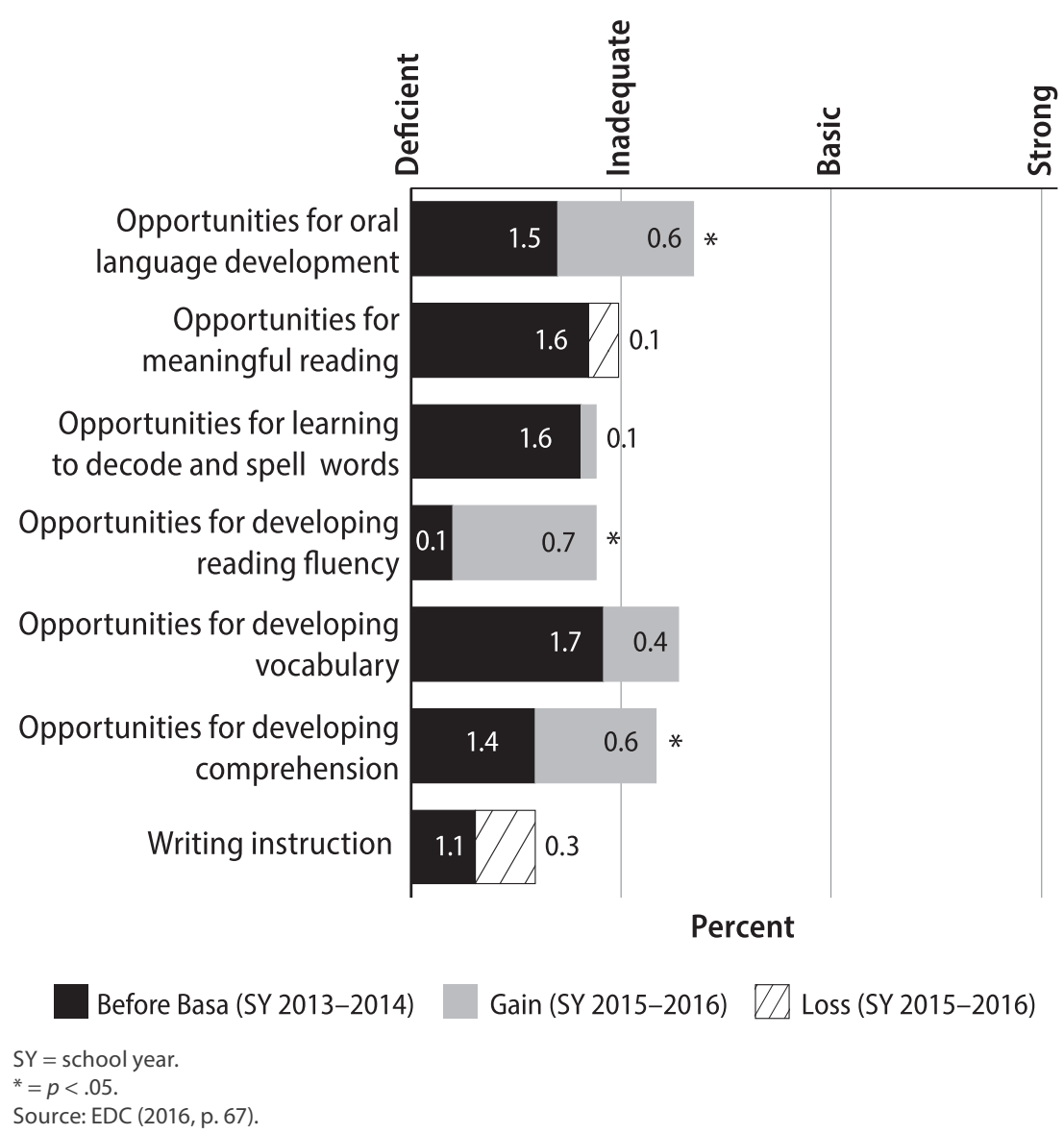

There is one general caveat: Basa teachers follow an instructional sequence in which all 14 domains of the kindergarten-grade 12 curricula are not taught every day but over a period of 5 days for Filipino and 10 days for English. This approach allows adequate time for pupils to complete skills-related tasks in their second and third languages. Depending on the lesson plan for the day, teachers would not be expected to teach all domains. In addition, domains such as phonics take on additional meaning in a language such as English, which has an opaque orthography, versus Filipino, a syllabic language that has a transparent orthography. Because 
the teachers were observed during their Filipino classes, one possible reason for the little-to-no increase in the score for opportunities for learning to decode and spell words items could be that Filipino has a relatively simple syllable structure, and phonics instruction need not be as intensive as is required in English.

Bivariate statistical analysis showed that the SCOPE-Literacy scores were significantly $(p<.001)$ positively correlated with average grade 2 Filipino EGRA scores; however, the relationship was relatively weak $(r=222)$. Providing opportunities for reflection, oral language development, vocabulary development, and comprehension development had the strongest correlations with average Filipino EGRA results (Pearson's $r$ ranged from 0.186 to 0.20 for these domains).

\section{Discussion}

\section{What Aspects of the Basa Approach to Professional Development Have Contributed to Positive Changes?}

By applying Desimone and colleagues' (2002) model of effective professional development to the Basa approach, we have determined the elements that most likely enhanced the effectiveness of Basa's professional development program: content focus, active learning, coherence, duration, and collective participation.

\section{Content Focus}

Basa's face-to-face training works to develop knowledge in the components of literacy (e.g., phonemic awareness, phonics, fluency, vocabulary, comprehension, concepts of print and writing) and embeds that knowledge in teachers' analysis of Basa materials, which include teacher guides, leveled readers, and read-aloud stories in four languages - two mother tongues, Filipino, and English. This professional development strategy of pairing pedagogical content knowledge and practice with teacher guides in Basa training reflects research that has shown that use of teacher guides in the classroom is more effective when it is supported by teacher knowledge of the subject and pedagogy (Shalem, Steinberg, Koornhof, \& de Clercq, 2016). For example, in one activity on day 1 of the October training each year, teachers are asked to analyze a particular week's lessons in their teacher guide by (1) identifying how the components of literacy are interwoven into the lessons and (2) identifying the opportunities for authentic writing and explaining what the pupils will gain from the writing activity. 
Table 4-3. Introduction of Filipino and English, by grade level and quarter

\begin{tabular}{|c|c|c|c|c|c|c|c|c|c|c|c|c|}
\hline & \multicolumn{4}{|c|}{ Grade 1} & \multicolumn{4}{|c|}{ Grade 2} & \multicolumn{4}{|c|}{ Grade 3} \\
\hline & Q1 & Q2 & Q3 & Q4 & Q1 & Q2 & Q3 & Q4 & Q1 & Q2 & Q3 & Q4 \\
\hline Mother tongue & \multicolumn{12}{|c|}{ As language and medium of instruction for all other subjects } \\
\hline Filipino language & & \multicolumn{3}{|c|}{ Oral } & \multicolumn{8}{|c|}{ Reading/writing } \\
\hline English language & & & \multicolumn{4}{|c|}{ Oral } & \multicolumn{6}{|c|}{ Reading/writing } \\
\hline
\end{tabular}

Source: EDC (2016, p. 4).

The Basa approach also emphasizes training teachers in techniques for bridging across languages. As per the DepEd policy of mother tongue-based multilingual education, the mother tongue is the language of instruction in public schools for grades 1 to 3, while Filipino and English are introduced gradually. Table 4-3 displays the sequence and timing of the introduction of Filipino and English.

One way of "showing" teachers how to build bridges between languages is with tailor-made videos; in previous research, videos have been found to be effective in fostering improved classroom practices (Gaudin \& Chaliès, 2015). On day 2 of the annual October training, teachers view a video that demonstrates bridging practices in action, and a "voiceover" narrative describes the effective practices and why they are effective. The video is designed to be viewed in segments, between which teachers are asked to engage in a related activity. For example, when the video is paused after the first segment, teachers in small groups are asked to discuss the following question and engage in the following activity: How do you help bridge between a language your pupils know and a language they are learning? Give an example for each of the domains [that are printed] in red [type]-phonological awareness; book and print knowledge; reading and listening comprehension; attitudes toward language, literacy, and literature; and study skills.

Using both lesson analysis and video training, Basa delivers content regarding language and literacy development to teachers with the aim of deepening their understanding of the reading process. Likewise, in both cases, the content is linked with pedagogy aiming to improve teachers' instructional practices. Another key feature of Basa professional development is the high level of support given to all instructors or facilitators in the form of a detailed instructor guide, full sets of slide presentations and other handouts, and featured videos. Beyond supporting instructors, these materials have increased the fidelity of delivery and the continuity among training sites and year of delivery. 


\section{Active Learning}

Well-designed lectures are critical in exposing teachers to new information on reading development and literacy instruction. Beyond these lectures, however, Basa professional development fosters interaction among teachers and instructors. During the trainings, teachers have opportunities to reflect on their own literacy practices and then share with a partner, in small groups, or with the large group. Video analysis and action planning are other activities that promote the application of new information in an interactive manner. For example, on day 2 of the October trainings, after a slide presentation on guided reading, grade 1 teachers watch two videos: the first video features a teacher using Basa leveled readers and conducting a guided reading lesson in the mother tongue; the second video follows the same steps for a lesson in Filipino. For grade 2 teachers, the videos include one lesson in Filipino and one in English rather than the mother tongue. Participants are asked to actively watch and take notes using the following prompt: As you watch, think about what each teacher is doing and what the pupils are doing. Identify three strategies the teacher asks pupils to do to make sure they are reading the word accurately.

After viewing each video, teachers first discuss in pairs and then in a small group the following questions: What did the teacher do to support pupils' accurate and fluent reading? How did the pupils respond? One pair from each group then shares with all participants. In this example, the teachers have multiple opportunities to actively participate in the learning process. They are also asked to reflect on what they have learned from the lecture and how it applies to real classrooms using the same Basa materials that they are incorporating into their teaching.

\section{Coherence}

Research has shown that new information or learning is more meaningful if the content of the face-to-face training is embedded in a teacher's daily instruction or current curriculum (Knowles, 1980). Achieving congruence between training and curriculum demands that division leaders, supervisors, school heads, and head teachers be well versed in the content and methods of the professional development that teachers are receiving in language and literacy. It also calls for providing ongoing support to teachers as they take on new learning and implement new materials and practices. As instructional leaders, school heads play an instrumental role in ongoing professional development designed to foster better literacy instruction. 
Under the guidance of school heads, Learning Action Cells support teachers' implementation of materials and instructional strategies learned in face-to-face training throughout the school year. DepEd has championed the use of Learning Action Cells, which convene at least monthly, for many years and thus has most enthusiastically supported their incorporation into Basa's approach to professional development. To help facilitators deepen their comfort and skill in leading the Cells, school principals and head teachers receive three days of training.

Facilitators use a highly specific Basa Learning Action Cell protocol to lead the sessions, although adaptation to school and session needs is encouraged. As indicated previously, school heads facilitate these conversations with teachers who (1) share their reflections on their instructional successes and challenges; (2) explore a content-specific topic (e.g., bridging from mother tongue to Filipino); (3) explore the upcoming lessons; and (4) share their plans for implementing the lessons. This coherence between teacher training and day-to-day teaching deepens and broadens Basa professional development.

\section{Duration}

According to Desimone (2011), a minimum of 20 hours of professional development is necessary to make positive changes in teacher practice. Face-to-face training must be bolstered by encouragement of teachers' reflection and sharing of their implementation of new teaching strategies "back at home." The Basa grades 1 and 2 teachers receive a minimum of 60 hours of professional development-48 hours of face-to-face training and 12 hours with Learning Action Cells-during their first year in the program. Moreover, with the ongoing support of the Cells, the initial investment in face-to-face training is sustained over time.

\section{Collective Participation}

In the Basa program, the collective participation of all teachers in grades 1, 2, and 3 builds coherence within a grade, between languages, and between grades. In addition, it fosters consistency in teaching strategies. Building a unified plan for literacy instruction in the early grades also takes place at the district, division, and regional levels. Moreover, because all schools within a Basa division are included in the professional development program, there is coherence across the division with division leaders working with the Basa team to implement new materials and instructional strategies. Building capacity with teachers and leaders along with the proven sustainability of the 
Basa approach promises to support continued improvement in instruction and student achievement.

\section{Limitations}

There are several limitations to this study. First, at its inception, the evaluation design did not include a comparison or control group. As a result, the findings cannot support claims regarding causal relationships. However, an effort was made to identify correlational evidence where appropriate, and the more descriptive approach permitted an examination of general trends and associations. Second, as noted throughout this chapter, the teacher sample was very small, so the design called for a longitudinal approach to collecting classroom instructional data. Every effort was made to prevent attrition over time, but the sample did fall from 40 teachers to 28 teachers. With such a small sample, the analyses and their interpretation must be approached cautiously. Nevertheless, the findings do illuminate some of the key features of professional development that have been incorporated into the Basa program.

\section{Conclusions}

As noted, although the data on changes in teacher instructional practices presented in this chapter were based on a small sample of teachers and classrooms, the results do indicate changes in teacher practice associated with the Basa professional development program. Teachers demonstrated progress in applying effective classroom management and literacy instructional practices; however, room for improvement remained, particularly among the more unfamiliar and/or complex teaching strategies. Continuing to improve teacher practices in areas such as effective grouping is likely to have a positive effect on student achievement in reading; thus, teachers will need continuing professional development to reinforce and deepen their understanding of effective literacy instruction to see continued progress in student achievement. In particular, training should focus on managing differentiated instruction and reinforcing the reading-writing connection. Although a causal relationship between teacher outcomes and the Basa professional development program cannot be determined due to the design of the study, as explained in the Limitations section, the relationship is associative but highly suggestive of the previously mentioned conclusions.

In addition to more training and support in implementing specific literacy instruction strategies, more rigorous ongoing supervision and coaching 
would further strengthen the Basa intervention. In another related study, the Basa project team found that schools with principals who reported checking lesson plans and observing classrooms frequently tended to perform better than those whose principals reported less frequent checking. We found positive associations between student achievement in reading and principals who reported attending Learning Action Cell training and providing instructional support to teachers on teaching reading. Previous research has documented the positive and important role principals play in supporting teachers' professional development-professional development that leads to improved classroom practice (Bredeson, 2000). Importantly, these associated data have highlighted a link between principal support to teachers and student achievement in reading.

As a mediator of student achievement, improved teacher practices supported gains in student reading and writing achievement. By the end of grade 2, after one full year of reading instruction in Filipino, students were demonstrating beginning reading skills in the language. Again, while no causal relationships can be claimed from this research, the Basa approach to professional development is associated or correlated with some student improvement in reading. A final takeaway is that effective professional development can be thought of as a three-legged stool: Face-to-face training, teaching and learning materials for both students and teachers, and ongoing support are the three legs. The legs on the stool are mutually supportive. If one leg is removed, the stool is not stable. All three combine to encourage teacher behavior change and student improvements in literacy achievement.

\section{Acknowledgments}

This chapter was made possible by the generous support of the American people through the United States Agency for International Development (USAID) under the Basa Pilipinas project and the Philippines Department of Education. The contents of this chapter are the sole responsibility of Education Development Center, Inc. (EDC), and do not necessarily reflect the views of USAID or the US government.

\section{References}

Bredeson, P. V. (2000). The school principal's role in teacher professional development. Journal of In-service Education, 26(2), 385-401. https://doi. org/10.1080/13674580000200114 
Darling-Hammond, L. (2000). Teacher quality and student achievement: A review of state policy evidence.Education Policy Analysis Archives, 8(1), 1-44. https://doi.org/10.14507/epaa.v8n1.2000

Davis, E. A., \& Varma, K. (2008). Supporting teachers in productive adaptation. In Y. Kali, M. C. Linn, \& J. E. Roseman (Eds.), Designing coherent science education (pp. 94-122). New York, NY: Teachers College Press.

Desimone, L. M. (2011). A primer on effective professional development. Phi Delta Kappan, 92(6), 68-71. https://doi.org/10.1177/003172171109200616

Desimone, L. M., \& Garet, M. S. (2015). Best practices in teachers' professional development in the United States. Psychology, Society, \& Education, 7(3), 252-263. https://doi.org/10.25115/psye.v7i3.515

Desimone, L. M., Porter, A. C., Garet, M. S., Yoon, K. S., \& Birman, B. F. (2002). Effects of professional development on teachers' instruction: Results from a three-year longitudinal study. Educational Evaluation and Policy Analysis, 24(2), 81-112. https://doi.org/10.3102/01623737024002081

Education Data, Research and Evaluation in Nigeria (EDOREN). (2014). Teacher competence: Improving teacher effectiveness by building skills and subject knowledge (Issue Brief No. 2). Abuja, Nigeria: Author. Retrieved from https://edorennigeria.files.wordpress.com/2014/07/policy-brief2teacher-competence.pdf

Education Development Center, Inc. (EDC). (2016). USAID/Philippines Basa Pilipinas Program: Final outcome evaluation report, 2013-2016. Waltham, MA: Author. Retrieved from http://pdf.usaid.gov/pdf_docs/ PA00MGD2.pdf

Gaudin, C., \& Chaliès, S. (2015). Video viewing in teacher education and professional development: A literature review. Educational Research Review, 16, 41-67. https://doi.org/10.1016/j.edurev.2015.06.001

Hammerness, K., Darling-Hammond, L., Grossman, P., Rust, F., \& Shulman, L. (2007). The design of teacher education programs. In L. DarlingHammond \& J. Bransford (Eds.), Preparing teachers for a changing world (pp. 390-441). San Francisco, CA: Jossey-Bass.

Hattie, J. (2009). Visible learning: A synthesis of over 800 meta-analyses relating to achievement. New York, NY: Routledge. 
Knowles, M. (1980). The modern practice of adult education: Andragogy versus pedagogy (revised and updated). Englewood Cliffs, NJ: Cambridge Adult Education. Retrieved from http://www.umsl.edu/ henschkej/articles/a_ The_\%20Modern_Practice_of_Adult_Education.pdf

Organisation for Economic Co-operation and Development. (2017). How can professional development enhance teachers' classroom practices? Paris, France: Author. Retrieved from http://www.oecd-ilibrary.org/education/ how-can-professional-development-enhance-teachers-classroompractices_2745d679-en

Popova, A., Evans, D. K., \& Arancibia, V. (2016). Training teachers on the job: What works and how to measure it (Policy Research Working Paper No. 7834). Washington, DC: World Bank. Retrieved from https:// openknowledge.worldbank.org/handle/10986/25150

Rowe, K. (2003). The importance of teacher quality as a key determinant of students' experiences and outcomes of schooling. Paper presented the Australian Council for Educational Research Conference, 19-21 October, Melbourne. Retrieved from https://research.acer.edu.au/ research_conference_2003/3

Sanders, W. L., \& Rivers, J. C. (1996). Cumulative and residual effects of teachers on future student academic achievement (Research Progress Report). Knoxville, TN: University of Tennessee Press.

Shalem, Y., Steinberg, C., Koornhof, H., \& de Clercq, F. (2016). The what and how in scripted lesson plans: The case of the Gauteng Primary Language and Mathematics Strategy. Journal of Education, 66, 13-36. Retrieved from https://www.researchgate.net/publication/313502983_The_what_and_ how_in_scripted_lesson_plans_the_case_of_the_Gauteng_Primary_ Language_and_Mathematics_Strategy 



\title{
Short Message Service (SMS)-Based Remote Support and Teacher Retention of Training Gains in Malawi
}

\author{
Timothy S. Slade, Scott Kipp, Stirling Cummings, and \\ Kondwani Nyirongo
}

\section{Introduction}

This chapter critically reviews the design, implementation, and evaluation of an attempt to study an exploratory short message service (SMS)-based intervention conducted under the auspices of the United States Agency for International Development's (USAID's) Malawi Early Grade Reading Activity (EGRA). ${ }^{1}$ The overall EGRA program, which was implemented from July 2013 to October 2016 in 1,614 schools across 11 educational districts, was designed to support Malawi's Ministry of Education, Science, and Technology (MOEST) to improve reading outcomes in both Chichewa and English languages among children in grades 1-3. The program addressed this goal through the development, production, and distribution of high-quality teaching and learning materials; regularly occurring training of teachers in phonics-based instructional methodologies; support for instructional coaching provided by MOEST's primary education advisors (PEAs); community-mobilization efforts focused on developing improved out-of-school literacy environments; and engagement of MOEST leadership to shape the educational policy environment in a way that would favor improved literacy instruction.

\footnotetext{
1 In the interest of space and in accordance with the activity's branding requirements, the authors of this chapter have used the abbreviation EGRA to indicate the USAID activity named in this chapter. We recognize that the same abbreviation is in widespread use for Early Grade Reading Assessment, which is an oral assessment of foundational literacy skills in developing countries. To avoid confusion, we have spelled out the name of the assessment when it occurs in the chapter.
} 


\section{Early Reading Outcomes in Malawi}

Early Grade Reading Assessments conducted during the EGRA's predecessor contract, the USAID Malawi Teacher Professional Development Support program, painted a dismal picture of reading and education in Malawi. In November 2010, a nationally representative sample of 996 students in grades 2 and 4 found that 72.8 percent of grade 2 children and 41.9 percent of grade 4 children could not read a single word on an oral reading fluency subtask; the proportions of zero scores on the associated reading comprehension subtask were 97.1 percent in grade 2 and 69.3 percent in grade 4 (RTI International, 2010). As of 2011, the official pupil-teacher ratio in Malawi was 76:1 (United Nations Educational, Scientific and Cultural Organization [UNESCO], 2014), although there is reason to believe the actual figure was substantially higher. ${ }^{2}$

Recent pre-service teacher-training curricula in Malawi have paid scant attention to reading pedagogy. In a 2015 study commissioned by the German aid agency Deutsche Gesellschaft für Internationale Zusammenarbeit, Jackson, Jere, Togher, and Webb noted, "there is no clear and progressive programme for teaching of reading," and further indicated that, from a cross-cutting perspective, there is "no evidence of progression in pedagogical practice" and "inadequate teaching methodology" to support the practicum experience teacher trainees are expected to undertake in the second and final year of the program (2015, pp. 10-11).

Many graduates of Malawi's pre-service Initial Primary Teacher Education program have thus been deployed to schools despite being ill-equipped to teach the subjects that are explicitly covered by the curriculum, let alone the complex process of learning to read, which is not covered by the curriculum. The EGRA implementation team recognized that, without some ongoing external support for more effective lesson delivery, merely introducing termly teacher training on reading instruction would be unlikely to cause teachers to alter their own pedagogical practices enough to drastically change reading outcomes.

\footnotetext{
2 Malawi's national media outlets decried the "ghost teacher" phenomenon (see, for example, Chauwa, 2015), which artificially inflated the number of teachers serving as the denominator in the pupil-teacher ratio. Anecdotally, one of the authors observed lessons in dozens of classrooms between July 2013 and July 2016 and never saw fewer than 90 children being taught by a single teacher - this despite pupil absenteeism averaging over 30 percent (relative to official enrollment) over the entire period of the EGRA's implementation.
} 


\section{Addressing Professional Development Through Coaching}

Altering teachers' standing pedagogical practice by providing routine, qualified support through an instructional coach has been shown elsewhere to be by far the more efficacious, though arduous, route for effecting such change (Fisher, Frey, \& Nelson, 2012; Kraft, Blazar, \& Hogan, 2017). The EGRA program team elected to provide that support by underwriting the cost of PEAs' visits to schools to observe teachers' lesson delivery and provide feedback. Indeed, analyses of EGRA coaching data found that, among teachers who received multiple coaching visits, the teachers' performance improved with each subsequent visit from a coach (Pouezevara, Pflepsen, Nordstrum, King, \& Gove, 2016). The metric for "performance" in this case consisted of how often a teacher exhibited behaviors and practices that were known to support reading acquisition, such as actively engaging individual students in oral reading practice activities and using varied modeling techniques for phonics instruction.

Unfortunately, separate analyses of the EGRA's monitoring and evaluation data indicated that coaching frequency (visits to schools by PEAs) was substantially below both the EGRA program's and MOEST's expectations (Slade, 2016; MOEST, 2015). Furthermore, visitation patterns suggested that PEAs' decisions regarding which schools and teachers to support were driven less by strategic concerns-such as the quality of teaching or student reading performance in a given school, the duration since the last visit to the school, or the arrival of newly transferred teachers-and more by pragmatic onessuch as proximity to the Teacher Development Center (the PEAs' office), ease of access from a paved road, etc. (See Table 5-1 and Figure 5-1, reproduced from Slade, 2016.)

Similar issues have been documented elsewhere. Piper \& Mugenda (2012) found that instructional coaching levels in Kenya were low (albeit higher than in Malawi), with more than 50 percent of teachers indicating they had been observed only once per term. Piper \& Zuilkowski (2015) identified a negative relationship between the number of teachers in a zone and the number of coaching visits received per teacher. RTI's qualitative analysis of outcomes in Liberia under the EGRA Plus: Liberia program (Piper \& Korda, 2011) found strong relationships between learning outcomes and the distance traveled by the coach to reach the school. ${ }^{3}$

\footnotetext{
3 Piper and Korda (2011) noted that it was less likely that a marginal coaching visit was what drove the stark differences in learning outcomes, and more likely that the distance traveled was related to other latent factors that may have influenced school-level outcomes.
} 
Table 5-1. Unique intervention schools receiving coaching in years 1 and 2 of the EGRA

\begin{tabular}{lll}
\hline Intervention school year & $\mathbf{2 0 1 3 - 2 0 1 4}$ & $\mathbf{2 0 1 4 - 2 0 1 5}$ \\
\hline No. of schools in intervention & 1,188 & 1,605 \\
\hline No. of unique schools coached $(\%)$ & $330(27.8 \%)$ & $1,025(63.9 \%)$ \\
\hline No. of schools not coached $(\%)$ & $858(72.2 \%)$ & $580(36.1 \%)$ \\
\hline
\end{tabular}

EGRA = Early Grade Reading Activity; no. = number.

Source: Slade (2016). Used by permission.

Figure 5-1. Distribution of coaching visits by EGRA PEAs, 2013-2015

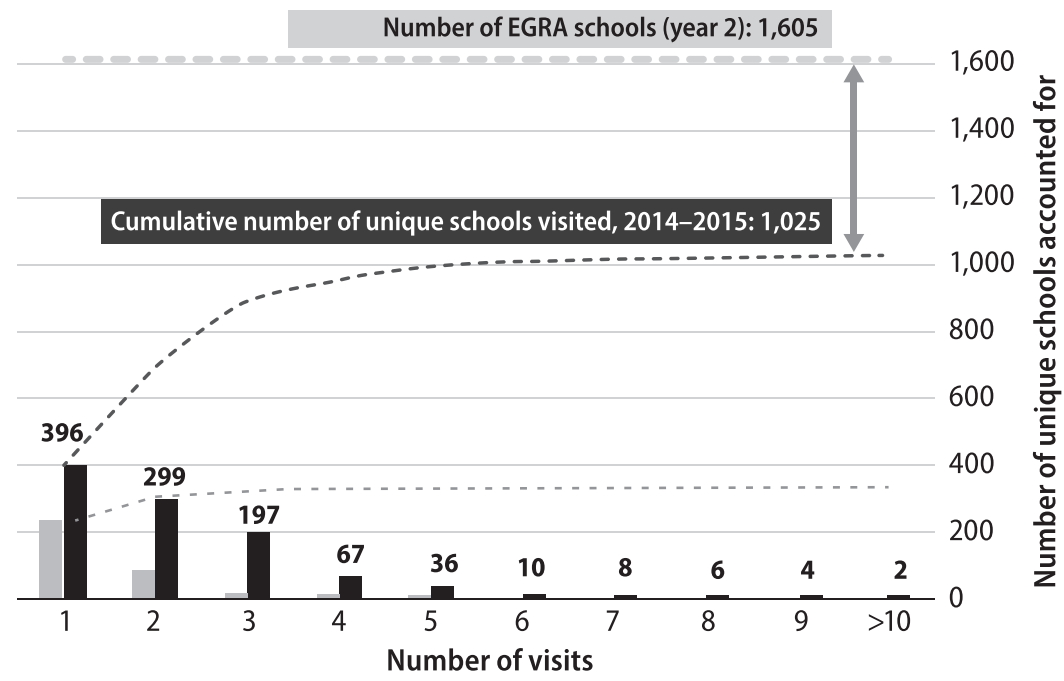

EGRA schools in 2014-2015: 1,605

Total unique schools: 1,025

Schools never visited: 580

EGRA = Early Grade Reading Activity; no. = number; PEA = primary education advisor. Source: Slade (2016). Used by permission.

Incentive structures that RTI has developed under the reading interventions it has implemented on USAID's behalf in Liberia, Malawi, and Kenya to encourage regular coaching visitation have had to balance simplicity (the coaches must be able to easily understand and respond to the incentives), power (the incentives must be strong enough to overcome coaches' tendencies to focus on other administrative or income-generating tasks), and 
affordability (projects must be able to afford the investment throughout implementation, and preferably not create unrealistic expectations once a project has closed). It is not an easy task to create an incentive structure that appropriately and successfully balances those competing priorities, let alone one that facilitates and encourages strategic decision-making as well.

Given the relatively high financial and opportunity costs of providing in-person coaching, instructional coaching in any educational intervention would ideally be strategically distributed, for example, by increasing coaching intensity to teachers who are underperforming while reducing coaching to teachers who are already performing well. An example of such an approach might be to prioritize an initial coaching visit each month (or term) to all schools within a PEA's zone, and then to prioritize the weaker-performing teachers and schools for additional visits within that month (or term). For the EGRA, the PEAs from three districts were trained in the last year of the activity on precisely the approach of targeting weaker schools and teachers in planning their coaching visits.

\section{Introducing SMS as a Component of Professional Development}

Understanding that severely uneven coaching across schools was the norm, and in search of cost-efficient means for providing more regular outreach and support between coaching visits, the EGRA team designed and conducted an SMS coaching intervention with a diverse set of primary teachers, as a means to sustain and extend pedagogical and motivational support for educators following face-to-face training.

At the same time, the EGRA team was looking to assess the professional development support it was providing to teachers by way of zone-level trainings. A questionnaire designed to gauge teachers' familiarity with and attitudes toward the pedagogical practices and beliefs promoted by the MOEST and EGRA activities was administered before and after professional development workshops and again after the SMS campaign. This method, described later in this chapter, was intended to allow the EGRA team to test the following hypothesis: An SMS campaign for teachers could help extend and sustain the support provided by in-person trainings and coaching visits.

Unfortunately, due to several critical flaws in the study's design, instrumentation, and implementation, the hypothesis could be neither confirmed nor refuted. Therefore, rather than focusing primarily on reporting the study's findings with respect to the intended research question, 
this chapter presents a critical review of the study process, including costs. The intent of this process review is to enable other implementers of similar programs to learn from its shortcomings and more effectively embed research on an SMS intervention into an existing program design.

\section{Design of the SMS Intervention}

The SMS campaign was an addition to the EGRA's standard three-level teacher-training cascade, which was delivered on a termly (thrice-yearly) basis. At the initial stage of the cascade, project staff (including the literacy specialist; teaching and learning materials coordinator; disability, gender, and vulnerable populations specialist; and national training coordinator) led a group of master trainers drawn primarily from local teachertraining colleges, universities, and the MOEST headquarters. At the intermediate stage, the master trainers would deploy to several locations around the country to train the PEAs and highly skilled "key teachers" assigned to assist the PEAs in delivering the final level of the training cascade.

At the final level, the PEAs would pair up with key teachers and deliver trainings to the teachers from their zone. Training content and duration were linked to the broader curriculum rollout strategy: longer, more intensive three- to five-day initial training sessions during the first term and year of a given subject's materials being present in a given grade and shorter, one- to three-day refresher trainings in subsequent terms and years. Moreover, the training content was informed by the findings of a weeklong period of intensive classroom observation conducted jointly by EGRA program staff and MOEST headquarters personnel.

Delivery and assessment of the SMS campaign were designed around the cascade. To evaluate its effectiveness using a comparison group, it was introduced only to a portion of the teachers. Program staff developed an assessment and administered it to all master trainers, all PEAs and key teachers, and a sample of teachers at the outset and conclusion of their respective training sessions, as described in the Methodology section.

The SMS content was developed by the authors of this chapter in collaboration with the program's monitoring and evaluation specialist, who assisted with the messages' translation into Chichewa. The 49 messages were grouped into eight themes, as indicated in Table 5-2.

The bulk of the messages- 34 of the 49 , or roughly 69 percent-were grouped within three themes: encouraging specific practices, reminders about student behavior, and encouragement and motivation. The messages 
Table 5-2. Message themes, counts, and examples

\begin{tabular}{|c|c|c|c|}
\hline No. & Theme & $\begin{array}{l}\text { No. of } \\
\text { messages }\end{array}$ & Examples of messages \\
\hline \multirow[t]{2}{*}{1} & $\begin{array}{l}\text { Introduction/ } \\
\text { welcome }\end{array}$ & 2 & $\begin{array}{l}\text { Hello \{Teacher_Name\}! You have been selected to } \\
\text { receive messages from the EGRA team. }\end{array}$ \\
\hline & & & $\begin{array}{l}\text { We appreciate your dedication to your learners, your } \\
\text { school and your community. }\end{array}$ \\
\hline \multirow[t]{3}{*}{2} & $\begin{array}{l}\text { Feedback for } \\
\text { students }\end{array}$ & 4 & $\begin{array}{l}\text { Be positive and remind learners to do their best. } \\
\text { Even if the learner spells part of the word correctly, } \\
\text { that is better than no correct part at all. }\end{array}$ \\
\hline & & & $\begin{array}{l}\text { Find a learner you have not heard read aloud in a } \\
\text { long time today and check on them. If they need } \\
\text { help, practice with I do / You do.* }\end{array}$ \\
\hline & & & $\begin{array}{l}\text { Have some of your learners made great } \\
\text { improvements this year? If so, be sure to tell them } \\
\text { today. }\end{array}$ \\
\hline \multirow[t]{3}{*}{3} & $\begin{array}{l}\text { Encouraging } \\
\text { specific practices }\end{array}$ & 10 & $\begin{array}{l}\text { Remember, you can explain vocabulary using a } \\
\text { picture, gestures, a song, or simple familiar words. }\end{array}$ \\
\hline & & & $\begin{array}{l}\text { The WORD EXPLORATION PROCESS has } 3 \text { steps: read } \\
\text { the word, use the word in a sentence, find another } \\
\text { word that means the same or the opposite. }\end{array}$ \\
\hline & & & $\begin{array}{l}\text { Any time you read words or sentences from the } \\
\text { board, be sure to model how to use finger-pointing } \\
\text { to read the sentence using letters as clues. }\end{array}$ \\
\hline \multirow[t]{4}{*}{4} & $\begin{array}{l}\text { Reminders about } \\
\text { student behavior }\end{array}$ & 10 & $\begin{array}{l}\text { Every learner should be reading from their own } \\
\text { pupil book during reading lessons. }\end{array}$ \\
\hline & & & $\begin{array}{l}\text { Remember: It is ok if your learners do not always } \\
\text { face the front of the class. Some activities will be } \\
\text { easier if they can work together reading in groups. }\end{array}$ \\
\hline & & & $\begin{array}{l}\text { It is ok for your learners to make mistakes. It is part } \\
\text { of learning. Praise them for trying; encourage them } \\
\text { to try on their own and listen to themselves. }\end{array}$ \\
\hline & & & $\begin{array}{l}\text { Even if your learners say no one at home can read, } \\
\text { still encourage them to take home books. They may } \\
\text { still be encouraged and might find someone who } \\
\text { can help. }\end{array}$ \\
\hline \multirow[t]{3}{*}{5} & $\begin{array}{l}\text { Lesson plans/ } \\
\text { curricular } \\
\text { reminders }\end{array}$ & 4 & $\begin{array}{l}\text { Today, please make sure you use I do, We do, You do } \\
\text { on each activity to help learners be successful with } \\
\text { the new skill and build learners' confidence. }\end{array}$ \\
\hline & & & $\begin{array}{l}\text { Good morning! Please try to review your reading } \\
\text { lesson plan carefully for } 15 \text { minutes today before } \\
\text { beginning. Your learners will benefit greatly. }\end{array}$ \\
\hline & & & $\begin{array}{l}\text { Plans and preparation are very important. It will make } \\
\text { your job easier and it will help your learners. Please } \\
\text { check on your notes and plans for today's lesson. }\end{array}$ \\
\hline
\end{tabular}


Table 5-2. Message themes, counts, and examples (Continued)

\begin{tabular}{|c|c|c|c|}
\hline No. & Theme & $\begin{array}{l}\text { No. of } \\
\text { messages }\end{array}$ & Examples of messages \\
\hline \multirow[t]{3}{*}{6} & $\begin{array}{l}\text { Reflection } \\
\text { reminders }\end{array}$ & 4 & $\begin{array}{l}\text { Think about today's reading lesson. Focus on } \\
\text { moments when your learners paid keen attention. } \\
\text { Try to make this moment happen again tomorrow. }\end{array}$ \\
\hline & & & $\begin{array}{l}\text { Was anything difficult for you in today's reading } \\
\text { lesson? If so, ask your head teacher about it-Asking } \\
\text { for help is how } \\
\text { we all learn! }\end{array}$ \\
\hline & & & $\begin{array}{l}\text { After your reading lesson today, look over the lesson } \\
\text { plan for } 15 \text { minutes and ask yourself if you followed } \\
\text { the plan. If you didn't, please try to tomorrow. }\end{array}$ \\
\hline \multirow[t]{3}{*}{7} & $\begin{array}{l}\text { Encouragement } \\
\text { and motivation }\end{array}$ & 14 & $\begin{array}{l}\text { If one of your fellow teachers is a strong example for } \\
\text { their peers in embodying the spirit of EGRA, let } \\
\text { them know today that you are thankful. }\end{array}$ \\
\hline & & & $\begin{array}{l}\text { Remember: Your learners are individuals, and each } \\
\text { one looks up to you for guidance. They may not } \\
\text { thank you today, so let us say THANK YOU! }\end{array}$ \\
\hline & & & $\begin{array}{l}\text { Teacher, you are a hero making the world a better } \\
\text { place, one child at a time. }\end{array}$ \\
\hline 8 & $\begin{array}{l}\text { End of term/ } \\
\text { campaign }\end{array}$ & 1 & $\begin{array}{l}\text { The EGRA team hopes you have enjoyed these } \\
\text { messages and found them useful. } \\
\text { Thank you for your hard work this year! }\end{array}$ \\
\hline
\end{tabular}

EGRA = Early Grade Reading Activity; no. = number.

* I do/We do/You do: The Malawi EGRA used a gradual-release, direct instructional technique that involved teacher modeling ("I do"), full-class practice ("We do"), and then individual student practice ("You do").

within the theme of lesson plans/curricular reminders were not specifically linked to the units and lessons the teachers were delivering on a given date, due largely to the complexity of (1) establishing with high reliability the specific lesson a teacher would be teaching on a given day and (2) efficiently routing the specific message appropriate to that lesson to the correct teachers. Future iterations of this kind of campaign and accompanying research should consider testing whether messages tightly linked to the teacher's lesson for the day would have a different impact.

By design, each teacher was to receive 49 SMS messages (an average of roughly seven messages per week) over a seven-week span following their trainings. The substantial majority of messages were sent on weekdays at 7 a.m.; in eight cases, an additional message (the second for the day) was sent at 10 a.m., and in five cases, a third message was sent at 3 p.m. (on the date 
of the campaign launch, three explanatory messages were sent out at 10 a.m., 12 p.m., and 3 p.m.). In total, the intervention delivered 20,689 messages to 485 teachers (an error in configuring the messaging list led to the first 14 messages, sent on May 25-June 8, reaching only 196 of the 485 SMS treatment teachers). Of these 485 SMS-receiving teachers, the project's monitoring and evaluation staff were able to follow up with 407 to assess the effects of the messaging campaign. To better explain the background and intentions of the SMS campaign, the following section describes only the literature relevant to the use of various technologies for behavior change and professional development.

\section{Literature Review}

Technologies of various types have long been investigated as a means of delivering or enhancing training focused on changing behavior. In some cases, a chosen technology is intent on replacing an in-person training (examples include distance education and massive open online courses); whereas in other cases, a technology is used during or after an in-person event as a supplemental tool. As astutely noted by Gaible and Burns (2005), however, the use of information and communication technology for such efficiencies or enhancements should never be conceived as a de facto improvement for an educational program designed to improve instructional quality; many technologies, whether by poor design or by way of a steep learning curve, can cost teachers and other users precious time and effort for little in return.

As the global imperative to improve instructional quality continues to increase, so do the capabilities and prevalence of powerful technologies. Many low-cost technologies, most notably mobile phones, have become particularly widespread and popular over the past 20 years in developingcountry contexts. For this reason, educational practitioners continue to explore whether such technologies can be effective in situations in which traditional training methods have proven insufficient or infrequent.

What Gaible and Burns (2005) provided in their review of technologies used for teacher professional development was a historical review of such cases, clearly indicating a powerful predictor of success for a given technological channel or tool: familiarity. They found that by virtue of context (that is, low-income developing countries), a tool or communication channel that was widely familiar to teachers (or, more broadly, to the adult 
population of that context) was very likely to have a low cost as well, given the scarcity of disposable income in the population.

The rapid ascent of mobile phones and SMS throughout sub-Saharan Africa provided the backdrop of user familiarity for the Malawi EGRA's messaging campaign, and several prior studies provided further encouragement for the design undertaken. Pouezevara (2015) presented an overview of many of the ways in which mobile devices were being used in low-income contexts for networking and learning, and it was the concept of spaced repetition (Cepeda, Pashler, Vul, Wixted, \& Rohrer, 2006) that was intended to be tested by this study.

At the core of the activity's intentions with the SMS campaign were two complementary goals: remind and reinforce. That is, the content of the SMS campaign itself was neither designed nor intended to replace any portion of in-person training activities but merely served as a timely, regular extension of training efforts and as a means to reinforce concepts and remind recipients to integrate them into their practice. While the authors did not conceive of the SMS messages as a substitute for face-to-face coaching, the messages were seen as a potentially effective supplement to face-to-face coaching that teachers could benefit from between visits from their designated coach.

In the health sector, interventions for medicinal adherence often share similar goals. As da Costa et al. (2012) demonstrated, the use of targeted SMS campaigns as a post-clinical outreach mechanism led to dramatic increases in patients' consistency in adherence to medication schedules and to increases in self-reported quality of care (e.g., reduced feelings of isolation). Fjeldsoe, Marshall, and Miller (2009) found similar results in a review of 14 studies evaluating the ability of SMS messages to positively affect behavior change with respect to medicinal adherence and clinical visitation schedules.

Aker, Ksoll, and Lybbert (2010) as well as Beltramo and Levine (2012) similarly demonstrated (in Niger and Senegal, respectively) that the familiarity of both the mobile phone and SMS messaging specifically could make them an effective modality for improving learning outcomes in adults participating in education programs. Researchers at Stanford University found positive effects on engagement and student learning when parents received text-message guidance for supporting literacy development (York \& Loeb, 2014). The researchers described the 
behavior-change aspect of the program as targeting "behavioral barriers to good parenting by breaking down the complexity of parenting into bite-sized pieces and providing continuous encouragement and support over long periods of time" (p. 31). These behavioral barriers are analogous to those that teachers experience when they are trying to learn new instructional methods.

More recently and more directly relevant for early grade teachers in Malawi, Jukes et al. (2016) identified SMS outreach as a key programmatic input of the Health and Literacy Intervention (HALI) project in Kenya. For the HALI project and similarly under the Primary Math and Reading (PRIMR) initiative in Kenya, the incremental value of SMS was not tested in an isolated control but as one component of a wider intervention (Jukes et al., 2016; RTI International, 2014). In Papua New Guinea and India, the SMS Story program provided daily teaching content to teachers via simple SMS, resulting in positive learning gains on early reading measures (Kaleebu et al., 2013; Pratham Education Foundation \& Voluntary Service Overseas, 2015).

Ramos and Trinoña (2009), in their analysis of Project MIND (Mobile Technology Initiatives for Nonformal Distance Education), did present controlled evidence for the relative effectiveness of including SMS messaging for increasing the learning gains of an educational program—not, however, as specifically concerned with teachers.

The Malawi EGRA efforts to use SMS messages after in-person trainings and between in-person coaching visits with teachers were intent on reinforcing the in-person training and support. The SMS approach thereby served as a tertiary bridging tool; it was meant to strengthen other training inputs and, holding other activities constant, test the added value of a targeted SMS support program to help translate training into teacher behavior change in the classroom.

\section{Methodology}

\section{Measurement Instruments}

The EGRA program team developed and deployed an assessment tool dubbed the Learning Gains instrument, with the goal of measuring the effectiveness of professional development activities. The instrument was divided into three sections (see Table 5-3), each focusing on one of three 
Table 5-3. Features of the Learning Gains instrument

\begin{tabular}{lll}
\hline Section & $\begin{array}{l}\text { Fixed-response } \\
\text { items }\end{array}$ & $\begin{array}{l}\text { Free-response } \\
\text { items }\end{array}$ \\
\hline 1: The lesson cycle & 5 & 3 \\
\hline 2: Classroom management in a context of large classes & 7 & 1 \\
\hline 3: Supplementary readers & 6 & 1 \\
\hline
\end{tabular}

salient aspects of the EGRA intervention and the Malawian educational context: teaching according to the lesson cycle, classroom management in a context of large classes, and utilization of supplementary readers. The lesson cycle section included one item requiring respondents to place the three stages of the EGRA lesson cycle ("I do," "We do," and "You do") in order and four multiple-choice questions. The classroom management and supplementary readers sections included pairs of contrasting statements; respondents were required to indicate the statement with which they most agreed. Each section also included free-response items (not included in this chapter's analysis).

The Learning Gains instruments used during the pre-training $\left(\mathrm{P}_{0}\right)$ and post-training $\left(\mathrm{P}_{1}\right)$ rounds of assessment were identical. The version of the instrument used during the follow-up $\left(\mathrm{P}_{2}\right)$ assessment included three additional yes/no questions to record whether the respondent had received SMS messages directly from the EGRA team; if so, whether they had shared them with peers; and, for those who had not received an SMS message directly, whether their peers had shown them the SMS messages to some extent. During each round of assessment, respondents completed the instrument independently of their peers and were not allowed to share their responses with other respondents.

The Learning Gains measurement instrument was administered both before and after the training workshops at the second level (training of trainers) and third level (zonal training workshops) of the EGRA's teachertraining cascade, described previously.

\section{Sample Selection}

All 350 facilitators (PEAs and key teachers) who were receiving training from the master trainers during the training-of-trainers stage of the EGRA's cascade completed the $\mathrm{P}_{0}$ and $\mathrm{P}_{1}$ assessments. (We incorporated their scores into some of the regression models that we built to analyze the SMS treatment 
Table 5-4. Allocation of sampled respondents to treatment and control groups

\begin{tabular}{lccc}
\hline \multirow{2}{*}{$\begin{array}{l}\text { Performance category per results on } \\
\mathbf{P}_{\mathbf{0}} \text { and } \mathbf{P}_{\mathbf{1}} \text { assessments }\end{array}$} & \multicolumn{3}{c}{ Number of teachers } \\
\cline { 2 - 4 } & Population & Treatment (50\%) & Control (50\%) \\
\hline Perfect score on both $\mathrm{P}_{0}$ and $\mathrm{P}_{1}$ & 122 & 61 & 61 \\
\hline Score improved from $\mathrm{P}_{0}$ to $\mathrm{P}_{1}$ & 518 & 259 & 259 \\
\hline No score improvement from $\mathrm{P}_{0}$ to $\mathrm{P}_{1}$ & 193 & 96 & 97 \\
\hline $\begin{array}{l}\text { Overall score decreased or remained } \\
\text { the same, despite new answers }\end{array}$ & 274 & 137 & 137 \\
\hline Total & $\mathbf{1 , 1 0 7}$ & $\mathbf{5 5 3}$ & $\mathbf{5 5 4}$ \\
\hline
\end{tabular}

$\mathrm{P}_{0}=$ pre-training; $\mathrm{P}_{1}=$ post-training.

effect; see Table 5-10 in the Findings section.) During the zonal training workshop stage of the cascade, 1,534 grades 1-3 teachers were selected to participate in the study via probability proportional to size (PPS) sampling, with the school as the sampling unit. This means that bigger schools had a higher chance of being included in the sample. Schools also were sampled using PPS, based on the number of grades 1-3 teachers in the school. Where the number of teachers required from the school was fewer than the number of grades 1-3 teachers on staff, participating teachers were selected at random. These teachers completed both $\mathrm{P}_{0}$ and $\mathrm{P}_{1}$ assessments at the training workshop.

Of the 1,534 teachers initially assessed at $\mathrm{P}_{0}$, the project monitoring and evaluation team was able to match $\mathrm{P}_{1}$ assessment records for 1,454 teachers. The EGRA's master database of teacher information contained telephone numbers for 1,107 of the 1,454 matched respondents; these 1,107 respondents were grouped based on their performance on the $\mathrm{P}_{0}$ and $\mathrm{P}_{1}$ assessments, and the groups were evenly allocated to SMS treatment or control. Table 5-4 illustrates the allocation of respondents.

Approximately 10 weeks $^{4}$ after the conclusion of the teacher training, EGRA personnel followed up with the teachers sampled at the zonal training workshop stage to administer the $\mathrm{P}_{2}$ assessment. These final $\mathrm{P}_{2}$ assessments were collected and matched at the 10 -week follow-up point. This phase of the

\footnotetext{
4 Teachers were trained in waves based on the classes they taught, starting on March 28, 2016; training had fully concluded by April 8. $\mathrm{P}_{2}$ follow-up data began to be collected on June 20, with most having been collected by July 1 but some lagging until July 14 . As a result, most respondents' $\mathrm{P}_{2}$ scores would have been collected 10-11 weeks following the training, but some may have been collected as late as 15 weeks after training had concluded.
} 
Table 5-5. Sample sizes and rates of attrition, by training cascade level

\begin{tabular}{|c|c|c|c|c|}
\hline Cascade level & $\begin{array}{l}\text { Sample: } \\
\text { Targeted or } \\
\text { achieved }\end{array}$ & $\begin{array}{l}\text { Training of } \\
\text { trainers: } \\
\text { No. of PEAs and } \\
\text { key teachers }\end{array}$ & $\begin{array}{l}\text { Zonal training } \\
\text { workshop: } \\
\text { No. of grades } \\
1-3 \text { teachers }\end{array}$ & $\begin{array}{l}\text { Teacher attrition } \\
\text { relative to initial } \\
\text { sample: } \\
\text { Count } \%\end{array}$ \\
\hline \multirow[t]{2}{*}{ Pre-training $\left(\mathrm{P}_{0}\right)$} & Targeted & 350 & 1,534 & \multirow[t]{2}{*}{$0(0 \%)$} \\
\hline & Obtained & 350 & 1,534 & \\
\hline \multirow{2}{*}{$\begin{array}{l}\text { Post-training } \\
\left(\mathrm{P}_{1}\right)\end{array}$} & Targeted & 350 & 1,534 & \multirow[t]{2}{*}{$80(5.22 \%)$} \\
\hline & Matched: $P_{0}-P_{1}$ & 350 & 1,454 & \\
\hline \multirow[t]{2}{*}{ Follow-up $\left(\mathrm{P}_{2}\right)$} & Targeted & $\mathrm{N} / \mathrm{A}$ & 1,107 & \multirow[t]{2}{*}{$280(25.3 \%)$} \\
\hline & Matched: $P_{1}-P_{2}$ & $\mathrm{~N} / \mathrm{A}$ & 827 & \\
\hline \multirow[t]{2}{*}{ Overall } & Targeted & $\mathrm{N} / \mathrm{A}$ & 1,534 & \multirow[t]{2}{*}{707 (46.1\%) } \\
\hline & $\begin{array}{l}\text { Matched: } \\
\mathrm{P}_{0}-\mathrm{P}_{1}-\mathrm{P}_{2}\end{array}$ & $\mathrm{~N} / \mathrm{A}$ & 827 & \\
\hline
\end{tabular}

No. $=$ number $; \mathrm{PEA}=$ primary education advisor.

study obtained results for 827 of the 1,107 teachers; the final-stage attrition rate of 25.3 percent was not statistically significantly different between treatment and control groups. Table 5-5 provides details of the sample size and attrition across the various levels of assessment.

As Table 5-5 indicates, attrition was significant, both between successive assessments and across the entire series. As a low-level measure to protect the respondents' anonymity, the respondents were requested to use a unique identifier (their participant number on the training session's pre-printed attendee registration sheet) at the top of each survey, rather than their names. Some respondents provided inaccurate information (such as entering the wrong participant number, established by determining that it matched a participant of a different sex whose records were successfully matched), while others omitted the item or wrote it illegibly. An inability to match some respondents' $\mathrm{P}_{1}$ scores to their $\mathrm{P}_{0}$ scores reduced the sample size from 1,534 to 1,454 (a loss of 80 respondents, or 5.22 percent of the initial sample).

Because the $\mathrm{P}_{2}$ assessment period did not coincide with a training workshop, it was not possible to use attendance register numbers as unique identifiers. Therefore, the team generated a second unique identifier that concatenated each participant's sex, grade level of instruction, district, zone, and school identity code; the resultant string of characters was both unique and persistent across time periods, as none of its component 
parameters changed from $\mathrm{P}_{0}$ through $\mathrm{P}_{1}$ and $\mathrm{P}_{2}$. This new identifier was provided to each PEA who administered the $\mathrm{P}_{2}$ follow-up assessment for their teachers to mark on their assessment forms. Of the 1,107 teachers for whom phone numbers were available and who were thus assigned to SMS treatment or control conditions, an inability to match respondents' $\mathrm{P}_{2}$ scores to their $\mathrm{P}_{1}$ and $\mathrm{P}_{0}$ scores further reduced the sample size from 1,107 to 827 (a loss of 280 respondents, or 25.3 percent of the sample). Overall, 707 respondents did not ultimately participate, or 46.1 percent of the initial sample.

\section{Findings}

\section{Effect of SMS on Teacher Knowledge Retention}

The Learning Gains measurement methodology and sampling were intended to evaluate the effectiveness of the additional SMS support on teachers' ability to retain information imparted during the training workshop about the activity's expected classroom teaching methods. If teachers in the treatment group scored significantly better on the $\mathrm{P}_{2}$ assessment than teachers in the control group, we could reasonably attribute that improvement to the effect of the messaging. However, teachers recorded high scores on the Learning Gains instrument at all three assessment points, with very little variation overall and no differences at the $p<.05$ level between treatment groups. (As will be discussed in the Limitations section, this lack of variability in outcomes posed an obstacle in detecting intervention effects.) While scores were high overall, there was some variation within and across sections. Table 5-6 shows the percentage of the respondents providing correct or positive answers to each of the assessment items.

The items under Section 1: The lesson cycle tended to target more factual responses, whereas items under Section 2: Classroom management and Section 3: Supplementary readers tended to target more attitudinal responses. When considering chi-square significance, only one of the five items in Section 1 yielded scores that were greater at $\mathrm{P}_{2}$ than at $\mathrm{P}_{1}$, with one additional item yielding scores that were improved at $P_{1}$ and $P_{2}$ relative to $P_{0}$. In contrast, scores improved from $P_{0}$ to $P_{1}$ for five of the seven items in Section 2; all scores on all items improved from $\mathrm{P}_{0}$ to $\mathrm{P}_{2}$; and scores on five out of seven items improved from $P_{1}$ to $P_{2}$. For Section 3, scores improved from $P_{0}$ to $P_{1}$ for two out of six items; scores on all items improved from $\mathrm{P}_{0}$ to $\mathrm{P}_{2}$; and scores on five out of six items improved from $P_{1}$ to $P_{2}$. 
Table 5-6. Respondent scores for each assessment item across three assessments, for teachers who recorded Learning Gains scores at each assessment round $(n=827)$

\begin{tabular}{|c|c|c|c|c|}
\hline \multicolumn{2}{|c|}{ Item } & $\begin{array}{l}\begin{array}{l}\text { Percent } \\
\text { correct at } P_{0}\end{array} \\
\end{array}$ & $\begin{array}{l}\text { Percent } \\
\text { correct at } P_{1}\end{array}$ & $\begin{array}{l}\text { Percent } \\
\text { correct at } P_{2}\end{array}$ \\
\hline \multicolumn{5}{|c|}{ Section 1: The lesson cycle } \\
\hline 1 & $\begin{array}{l}\text { Order of the three stages of the lesson } \\
\text { cycle }\end{array}$ & $89 \%$ & $94 \% *$ & $94 \% *$ \\
\hline 2 & Purpose of the "I do" stage & $80 \%$ & $81 \%$ & $82 \%$ \\
\hline 3 & Purpose of the "We do" stage & $96 \%$ & $96 \%$ & $98 \%$ \\
\hline 4 & Purpose of the "You do" stage & $86 \%$ & $89 \%$ & $92 \% *+$ \\
\hline \multirow[t]{2}{*}{5} & During "You do," teacher should ... & $94 \%$ & $95 \%$ & $95 \%$ \\
\hline & The lesson cycle subtotal & 4.46 & $4.55^{*}$ & $4.61 *+$ \\
\hline \multicolumn{5}{|c|}{ Section 2: Classroom management } \\
\hline 1 & More than half the class is able to read & $70 \%$ & $76 \% *$ & $79 \% *$ \\
\hline 2 & $\begin{array}{l}\text { Learners in the infant classes can be } \\
\text { trained }\end{array}$ & $95 \%$ & $97 \%$ & $99 \% *+$ \\
\hline 3 & $\begin{array}{l}\text { Different activities require different kinds } \\
\text { of learner seating }\end{array}$ & $71 \%$ & $76 \% *$ & $81 \% *+$ \\
\hline 4 & $\begin{array}{l}\text { Lesson preparation is essential for } \\
\text { classroom management }\end{array}$ & $93 \%$ & $95 \%$ & $97 \% *+$ \\
\hline 5 & $\begin{array}{l}\text { Young learners learn better when they } \\
\text { have books in their hands }\end{array}$ & $65 \%$ & $71 \% *$ & $78 \% *+$ \\
\hline 6 & $\begin{array}{l}\text { Allowing children to make mistakes is } \\
\text { helpful }\end{array}$ & $90 \%$ & $93 \% *$ & $97 \% *+$ \\
\hline \multirow[t]{2}{*}{7} & I will definitely implement & $95 \%$ & $98 \% *$ & $98 \% *$ \\
\hline & Classroom management subtotal & 5.81 & $6.07^{*}$ & $6.29 *+$ \\
\hline \multicolumn{5}{|c|}{ Section 3: Supplementary readers } \\
\hline 1 & $\begin{array}{l}\text { Supplementary readers are for all the } \\
\text { learners }\end{array}$ & $93 \%$ & $95 \%$ & $97 \% *$ \\
\hline 2 & Parents who are illiterate can help & $76 \%$ & $83 \% *$ & $88 \% *+$ \\
\hline 3 & My learners need to have a chance to read & $89 \%$ & $93 \% *$ & $96 \% *+$ \\
\hline 4 & $\begin{array}{l}\text { Parents are very keen for their children to } \\
\text { borrow books }\end{array}$ & $85 \%$ & $86 \%$ & $91 \% *+$ \\
\hline 5 & $\begin{array}{l}\text { Use the supplementary readers for group } \\
\text { and individual reading }\end{array}$ & $79 \%$ & $81 \%$ & $86 \% *+$ \\
\hline \multirow[t]{3}{*}{6} & $\begin{array}{l}\text { Will definitely allow learners to borrow } \\
\text { books }\end{array}$ & $95 \%$ & $96 \%$ & $99 \% *+$ \\
\hline & Supplementary readers subtotal & 5.17 & $5.35^{*}$ & $5.56 *+$ \\
\hline & Overall total & 15.43 & $15.96^{*}$ & $16.46 *+$ \\
\hline
\end{tabular}

$\mathrm{P}_{0}=$ pre-training; $\mathrm{P}_{1}=$ post-training; $\mathrm{P}_{2}=$ follow-up.

${ }^{*}=p<.05$ when comparing $\left(\mathrm{P}_{0}\right.$ and $\left.\mathrm{P}_{1}\right)$ or $\left(\mathrm{P}_{0}\right.$ and $\left.\mathrm{P}_{2}\right) ;{ }^{\dagger}=p<.05$ when comparing $\mathrm{P}_{1}$ and $\mathrm{P}_{2}$. 
Table 5-7. Scores of respondents matched across three assessments, by treatment stage

\begin{tabular}{|c|c|c|c|c|c|c|c|c|}
\hline \multirow[b]{2}{*}{$\begin{array}{l}\text { Treatment } \\
\text { stage }\end{array}$} & \multicolumn{4}{|c|}{ Treatment } & \multicolumn{4}{|c|}{ Control } \\
\hline & $n$ & $\begin{array}{l}\text { Mean } \\
\text { score }\end{array}$ & SD & SE & $n$ & $\begin{array}{l}\text { Mean } \\
\text { score }\end{array}$ & SD & SE \\
\hline$P_{0}$ & 414 & 15.38 & 2.41 & 0.12 & 413 & 15.49 & 2.16 & 0.11 \\
\hline$P_{1}$ & 414 & 15.84 & 2.18 & 0.11 & 413 & 16.08 & 1.92 & 0.09 \\
\hline$P_{2}$ & 414 & 16.44 & 1.69 & 0.08 & 413 & 16.48 & 1.69 & 0.08 \\
\hline
\end{tabular}

$P_{0}=$ pre-training; $P_{1}=$ post-training; $P_{2}=$ follow-up; $S D=$ standard deviation; $S E=$ standard error.

Tables 5-7 and 5-8 detail respondent scores for $\mathrm{P}_{0}, \mathrm{P}_{1}$, and $\mathrm{P}_{2}$ by treatment status (teachers who received EGRA SMS messages versus those who did not). There were no statistically significant differences in scores between treatment and control teachers at any of the points of assessment, either before the intervention or after.

\section{SMS Sharing Among Teachers}

Over the course of the SMS intervention, the project team (including the chapter authors) became aware that some teachers who had been selected into the treatment group were sharing SMS messages with their peers. As the campaign designers, we had not anticipated this behavior and as such we neither encouraged nor discouraged it; as a result, the $\mathrm{P}_{2}$ instrument was modified from the $\mathrm{P}_{1}$ and $\mathrm{P}_{0}$ instrument by the addition of three simple questions that aimed to quantify the phenomenon. Table 5-9 summarizes these yes/no and other responses that were provided by the teachers whose scores could be matched across all three assessments.

Interpretation of these data requires caution because the data appear somewhat inconsistent with respect to skip logic. For instance, the number of total respondents ("Yes" respondents plus "No" respondents) who answered item \#9 ("If yes, did you share them with your peers?") does not tally with the number of respondents who had acknowledged receiving EGRA SMS messages; the number of respondents who replied to item \#10 ("If no in 8 above, did a peer who received these messages share them with you?") likewise does not tally with the number of respondents who indicated they had not received EGRA SMS messages. These results pose a limitation in understanding the extent of SMS-sharing behaviors among teachers receiving the messages. While the numbers suggest that the overwhelming majority of teachers who received SMS messages (322 out of 329, or 97.9 percent) shared 
Table 5-8. Respondent scores for each assessment item across three assessments, by treatment status

\begin{tabular}{|c|c|c|c|c|c|c|c|}
\hline \multirow{2}{*}{\multicolumn{2}{|c|}{ Item }} & \multicolumn{3}{|c|}{$\begin{array}{l}\text { Treatment } \\
\text { (received SMS directly) } \\
(n=413)\end{array}$} & \multicolumn{3}{|c|}{$\begin{array}{l}\text { Control (did not receive } \\
\text { SMS directly but received } \\
\text { the same training) } \\
(n=414)\end{array}$} \\
\hline & & $\begin{array}{l}\% \\
\text { correct } \\
\text { at } \mathrm{P}_{0}\end{array}$ & $\begin{array}{l}\% \\
\text { correct } \\
\text { at } P_{1}\end{array}$ & $\begin{array}{l}\% \\
\text { correct } \\
\text { at } P_{2}\end{array}$ & $\begin{array}{l}\% \\
\text { correct } \\
\text { at } P_{0}\end{array}$ & $\begin{array}{l}\% \\
\text { correct } \\
\text { at } P_{1}\end{array}$ & $\begin{array}{l}\% \\
\text { correct } \\
\text { at } \mathbf{P}_{2}\end{array}$ \\
\hline \multicolumn{8}{|c|}{ Section 1: The lesson cycle } \\
\hline 1 & $\begin{array}{l}\text { Order of the three stages } \\
\text { of the lesson cycle }\end{array}$ & $91 \%$ & $96 \%$ & $94 \%$ & $88 \%$ & $92 \%$ & $95 \%$ \\
\hline 2 & Purpose of the "I do" stage & $79 \%$ & $81 \%$ & $83 \%$ & $80 \%$ & $81 \%$ & $81 \%$ \\
\hline 3 & $\begin{array}{l}\text { Purpose of the "We do" } \\
\text { stage }\end{array}$ & $97 \%$ & $97 \%$ & $99 \%$ & $96 \%$ & $96 \%$ & $97 \%$ \\
\hline 4 & $\begin{array}{l}\text { Purpose of the "You do" } \\
\text { stage }\end{array}$ & $85 \%$ & $88 \%$ & $92 \%$ & $88 \%$ & $89 \%$ & $92 \%$ \\
\hline \multirow[t]{2}{*}{5} & $\begin{array}{l}\text { During "You do," teacher } \\
\text { should ... }\end{array}$ & $94 \%$ & $95 \%$ & $96 \%$ & $94 \%$ & $94 \%$ & $95 \%$ \\
\hline & The lesson cycle subtotal & 4.46 & 4.57 & 4.63 & 4.45 & 4.52 & 4.59 \\
\hline \multicolumn{8}{|c|}{ Section 2: Classroom management } \\
\hline 1 & $\begin{array}{l}\text { More than half the class is } \\
\text { able to read }\end{array}$ & $70 \%$ & $77 \%$ & $80 \%$ & $71 \%$ & $76 \%$ & $78 \%$ \\
\hline 2 & $\begin{array}{l}\text { Learners in the infant } \\
\text { classes can be trained }\end{array}$ & $97 \%$ & $97 \%$ & $99 \%$ & $94 \%$ & $97 \%$ & $99 \%$ \\
\hline 3 & $\begin{array}{l}\text { Different activities require } \\
\text { different kinds of learner } \\
\text { seating }\end{array}$ & $74 \%$ & $79 \%$ & $83 \%$ & $68 \%$ & $74 \%$ & $79 \%$ \\
\hline 4 & $\begin{array}{l}\text { Lesson preparation is } \\
\text { essential for classroom } \\
\text { management }\end{array}$ & $92 \%$ & $94 \%$ & $97 \%$ & $94 \%$ & $95 \%$ & $97 \%$ \\
\hline 5 & $\begin{array}{l}\text { Young learners learn } \\
\text { better when they have } \\
\text { books in their hands }\end{array}$ & $63 \%$ & $71 \%$ & $73 \%$ & $67 \%$ & $72 \%$ & $82 \%$ \\
\hline 6 & $\begin{array}{l}\text { Allowing children to make } \\
\text { mistakes is helpful }\end{array}$ & $91 \%$ & $93 \%$ & $98 \%$ & $90 \%$ & $93 \%$ & $96 \%$ \\
\hline \multirow[t]{2}{*}{7} & I will definitely implement & $97 \%$ & $99 \%$ & $99 \%$ & $94 \%$ & $97 \%$ & $98 \%$ \\
\hline & $\begin{array}{l}\text { Classroom management } \\
\text { subtotal }\end{array}$ & 5.84 & 6.09 & 6.28 & 5.78 & 6.04 & 6.3 \\
\hline \multicolumn{8}{|c|}{ Section 3: Supplementary readers } \\
\hline 1 & $\begin{array}{l}\text { Supplementary readers are } \\
\text { for all the learners }\end{array}$ & $94 \%$ & $96 \%$ & $97 \%$ & $92 \%$ & $94 \%$ & $96 \%$ \\
\hline 2 & $\begin{array}{l}\text { Parents who are illiterate } \\
\text { can help }\end{array}$ & $76 \%$ & $85 \%$ & $88 \%$ & $75 \%$ & $81 \%$ & $87 \%$ \\
\hline
\end{tabular}


Table 5-8. Respondent scores for each assessment item across three assessments, by treatment status (Continued)

\begin{tabular}{|c|c|c|c|c|c|c|c|}
\hline \multirow[b]{2}{*}{ Item } & & \multicolumn{3}{|c|}{$\begin{array}{c}\text { Treatment } \\
\text { (received SMS directly) } \\
(n=413)\end{array}$} & \multicolumn{3}{|c|}{$\begin{array}{l}\text { Control (did not receive } \\
\text { SMS directly but received } \\
\text { the same training) } \\
\text { ( } n=414)\end{array}$} \\
\hline & & $\begin{array}{l}\% \\
\text { correct } \\
\text { at } \mathrm{P}_{0}\end{array}$ & $\begin{array}{l}\% \\
\text { correct } \\
\text { at } \mathrm{P}_{1}\end{array}$ & $\begin{array}{l}\% \\
\text { correct } \\
\text { at } P_{2}\end{array}$ & $\begin{array}{l}\% \\
\text { correct } \\
\text { at } P_{0}\end{array}$ & $\begin{array}{l}\% \\
\text { correct } \\
\text { at } \mathbf{P}_{1} \\
\end{array}$ & $\begin{array}{l}\% \\
\text { correct } \\
\text { at } \mathbf{P}_{2}\end{array}$ \\
\hline 3 & $\begin{array}{l}\text { My learners need to have a } \\
\text { chance to read }\end{array}$ & $90 \%$ & $95 \%$ & $96 \%$ & $88 \%$ & $91 \%$ & $95 \%$ \\
\hline 4 & $\begin{array}{l}\text { Parents are very keen for } \\
\text { their children to borrow } \\
\text { books }\end{array}$ & $84 \%$ & $86 \%$ & $91 \%$ & $85 \%$ & $86 \%$ & $92 \%$ \\
\hline 5 & $\begin{array}{l}\text { Use the supplementary } \\
\text { readers for group and } \\
\text { individual reading }\end{array}$ & $79 \%$ & $82 \%$ & $85 \%$ & $79 \%$ & $81 \%$ & $87 \%$ \\
\hline \multirow[t]{2}{*}{6} & $\begin{array}{l}\text { Will definitely allow } \\
\text { learners to borrow books }\end{array}$ & $95 \%$ & $98 \%$ & $99 \%$ & $95 \%$ & $95 \%$ & $98 \%$ \\
\hline & $\begin{array}{l}\text { Supplementary readers } \\
\text { subtotal }\end{array}$ & 5.19 & 5.41 & 5.56 & 5.15 & 5.28 & 5.56 \\
\hline
\end{tabular}

$P_{0}=$ pre-training; $P_{1}=$ post-training; $P_{2}=$ follow-up; $S M S=$ short message service.

Table 5-9. Self-reported SMS receipt and sharing practices

\begin{tabular}{lcccc}
\hline Item & Frequency & Percent & $\begin{array}{l}\text { Cumulative } \\
\text { frequency }\end{array}$ & $\begin{array}{l}\text { Cumulative } \\
\text { percent }\end{array}$ \\
\hline $\begin{array}{l}\text { 8. Over the past several weeks, EGRA sent frequent SMS } \\
\text { of teachersages to a random sample }\end{array}$ \\
\hline No response: Missing & 28 & $3.4 \%$ & 28 & $3.4 \%$ \\
\hline No & 470 & $56.8 \%$ & 498 & $60.2 \%$ \\
\hline Yes & 329 & $39.8 \%$ & 827 & $100.0 \%$ \\
\hline 9. If yes, did you share them with your peers? & & & \\
\hline No response: Missing & 100 & $12.1 \%$ & 100 & $12.1 \%$ \\
\hline No & 216 & $26.1 \%$ & 316 & $38.2 \%$ \\
\hline Yes & 322 & $38.9 \%$ & 638 & $77.2 \%$ \\
\hline No response: Skipped & 189 & $22.9 \%$ & 827 & $100.0 \%$ \\
\hline 10. If no in 8 above, did a peer who received these messages share them with you? \\
\hline No response: Missing & 53 & $6.4 \%$ & 53 & $6.4 \%$ \\
\hline No & 333 & $40.3 \%$ & 386 & $46.7 \%$ \\
\hline Yes & 249 & $30.1 \%$ & 635 & $76.8 \%$ \\
\hline No response: Skipped & 192 & $23.2 \%$ & 827 & $100.0 \%$ \\
\hline
\end{tabular}

EGRA = Early Grade Reading Activity; SMS = short message service. 
them with peers, and a significant majority of the teachers in the control group may have received them from peers (333 out of 470 , or 70.9 percent), it is not clear that these figures are wholly trustworthy.

We fit several regression models in an attempt to understand whether the SMS intervention had an effect when we controlled for other factors such as sex, educational district, the quality of the trainers delivering the workshop (measured using the Learning Gains instrument), the number of coaching visits received, and the teachers' most recent scores on the EGRA teacher observation instrument, which was used to create a teacher performance index. (Details regarding the construction of the performance index can be found in Pouezevara et al., 2016). Table 5-10 presents the results of several such models.

First, we established a "base" model using the respondents' $\mathrm{P}_{2}$ scores as the dependent variable. The base model included the respondents' $P_{1}$ scores, their sex, their treatment status, and the district in which they were trained and were working. In some variants, the number of coaching visits the respondents had received over the lifetime of the project was included as well; where the coaching visits were included, the respondents' latest score on an index of teacher practices that supported reading acquisition was also included. However, since including the coaching visitation variable significantly reduced the number of respondents, we ran some of the models without it as well as coaching-related factors.

Generally speaking, the regression models suggested that the only factor that was consistently predictive of a teacher's Learning Gains score at $\mathrm{P}_{2}$ was that teacher's score at $\mathrm{P}_{1}$. Model 1 , which incorporated the proportion of trainers (PEAs and key teachers) who had earned perfect scores on their own $\mathrm{P}_{0}$ and $\mathrm{P}_{1}$ assessments, found it to be significant at $p<.05$. A regional (geographic) factor was significant at $p<.05$ in six of nine districts, but only in Model 4 , which included the number of trainers present at the training as an additional factor. While the presence of regional (geographic) variation in scores tallied with EGRA team members' anecdotal observations that the quality and degree of implementation of the EGRA's overall reading intervention varied substantially from district to district, the fact that it is present in only one model of the four suggests it may have been a spurious result.

The alternative "base" model, which incorporated coaching-related factors, is not presented here for the sake of parsimony. With the addition of the coaching factors, the respondents' sex became significant at $p<.05$ for all models; however, nothing else was significant apart from the $\mathrm{P}_{1}$ score. It did, 
Table 5-10. Results of regression models controlling for non-intervention factors

\begin{tabular}{lllll}
\hline Factor & Model 1 & Model 2 & Model 3 & Model 4 \\
\hline Analysis population & 768 & 768 & 768 & 768 \\
\hline $\mathrm{R}^{2}$ & 0.15 & 0.15 & 0.15 & 0.15 \\
\hline Model $p$-value (F-test) & $<.0001$ & $<.0001$ & $<.0001$ & $<.0001$ \\
\hline Intercept & $11.54^{* * *}$ & $11.79^{* * *}$ & $11.41^{* * *}$ & $12.52^{* * *}$ \\
\hline $\mathrm{P}_{1}$ total score & $0.30^{* * *}$ & $0.30^{* * *}$ & $0.30^{* * *}$ & $0.31^{* * *}$ \\
\hline Female teacher & 0.11 & 0.1 & 0.08 & 0.06 \\
\hline Treatment group & 0.07 & 0.03 & 0.1 & 0.16 \\
\hline District & & & & \\
\hline Mzimba North & 1.57 & 1.57 & 1.35 & 0.44 \\
\hline Ntchisi & -0.29 & -0.19 & -0.36 & $-1.23^{*}$ \\
\hline Salima & 0.06 & 0.08 & 0.14 & -0.78 \\
\hline Lilongwe Rural East & -0.1 & -0.21 & -0.11 & $-0.98^{*}$ \\
\hline Lilongwe Rural West & -0.16 & -0.12 & -0.13 & $-0.99^{*}$ \\
\hline Ntcheu & 0.02 & 0.02 & 0.02 & 0.27 \\
\hline Balaka & -0.14 & -0.11 & -0.12 & $-1.12^{*}$ \\
\hline Machinga & -0.04 & -0.08 & -0.02 & $-0.95^{*}$ \\
\hline Zomba Rural & -0.17 & -0.16 & -0.14 & $-0.97^{*}$ \\
\hline Proportion of "perfect-score" facilitators & $0.36^{*}$ & & & \\
\hline $\begin{array}{l}\text { Average facilitator difference from } \\
\text { perfect score }\end{array}$ & & -0.07 & & \\
\hline $\begin{array}{l}\text { Proportion of "perfect" or "improved" } \\
\text { facilitators }\end{array}$ & & & 0.32 & \\
\hline $\begin{array}{l}\text { Number of trainers present at } \\
\text { workshop/training }\end{array}$ & & & & -0.1 \\
\hline $\begin{array}{l}\mathrm{P}_{1}=\text { post-training. } \\
\text { * } p<.05{ }^{* * *}=p<.001 .\end{array}$ & & & & \\
\hline & & & & \\
\hline
\end{tabular}

however, increase the amount of variance explained in $\mathrm{P}_{2}$ scores $\left(\mathrm{R}^{2}\right)$ to 24 percent for all models, as compared with the 15 percent that was explained by the original base model.

In sum, the intervention appears to have had no effect on $\mathrm{P}_{2}$ scores. The only factor consistently correlated with $\mathrm{P}_{2}$ scores was $\mathrm{P}_{1}$ scores.

\section{Costs}

The cost of the SMS intervention was modest. In this section, we detail costs for two reasons: to provide clarity on the specifics of our fieldwork and to 
Table 5-11. EGRA SMS traffic during SMS campaign, with worst-case cost projections and actual costs

\begin{tabular}{llllll}
\hline Month & $\begin{array}{l}\text { Total EGRA } \\
\text { SMS } \\
\text { messages }\end{array}$ & $\begin{array}{l}\text { Messages } \\
\text { sent for SMS } \\
\text { study }\end{array}$ & $\begin{array}{l}\text { SMS messages } \\
\text { payable at } \\
\text { marginal rate }\end{array}$ & $\begin{array}{l}\text { Real cost in } \\
\text { USD/kwacha }\end{array}$ & $\begin{array}{l}\text { Projected cost in } \\
\text { USD/kwacha } \\
\text { absent CSR } \\
\text { pricing* }\end{array}$ \\
\hline May & 1,372 & 1,372 & 0 & $\begin{array}{l}\text { USD 0.00/0 } \\
\text { kwacha }\end{array}$ & $\begin{array}{l}\text { USD 52.68/ } \\
32,298 \text { kwacha }\end{array}$ \\
\hline June & 13,913 & 12,042 & 3,913 & $\begin{array}{l}\text { USD 38.52/ } \\
25,825 \text { kwacha }\end{array}$ & $\begin{array}{l}\text { USD 462.41/ } \\
289,008 \text { kwacha }\end{array}$ \\
\hline July & 8,403 & 7,275 & 0 & $\begin{array}{l}\text { USD 0.00/ } \\
\text { 0 kwacha }\end{array}$ & $\begin{array}{l}\text { USD 279.36/ } \\
174,600 \text { kwacha }\end{array}$ \\
\hline
\end{tabular}

CSR = corporate social responsibility; EGRA = Early Grade Ready Activity; SMS = short message service.

* This estimate is based on a worst-case assumption that none of the teachers would have had Airtel Malawi phone numbers, so the SMS messages would have been charged at out-of-network rates ( $24 \mathrm{kwach} / \mathrm{USD}$ 0.038 ) rather than at in-network rates ( $15 \mathrm{kwach} / \mathrm{USD} 0.024)$. In fact, roughly 50 percent of EGRA teachers used Airtel, and roughly 50 percent used Telekom Networks Malawi (TNM), Malawi's second-largest telecom firm at the time.

voice our support for future related work to track and report the costs associated with the use of SMS messaging or other technologies in education systems because the financial implications of any research-based intervention must be clear if the research activity is to inform a discussion about systemic uptake or policy reform.

Through a corporate social responsibility (CSR) arrangement the EGRA team had negotiated with Airtel Malawi two years prior, the cost of the EGRA's first 10,000 SMS messages in any month was borne entirely by the telecom company; beyond 10,000 SMS messages, the EGRA incurred a unit cost of 6.60 kwacha (approximately USD 0.010). ${ }^{5}$ Table 5-11 shows the volume of SMS traffic and the EGRA's associated costs, as well as projections of what the costs would have been absent its CSR arrangement with Airtel Malawi.

Table 5-12 details the setup and infrastructure maintenance costs.

Table 5-13 compares the actual costs incurred by the EGRA's SMS campaign and a worst-case projection of costs had the CSR arrangement not been in place.

\footnotetext{
5 Malawi's currency, the kwacha, depreciated substantially over the lifespan of the EGRA intervention. Costs under the CSR arrangement remained fixed in kwacha terms throughout the program, but the equivalent costs in US dollars plummeted. For this chapter's purposes, we estimated infrastructure fees in dollar terms using the exchange rate of 489.8 kwacha per USD 1.00 that was in place on November 27,2014, when the CSR arrangement was formalized. We estimated per-SMS costs using the exchange rate of $670.5 \mathrm{kwach}$ per USD 1.00 that was in place on May 25, 2016, when the campaign was launched.
} 
Table 5-12. Breakdown of SMS campaign costs and estimate of per-participant expense (in USD)

\begin{tabular}{llll}
\hline Expense item & Cost & Recurrence & Cost per month \\
\hline Telerivet* annual fee & $\$ 2,304.00$ & Yearly & $\$ 192.00$ \\
\hline Airtel integration & $\$ 120.00$ & Monthly & $\$ 120.00$ \\
\hline Airtel one-time setup & $\$ 408.32$ & One-off & $\$ 34.03$ \\
\hline RTI one-time setup & $\$ 476.00$ & One-off & $\$ 39.67$ \\
\hline Short code** maintenance & $\$ 100.00$ & Yearly & $\$ 8.33$ \\
\hline Infrastructure costs for seven-week campaign: & & $\$ 479.55$ \\
\hline
\end{tabular}

SMS = short message service.

* Telerivet (http://telerivet.com) operates an international SMS web portal that facilitates voice calls for surveys and mass-messaging campaigns. It is roughly akin to its somewhat better-known competitor Frontline SMS.

** Short codes are brief sequences of digits (shorter than typical phone numbers) that mobile networks use for addressing SMS messages.

Table 5-13. Comparison of actual costs and projected costs absent CSR pricing (in USD)

\begin{tabular}{|c|c|c|c|c|}
\hline \multirow[b]{2}{*}{ Campaign costs } & \multicolumn{2}{|c|}{ Actual costs incurred } & \multicolumn{2}{|c|}{$\begin{array}{c}\text { Projected costs absent CSR } \\
\text { pricing }\end{array}$} \\
\hline & Cost & Percent of total & Cost & Percent of total \\
\hline Infrastructure & $\$ 689.55$ & $94.7 \%$ & $\$ 689.55$ & $48.2 \%$ \\
\hline SMS delivery & $\$ 38.52$ & $5.3 \%$ & $\$ 740.55$ & $51.7 \%$ \\
\hline Total & $\$ 728.07$ & $100.0 \%$ & $\$ 1,430.09$ & $100.0 \%$ \\
\hline $\begin{array}{l}\text { Cost per teacher receiving } \\
\text { messages ( } 485 \text { participants) }\end{array}$ & $\$ 1.50$ & & $\$ 2.95$ & \\
\hline
\end{tabular}

$\mathrm{CSR}=$ corporate social responsibility; SMS = short message service.

The cost of the intervention is thus estimated to have been USD 728.07, with USD 689.55 (94.7 percent) of that expense being infrastructure costs and only USD 38.52 (5.3 percent) being delivery costs. For the 485 teachers who received the SMS messages in the seven-week campaign, the cost per teacher was approximately USD 1.50. Absent a CSR arrangement, the cost would have nearly doubled, and the SMS delivery costs would have accounted for 51.7 percent of the cost of the campaign.

These figures represent direct costs only and as such do not attempt to factor in the costs of labor spent in the SMS system setup or SMS content management. That said, the Telerivet contact-management, message-creation, and scheduling interfaces were all fairly simple to master-requiring an investment of a few hours, not days - and once the initial configuration was 
complete, the campaign was an entirely hands-off affair. That is, the project team created recipient lists (based on the assignment of respondents to the "SMS treatment" groups), typed in the messages, and scheduled them for delivery at specific times on later dates. After those tasks had been completed, the campaign required no further input; staff simply performed periodic verifications that the number of system-confirmed recipients matched the number expected upon initial setup.

\section{Limitations}

As indicated previously, this study faced several limitations. First and foremost, the instrument used to assess teacher content mastery was hampered by ceiling effects and thus appears to have been unable to distinguish between higher-performing teachers and lower-performing teachers. For 7 of the 18 items, over 90 percent of the teachers assessed answered the item correctly at the $\mathrm{P}_{0}$ time point; for 5 more of the items, over 84 percent of respondents answered the item correctly at $\mathrm{P}_{0}$. The combination of such a high initial score and a limited number of discrete items (18) resulted in limited scope for improvement. A more sophisticated assessment instrument featuring items tightly tied to the broader EGRA intervention design, in more subtle or less obvious ways-and relying on a harder-to-game evaluation approach (such as a principal components analysis) rather than simple scoring - might have revealed different outcomes by way of being a more genuine and precise measurement.

Equally important, the particular constructs being assessed-PEAs' and teachers' knowledge of certain concepts related to reading instruction, classroom management in a context of extreme class sizes, and the use of supplementary readers to complement curricular materials-are distinct from teacher practice. A teacher may be highly knowledgeable, yet incapable of delivering a high-quality lesson to his or her students. Similarly, a teacher may have performed poorly on the particular items included on this assessment and still have been an effective instructor in the classroom. While some of the regression models incorporated data from classroom observation records, the lack of observation data from the $\mathrm{P}_{2}$ time point impeded a rigorous analysis of the relationships between the assessment scores and teaching practice. Conducting nuanced observations of the teachers' classroom practices would have added significant value to understanding the relationships among the SMS campaign, the assessment instrument, and potential classroom outcomes. 
Because the EGRA SMS campaign and Learning Gains assessment represented an exploratory and observational study, differences in teachers' scores in the $\mathrm{P}_{1}-\mathrm{P}_{2}$ interval could not be conclusively attributed to the SMS intervention. Furthermore, as described previously, a degree of contamination was observed in the SMS intervention. Brief telephone calls were placed to a handful of teachers within the first week of the SMS campaign to confirm that messages were being received and that message timing was appropriate. During those calls, some teachers indicated that they were sharing the messages they received with their peers. While the EGRA program had not explicitly forbidden this behavior, it also had not encouraged it. Still, upon learning of the SMS sharing, the EGRA team did not intervene to attempt to promote or discourage this practice. Rather, the EGRA team sought simply to measure the prevalence of the SMS sharing, and for this reason the $\mathrm{P}_{2}$ version of the assessment instrument was modified to include the three questions intended to understand the extent of these sharing practices.

However, two factors impeded a rigorous analysis of the data on the sharing of SMS messages among teachers. First, the questions did not specifically ask about sharing with peers who were included in the study; as a result, we have limited insight into the extent of contamination. (For instance, the receiving teacher may have shared the SMS messages with peers who were not included in the study's control group; in such a case, there would be no contamination.) The study would have been strengthened by foreseeing the potential for such behavior from the outset and designing the sampling and analysis plan accordingly. For example, had we assigned entire schoolsrather than individual teachers-into treatment or control groups, it is conceivable that we would have minimized contamination effects because teachers would have been less likely to share SMS messages with their closest peers. Second, the instrument was not designed either to ascertain whether recipients had retained any of the messages or themes included in the SMS messages or to probe their thoughts and feelings about receiving the messages.

The study of the SMS campaign would have been strengthened by including a qualitative element (such as focus group discussions) to examine the nature of teachers' interactions with the SMS messages themselves. In a similar vein, the EGRA program made no attempt to test out the effectiveness of different SMS campaign types; for example, could more frequent messages, 
of a different tone and directly relevant for a geographic area, have been more impactful? As noted in the discussion of Table 5-2, messages were not specifically linked to the content of the lessons the teachers were teaching. Anecdotally, on any given day, the teachers participating in the EGRA could have been teaching very different lessons; some might have been far ahead of the expected pace, others far behind. In the absence of a sophisticated and adaptive messaging system, targeting SMS content to a teacher's lesson for the day would have required a substantially greater investment in labor than the EGRA program could afford. Our analysis is therefore unable to provide insight into the possible impact of a similar SMS intervention that would tightly link message content with lesson content for each teacher. ${ }^{6}$

For this chapter, we did make an effort to accurately capture all historical classroom observation data (rather than those from just the visits during the $\mathrm{P}_{1}-\mathrm{P}_{2}$ interval). However, a review of the visit data suggested that the number of coaching visits between the treatment and control groups was unbalanced, with control group teachers receiving, on average, more coaching visits than the treatment group teachers. Table 5-14 presents the number of coaching visits received by the respondents.

Only 249 of the teachers who were assigned to the control group ever received a coaching visit under the EGRA; the substantial majority of teachers sampled for this study were visited only once or twice, as Figures 5-1 and 5-2 underscore. As a result, incorporating the teacher observation instrument data into regression models added only limited additional value and did so at the cost of a substantial reduction in the number of respondents upon which the model could draw.

Another limitation of the SMS campaign related to its timing. When the trainings for teachers at the $\mathrm{P}_{1}$ time point concluded, the participating teachers' mastery and retention of training concepts was presumably at its peak. Due to some logistical constraints and the time needed to draw the sample frame for the study, the SMS campaign did not begin until approximately five weeks after the $\mathrm{P}_{1}$ assessment. Had the campaign begun immediately after the conclusion of zonal trainings, or shortly thereafter, it is

6 Since 2015, RTI has been using a software system called Gooseberry to support multistep, interactive registration of teachers via SMS during trainings for the Tusome Early Grade Reading Activity. Gooseberry is highly configurable and relatively simple to manage. A replication of this study could be strengthened by using Gooseberry to provide teachers with a toll-free telephone number to which they could send their lesson day and week and from which they would subsequently receive a response based on that information. 
Table 5-14. Number of teachers of each treatment status receiving the listed number of coaching visits, over the entire lifespan of the EGRA's implementation

\begin{tabular}{|c|c|c|c|c|c|}
\hline \multirow[b]{2}{*}{ No. of visits } & \multicolumn{2}{|c|}{ Control teachers } & \multicolumn{2}{|c|}{ Treatment teachers } & \multirow{2}{*}{$\begin{array}{l}\text { Cumulative } \\
\text { total }\end{array}$} \\
\hline & $\%$ & $n$ & $\%$ & $n$ & \\
\hline 0 & $39.7 \%$ & 164 & $57.5 \%$ & 238 & 402 \\
\hline 1 & $39.0 \%$ & 161 & $25.1 \%$ & 104 & 667 \\
\hline 2 & $15.3 \%$ & 63 & $13.0 \%$ & 54 & 784 \\
\hline 3 & $4.8 \%$ & 20 & $3.4 \%$ & 14 & 818 \\
\hline 4 & $1.2 \%$ & 5 & $0.7 \%$ & 3 & 826 \\
\hline 5 & - & - & - & - & - \\
\hline 6 & $0 \%$ & 0 & $0.2 \%$ & 1 & 827 \\
\hline Total & 100.0 & 413 & 100.0 & 414 & 827 \\
\hline
\end{tabular}

EGRA = Early Grade Reading Activity; no. = number.

conceivable that the SMS content would have more clearly facilitated knowledge retention.

\section{Conclusions}

As our review of the literature indicates, there is strong reason to believe that an SMS-based intervention could be a powerful mechanism to support behavior change. The causal theory at play-that familiar technology can help reinforce learning and behaviors with short and timely reminders-is well documented in education and elsewhere. Unfortunately, our study design and implementation contained flaws that precluded us from drawing evidencebased conclusions about such a program's effectiveness. We believe, however, that a critical examination of our missteps may prove instructive for others who would seek to add to the research base regarding the use of SMS to support behavior change in development programs. We use this Conclusions section to provide actionable guidance to those who would succeed and improve upon our efforts.

The results of our study suggest that further investigation is warranted, using a better-calibrated instrument allowing for greater discrimination in teacher knowledge across a wider range of scores. While our analyses found no impact from the SMS campaign on their own, given the substantial limitations noted earlier, it would be premature to conclude that a moretailored, better-targeted SMS campaign whose impact is measured with a better assessment tool may not demonstrate a meaningful impact. 


\section{Avenues for Further Exploration of Teachers' SMS-Sharing Behaviors}

One of the most interesting findings - and one that also warrants more investigation, given its potential implications for social behavior-change communication campaigns with teachers-relates to the SMS recipients' sharing behaviors. As mentioned in the Limitations section, teachers who were selected to receive the SMS treatment were neither instructed to share the SMS messages with peers nor explicitly requested to avoid doing so. However, nearly all of the teachers in the treatment group (97.9 percent) appeared to have done so of their own volition. With the caveat that the figures reported by teachers were inconsistent with the expected skip logic, it appeared that up to 70.9 percent of the teachers assigned to the SMS control group may have been "contaminated" by such well-meaning sharing of the messages. This finding led us to believe that teachers found value in the messages, even if the effect of messaging on teacher content knowledge could not be directly linked.

This behavior presents multiple opportunities for further exploration. A carefully designed improvement on this study could qualitatively explore the factors that led to certain teachers choosing to share SMS messages with peers while others did not; whether they passed the messages to teachers at their own school or at others; whether they shared only with teachers in the EGRA grades (1-3) or even with colleagues in higher grades; and so on. It could also quantitatively explore whether certain messages (or message types) were more or less likely to be shared; whether those sharing patterns were consistent across all teachers or whether they varied according to teacher characteristics; and whether the act of sharing spurred peer discussions about teaching or classroom management practices. Including a treatment arm in which teachers received only generic "encouraging" SMS messages completely unrelated to the technical substance of the reading intervention, rather than messages focused on instructional issues, would enable a more nuanced understanding of teachers' sharing behaviors.

\section{SMS and Social Learning as an Entry Point for Changing Teacher Practice}

As suggested in the Literature Review section, the motivation to use technology in education programs must be based on the added value of the technology to do something that traditional methods as yet have not been able to do. In many cases, this added value comes in the form of increasing access to or receipt of information-although it may depend on what the user 
does with the information as a result. The ease with which teachers received and shared simple instructions via text messages seems to have facilitated ongoing social learning to some extent, but as the teachers' SMS sharing was unplanned and as such unstructured, future research might consider how the SMS medium (or related tools) could be used to change pedagogical practice as a precursor to influencing changes in teachers' attitudes and beliefs about instruction.

The purpose of teacher professional development programs is to improve student outcomes through some effect on teachers' knowledge, pedagogical practices, beliefs, and attitudes. As Guskey (2002) pointed out, the presumption among designers of professional development programs has historically been that changing a teacher's beliefs about a particular instructional innovation will lead to the adoption of that innovation, which in turn will lead to improved student outcomes. Guskey noted, however, that at least in the case of experienced teachers, this presumption likely does not hold. Instead, Guskey (1986) proposed a model in which teachers' behaviors and attitudes are the last thing to change. That is, before teachers will update their belief systems about what works, they must first see concrete improvements in their students' outcomes as a direct result of specific pedagogical innovations they have introduced and tested in their classrooms.

A crucial element in Guskey's model is thus teachers' willingness to at least pilot the pedagogical innovations in their classrooms. If the piloting bears fruit in terms of improved student outcomes, updated beliefs and attitudes will follow, and long-term shifts in teacher practice may take hold. If the piloting never happens in the first place, however, there is no opportunity for student outcomes to increase as a result of the pedagogical innovation, and teacher practice will not change.

Future studies could be explicitly designed to explore the relationship between teachers' willingness to share the SMS messages they received, social learning, and the first crucial step in Guskey's model of teacher behavior change: willingness to try small changes to classroom practice. For instance, SMS messages could be used to nudge teachers to pilot in their classrooms the new techniques on which they were trained and to discuss with peers their sense of whether the techniques "worked." Different formulations of the SMS nudges could be tested out to see whether any were more consistently effective in catalyzing action on the teachers' part and whether the type of action (e.g., piloting new techniques, discussing the results with peers, attempting to 
fully adopt new techniques) varied at all as a function of the message content or message frequency. If certain formulations seemed to lead to greater discussion among peer teachers, would that social element lead to greater piloting and/or long-term uptake of the new techniques?

\section{Avenues for Further Exploring the Role of SMS Interventions in the Design of Teacher-Training Strategies}

Given the low marginal cost of the EGRA SMS messages (albeit after a moderately substantial initial investment), the finding that 10 weeks of SMS as a medium could influence teachers' retention or consolidation of factual knowledge (or increase their alignment with desired attitudes and beliefs) would have significant implications for educational interventions attempting to reach teachers at scale and across large physical distances. Although the EGRA team's SMS campaign did benefit from a subsidized SMS rate from Airtel Malawi, it is worth noting that, absent this corporate support, the per-teacher campaign cost was still estimated to have been less than USD 3.00. Although the CSR support that the EGRA received should be acknowledged and sought in any replication of this study, the incremental costs without this support would not drastically change the business case for including similar campaigns as part of a broader literacy intervention, as evidenced by the HALI and PRIMR projects described in this chapter.

A tightly designed replication of the study that rigorously isolates and identifies effects attributable to SMS would point to several additional avenues of investigation. For instance, might there be a limit to the duration of the effect of an SMS campaign or an inflection point at which additional messaging might cease to generate a return? Sending a teacher too many SMS messages in a given period might lead to a sort of saturation in which the teacher might begin tuning out the messages; alternatively, even if a saturation point were not reached, the SMS messages might have initially been a welcome novelty but cease to be exciting after four months or so of continual receipt. In either case, the impact of the messaging intervention might then diminish or disappear altogether. Further research might also investigate other noncognitive effects of the SMS program, such as maintaining motivation and engagement with a professional development program (Dubeck, Jukes, Brooker, Drake, \& Inyega, 2015).

Understanding such effects would have actionable implications for the deployment of an SMS campaign in places like Malawi, where each academic 
term is often 12-14 weeks in length and teacher-training programs often happen during inter-term breaks. If the influence of an SMS messaging campaign were found to be persistent over a substantial period of time-say, 10-12 weeks - the SMS medium might prove to be an effective way of ensuring that a Term 2 training program is building upon a more solid foundation (with respect to retention of Term 1 training content) than would otherwise be the case. This would, in turn, have implications for the design and delivery of training content, in that less time might need to be spent on remediation or review, and more time could be spent on delivering and reinforcing new content.

Besides the implications for training design, an SMS-based teacher support campaign would be intriguing from a cost perspective. As reported previously, the direct cost per teacher of the SMS campaign using the EGRA setup was USD 1.50; under the EGRA's reimbursement model, the amount budgeted to support PEAs' coaching visits each month was 25,000 kwacha/ USD 37.29. Obviously, the value of that trade-off would depend largely on how much coaching actually happened. Because analyses of the EGRA's coaching data suggested that the substantial majority of EGRA teachers received no coaching visits in any given six-week span, the project would have realized only minimal savings because the actual expenditures on coaching did not approach the budgeted allocations for coaching. For a program that enjoys greater success in mobilizing instructional coaches, however, an SMS intervention might provide some of the same benefits as a coaching visit in terms of teachers' consolidation of knowledge gained from training workshops.

\section{Integrating SMS Interventions Into Teacher Coaching Processes}

We are not implying that an SMS-based system, were it shown to be legitimately impactful, could or should be construed as an adequate substitute for in-person coaching. While in-person coaching is expensive in direct costs, opportunity costs, and administrative complexity, it is probable that more substantial additional benefits accrue through that relational experience than can be transmitted in a 160-character impersonal text message. Considering as well that coaching visits are rarely limited to classroom instructional support-they frequently provide valuable opportunities for administrative discussions with head teachers, inspection-type functions, and conversations with parents or school management committees, all of which can help 
improve school quality in both tangible and intangible ways-there would not be a strong argument for replacing coaching with SMS-based support.

One could imagine, however, designing a coaching system that attempted to use SMS-based "nudges" to complement in-person coaching. In a mixedmethods study of teachers' classroom practices conducted earlier in the EGRA's period of performance, Mattos and Sitabkhan (2016) made note of teachers' on-the-fly modifications to the prescribed lesson plan and then interviewed them to understand the reasoning behind those modifications. The authors found that over half of the modifications affected the content of the lesson (52 percent), with nearly another quarter affecting the structure of the lesson (23 percent); their expert judgment was that 52 percent of the content modifications and 79 percent of the structural modifications were detrimental to the goal of the lesson. Such changes to lesson structure and content could be identified and recorded by non-expert coaches using classroom observation software such as RTI's Tangerine:Tutor ${ }^{\circledR}$ platform. Integrating Tutor with an SMS delivery mechanism could allow a program, in the weeks and months following an observation, to send the teacher SMS messages tailored specifically to address the motivations, points of confusion, or areas of weakness that led him or her to make those changes in the first place.

For those SMS messages to be maximally effective, however, the program would need to understand teachers' reactions to such messages. Would they welcome them and find them helpful or consider them intrusive and frustrating? Would teachers recognize the intended link between the SMS messages and their own classroom practices, or would they see the two as fundamentally unrelated? Even if they recognized the link, there is a difference between knowing about the effectiveness or importance of a given practice and actually implementing it within a lesson. Would even highly targeted SMS messages translate into observable differences in pedagogy that persisted between coaching visits? We would recommend that researchers interested in the use of SMS to support teacher behavior change invest prudently in up-close, expert qualitative inquiry to understand how teachers engage with the SMS medium and the messages' content, as well as whether and how that engagement affects classroom practice.

However, sound evidence regarding the mechanism by which instructional coaching drives improved student outcomes in the developing world remains far too limited. If the mechanism of change is merely a function of a 
Hawthorne or observer effect-in which the simple awareness that someone is paying attention to the teachers' actions leads them to be more conscientious and diligent in their work, or encourages them to care more and thus invest more time and effort in preparing their lessons, etc.- then an SMS-based system might have a useful role as a low-cost reminder to the teachers that their work matters and is being tracked. Given what we have observed and reported with respect to the teachers' sharing of SMS messages among peers, it is quite plausible that teachers themselves valued the SMS content to some degree, and this alone merits further testing as to how best to leverage this cost-efficient, familiar medium for more sustained professional development efforts targeting early grade teachers.

\section{Acknowledgments}

The authors wish to thank the education office of the United States Agency for International Development (USAID)/Malawi for its leadership and support throughout the implementation of the Malawi Early Grade Reading Activity (EGRA) covered in this case study. Special appreciation goes to Kevin Roberts (Contracting Officer's Representative [COR]), Ramsey Sosola (Alternate COR), and Christine Djondo (Education Office Chief for the majority of EGRA's period of performance). All four authors were assigned to EGRA during its implementation and played major roles in the short message service (SMS) campaign described in this chapter. The contents of this chapter are the responsibility of the authors and do not necessarily reflect the views of USAID or the US government.

\section{References}

Aker, J., Ksoll, C., \& Lybbert, T. J. (2010). ABC, 123: The impact of a mobile phone literacy program on educational outcomes (Working Paper 223). Washington, DC: Center for Global Development. Retrieved from https:// www.cgdev.org/publication/abc-123-impact-mobile-phone-literacy-programeducational-outcomes-working-paper-223

Beltramo, T., \& Levine, D. I. (2012). Do SMS text messaging and SMS community forums improve outcomes of adult and adolescent literacy programs? (Working Paper No. 015). Berkeley, CA: Center for Effective Global Action, University of California. Retrieved from http://escholarship.org/uc/item/1c31c2m4 
Cepeda, N. J., Pashler, H., Vul, E., Wixted, J. T., \& Rohrer, D. (2006). Distributed practice in verbal recall tasks: A review and quantitative synthesis. Psychological Bulletin, 132, 354-380. https://doi.org/10.1037/ 0033-2909.132.3.354

Chauwa, A. (2015, March). Malawi losing billions on ghost teachers, nationwide strike looming. Nyasa Times. Retrieved from http://www.nyasatimes.com/ malawi-losing-billions-on-ghost-teachers-nationwide-strike-looming/

da Costa, T. M., Barbosa, B. J. P., Gomes e Costa, D. A. G., Sigulem, D., de Fátima Marin, H., Filho, A. C., \& Pisa, I. T. (2012). Results of a randomized controlled trial to assess the effects of a mobile SMS-based intervention on treatment adherence in HIV/AIDS-infected Brazilian women and impressions and satisfaction with respect to incoming messages. International Journal of Medical Informatics, 81(4), 257-269. https://doi.org/10.1016/j.ijmedinf.2011.10.002

Dubeck, M. M., Jukes, M. C. H., Brooker, S. J., Drake, T. L., \& Inyega, H. N. (2015). Designing a program of teacher professional development to support beginning reading acquisition in coastal Kenya. International Journal of Educational Development, 41, 88-96. https://doi.org/10.1016/j. ijedudev.2014.11.022

Fisher, D., Frey, N., \& Nelson, J. (2012). Literacy achievement through sustained professional development. The Reading Teacher, 65(8), 551-563. https://doi.org/10.1002/TRTR.01082

Fjeldsoe, B. S., Marshall, A., \& Miller, Y. (2009). Behavior change interventions delivered by mobile telephone short-message service. American Journal of Preventive Medicine, 36(2), 165-173. https://doi.org/ 10.1016/j.amepre.2008.09.040

Gaible, E., \& Burns, M. (2005). Using technology to train teachers: Appropriate uses of ICT for teacher professional development in developing countries. Washington, DC: infoDev/World Bank. Retrieved from http://www.infodev.org/articles/using-technology-train-teachers

Guskey, T. R. (1986). Staff development and the process of teacher change. Educational Researcher, 15(5), 5-12. https://doi.org/10.3102/ 0013189x015005005

Guskey, T. R. (2002). Professional development and teacher change. Teachers and Teaching, 8(3), 381-391. https://doi.org/10.1080/135406002100000512 
Jackson, D., Jere, M., Togher, A., \& Webb, D. (2015). Initial Primary Teacher Education (IPTE) Programme: An independent review of the IPTE Curriculum undertaken on behalf of the Malawi Institute of Education and the Department of Teacher Education and Development. Lilongwe, Germany: GIZ (Deutsche Gesellschaft für Internationale Zusammenarbeit).

Jukes, M. C. H., Turner, E. L., Dubeck, M. M., Halliday, K. E., Inyega, H. N., Wolf, S., Zuilkowski, S. S., \& Brooker, S. J. (2016). Improving literacy instruction in Kenya through teacher professional development and text messages support: A cluster randomized trial. Journal of Research on Educational Effectiveness, 1-33. https://doi.org/10.1080/19345747.2016.12 21487

Kaleebu, N., Gee, A., Maybanks, N., Jones, R., Jauk, M., \& Watson, A. H. A. (2013). SMS story: Early results of an innovative education trial. DWU Research Journal, 19(November), 50-62. Retrieved from http://www.dwu. ac.pg/en/images/Research_Journal/2013_Vol_19/5_Kaleebu_Gee_ Maybanks_Jones_Jauk__Warson_SMS_Story.pdf

Kraft, M. A., Blazar, D., \& Hogan, D. (2017). The effect of teacher coaching on instruction and achievement: A meta-analysis of the causal evidence (Working Paper). Providence, RI: Brown University and Harvard University. Retrieved from https://scholar.harvard.edu/files/mkraft/files/ kraft_blazar_hogan_2016_teacher_coaching_meta-analysis_wp_w_ appendix.pdf

Mattos, M., \& Sitabkhan, Y. (2016). Malawi Early Grade Reading Activity: Scripting study report. Prepared for USAID/Malawi under the Malawi Early Grade Reading Activity, Contract AID-612-C-13-0002. Research Triangle Park, NC: RTI International. Retrieved from http://pdf.usaid.gov/ pdf_docs/pa00mdzf.pdf

Ministry of Education, Science, and Technology (MOEST) [Malawi]. (2015). Handbook for inspectors and advisors: September 2015. Lilongwe, Malawi: Author.

Piper, B., \& Korda, M. (2011). EGRA Plus: Liberia. Understanding the causal mechanisms: EGRA Plus's effectiveness. Prepared for USAID/Liberia under the Education Data for Decision Making (EdData II) project, Early Grade Reading Assessment (EGRA): Plus Project, Task Order No. EHC-E-0604-00004-00 (RTI Task 6). Research Triangle Park, NC: RTI International. Retrieved from http://pdf.usaid.gov/pdf_docs/pnaea386.pdf 
Piper, B., \& Mugenda, A. (2012). The Primary Math and Reading (PRIMR) Initiative: Baseline report. Prepared under the USAID EdData II project, Task Order No. AID-623-M-11-00001 (RTI Task 13). Research Triangle Park, NC: RTI International. Retrieved from http://pdf.usaid.gov/pdf_docs/pa00hx75.pdf

Piper, B. P., \& Zuilkowski, S. S. (2015). Teacher coaching in Kenya: Examining instructional support in public and nonformal schools. Teaching and Teacher Education, 47, 173-183. https://doi.org/10.1016/j.tate.2015.01.001

Pouezevara, S. (2015). Revisiting the ' $m$ ' in m-learning: Making the most of mobile environments for teaching and learning in developing countries [Chesapeake, VA: Association for the Advancement of Computing in Education] [AACE]. Proceedings of E-Learn: World Conference on E-Learning in Corporate, Government, Healthcare, and Higher Education, 2015 (pp. 1350-1360). Retrieved from https://www.learntechlib.org/p/152173

Pouezevara, S., Pflepsen, A., Nordstrum, L., King, S., \& Gove, A. (2016). Measures of quality through classroom observation for the Sustainable Development Goals: Lessons from low- and middle-income countries. Background paper prepared for the 2016 Global Education Monitoring Report. Education for people and planet: Creating sustainable futures for all. Paris, France: UNESCO. Retrieved from http://unesdoc.unesco.org/ images/0024/002458/245841E.pdf

Pratham Education Foundation \& Voluntary Service Overseas (VSO). (2015). SMS Story Project: Bundi, Rajasthan (Impact Assessment Report).

Mumbai, India: Author. Retrieved from https://www.vsointernational.org/ sites/default/files/sms_report_final_v1_4.pdf

Ramos, A. J., \& Trinoña, J. P. (2009). Mobile technology in nonformal distance education. In J. Baggaley \& T. Belawati (Eds.), Distance education technology in Asia (pp. 231-256). Lahore, Pakistan: University of Pakistan. Retrieved from http://www.pandora-asia.org/downloads/Book-2/ PANdora-book2_v6.pdf

RTI International. (2010). USAID funded Malawi Teacher Professional Development Support (MTPDS) Program. 2010 Early Grade Reading Assessment: National baseline report. Prepared for Creative Associates International and USAID under ABE/LINK Task Order No. EDH-I-0405-00026-00. Research Triangle Park, NC: Author. Retrieved from https:/globalreadingnetwork.net/sites/default/files/eddata/Malawi_ National_Baseline_EGRA_2010.pdf 
RTI International. (2014). USAID/Kenya Primary Math and Reading (PRIMR) Initiative: Final report. Prepared for USAID under the EdData II project, Task Order No. AID-623-M-11-00001 (RTI Task 13). Research Triangle Park, NC: Author. Retrieved from http://pdf.usaid.gov/pdf_docs/ PA00K282.pdf

Slade, T. S. (2016, March). Getting instructional coaching right is hard-Why do we bother? Observations from USAID's Malawi Early Grade Reading Activity. Delivered as part of the panel "Coaching Support for Teachers to Improve Early Grade Reading: Experiences, Results and Future Directions," 2016 Annual Conference of the Comparative and International Education Society (CIES), Vancouver, Canada.

United Nations Educational, Scientific and Cultural Organization (UNESCO). (2014). Teaching and learning: Achieving quality for all. Malawi: Fact sheet (EFA Global Monitoring Report 2013/4). Paris, France: UNESCO. Retrieved from http://www.unesco.org/new/fileadmin/ MULTIMEDIA/HQ/ED/GMR/pdf/Malawi_Factsheet.pdf

York, B., \& Loeb, S. (2014). One step at a time: The effects of an early literacy text messaging program for parents of preschoolers (NBER Working Paper Series, No. 20659). Cambridge, MA: National Bureau of Economic Research. https://doi.org/10.3386/w20659 



\title{
Relationships Between Coach Support and Teachers' Adoption of New Instructional Practices: Findings from the Nigeria Reading and Access Research Activity (RARA)
}

\author{
Karon Harden, Alison Pflepsen, and Simon King
}

\section{Introduction}

Teacher quality is key to student learning (Darling-Hammond, 2000; Goe, 2007). However, pre-service and in-service professional development alone may not be sufficient to ensure high-quality teacher practice (De Alba-Johnson et al., 2004; Neuman \& Cunningham, 2009); teachers' adoption of new practices benefits from follow-up support on-site in their classrooms such as that provided by pedagogical coaches (Coburn \& Woulfin, 2012; Sailors \& Price, 2010; Tschannen-Moran \& McMaster, 2009).

Coaching can be defined as "providing on-site, job-embedded, sustained professional development for teachers" (Bean, 2014, p. 7). Numerous studies have shown coaching to be an effective way to improve teacher practice in developed countries (Carlisle, Cortina, \& Katz, 2011; Kretlow \& Bartholomew, 2010; Powell, Diamond, Burchinal, \& Koehler, 2010; Walpole, McKenna, Uribe-Zarain, \& Lamitina, 2010; see also Kraft, Blazar, \& Hogan, 2018, for a meta-analysis of 37 studies). Other studies have found coaching to have an impact on student achievement (Bean, Draper, Hall, Vandermolen, \& Zigmond, 2010; Biancarosa, Bryk, \& Dexter, 2010; Blachowicz, Obrochta, \& Fogelberg, 2005; Elish-Piper \& L'Allier, 2011).

Given the success of coaching in high-income countries, many literacy interventions in low- and middle-income countries now include substantial resource investment in this model of teacher professional development. Though still promising, the research base on the effectiveness of such coaching in low- and middle-income countries is much more limited 
(Sailors, Hoffman, Pearson, Shin, \& McClung, 2012; Tolley, Johnson, \& Koszalka, 2012; Hussain \& Ali, 2010; Piper, Zuilkowski, \& Mugenda, 2014; Piper \& Zuilkowski, 2015; Piper, 2009).

Although these studies have begun to elucidate the characteristics of coaching that have an impact on teacher change and student gains, and many have used direct observations of coaching in action, more research is needed to clarify exactly what makes coaching effective, how it works in less-thanideal circumstances, and how it can successfully be taken to scale. To that end, this present study uses secondary analysis of archival data from a literacy intervention in Nigeria that trained grade 2 teachers in evidence-based literacy practices, provided them with instructional materials, and trained coaches to visit the teachers regularly and support them in their implementation of the new practices.

The original study focused on contrasting the changes in teacher instructional practices and student reading gains in an intervention group with those in a control group. While coaching support was presumed to be one element that contributed to the gains in the intervention group, the original study was not set up to probe the role of coaching support specifically. After the intervention ended, the authors of this present study decided to examine the coach and teacher data together to see what, if anything, could be learned from them. In this chapter, we explore associations between the improvements in these teachers' instructional practices and characteristics of the coaching support they received.

\section{Literature Review}

\section{Models of Coaching}

\section{What Coaches Do}

While coaches' responsibilities vary from one setting to another (Bean et al., 2010), they most commonly include supporting teachers one-on-one to promote improvements in their instructional practices; facilitating teachers' professional development in groups; and providing leadership for and advocating for literacy at the school and community level (L'Allier, ElishPiper, \& Bean, 2010; Printy, 2008; Quatroche \& Wepner, 2008). The oneon-one support typically takes the form of co-teaching, modeling, or demonstrating teaching; observing the teacher teach a lesson; conferencing with the teacher after the observation, giving feedback, and reflecting together; providing resources; administering assessments; and discussing 
student progress and needs (Bean, 2009; Elish-Piper \& L'Allier 2011; Joyce \& Showers, 2002). Coach-led group meetings are considered effective in combination with differentiated, one-on-one mentoring (National Institute for Excellence in Teaching, 2012). In many low- and middle-income countries, resource constraints and heavy administrative duties prevent coaches from spending as much time with teachers as they otherwise might.

\section{Hard, Soft, and Balanced Coaching Models}

A distinction has been made in the literature between two basic approaches to coaching: hard (or directive) coaching on one hand versus soft (or responsive or reflective) coaching on the other. Hard coaching stresses the teachers' conformity to a pre-established, desired practice, while soft coaching focuses more on the teachers' development into reflective practitioners who continuously examine and improve their own practice. A third approach, "balanced coaching" (Ippolito, 2010), seeks to combine elements of the first two. Table 6-1 presents descriptions that have been attributed to each of these approaches.

Table 6-1. Descriptive phrases pertaining to hard, soft, and balanced coaching models

\begin{tabular}{|c|c|}
\hline Hard (or directive) coaching & Soft (or responsive or reflective) coaching \\
\hline $\begin{array}{l}\text { "... coaching for the implementation of } \\
\text { particular practices" (Ippolito, 2010, p. 164). }\end{array}$ & $\begin{array}{l}\text { "...coaching for teacher self-reflection" } \\
\text { (Ippolito, 2010, p. 164). }\end{array}$ \\
\hline $\begin{array}{l}\text { Some instructional approaches are better than } \\
\text { others; the coach's job is to ensure that the } \\
\text { teachers follow best practices (Bean, 2014). }\end{array}$ & $\begin{array}{l}\text { "... supporting teachers in moving from } \\
\text { where they are to where they want to be... } \\
\text { developing teachers' abilities to be reflective }\end{array}$ \\
\hline $\begin{array}{l}\text { "Coaches assume the role of expert and are } \\
\text { assertive about what instructional practices }\end{array}$ & $\begin{array}{l}\text { in their instructional decision-making" (Costa \& } \\
\text { Garmston, 2002, cited in Bean, 2014, p. 8). }\end{array}$ \\
\hline $\begin{array}{l}\text { teachers must implement" (Ippolito, 2010, } \\
\text { p. 165). }\end{array}$ & $\begin{array}{l}\text { "... invitational in nature, respecting teacher } \\
\text { expertise, embracing multiple perspectives }\end{array}$ \\
\hline $\begin{array}{l}\text { "Coaches may challenge the work of } \\
\text { teachers... and confront teachers who are } \\
\text { resistant to changing instructional practices" }\end{array}$ & $\begin{array}{l}\text { of teaching literacy, and generally non- } \\
\text { confrontational" (McKenna \& Walpole, 2008, } \\
\text { cited in Bean, 2014, p. 8). }\end{array}$ \\
\hline (Bean, 2014, p. 8) & “... language and procedures designed to \\
\hline “... synonymous with fidelity to & engage teachers' thinking in reflective ways" \\
\hline $\begin{array}{l}\text { implementation efforts or the degree to } \\
\text { which teachers implement the program as }\end{array}$ & $\begin{array}{l}\text { (Costa \& Garmston, 1994, cited in Heineke, } \\
\text { 2013, p. 411). }\end{array}$ \\
\hline designed" (Bean, 2014, p. 8). & “...joint experimentation” (Schön, 1987, \\
\hline $\begin{array}{l}\text { “. . .'Follow me!'” (Schön, 1987, p. 212, cited } \\
\text { in Heineke, 2013, p. 411). }\end{array}$ & p. 212 , cited in Heineke, 2013, p. 411). \\
\hline
\end{tabular}

\section{Balanced coaching}

"... respond[ing] to teacher needs while promoting specific instructional approaches or practices. Coaches may be directive but also seek teacher input and provide opportunities for teachers to reflect on their work" (Bean, 2014, p. 8).

"... a mixture of pressure and support" (Ippolito, 2010, p. 164). 
Bean (2014) suggests that hard coaching might be appropriate or preferable in contexts in which teachers, as well as coaches, do not have much preservice training in effective literacy instruction; teachers are first learning to implement new, evidence-based instructional practices such as in the early phases of an initiative; coaches have traditionally played a supervisory or inspectorial role; or the program places high stakes on fidelity of implementation. Balanced coaching, on the other hand, may be more appropriate for well-resourced contexts with strong leadership and experienced personnel. In those contexts, coaches can reduce their scaffolding and allow teachers more agency to make decisions based on reflection (Bean, 2014). Also, a coach's approach may evolve over time as the relationship between the coach and teacher develops and as the teacher's level of expertise and needs evolves (Collet, 2012; Zigmond, Bean, Kloo, \& Brydon, 2010, as cited in Bean, 2014).

\section{Characteristics of Effective Coach Support Coach Background Characteristics}

Descriptions of the desirable profile for a coach to have abound in the literature, beginning with technical expertise in the content (Frost \& Bean, 2006). For literacy, this means "in-depth knowledge of [the] reading process, acquisition, assessment, and instruction" (International Reading Association, 2004 , p. 3). Researchers consider that expertise is built from both experience and formal training. Coaches should have teaching experience in the content area and at the relevant grade levels and preferably also experience working with other teachers in peer-learning situations (International Reading Association, 2004; L'Allier et al., 2010). The International Literacy Association (formerly the International Reading Association) has recommended that literacy coaches in the United States have at least a reading specialist certificate, which is based on university coursework (International Reading Association, 2004).

The research on the impact of academic preparation is mixed. For example, Bean et al.'s (2010) study of 20 reading coaches found "no significant relationships among coach qualifications (e.g., years of teaching experience, years of coaching experience, reading specialist certification) and student achievement nor any significant relationships between coach qualifications and coach behaviors" (p. 106). However, another study of 5 literacy coaches, 65 early primary classroom 
teachers, and 1,596 students found that coaches with a reading teacher endorsement were associated with the highest gains in student reading achievement, and vice versa, although this study did not analyze the coaches' years of prior experience (L'Allier \& Elish-Piper, 2006, as cited in L'Allier et al., 2010).

Recruiting, developing, and retaining a competent corps of coaches is a challenge even in high-resource contexts (Kraft et al., 2018), and potentially even more so in low-resource contexts, where highly trained and skilled coaches-and teachers-are chronically in short supply. Two common sources of candidates in these contexts both carry disadvantages: tapping highly skilled teachers removes them from the classroom where they are sorely needed, and promoting long-serving educators regardless of their skills or expertise opens the door to potentially ineffective coaches.

\section{Quantity of Coaching}

Effective coaching support requires a time investment. Bean (2014) asserted that "coaching has to be intense and of sufficient duration to make a positive difference" (p. 17). Indeed, many studies have found that the number of coach visits or quantity of time a coach spends with a teacher is related to student reading gains (Bean et al., 2010; Elish-Piper \& L'Allier, 2011; Piper \& Mugenda, 2013; Pouezevara, Costello, \& Banda, 2012; Ross, 1992; Shidler, 2009). However, in Kraft, Blazar, and Hogan's (2018) exploratory meta-analysis of coach studies, they found no relationship between the dosage of coach support and changes in teacher instruction and student achievement. They concluded that "the quality and focus of coaching may be more important than the actual number of contact hours" (p. 21).

The optimum quantity of coach visits has direct financial implications because of personnel and transportation costs and, as just noted, the scarcity of qualified coaches. More research on the impact and the most cost-effective dosage and frequency of coach contact is needed.

\section{Quality of Coaching}

Not all coaches are equally effective (Blazar \& Kraft, 2015). In the attempt to define "quality coaching," researchers have focused on the relationship between the coach and the teacher and the nature of the activities that they do together. 
Multiple sources have stressed the importance of a positive, collaborative, trusting relationship, or good rapport, between the coach and the teacher (L'Allier et al., 2010). For teachers to benefit from the coaching support, they need to feel comfortable in the coach's presence, as well as open to and unthreatened by critique and change (Kraft et al., 2018). Perkins (1998) found that experienced coaches build rapport by asking teachers open-ended questions, paraphrasing back to them their concerns and comments, and demonstrating respect for their opinions. Heineke (2013) also highlighted the importance of the coach eliciting input from the teacher to "extend the talk and thus hold more potential for the joint construction of meaning" (p. 422). When the coach does all or most of the talking, the teacher's engagement and opportunity for learning is reduced. Heineke (2013) called interrupting an "aggressive verbal move" that silences the teacher and asserts dominance rather than collaboration (p. 422). To be effective, the coach must not only elicit the teacher's input but also listen and respond to it with sensitivity and affirmation.

Taking an evaluative stance can inhibit rapport. If teachers perceive that coaches look down on them, focus only on their shortcomings, patronize them, or ignore their expertise, teachers will be quick to erect walls of resistance (Heineke, 2013; Kraft et al., 2018). For this reason, ideally, the role of coach does not overlap with supervision or inspection, which might introduce a stifling element of fear into the relationship. However, in many developing-country contexts, including Nigeria, the existing education systems have supervisors who, at least on paper, have both pedagogical support and inspectorial responsibilities, even if they practice more of the latter than the former. Education initiatives that include a coaching component and seek to work within existing structures for the sake of long-term sustainability often assign the coaching responsibilities to these existing positions. This approach can create tension in the dual role of the coach-inspector and in the traditionally hierarchical nature of the relationship between the coach and teacher.

In addition to establishing a positive rapport with teachers, the literature base suggests that high-quality coaches provide opportunities for teachers to reflect critically on their current practice and strategize about ways to improve it (Collet, 2012; Duffy, 2003; Heineke, 2013; Joyce \& Showers, 2002; Richardson, 1994; Schön, 1987). Accordingly, the following coaching practices are considered high leverage for fostering teacher change 
(Bean et al., 2010; Kise, 2006; McCombs \& Marsh, 2009; Stover, Kissel, Haag, \& Shoniker, 2011):

- modeling instruction

- observing the teacher in action

- eliciting the teacher's views and offering supportive feedback after the observed lesson

- examining student learning outcomes and assessment results together

- helping the teacher set specific goals or an action plan

- following up on the action plan at subsequent visits

- differentiating support according to teacher and student needs

In particular, focusing on the students - their progress and their needsnot only gives the teacher data on which to base instructional decisions but also helps the coach steer clear of an evaluative stance vis-à-vis the teachers themselves (L'Allier et al., 2010).

According to Blazar and Kraft (2015), even in high-income countries, "little is known about particular skill sets that translate into being a good coach and the necessary conditions that make for a positive teachercoach relationship" (p. 563). More information is needed about effective coaching practices in low-income countries as well, especially in contexts without a long history of a balanced model of pedagogical coaching. This information would help guide the practitioners responsible for planning and implementing education improvement programs that include a coaching element in sub-Saharan Africa or other low-income regions.

\section{Methodology}

\section{Research Questions}

This exploratory study builds on the prior knowledge base in two primary ways. First, it examines the use of a balanced model of coaching with inexperienced coaches and teachers in sub-Saharan Africa, under conditions common to many other low-income regions or countries where similar coaching models are being introduced. Second, it analyzes the role of specific constructs of coach background and coaching quality, as well as the quantity 
of coach visits, by examining the association of those variables with changes in the teachers' literacy instruction.

Specifically, this study sought to answer four questions in this and similar contexts:

1. What is the relationship between coach background and coaching quality? Do coaches with higher academic credentials or more prior experience as a pedagogical supervisor, head teacher, or teacher tend to demonstrate better coaching practices?

2. What is the relationship between coach background and teacher instructional practices? Do teachers who receive support from coaches with higher academic credentials or more prior experience in education tend to change their practices more than teachers whose coaches have lower credentials or less experience?

3. What is the relationship between the quantity of coach visits and teacher instructional practices? Do teachers who are visited more frequently by a coach change their practices more than teachers who are visited less frequently?

4. What is the relationship between coaching quality and teacher instructional practices? Do teachers whose coaches demonstrate better coaching practices during their visits change their practices more than teachers whose coaches provide a lower quality of support?

\section{Data Sources}

\section{Background}

The data for this chapter were generated as part of an evaluation of an early grade literacy improvement intervention for the Hausa language, which was implemented with grade 2 children in 60 public primary schools in the Bauchi and Sokoto states of Nigeria. The Nigeria Reading and Access Research Activity (RARA), funded by the United States Agency for International Development (USAID), was an initiative implemented by RTI International in northern Nigeria from 2014 to 2015 (for details, see Pflepsen, Harden, Dubeck, Sankey, \& King, 2017; Pouezevara, Pflepsen, Nordstrum, King, \& Gove, 2016; RTI International, 2014, 2016a, 2016b).

Before the intervention, results from Early Grade Reading Assessments (EGRAs) in these states showed very low literacy levels in the dominant 
language, Hausa, in the early grades (RTI International, 2013a, 2013b). Pflepsen et al. (2017) cited the following contributing factors, among others: gaps in teacher training and support; lack of curricular guidance for Hausa literacy education; lack of instructional materials; and poor-to-nonexistent instruction in foundational literacy skills such as phonological awareness, alphabetic principle, fluency, and reading comprehension.

The minimum credential for public primary school teachers in Nigeria is the National Certificate of Education, which requires completion of a threeyear program in a state or federal college of education, including a six-month practicum. However, a 2013 statewide survey of a representative sample of teachers in Bauchi and Sokoto states found that few public school Hausa teachers had received any pre-service pedagogical training specifically in Hausa literacy: only 25 percent in Sokoto and 35 percent in Bauchi (RTI International, 2013a, 2013b).

The intervention theory of change hypothesized that an intervention package of teaching and learning materials, formal training, and ongoing pedagogical support from coaches would result in teachers using more effective instructional practices and, consequently, in student gains in reading and writing.

\section{Intervention Coaching Model}

The coaches participating in the intervention were 24 government school support officers (SSOs) whose regular responsibilities included supervising teachers in the intervention schools. Although pedagogical support is among their official duties, outside of this intervention SSOs play a predominantly inspectorial role over the teachers.

For the intervention, the coach visit protocol called for the coach to meet with the teacher briefly first to explain the purpose of the coach visit, which was to help them both learn more about how to improve the literacy skills of the learners and to identify ways of improving the instructional materials and the teacher support and training. After this introduction, the coach observed the teacher teaching an entire Hausa literacy lesson. (Modeling or co-teaching during the lesson was not part of the visit protocol.) While observing the teacher's lesson, the coach filled out an observation checklist on paper (RTI International, 2016a; see also Pouezevara, Pflepsen, Nordstrum, King, \& Gove, 2016). The items on the observation instrument followed the lesson plan step by step, and the coach marked whether the teacher did each activity on the list. 
At the end of the lesson, the coach administered a brief literacy assessment to four students chosen at random. Then the coach entered the data from the lesson observation and the assessments into a hand-held electronic tablet before meeting with the teacher. Based on this input, the tablet prompted the coaches with a list of related talking points to discuss with the teacher during the conference. The coaches were trained to consolidate on paper the feedback from the tablet with their own thoughts before beginning the conference with the teacher and to refer to these points during the conference.

The coaching model promoted through the intervention can be characterized as a balanced approach. It included hard (or directive) coaching, in that coaches were required to observe the teacher teaching a lesson and to record the teachers' fidelity of implementation using a specific observation instrument. Coaches were then expected to provide feedback to the teacher that focused on the main components of the lesson. At the same time, the coaching model included elements of soft (or responsive) coaching, in that the coaches were trained to actively seek the teacher's input, to encourage the teacher to ask questions, to develop an action plan for improvement, and to track improvement over time vis-à-vis this action plan. (Originally, the teachers were also supposed to keep a reflection journal [RTI International, 2015b] in between visits, and the coach was supposed to review these entries with the teacher during the conference. However, the journal piece proved to be challenging to implement for both coaches and teachers and was discontinued.)

\section{Intervention Coach Training and Support}

The coaches who participated in the intervention received the following inputs:

- Nine days of training in coaching, including a four-day initial orientation to the intervention's model of coaching (teacher visit protocol, roles, responsibilities, etc.) in December 2014; a three-day refresher training in March 2015; and two one-day meetings, one in January and one in May 2015, to help them prepare for facilitating cluster meetings with their teachers. The trainings were led by the staff and master trainers from Nigeria's colleges of education, polytechnic universities, and state boards of education (the entities responsible for education planning and implementation at the state level). In addition to the trainings focused specifically on coaching, the coaches also attended 10 days of teacher training along with the teachers (described in the next subsection). 


\section{- Regular observations and support by the staff and master trainers.}

Fourteen staff members and master trainers sat in on and observed the coach-teacher visits between two and eight times per coach between January and June 2015, for a total of 110 observations. The average number of times each coach was observed was 6.1, with a minimum of 2 and maximum of 8 . The observed sessions covered only a small number of the total visits that coaches made to teachers (402 visits from December 2014 to July 2015). At each observation, the staff or master trainer filled out a checklist about what the coaches did and how they interacted with the teachers during their visits. The points on the observation checklist corresponded with the visit protocol that the coaches had been trained to follow. The supervising staff then discussed their observations with the coaches in private at the end of their visits with the teachers. The instrument used by the staff and master trainers to observe and support the coaches is available in the activity's final report (RTI International, 2016a).

- Materials, including the lesson observation tool (RTI International, 2016a); a tablet loaded with the observation tool, suggested talking points, and the student literacy assessments using Tangerine software; and transportation funds for each teacher visit. The coaches' participation in the intervention was considered part of the regular responsibilities of their employment, and they did not receive any additional compensation for it.

All of the coaches received the same training and professional development, but the coaches were observed by different research staff or master trainers a different number of times and at different time points between January and June 2015.

\section{Intervention Teacher Training and Support}

The teacher participants were the 73 public school teachers charged with teaching grade 2 Hausa literacy in the 60 intervention schools. Each teacher received:

- Twelve days of training and ongoing professional development, including a six-day initial orientation to the activity's materials and approach to literacy instruction in November 2014 and a four-day refresher training in March 2015. These trainings were conducted by the 
research team and master trainers and attended by both teachers and coaches. The teachers also attended two one-day cluster meetings (with the teachers from two or three neighboring schools), which were facilitated by their coach, one in January and one in May 2015.

- Regular site visits and pedagogical support by their coaches, as described in the Intervention Coaching Model subsection. The coaches were assigned to cover three schools each (because Nigeria's SSOs are assigned to support a relatively low number of schools, the activity's ratio of one coach to three schools was designed to mirror realistic conditions in this context). The coaches whose data we examined for this chapter made a total of 402 visits to their teachers. Each of these teachers received on average 8.7 visits from his or her coach over the course of seven or eight months from December to June or July. (Due to a strike in Bauchi state, the school year there was extended by one month.) The lowest number of coach visits received was 2 , and the highest was 16.

- Materials, including a teacher's guide with daily structured lesson plans that incorporated five key components of literacy instruction (phonemic awareness, phonics, vocabulary, fluency, and comprehension) plus oral language and handwriting (RTI International, 2015c); a corresponding student textbook (RTI International, 2015d) at a ratio of one per student; and a book of stories for the teacher to read aloud to the students to develop oral language and comprehension (RTI International, 2015e). Other than these materials and funds to cover their attendance at the training workshops, the teachers did not receive any additional compensation for adopting the new instructional approach.

All of the teachers received the same materials, training, and professional development, but most of them were supervised by different coaches, and they received a varying number of coach visits and at different points in time from December 2014 to July 2015.

\section{Intervention Results}

Overall, the research activity found that an intervention package of training, ongoing pedagogical support, and instructional materials had a positive effect on teachers' instructional practices and student learning outcomes. At endline, teachers in the intervention schools were using effective instructional practices at significantly higher rates and devoting significantly more class 
time to literacy instruction than their control school counterparts were. In turn, students in intervention schools showed statistically significant gains in literacy skills over students in control schools, even though levels remained low in general. For example, the percentage of students in the intervention schools who could not identify a single letter sound decreased from more than 90 percent at the beginning of the year to 68 percent at the end, while the percentage in control schools actually increased slightly over the same period (RTI International, 2016a). For more detailed descriptions of the research findings in terms of the changes in teachers' instructional practices and student learning outcomes as a result of the overall intervention package, consult RTI International (2016a) and Pflepsen et al. (2017). This chapter builds on the literature base by examining more specifically the influence of the coaches' support on the teachers' practices.

\section{Sample}

The larger literacy intervention from which the data for this chapter were drawn was set up as a cluster randomized controlled trial to study the impact of the intervention package on teachers' instruction and grade 2 students' literacy skills. A four-step sampling process was used to randomize clusters of schools into control and treatment groups of 60 schools each.

While the control schools had SSOs assigned to them, those SSOs did not receive training in the activity's model of coaching, and the staff did not tally or observe those SSOs' visits to their teachers (if any). Consequently, the analysis in this chapter is limited to the treatment school coaches and teachers only.

In the 60 treatment schools, 73 teachers were responsible for teaching grade 2 Hausa literacy, and 24 SSOs were assigned by the state boards of education to supervise them. All of these teachers and SSOs were recruited and agreed to participate in the intervention, and the SSOs were trained as the coaches. For the impact evaluation in the original study, one grade 2 Hausa teacher per school was randomly selected for observation teaching a Hausa literacy class, once at baseline (i.e., pre-intervention) and once at endline (i.e., post-intervention), and the sample was redrawn at endline, meaning that the teacher observed at baseline was not necessarily the same teacher at endline. For the purpose of this chapter, we needed data from the same teacher being observed at both baseline and endline to calculate the gains in that teacher's instructional practices. Therefore, the data from any schools at which a different teacher was observed at baseline and 
endline had to be excluded from our sample. In the end, we were able to use the data from 46 teachers (19 in Bauchi, 27 in Sokoto) and the 18 coaches assigned to them.

\section{Data for Coach Background}

The data on coach background were self-reported by the coaches during an oral interview in Hausa at endline. Demographic information included the level of highest academic credential and years of experience as a teacher, as a head teacher, and as an SSO (RTI International, 2016a).

Table 6-2 presents the characteristics of the 18 coaches in our sample. Only one coach was female. The majority (77.8 percent) were credentialed with the National Certificate of Education, the minimum required certification for primary-grade teachers in Nigeria, as noted previously. Coaches averaged 21 years of prior experience as a teacher, 10 years as a head teacher, and 7.5 years as an SSO (in the Nigerian context, head teachers have administrative duties consistent with a principal or a school director, although they often continue to teach as well due to personnel shortages).

\begin{tabular}{ll}
\hline Table 6-2. Coach characteristics & \\
\hline Characteristic & $\begin{array}{l}\text { Percentage or mean } \\
(\boldsymbol{n}=\mathbf{1 8})\end{array}$ \\
\hline Sex (\% female) & $5.6 \%$ \\
\hline Highest academic credential (in ascending order): & \\
$\%$ Diploma & $11.1 \%$ \\
$\%$ Grade II & $5.6 \%$ \\
$\%$ National Certificate of Education & $77.8 \%$ \\
$\%$ Bachelor of Education & $5.6 \%$ \\
\hline Years of experience as a teacher: & \\
Mean & 20.9 \\
Minimum/maximum & 10,30 \\
\hline Years of experience as a head teacher: & \\
Mean & 9.8 \\
Minimum/maximum & 1,23 \\
\hline Years of experience as an SSO: & \\
Mean & 7.4 \\
Minimum/maximum & 1,15 \\
\hline
\end{tabular}

SSO $=$ school support officer. 


\section{Data for Quantity of Coach Visits}

The data on quantity of coach visits came from the log of visits to each teacher that the coaches recorded on the tablets provided to them by the intervention team. As noted earlier in this chapter, the teachers in our sample received on average 8.7 visits (minimum 2, maximum 16) from their coaches from December 2014 to July 2015.

\section{Data for Coaching Quality}

The data on coaching quality came from the staff and master trainers' observations of 110 (27 percent) of the 402 visits that these coaches made to the teachers in the sample, as described in the Intervention Coach Training and Support subsection. (The full coach observation instrument is available in RTI International, 2016a.) Because the staff and master trainers were the ones who had trained the coaches, they were familiar with all aspects of the coach visit protocol. The staff responsible for observing the coaches conducted internal training to ensure that they were recording observations consistently; during this exercise, 97.8 percent of the answers that they recorded about that coach-teacher visit matched one another, indicating a high degree of reliability in drawing summaries from the tool.

For the purpose of this study, we scored the coaches on 14 binary variables derived from items on the coach observation instrument (Table 6-3), for a possible high score of 14 . The variables were selected based on theoretical underpinnings (variables that were presumed in the literature to be associated with quality coaching support) as well as variability in the coaches' scores. Practices that coaches implemented in fewer than 10 percent or more than 90 percent of the observations were excluded because they would contribute relatively little to an analysis of variability. The selected variables emphasize the "softer" aspects of the intervention's coaching model-i.e., those related to establishing a good rapport with the teacher and strategically guiding the teacher to reflect on his or her practice and set goals for improvement.

During the intervention, the purpose of staff and master trainer observation of the coaches was to support and help the coaches grow in their role as coaches (i.e., "coaching the coaches"). Therefore, the number and timing of visits to each coach was not standardized across the sample but rather was differentiated according to each coach's needs. Accordingly, some coaches received more visits and observations by the staff or master trainers than did others; some coaches continued to be observed as late as May or June 


\section{Table 6-3. Items from the staff observation of coach-teacher visits used to measure coaching quality}

\begin{tabular}{ll}
\hline 1 & Does the coach ask the teacher for input and not do all of the talking? \\
\hline 2 & Does the coach listen to the teacher and value what the teacher has to say? \\
\hline 3 & $\begin{array}{l}\text { Does the coach balance feedback on what the teacher did well and what needs to be } \\
\text { improved? }\end{array}$ \\
\hline 4 & Does the coach provide helpful feedback to the teacher (constructive criticism)? \\
\hline 6 & $\begin{array}{l}\text { Is the teacher comfortable in the coach's presence? (e.g., does not seem shy, nervous, or } \\
\text { fearful, but engages in useful discussion) }\end{array}$ \\
\hline 7 & Does the teacher ask questions or provide input? \\
\hline 8 & $\begin{array}{l}\text { Are there any negative aspects regarding the interaction between the coach and the } \\
\text { teacher? (e.g., rudeness, disrespect, not listening)* }\end{array}$ \\
\hline 9 & $\begin{array}{l}\text { Did the coach provide an opportunity for the teacher to reflect upon and provide his/her } \\
\text { thoughts on lesson delivery? (strengths and areas for improvement) }\end{array}$ \\
\hline 10 & Did the coach fill out the Teacher-Coach Feedback summary sheet? \\
\hline 11 & Rate the coach's feedback on the teacher strengths. (i.e., Excellent, Good, Fair, or Poor)** \\
\hline 12 & Rate the coach's feedback on areas for improvement. (i.e., Excellent, Good, Fair, or Poor)** \\
\hline 13 & Did the coach and the teacher discuss an action plan for improvement? \\
\hline 14 & $\begin{array}{l}\text { Did the coach and teacher discuss or review previous plans for improvement, or } \\
\text { progress that has been made since the last observation? }\end{array}$ \\
\hline
\end{tabular}

* For this study, a coach was assigned one point for a positive response to all items except item 8 , for which the desired response was "no negative aspects observed."

** For this study, the responses for items 11-12 were combined into a binary option with "Excellent" or "Good" in one category and "Fair" or "Poor" in the other.

2015, while one coach was observed only in January 2015. As stated earlier, the average number of times each coach was observed was 6.1 (minimum 2, maximum 8).

In addition to the variation in number and timing of the observations per coach, the quality of coaching fluctuated over the course of the academic year; 4 coaches (22 percent) consistently implemented most or all of the practices that constituted our measures of coaching quality (Table 6-3), 10 coaches (56 percent) gradually improved over time, and 4 coaches (22 percent) stagnated or regressed over time. On average, coaches scored 7.9 on the 14 coaching quality variables during their first observation by staff and master trainers, compared with 11.3 at their final observation.

For our analysis for this chapter, we used each coach's mean observation score from the month of February 2015. The staff and master trainers conducted 45 observations of these coaches in February 2015; some coaches 
were observed only once during that month, and some coaches were observed multiple times (one coach was not observed in February but consistently scored 14 out of 14 variables on all six observations of him, all of which took place in January; thus, we assumed that he continued at that level of performance and used 14 as his mean score). On average, the coaches scored 10.0 on the 14 coaching quality variables during their February observations.

The coaches' February mean scores did not differ greatly from their overall mean scores; across all observations by staff and master trainers, coaches scored 9.9 on the 14 coaching quality variables. However, limiting the data to the February observations offered the advantage of comparing all the coaches' performance over a narrower slice of time, thus reducing the likelihood of external factors creating differential effects.

\section{Data for Teachers' Gains in Instructional Practices}

Finally, to measure the changes in the teachers' instructional practices, we used the data from the untimed classroom observations conducted by 29 external enumerators (i.e., not the coaches) at baseline and endline for the impact evaluation of the intervention (Pouzevara et al., 2016; RTI

International, 2014, 2016a). The enumerators were trained during a five-day workshop before the baseline data collection and a four-day refresher workshop before endline. At the end of the training, the enumerators were tested and required to score at least 80 percent accuracy in simulated observations to participate in the official data collection. At baseline, the enumerators averaged 83.4 percent accuracy on the final simulated untimed classroom observation.

During the data collection, the enumerators used an untimed classroom observation instrument to record data on the teacher's instructional practices. (The full classroom observation instrument is available in RTI International, 2016a.) The instrument was primarily (although not entirely) a checklist of essential instructional activities known to promote literacy development, with binary-response options-that is, yes for "observed" or no for "not observed" at any time in the lesson. All of these activities were emphasized in the intervention's teacher training and lesson plans, so in that respect, the observation tool was essentially a checklist for fidelity of implementation to the intervention's approach to literacy instruction.

The baseline observation took place immediately before the teachers received the intervention training or materials, and the endline observation 


\section{Table 6-4. Items from the classroom observation used to measure gains in teachers' instructional practices}

\begin{tabular}{ll}
\hline 1 & Does the teacher present letter sounds? \\
\hline 2 & Do the students practice letter sounds? \\
\hline 3 & $\begin{array}{l}\text { Does the teacher introduce syllables or sounds (word parts) to form or break apart } \\
\text { whole words, or blend letters together to make sounds? }\end{array}$ \\
\hline 4 & Does the teacher task the students to write letters or words? \\
\hline 5 & Does the teacher read a passage out loud to all the students? \\
\hline 6 & Does the teacher allow the students to read the passage aloud or independently? \\
\hline 8 & Does the teacher ask the students comprehension questions about the passage? \\
\hline 9 & $\begin{array}{l}\text { Ore the majority of students' eyes on text (in a book or similar material, not just the } \\
\text { and group activities? }\end{array}$
\end{tabular}

seven to nine months afterward. At neither observation did teachers see the observation instrument or know what the enumerators were watching for specifically. For this chapter, we calculated the teachers' gains in instructional practices as their score on nine practices from the endline lesson observation minus their baseline score on the same nine practices. The nine practices are presented in Table 6-4.

Overall, the teachers in this sample made significant gains from baseline to endline in incorporating these instructional activities into their lessons (Figure 6-1). At baseline, represented by the lighter bars in Figure 6-1, their implementation of these practices was low across the board, with the exception of syllable instruction (65 percent). They averaged 2.5 of the 9 practices at baseline. By endline, represented by the darker bars, they had increased their usage of all of these practices and averaged 8.2 out of 9 , an average gain of 5.7 practices.

\section{Findings}

To answer our research questions, we conducted regression analyses to test for the relationships among our constructs for coach background, quantity of visits, coaching quality, and teacher gains in instructional practice. The sample size and the $\mathrm{R}^{2}$ on the regression were too small for prediction, but the analysis revealed both positive and negative statistically significant associations between coach characteristics and outcomes, which are presented in this section. 
Figure 6-1. Percentage of teachers implementing each instructional practice, at baseline and endline

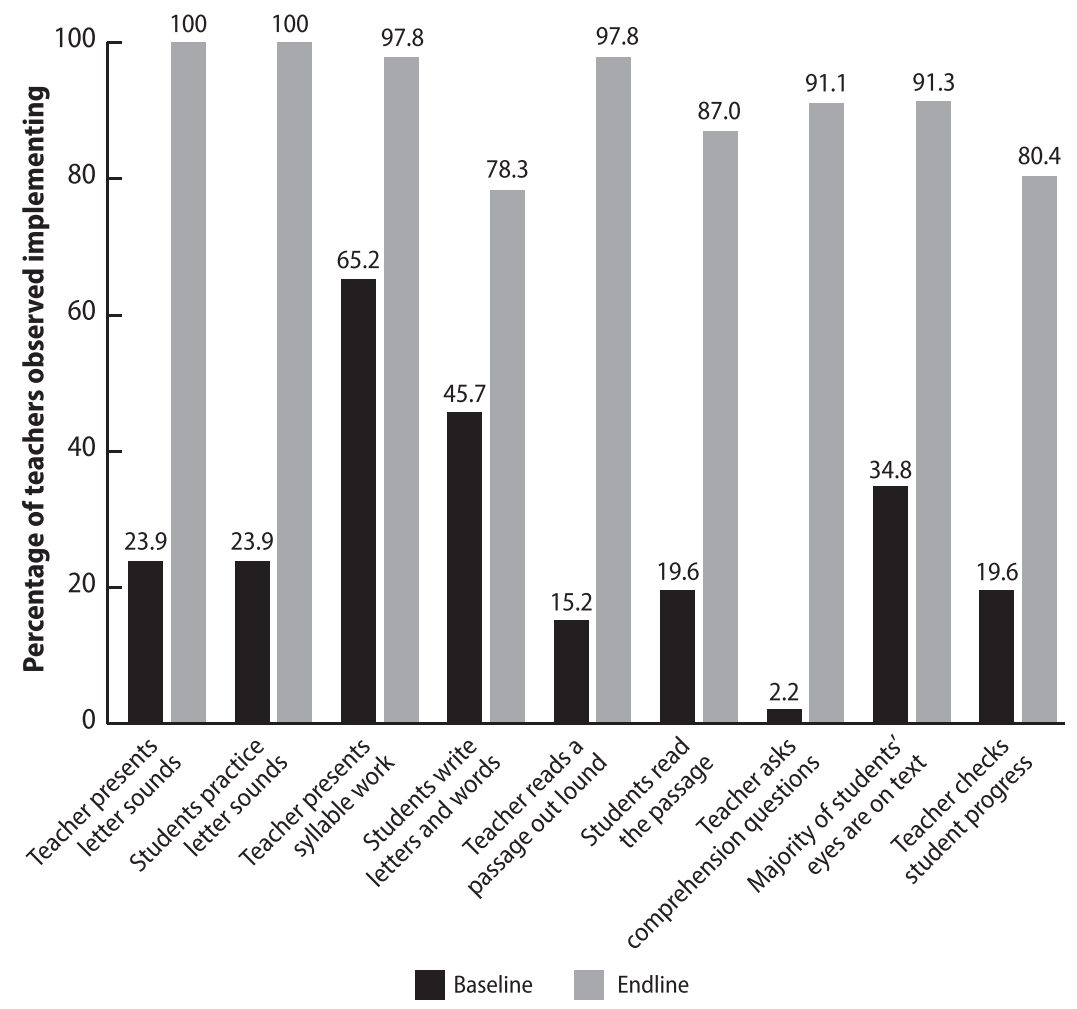

Relationships Between Coach Background Characteristics and Coaching Quality

To answer the first research question-What is the relationship between coach background and coaching quality?-we tested for associations between the coach background variables of highest academic credential and years of experience (predictor variables) and the coaching quality (outcome variable) as measured by the project staff members' and master trainers' observations of the coach-teacher visits (Table 6-5).

The coaches' academic credentials were positively associated with our measures of the quality of their performance as a coach $(p<.10)$. No other background characteristics showed a statistically significant positive association with their performance as a coach. However, greater years of experience as a head teacher was negatively associated with our measures of coaching quality $(p<.05)$. 
Table 6-5. Associations between coach background characteristics and coaching quality

\begin{tabular}{|c|c|c|c|c|c|c|c|}
\hline Predictor variable & $\begin{array}{l}\text { Outcome } \\
\text { variable }\end{array}$ & Coeff. & SE & $t$ & $p$ value & $\begin{array}{l}\text { Lower } \\
\mathrm{Cl}\end{array}$ & $\begin{array}{l}\text { Upper } \\
\mathrm{Cl}\end{array}$ \\
\hline $\begin{array}{l}\text { Coach's highest } \\
\text { academic credential }\end{array}$ & $\begin{array}{l}\text { Coaching } \\
\text { quality }\end{array}$ & 1.05 & 0.53 & 1.97 & $.06^{*}$ & -0.03 & 2.13 \\
\hline $\begin{array}{l}\text { Coach's years of } \\
\text { experience as a teacher }\end{array}$ & $\begin{array}{l}\text { Coaching } \\
\text { quality }\end{array}$ & 0.08 & 0.08 & 0.99 & .326 & -0.08 & 0.25 \\
\hline $\begin{array}{l}\text { Coach's years of } \\
\text { experience as a head } \\
\text { teacher }\end{array}$ & $\begin{array}{l}\text { Coaching } \\
\text { quality }\end{array}$ & -1.48 & 0.06 & -2.44 & $.02^{* *}$ & -2.71 & -0.026 \\
\hline $\begin{array}{l}\text { Coach's years of } \\
\text { experience as an SSO }\end{array}$ & $\begin{array}{l}\text { Coaching } \\
\text { quality }\end{array}$ & -0.09 & 0.10 & -0.87 & .39 & -0.29 & -0.12 \\
\hline Constant & & 3.66 & 2.63 & 1.39 & .17 & -1.64 & 8.97 \\
\hline
\end{tabular}

$\mathrm{Cl}=$ confidence interval; coeff. = coefficient; $\mathrm{SE}=$ standard error; $\mathrm{SSO}=$ school support officer; $t=$ the sample value of the $t$-test statistic.

${ }^{*}=p<.10,{ }^{* *}=p<.05,{ }^{* * *}=p<.01$.

Notes: $F(4,41)=5.46 ; p=.001 ; R^{2}=0.35$.

\section{Relationships Between Coach Background Characteristics and Teacher Instructional Practices}

For the second research question-What is the relationship between coach background and teacher instructional practices?-we examined associations between the coach background variables of highest academic credential and years of experience (predictor variables) and the teachers' gains in instructional practices (outcome variable), as measured by their endline score on nine practices from the classroom observation minus their score on the same practices at baseline.

The analysis found a statistically significant positive association between a coach's years of experience as a teacher $(p<.05)$, as well as having been an SSO $(p<.05)$, and their assigned teachers' adoption of the instructional practices (Table 6-6). However, neither the coaches' experience as a head teacher nor their highest academic credential showed a statistically significant association with teachers' gains in instructional practice.

\section{Relationship Between Quantity of Coach Visits and Teacher Instructional Practices}

For the third question-What is the relationship between the quantity of coach visits and teacher instructional practices? - we examined the association between the number of coach visits the teachers received and their gains in instructional practices. 
Table 6-6. Associations between coach background characteristics and teacher gains in instructional practices

\begin{tabular}{|c|c|c|c|c|c|c|c|}
\hline $\begin{array}{l}\text { Predictor } \\
\text { variable }\end{array}$ & $\begin{array}{l}\text { Outcome } \\
\text { variable }\end{array}$ & Coeff. & SE & $t$ & $p$ value & $\begin{array}{l}\text { Lower } \\
\text { CI }\end{array}$ & $\begin{array}{l}\text { Upper } \\
\text { CI }\end{array}$ \\
\hline $\begin{array}{l}\text { Coach's highest } \\
\text { academic } \\
\text { credential }\end{array}$ & Teacher gains & 0.00 & 0.22 & 0.02 & .982 & -0.45 & 0.45 \\
\hline $\begin{array}{l}\text { Coach's years of } \\
\text { experience as a } \\
\text { teacher }\end{array}$ & Teacher gains & 0.07 & 0.03 & 2.09 & $.043^{* *}$ & 0.00 & 0.14 \\
\hline $\begin{array}{l}\text { Coach's years of } \\
\text { experience as a } \\
\text { head teacher }\end{array}$ & Teacher gains & -0.03 & 0.03 & -1.04 & .303 & -0.08 & 0.03 \\
\hline $\begin{array}{l}\text { Coach's years of } \\
\text { experience as an } \\
\text { SSO }\end{array}$ & Teacher gains & 0.09 & 0.04 & 2.11 & $.041^{* *}$ & 0.00 & 0.17 \\
\hline Constant & & 1.43 & 1.10 & 1.30 & .201 & -0.79 & 3.65 \\
\hline
\end{tabular}

$\mathrm{Cl}=$ confidence interval; coeff. = coefficient; $\mathrm{SE}=$ standard error; $\mathrm{SSO}=$ school support officer; $t$ = the sample value of the $t$-test statistic.

** $=p<.05$.

Notes: $F(4,40)=1.45 ; p=.237 ; R^{2}=0.13$.

Table 6-7. Association between quantity of coach visits and teacher gains in instructional practices

\begin{tabular}{|c|c|c|c|c|c|c|c|}
\hline $\begin{array}{l}\text { Predictor } \\
\text { variable }\end{array}$ & $\begin{array}{l}\text { Outcome } \\
\text { variable }\end{array}$ & Coeff. & SE & $t$ & $p$ value & $\begin{array}{l}\text { Lower } \\
\text { CI }\end{array}$ & $\begin{array}{l}\text { Upper } \\
\mathrm{Cl}\end{array}$ \\
\hline $\begin{array}{l}\text { Number of coach visits } \\
\text { received }\end{array}$ & $\begin{array}{l}\text { Teacher } \\
\text { gains }\end{array}$ & 0.15 & 0.03 & 4.65 & $.000^{* * *}$ & 0.08 & 0.22 \\
\hline Constant & & 2.03 & 0.30 & 6.70 & $.000^{* * *}$ & 1.42 & 2.64 \\
\hline
\end{tabular}

$\mathrm{Cl}=$ confidence interval; coeff. $=$ coefficient; $\mathrm{SE}=$ standard error; $t=$ the sample value of the $t$-test statistic. **** $=p<.01$.

Notes: $F(1,43)=21.59 ; p<.01 ; R^{2}=0.33$.

The analysis found a positive association $(p<.01)$ between the two variables (Table 6-7). In other words, the more frequently a teacher was visited by his or her coach, the more likely the teacher was to adopt the new practices.

\section{Relationship Between Coaching Quality and Teacher Instructional Practices}

For the final question-What is the relationship between coaching quality and teacher instructional practices? - we tested for an association between our measures of coaching quality (predictor variable) from the staff members' 
Table 6-8. Association between coaching quality and teacher gains in instructional practices

\begin{tabular}{llllllll}
\hline $\begin{array}{l}\text { Predictor } \\
\text { variable }\end{array}$ & $\begin{array}{l}\text { Outcome } \\
\text { variable }\end{array}$ & Coeff. & SE & $\boldsymbol{t}$ & $\boldsymbol{p}$ value & $\begin{array}{l}\text { Lower } \\
\mathbf{C l}\end{array}$ & $\begin{array}{l}\text { Upper } \\
\mathbf{C l}\end{array}$ \\
\hline $\begin{array}{l}\text { Coaching } \\
\text { quality }\end{array}$ & $\begin{array}{l}\text { Teacher } \\
\text { gains }\end{array}$ & -0.10 & 0.05 & -1.85 & $.071^{*}$ & -0.21 & 0.01 \\
\hline Constant & & 3.98 & 0.37 & 10.74 & $.000^{* * *}$ & 3.24 & 4.73 \\
\hline
\end{tabular}

$\mathrm{Cl}=$ confidence interval; coeff. $=$ coefficient; $\mathrm{SE}=$ standard error; $t=$ the sample value of the $t$-test statistic.

${ }^{*}=p<.10,{ }^{* * *}=p<.01$.

Notes: $F(1,43)=3.42 ; p=.07 ; R^{2}=0.07$.

and master trainers' observations of the coach-teacher visits and the teachers' gains in instructional practices (outcome variable).

The analysis found a negative association $(p<.10)$ between the two variables (Table 6-8). In other words, a higher quality of coaching (as measured by the staff members' and master trainers' observations of the coach-teacher visits) was not associated with greater teacher adoption of the instructional practices.

\section{Discussion}

This section discusses the results presented and draws some implications for practice and further research for the use of pedagogical coaching in improving literacy instruction in similar contexts. The first part treats the first two research questions concerning the influence of the coaches' background on their performance as a coach and on changes in their assigned teachers' instructional practices. The second part addresses the third and fourth research questions about the influence of the quantity and quality of coach visits on the teachers' instructional practices.

\section{What Influence Does a Coach's Background Have on His or Her Performance as a Coach and on Teacher Behavior Change?}

In our analysis for this chapter, the coaches with higher academic credentials scored higher on our measures of coaching quality, but their academic credentials had no discernible association with their teachers' adoption of the new practices for teaching literacy. Because the pre-service teacher education program in Nigeria does not cover the same content as did the intervention's approach to literacy instruction, it is not surprising to find little association between the coaches' academic background and their ability to influence their assigned teachers' adoption of the new approach. At 
the same time, however, their higher level of education in general may have made some coaches more receptive to adopting the intervention's model of coaching, as evidenced by their better performance on our measures of coaching quality.

As for professional experience, the coaches' prior experience in a supervisory role-that is, as a head teacher or SSO-was negatively associated with our measures of coaching quality. This result may be because the role of a head teacher and SSO in this context has traditionally been more as inspector than as pedagogical coach or mentor. The protocol for the coachteacher conference included but went beyond an observation checklist for fidelity of implementation, because the coach was to elicit the teacher's input, guide the teacher to think reflectively about his or her own practice, and set specific goals for improvement. Our measures of coaching quality emphasized the "softer" aspects of collaborative rapport and reflection in coaching. As a result, our findings may reflect a situation in which coaches with years of experience in a traditional supervisory or inspectorial role were not able to easily translate that experience into the practices that we measured for quality in this model of coaching.

In contrast, the coaches' years of experience as teachers, but not as head teachers, were positively associated with changes in their teachers' practices, even though the coaches had no previous experience with the intervention's specific approach to literacy instruction. This finding suggests that the coaches' general classroom teaching experience was beneficial to their influence as a coach, and more so than their administrative experience. The coaches' years of experience as an SSO were also positively associated with changes in their teachers' practices, but not with our measures of coaching quality, suggesting that experienced SSOs were able to draw on something from their experience in the traditional SSO role to influence teacher change-perhaps the traditional, "directive" coaching style-even if those skills were not well captured by our measures of coaching quality.

Taken together, these findings suggest that coaches' academic preparation and prior experience were an asset in some ways, but not necessarily significant or advantageous in others. This finding is important because education planners in many low-resource contexts face a shortage of highly credentialed candidates to serve as literacy coaches, in terms of both their academic degrees and their professional experience. The pool of potential candidates may be further constrained by a career ladder with typical rungs going from teacher to administrator (e.g., school head) to supervisor, based 
on the assumption that only those who have ascended to the position of supervisor are qualified to serve as coaches. Our findings suggest that neither academic credentials nor previous experience as an administrator or as a supervisor is a determining factor of coaching quality. Rather, our research suggests that classroom experience as a teacher is more beneficial to the coach role than administrative experience as a head teacher.

Education planners in similar contexts may benefit from the flexibility to think beyond the traditional career trajectory for pedagogical coaches in their context and prioritize instead successful classroom teaching experience in their coach recruitment criteria. This point is in line with the International Literacy Association's recommendation that coaches have expertise in literacy pedagogy and experience teaching literacy at the relevant grade level (International Reading Association, 2004). If such expertise or experience is lacking in the available candidate pool, then the coaches will need targeted training, practice, and ongoing support ("coaching of the coaches") to help address these weaknesses.

Better understanding of the influences of pre-service preparation, pedagogical knowledge, teaching experience, and administrative and supervisory experience could help education planners recruit the candidates most disposed to becoming successful coaches, as well as tailor the coach training program to both accentuate their coaches' strengths and mitigate the potential liabilities of their background.

\section{What Is the Relative Influence of Quantity Versus Quality of Coaching Support?}

In our study, the quantity of coach visits was positively associated with teacher change, whereas our measures of coaching quality were not.

The finding that a higher number of coach visits was associated with greater teacher change is not surprising. As mentioned earlier, multiple studies have shown a similar association between the quantity of contact between coaches and teachers and changes in teacher practice.

On the other hand, our data did not reveal a positive association between our measures of coaching quality and teacher change. However, to conclude that coaching quality does not matter at all would contradict the strong literature base behind the variables that we measured as important qualities of effective coaching support. The full importance of coaching quality may have been obscured by the limitations of this study, which we discuss in the next section. 
Another possible reason that our research did not detect a relationship between coaching quality and teacher change is that the specific measures of coaching quality constructed for this study may matter less in the earlier stages of adoption of new practices than in a later stage of teacher development. As mentioned in the literature review, some experts believe that hard (or directive) coaching may be more effective at ensuring fidelity of implementation of new practices, and soft or balanced coaching may work better with more experienced teachers who are ready to strategically modify their instruction based on critical reflection (Bean, 2014). Our measure of teacher improvement was essentially a measure of fidelity of implementation to the intervention's approach to literacy instruction.

In addition, although the coaching model in this intervention contained elements of both hard and soft coaching, the variables that we used to measure coaching quality emphasized the soft aspects of rapport and reflection over the hard aspects of accountability to a set standard. In the case of our study, it may be that the coach visits served as a mechanism (and thus a proxy variable) for accountability, which was a bigger driver of change than coach rapport or teacher reflection at this stage. When teachers are first learning a new skill set, and fidelity of implementation is the priority concern, just having the coach show up may matter more than the quality of coaching itself. Once teachers have mastered the basics and are ready to be more critical, responsive, and flexible in their implementation, the soft aspects of a balanced model of coaching may take on more importance.

In the meantime, one might argue that ensuring that a coach logs a given number of visits to a teacher is easier than ensuring the quality of support the coach provides while there. Nonetheless, because the quantity of coach visits has financial implications, particularly for those implementing a coaching program at a large scale, maximizing the impact of each visit is important. Although it remains theoretically possible that higher-quality coaches can more efficiently effect change with fewer visits, this study was not able to shed light on how to do so.

Our findings suggest that education planners need to carefully consider and allow for adequate contact time for coaches to motivate and accompany teachers as they adopt new practices. However, more research is needed to determine the best cost-efficiency of a coach program for a given context, including the optimal number, timing, frequency, and duration of the coach visits. Because some teachers will require more or fewer visits than others, 
and because teachers' needs will evolve over time, a program that provides flexible and differentiated support could also increase efficiency.

In addition, if coach visits are simply a proxy for accountability to fidelity of implementation, it may be worthwhile to explore whether other means of holding teachers accountable for implementation could be more cost effective. For example, while the coaches' prior experience as a head teacher did not show any association with teacher gains in our analyses (and negative associations with our measure of coaching quality), one area for exploration is whether a head teacher, lead teacher, peer group or community of practice, members of the school-based management committee, or someone else would be able to provide on-site accountability and achieve results similar to the coach visits. Another possibility for lowering costs may be the use of technology-assisted means of communication, accountability, and support, such as Skype, SMS, social media platforms, or cameras (e.g., Bruns, Costa, \& Cunha, 2017; Duflo, Hanna, \& Ryan, 2012; Ibrahim, 2017; Jukes et al., 2016; Kipp, 2017).

\section{Limitations}

The study had several limitations that led us to interpret its conclusions with caution. Because we used data that were not originally collected for the purpose of the analyses to which we subjected them, some aspects of the data were less than ideal for answering our research questions.

First, because the sample size for the model was relatively small ( $n=40$ to 46 ), the $\mathrm{R}^{2}$ on the regression was also small, which precluded our ability to say that certain variables predicted specific outcomes. Nonetheless, due to the uniqueness of the study design and the data collected, the authors believe the findings are valuable and should be replicated with a larger study.

Second, the intervention time was relatively short (eight months). As mentioned earlier, it is possible that the particular aspects of coaching quality that we measured in this study become more significant at a later stage of teacher development, which the time frame did not allow us to see.

Third, our measures of coaching quality were our best estimate given the observation instruments used and the data collected, but they were not definitive. On one hand, coach performance was a moving target; that is, it fluctuated from one visit to the next. The staff were not able to observe every visit that the coaches made to their teachers, and there was wide variation in when and how often they did, resulting in differences in the amount and 
timing of data that we had on each coach's performance. In addition, some aspects of coaching quality that have been theorized to be high leverage were not captured by the observation instrument, including whether the coaches modeled how to do parts of the lesson or discussed assessment data with the teachers.

Finally, we did not have a record of the specific nature of the feedback that the coaches gave to each teacher, which may have played a role in teacher change that we could not capture. Further refinement of the tools for capturing the characteristics and activities of coach visits that have the biggest impact on teachers (and on student outcomes) in contexts like these is an area for future research.

Fourth, the teacher observation instrument captured whether the teachers used a given practice but not necessarily the quality or appropriateness of the activity for the students. It may be that in responsiveness to students' needs, a teacher may have purposefully diverged from strict fidelity of implementation to the lesson plan, and that this divergence ultimately resulted in better instruction (e.g., see Mattos \& Sitabkhan, 2016, for a study of such lesson plan deviations in Malawi). However, such a case would be indistinguishable on our measure of teacher gains from that of a teacher whose failure to implement a given practice was unjustified and resulted in a poorer quality of instruction.

Fifth, the study did not examine individual teacher characteristics that might have influenced teachers' uptake of the new practices or their receptiveness to coaching support, including their background characteristics or their disposition to innovation (Atteberry \& Bryk, 2011). It may be that such characteristics interact with those of coaches in complex ways that result in more or less improvement in their instruction.

In light of these limitations, the quality of coaching support and other factors may have had a greater influence on the teachers' instructional practices than our study allowed us to detect at this time.

\section{Conclusions}

In summary, using archival data from a literacy intervention in public primary schools in northern Nigeria, this chapter examined associations between the characteristics of coaching support that teachers receivedincluding the coaches' background and the quantity and quality of coach visits-and the changes in the teachers' instructional practices. 
Regression analysis showed that coaches with higher academic credentials performed significantly better on our measures of coaching quality, which were based primarily on positive coach-teacher rapport and reflective activities, but their credentials had no discernible association with their teachers' changes in practice. We also found positive associations between the coaches' years of prior experience as a teacher and as an SSO (but not as a head teacher) and changes in their assigned teachers' practices, but their prior experience in supervisory roles (as a head teacher and SSO) was negatively associated with our measures of coaching quality. Lastly, the more coach visits the teachers received, the more likely they were to adopt the new instructional practices, but we found no positive association between our measures of the quality of those visits and teacher change.

While the study was limited by a small sample size and a short intervention period, the findings suggest that, in both recruiting and training coaches, education planners need to consider how the candidates' background could both contribute to and detract from their effectiveness as a coach, and how to adjust the coach training and support accordingly. Second, the findings suggest that coach visits may serve as a form of accountability to support fidelity of implementation of new practices. Consequently, education planners need to ensure that teachers receive adequate follow-up when they are learning new practices. Although our study did not reveal a positive association between our measures of quality coaching and teacher change, the literature base nonetheless suggests that it plays an important role in teacher development. More research is needed as to how education systems in similar contexts can maximize the effectiveness of pedagogical coaching support with regard to quantity and quality within the resource constraints that they face.

\section{Acknowledgments}

The authors would like to thank Swadchet Sankey, R. Drake Warrick, Bilyaminu Inuwa, Muhammad Bello, Zahra'u Maishanu, and the rest of the Nigeria Reading and Access Research Activity (RARA) team for their leadership and support of the reading coaches and teachers who participated in the original intervention and for their willingness to respond to our inquiries for clarification on certain aspects of the project. We also extend our appreciation and admiration to the coaches and teachers for their tireless dedication to their own professional development and to improving students' learning outcomes in early grade reading. Finally, we would like to acknowledge the State Universal Basic 
Education Boards in Bauchi and Sokoto states for their support of this coaching work and in improving early grade reading generally.

\section{References}

Atteberry, A., \& Bryk, A. (2011). Analyzing teacher participation in literacy coaching activities. The Elementary School Journal, 112(2), 356-382. https://doi.org/10.1086/661994

Bean, R. M. (2009). The reading specialist: Leadership for the classroom, school, and community. New York, NY: The Guilford Press.

Bean, R. M. (2014). The power of coaching: Improving early grade reading instruction in developing countries. Report produced for the United States Agency for International Development. Silver Spring, MD: Aguirre Division of JBS International, Inc. Retrieved from http://pdf.usaid.gov/ pdf_docs/PA00JV67.pdf

Bean, R. M., Draper, J. A., Hall, V., Vandermolen, J., \& Zigmond, N. (2010). Coaches and coaching in reading first schools. The Elementary School Journal, 111(1), 87-114. https://doi.org/10.1086/653471

Biancarosa, G., Bryk, A., \& Dexter, E. (2010). Assessing the value-added effects of literacy collaborative professional development on student learning. The Elementary School Journal, 111(1), 7-34. https://doi.org/10.1086/653468

Blachowicz, C. L. Z., Obrochta, C., \& Fogelberg, E. (2005). Literacy coaching for change. Educational Leadership, 62(6), 55-58.

Blazar, D., \& Kraft, M. (2015). Exploring mechanisms of effective teacher coaching: A tale of two cohorts from a randomized experiment. Educational Evaluation and Policy Analysis, 37(4), 542-566. https://doi.org/10.3102/0162373715579487

Bruns, B., Costa, L., \& Cunha, N. (2017). Through the looking glass: Can classroom observation and coaching improve teacher performance in Brazil? (Policy Research Working Papers). Washington, DC: World Bank. https://doi.org/10.1596/1813-9450-8156

Carlisle, J. F., Cortina, K. S., \& Katz, L. A. (2011). First-grade teachers' response to three models of professional development in reading. Reading \& Writing Quarterly, 27(3), 212-238. https://doi.org/10.1080/ 10573569.2011.560482 
Coburn, C. E., \& Woulfin, S. L. (2012). Reading coaches and the relationship between policy and practice. Reading Research Quarterly, 47(1), 5-30. https://doi.org/10.1002/RRQ.008

Collet, V. S. (2012). The gradual increase of responsibility model: Coaching for teacher change. Literacy Research and Instruction, 51(1), 27-47. https://doi.org/10.1080/19388071.2010.549548

Costa, A. L., \& Garmston, R. J. (1994). Cognitive coaching: A foundation for renaissance schools. Norwood, MA: Christopher-Gordon.

Costa, A. L., \& Garmston, R. J. (2002). Cognitive coaching: A foundation for renaissance schools (2nd ed.). Norwood, MA: Christopher-Gordon.

Darling-Hammond, L. (2000). Teacher quality and student achievement: A review of state policy and evidence. Education Policy Analysis Archives, 8, 1-44. https://doi.org/10.14507/epaa.v8n1.2000

De Alba-Johnson, N. F., Rodriguez, M., Arias, L., Johnson, C. Z., McConnell, S., McEvoy, M., Horst, K., \& Passe, A. (2004, April). Is professional training enough? The effect of coaching in the practice of early literacy instruction. Paper presented at the annual meeting of the American Educational Research Association, San Diego, CA. Retrieved from http://edmeasurement.net/research/coaching.pdf

Duffy, F. M. (2003). I think, therefore I am resistant to change. Journal of Staff Development, 24(Winter), 30-36.

Duflo, E., Hanna, R., \& Ryan, S. P. (2012). Incentives work: Getting teachers to come to school. The American Economic Review, 102(4), 1241-1278.

Elish-Piper, L., \& L'Allier, S. K. (2011). Examining the relationship between literacy coaching and student reading gains in grades $\mathrm{K}-3$. The Elementary School Journal, 112(1), 83-106. https://doi.org/10.1086/660685

Frost, S., \& Bean, R. M. (2006). Qualifications for literacy coaches: The gold standard [4-page brief for Literacy Coaching Clearinghouse]. Retrieved from https://files.eric.ed.gov/fulltext/ED530335.pdf

Goe, L. (2007). The link between teacher quality and student outcomes: A research synthesis. Washington, DC: National Comprehensive Center for Teacher Quality. Retrieved from http://files.eric.ed.gov/fulltext/ ED521219.pdf 
Heineke, S. (2013). Coaching discourse: Supporting teachers' professional learning. The Elementary School Journal, 113(3), 409-433. https://doi.org/10.1086/668767

Hussain, R., \& Ali, S. (2010). Improving public school teachers in Pakistan: Challenges and opportunities. Improving Schools, 13(1), 70-80. https://doi.org/10.1177/1365480209352404

Ibrahim, M. (2017). Building a knowledge network through RANA's community of practice. Paper presented at the 61st annual meeting of the Comparative and International Education Society, Atlanta, GA.

International Reading Association. (2004). The role and qualifications of the reading coach in the United States [4-page brochure].

Newark, DE: Author. Retrieved from http://www.literacyworldwide.org/ docs/default-source/where-we-stand/reading-coach-position-statement. pdf?sf

Ippolito, J. (2010). Three ways that literacy coaches balance responsive and directive relationships with teachers. The Elementary School Journal, 111(1), 164-190.

Joyce, B., \& Showers, B. (2002). Student achievement through staff development (3rd ed.). Alexandria, VA: Association for Supervision and Curriculum Development.

Jukes, M. C. H., Turner, E. L., Dubeck, M. M., Halliday, K. E., Inyega, H. N., Wolf, S., .. Brooker, S. J. (2016). Improving literacy instruction in Kenya through teacher professional development and text messages support: A cluster randomized trial. Journal of Research on Educational Effectiveness, 10, 1-33.

Kipp, S. (2017). Low-cost, familiar tech for teacher support: Evidence from an SMS campaign for early grade teachers in Malawi. Presentation at the 61st annual meeting of the Comparative and International Education Society, Atlanta, GA.

Kise, J. A. G. (2006). Differentiated coaching: A framework for helping teachers change. Thousand Oaks, CA: Corwin.

Kraft, M. A., Blazar, D., \& Hogan, D. (2018). The effect of teacher coaching on instruction and achievement: A meta-analysis of the causal evidence. Review of Educational Research, 88(4). https://doi.org/10.3102/ 0034654318759268 
Kretlow, A. G., \& Bartholomew, C. C. (2010). Using coaching to improve the fidelity of evidence-based practices: A review of studies. Teacher Education and Special Education, 33(4), 279-299. https://doi. org/10.1177/0888406410371643

L'Allier, S. K., \& Elish-Piper, L. (2006, December). An initial examination of the effects of literacy coaching on student achievement in reading in grades $K-3$. Paper presented at the 55th Annual Meeting annual conference of the National Reading Conference, Los Angeles, CA.

L'Allier, S. K., Elish-Piper, L., \& Bean, R. M. (2010). What matters for elementary literacy coaching? Guiding principles for instructional improvement and student achievement. The Reading Teacher, 63(7), 544-554. https://doi.org/10.1598/RT.63.7.2

Mattos, M., \& Sitabkhan, Y. (2016). Malawi Early Grade Reading Activity: Scripting study report. Prepared under USAID/Malawi Contract No. AID-612-C-13-00002. Research Triangle Park, NC: RTI International. Retrieved from https://ierc-publicfiles.s3.amazonaws.com/public/resources/ Malawi_Scripting\%20Study.pdf

McCombs, J. S., \& Marsh, J. A. (2009). Lessons for boosting the effectiveness of reading coaches. Phi Delta Kappan, 90(7), 501-507. https://doi.org/10.1177/003172170909000710

McKenna, M. C. A., \& Walpole, S. (2008). The literacy coaching challenge: Models and methods for grades K-8. New York, NY: Guilford Press.

National Institute for Excellence in Teaching (NIET). (2012). Beyond " jobembedded": Ensuring that good professional development gets results. Santa Monica, CA: Author. Retrieved from http://www.niet.org/assets/PDFs/ beyond_job_embedded_professional_development.pdf

Neuman, S., \& Cunningham, L. (2009). The impact of professional development and coaching on early language and literacy instructional practices. American Educational Research Journal, 46(2), 532-566. https://doi.org/10.3102/0002831208328088

Perkins, S. J. (1998). On becoming a peer coach: Practices, identities, and beliefs of inexperienced coaches. Journal of Curriculum and Supervision, 13(3), 235-254. 
Pflepsen, A., Harden, K., Dubeck, M., Sankey, S., \& King, S. (2017). Improving early grade literacy instruction and student outcomes: Findings from a cluster randomized controlled trial in northern Nigeria. Manuscript submitted for publication.

Piper, B. (2009). Student-centered pedagogy's causal mechanisms: An explanatory mixed methods analysis of the impact of in-service teacher professional development on student and teacher outcomes in Ethiopia (Unpublished doctoral dissertation). Harvard Graduate School of Education, Cambridge, MA.

Piper, B., \& Mugenda, A. (2013). The Primary Math and Reading (PRIMR) Initiative: Midterm impact evaluation. Prepared under the USAID Education Data for Decision Making (EdData II) project, Task Order No. AID-623-M-11-00001 (RTI Task 13). Research Triangle Park, NC: RTI International. Retrieved from http://pdf.usaid.gov/pdf_docs/pdacy060.pdf

Piper, B., \& Zuilkowski, S. S. (2015). Teacher coaching in Kenya: Examining instructional support in public and nonformal schools. Teaching and Teacher Education, 47, 173-183. https://doi.org/10.1016/j.tate.2015.01.001

Piper, B., Zuilkowski, S. S., \& Mugenda, A. (2014). Improving reading outcomes in Kenya: First-year effects of the PRIMR Initiative. International Journal of Educational Development, 37, 11-21. https://doi.org/10.1016/j.ijedudev.2014.02.006

Pouezevara, S., Costello, M., \& Banda, O. (2012). Malawi teacher development support. Malawi reading intervention early grade reading assessment - final assessment. Prepared for the United States Agency for International Development under the Malawi Teacher Professional Development Support (MTPDS) project, Contract No. EDH-1-00-05-00026-02. Research Triangle Park, NC: RTI International. Retrieved from http://pdf.usaid.gov/pdf_docs/PA00JQJ4.pdf

Pouezevara, S., Pflepsen, A., Nordstrum, L., King, S., \& Gove, A. (2016). Measures of quality through classroom observation for the Sustainable Development Goals: Lessons from low- and middle-income countries. Background paper prepared for the 2016 Global Education Monitoring Report. Education for people and planet: Creating sustainable futures for all. Paris, France: UNESCO. Retrieved from http://unesdoc.unesco.org/ images/0024/002458/245841E.pdf 
Powell, D. R., Diamond, K. E., Burchinal, M. R., \& Koehler, M. J. (2010). Effects of an early literacy professional development intervention on Head Start teachers and children. Journal of Educational Psychology, 102(2), 299-312. https://doi.org/10.1037/a0017763

Printy, S. (2008). Leadership for teacher learning: A community of practice perspective. Educational Administration Quarterly, 44(2), 187-226. https://doi.org/10.1177/0013161X07312958

Quatroche, D. J., \& Wepner, S. B. (2008). Developing reading specialists as leaders: New directions for program development. Literacy Research and Instruction, 47(2), 99-115. https://doi.org/10.1080/19388070701878816

Richardson, V. (1994). Conducting research on practice. Educational Researcher, 23(5), 5-10. https://doi.org/10.3102/0013189X023005005

Ross, J. A. (1992). Teacher efficacy and the effects of coaching on student achievement. Canadian Journal of Education, 17(1), 51-65. https://doi.org/10.2307/1495395

RTI International. (2013a). Results of the early grade reading and early grade mathematics assessments (EGRA \& EGMA) in Bauchi State: Nigeria Northern Education Initiative (NEI). Prepared for USAID and Creative Associates International under Contract No. EDH-I-00-05-00026-00, Subcontract No. 778-04 RTI. Research Triangle Park, NC: Author. Retrieved from https:/globalreadingnetwork.net/eddata/northern-nigeria-educationinitiative-nei-results-early-grade-reading-and-early-grade

RTI International. (2013b). Results of the early grade reading and early grade mathematics assessments (EGRA \& EGMA) in Sokoto State: Nigeria Northern Education Initiative (NEI). Prepared for USAID and Creative Associates International under Contract No. EDH-I-00-05-00026-00, Subcontract No. 778-04 RTI. Research Triangle Park, NC: Author. Retrieved from https:// globalreadingnetwork.net/eddata/northern-nigeria-education-initiativenei-results-early-grade-reading-and-early-grade

RTI International. (2015a). Nigeria Reading and Access Research Activity (RARA): Results of the 2014 baseline data collection in government primary schools in Bauchi and Sokoto states. Prepared for USAID under the Education Data for Decision Making (EdData II project, Task Order No. AID-620-BC-14-00002, RTI Task 26). Research Triangle Park, NC: Author. Retrieved from http://pdf.usaid.gov/pdf_docs/PA00KM2J.pdf 
RTI International. (2015b). Nigeria Reading and Access Research Activity: Teacher's reflection journal [in Hausa]. Prepared for USAID under the EdData II project, Task Order No. AID-620-BC-14-00002 (RTI Task 26). Research Triangle Park, NC: Author. Retrieved from http://pdf.usaid.gov/ pdf_docs/pa00kx7v.pdf

RTI International. (2015c). Nigeria Reading and Access Research Activity: Primary 2 teacher's guide [in Hausa]. Prepared for USAID under the EdData II project, Task Order No. AID-620-BC-14-00002 (RTI Task 26). Research Triangle Park, NC: Author. Retrieved from http://pdf.usaid.gov/pdf_docs/PA00KM44.pdf

RTI International. (2015d). Nigeria Reading and Access Research Activity: Primary 2 pupil reading book [in Hausa]. Prepared for USAID under the EdData II project, Task Order No. AID-620-BC-14-00002 (RTI Task 26). Research Triangle Park, NC: Author. Retrieved from http://pdf.usaid.gov/pdf_docs/PA00KX7N.pdf

RTI International. (2015e). Nigeria Reading and Access Research Activity: Story read-aloud for primary 2 [in Hausa]. Prepared for USAID under the EdData II project, Task Order No. AID-620-BC-14-00002 (RTI Task 26). Research Triangle Park, NC: Author. Retrieved from http://pdf.usaid.gov/ pdf_docs/PA00KX7R.pdf

RTI International. (2016a). Nigeria Reading and Access Research Activity (RARA): Results of an approach to improve early grade reading in Hausa in Bauchi and Sokoto states. Prepared for USAID under the EdData II project, Task Order No. AID-620-BC-14-00002 (RTI Task 26). Research Triangle Park, NC: Author. Retrieved from http://pdf.usaid.gov/pdf_docs/ PA00KVM1.pdf

RTI International. (2016b). Nigeria Reading and Access Research Activity (RARA): Final activity report. Prepared for USAID under the EdData II project, Task Order No. AID-620-BC-14-00002 (RTI Task 26). Research Triangle Park, NC: Author. Retrieved from http://pdf.usaid.gov/pdf_docs/ PA00KVRM.pdf

Sailors, M., Hoffman, J. V., Pearson, P. D., Shin, J., \& McClung, N. (2012, November). Improving reading practices and student outcomes through Read Malawi: Challenges, opportunities and outcomes. San Diego, CA: Literacy Research Association. 
Sailors, M., \& Price, L. R. (2010). Professional development that supports the teaching of cognitive reading strategy instruction. The Elementary School Journal, 110(3), 301-322. https://doi.org/10.1086/648980

Schön, D. A. (1987). Educating the reflective practitioner: Toward a new design for teaching and learning in the professions. San Francisco, CA: Jossey-Bass.

Shidler, L. (2009). The impact of time spent coaching for teacher efficacy on student achievement. Early Childhood Education Journal, 36(5), 453-460. https://doi.org/10.1007/s10643-008-0298-4

Stover, K., Kissel, B., Haag, K., \& Shoniker, R. (2011). Differentiated coaching: Fostering reflection with teachers. The Reading Teacher, 64(7), 498-509. https://doi.org/10.1598/RT.64.7.3

Tolley, L. M., Johnson, L., \& Koszalka, T. A. (2012). An intervention study of instructional methods and student engagement in large classes in Thailand. International Journal of Educational Research, 53, 381-393. https://doi.org/10.1016/j.ijer.2012.05.003

Tschannen-Moran, M., \& McMaster, P. (2009). Sources of self-efficacy: Four professional development formats and their relationship to self-efficacy and implementation of a new teaching strategy. The Elementary School Journal, 110(2), 228-245. https://doi.org/10.1086/605771

Walpole, S., McKenna, M., Uribe-Zarain, X., \& Lamitina, D. (2010). The relationships between coaching and instruction in the primary grades. The Elementary School Journal, 111(1), 115-140. https://doi.org/10.1086/653472

Zigmond, N., Bean, R., Kloo, A., \& Brydon, M. (2010). Policy, research, and Reading First. In A. McGill-Franzen, R. L. Allington, G. Hruby, J. Elkins, P. Johnston, S. J. Samuels, ... Wilson, V. L. (Eds.), Handbook of reading disability research (pp. 464-476). New York, NY: Routledge Publishing. 


\section{Using Activity Theory to Understand Teacher Peer Learning in Indonesia}

Sarah Pouezevara, Feiny Sentosa, and Tifa Asrianti

\section{Introduction}

Improving the quality of educational outcomes depends on teachers who are ultimately responsible for translating curriculum and materials into meaningful learning for students. Yet teachers are also a diverse group of learners themselves, and how to effectively prepare teachers with the knowledge and skills they need for classroom instruction is a fundamental question in school reform movements. It is a particularly critical question in low-resource contexts, where large numbers of teachers need to be trained effectively and few resources are available. Cluster-based professional development, school-based peer learning, and continuous learning through communities of practice are attractive options for reasons of costeffectiveness, but the ability to innovate and yet ensure quality and consistency in methodological discussion is reason for hesitation.

The Prioritizing Reform, Innovation, and Opportunities for Reaching Indonesia's Teachers, Administrators, and Students (PRIORITAS) program in Indonesia was a five-year (May 2012-September 2017) partnership between the United States Agency for International Development (USAID) and the Indonesian government to improve access to high-quality education for children (from hereon, the program is referred to as USAID/ PRIORITAS). It included the following key components designed to improve student learning in reading and other subjects in primary and junior secondary school:

- a critical mass of activities to promote reading culture

- teachers engaging in study visits to "good-practice" schools

- professional development workshops with a practical focus 
- peer mentoring at school-cluster and classroom levels

- local governments and administrators committed to building demand by showcasing good practice

Routine program monitoring demonstrated improvements in classroom teaching in schools where the mentoring program was being implemented through USAID/PRIORITAS (see the midterm external evaluation, Dall et al., 2015). Among the early grade reading programs that have been supported by RTI International, USAID/PRIORITAS was recognized internally as having one of the most well-developed peer-learning models in place.

To understand more about how teachers were learning to improve their practice through peer mentoring, data were collected through interviews and school visits in August 2016. The main purpose of the case study was to understand the scope and implementation considerations of school-based and peer-to-peer approaches to teacher behavior change, with particular focus on improving reading instruction. We particularly have tried to uncover the implementation factors that influenced the possibility of success of peer mentoring in Indonesia under USAID/PRIORITAS, including issues of intrinsic and extrinsic motivation, readiness for self-directed learning, and the relative importance of the foundation laid by the preexisting schoolcluster structure described in the Methodology section.

This case study explores the methods and implementation considerations of peer-learning approaches to changing teaching practice in the Indonesian context, where cluster-based training is deeply embedded in the education system. These clusters were leveraged by USAID/PRIORITAS to disseminate professional development through a structured lesson-study approach.

\section{Literature Review}

\section{The Challenge of Teacher Preparation}

Learning to be an effective teacher in any context or subject matter is a long-term endeavor (Nir \& Bogler, 2008). Students change, curricula change, and teachers themselves change over their lifetime. As such, methods learned during teaching certification cover only a fraction of the decisions teachers need to make on the job. How to best prepare and support effective teachers is an ongoing topic of research and policy debates in developed and developing countries alike. As pointed out by Pouezevara, Pflepsen, Nordstrum, King, 
and Gove (2016), teacher characteristics such as certifications, training, and education levels have proven to be weak predictors of student learning. Yet teaching practice remains the critical link to student achievement. There is considerable consensus that isolated training events are rarely, if ever, sufficient for sustained improvements in teaching practice (Hardman et al., 2015; Knight, 2009; Organisation for Economic Co-Operation and Development [OECD], 2011; Orr et al., 2013). So how do teachers learn to be effective under changing circumstances?

Although training workshops are valuable and practical for many forms of information dissemination (introducing a program and materials, seeing examples of good practice, etc.), experience increasingly suggests that sustainable teacher learning is highly dependent on horizontal (i.e., peer-topeer), contextualized, and socially constructed transformation of existing knowledge, beliefs, and practices rather than vertical transferring of external knowledge and methods through training (Dubeck, Jukes, Brooker, Drake, \& Inyega, 2015; Hardman et al., 2009; Johnson \& Golombek, 2003; Orr et al., 2013; Popova, Evans, \& Arancibia, 2016). A systematic review by Orr et al. (2013) on methods of professional development for undertrained teachers noted that "it was the social nature of face-to-face tutorials, peer learning, workshops and in-class support that appeared to have the most positive impact" (p. 53). Broader lessons from the field of adult learning and cognitive neuroscience also point out the importance of gradual acquisition of mastery through socially situated or on-the-job learning opportunities involving practice and reflection (Feryok, 2009; Guskey, 2002; Kolb, 1984; Lave \& Wenger, 1991; Nir \& Bogler, 2008).

Adult learning, as described by the concept of "andragogy" (Knowles \& Associates, 1984) emphasizes that learning must be highly relevant and immediately applicable for adults, more so than for children. Teachers are also adults, and training needs to match their developmental stage in life as well as their level of experience (Popova, Evans, \& Arancibia, 2016). In the case of teacher professional development, this concept implies investments in a variety of activities on a continuum of contact points, from pre-service training to sustained school-based support, that integrate practice, feedback, and evaluation into a cycle of reflection and change. Beyond these activities, the transfer of training into applied classroom teaching strategies also requires many non-training inputs, including appropriate incentives, classroom resources, and accountability mechanisms (Crouch \& DeStefano, 
2015; Popova et al., 2016). Finding the most effective balance of investments is the challenge for many school systems and their funding partners.

\section{Addressing Teacher Performance Through Coaching}

Perhaps because of a lack of empirical results from formal, workshop-based learning, large-scale instructional improvement programs are increasingly turning to teacher monitoring and coaching as alternative strategies to enhance the quality of teaching and upgrade the pedagogical skills of undertrained and underqualified teachers (Nordstrum, 2013, 2015; Popova et al., 2016).

In international development contexts, a common model of teacher coaching takes the form of regional or district officials who visit schools periodically to provide coaching (see the Nigeria chapter; Pouezevara et al., 2016). Coaches are typically assigned to a set of schools in a cluster, among which they circulate to observe teaching practice. Coaches are equipped with guidelines and checklists for observing teachers and providing feedback based on what they see and hear. They collect some basic information that can be used for ongoing monitoring, and they may also facilitate peer-learning meetings for their assigned cluster. Their main function is to help teachers apply the methods and materials introduced during in-service training workshops by providing feedback in a supportive environment.

Coaching is not synonymous with "inspection" or performance evaluation. The simple act of measuring teacher behaviors in the classroom may improve accountability and even teacher presence (Glewwe \& Muralidharan, 2015; Piper \& Zuilkowski, 2015) — both of which have an impact on student learning-but it does not necessarily directly contribute to improving teaching practice (Berwick, James, \& Coye, 2003). Coaching is designed to be a more collegial activity that entails collaborative work focused on instructional change (Flaherty, 1998; Knight, 2009; Showers, 1984; Showers \& Joyce, 1996). Studies have shown that instructional coaching can be an effective way to reinforce training content, support and motivate teachers, and improve accountability and implementation, particularly in low-resource contexts where major curricular changes are being introduced (Kraft, Blazar, \& Hogan, 2017; Piper \& Zuilkowski, 2015). An evaluation of a teacher professional development program in Uganda noted that ongoing professional mentoring in the subject area after a workshop improved teachers' motivation and job satisfaction (Luigi Giussani Institute of Higher Education [LGIHE], 2016). 
On the other hand, a limitation of this approach is that the individual assigned to be the coach may not have significant prior experience as a teacher or be well versed in the content or pedagogy that is being observed, and therefore investments in this model need to address coach professional development (Hardman et al., 2009; Pflepsen, Harden, Dubeck, Sankey, \& King, 2017). Furthermore, despite positive evidence that coaching can work in low-income countries, it has usually been in the context of external funding support for coach transportation, and there is not yet evidence that education systems can sustain these processes at levels sufficient to influence teacher change.

Even where sources of funding are available, it is not always possible to mobilize the human resources needed to visit every school and provide coaching to every teacher more than once per term. Piper and Zuilkowski (2015) and Knight (2012) agreed that a ratio of 10 to 15 teachers per coach per year is desirable in terms of costs and quality, and the systematic review of teacher training by Orr et al. (2013) noted that successful support programs engaged teachers regularly_as much as once every two weeks. Otherwise, limited detailed financial analysis has been published to date regarding the cost of coaching in international cooperation projects, and determining costs in other contexts has proven difficult due to variations in coaching implementation and a variety of hidden and opportunity costs to consider (Knight, 2012; Orr et al., 2013).

\section{Peer Coaching}

Because of the cost constraints to instructional coaching by a regional or cluster-based expert, local peer coaching ${ }^{1}$ within and between schools and permanent school-based subject-matter experts are forms of coaching that are also being used. A typical peer coaching model in any country might be designed to resemble the following: Within a school and cluster, teachers plan to meet regularly to demonstrate and discuss teaching experiences, share

\footnotetext{
1 For the purposes of this case study, we use the terms "coaching" and "mentoring" synonymously to broadly describe a process of supporting development of professional mastery through observation and reflection among two or more individuals in the same discipline. "Peers" are people in a similar functional role, with approximately the same amount of experience and authority. We define "school-based coaching" as any activities in which regular school staff-teachers, head teachers, administrators-engage in activities that aim to improve teaching and learning. It is distinguished from "external coaching," which is when an individual from the district, region, project, or other entity visits periodically to engage in activities that aim to improve teaching and learning.
} 
successes, discuss challenges they are facing, and collaboratively work to address those challenges and improve practice. A mentor or other advisor may also attend to help address challenges, introduce innovations, and share lessons among the peer groups in different clusters.

In some cases, once implementation of new approaches has begun, teachers who demonstrate mastery are identified as master teachers or model teachers. They may be asked to support other teachers in various ways, depending on what is feasible. For example, they can play a larger role in in-school or cluster meetings; other teachers can come to observe their lessons; they can be video-recorded so other teachers can see a good teaching model without having to attend "live"; or they can observe other teachers in their classrooms and provide feedback.

Again, these are generic models, and many variations or combinations of peer-learning approaches have been used. For example, in a study in Tanzania (Hardman et al., 2015), teachers began with a face-to-face workshop and then continued their school-based learning using self-directed learning materials and peer collaboration. In an experience in Bangladesh (Pouezevara $\&$ Khan, 2007), researchers converted a face-to-face workshop to distancelearning format, integrating weekly conference calls with a remote coach. This model encouraged situated learning through the weekly process of group review of course materials, conversations with the remote tutor, and implementation and observation of each other's lessons, ending with group reflection on the practice.

There is evidence from high- and low-income countries that school-based peer learning can be effective. Researchers at the Brookings Institution (Winthrop, McGivney, Williams, \& Shankar, 2016), studying major educational reforms around the world, found that 78 percent of the innovations aimed to improve teaching through teacher training; however, they found "the most promising innovations went about this [improving teaching through teacher training] by improving collaboration and peer learning between teachers" (p. 41). The OECD study (2011) linked opportunities for peer planning, mentoring, and research to high-performing education systems. Haßler, Hennessy, Cross, Chileshe, and Machiko (2015) referred to an "established body of research [showing] that learners can gain valuable insights from peers' perspectives when required to express and explain their ideas to other learners who may disagree, requiring further thinking by all as they formulate, articulate, explain and self-evaluate their responses" (p. 808). 
These findings corroborate theories of learning and cognitive development that stress the way in which learners (adults and children) achieve optimal levels of performance when they are provided with appropriately tailored contextual supports, such as familiar materials, practice, interaction, and reflection (Knight \& Sutton, 2004; Kolb, 1984).

The evidence does not imply that peer learning is easy to implement, however. The constraints to cascade training by peers at the school level in Kenya were well documented by Hardman and colleagues (2009). In a review of a peer-learning program in Tanzania (Hardman et al., 2009), education stakeholders were in favor of scaling up the model nationally and devolving ownership to decentralized levels, including schools. Yet they recognized that this initiative would require providing incentives for those teachers and teacher educators who took part in the training and, as such, also devolving "powers, responsibilities and resources to local government authorities" (p. 618). Finding the key drivers of success and sustainability will be critical for expanding these models elsewhere. A particular barrier or risk to peer mentoring, as noted previously, is the lack of qualified experts to serve in this role (Gove, Korda Poole, \& Piper, 2017; Orr et al., 2013); in other words, can teachers really learn from other teachers who have little experience or no more experience than they do?

One area that may influence the adoption of a continuous culture of peer learning-especially one in which the learners are responsible for planning and implementing the learning opportunities-is teachers' motivation and readiness to engage in this type of professional development model. Costa and Kallick (2004) described three major categories of readiness for self-directed learning that individuals must be capable of.

- Self-managing: Able to proactively initiate actions; maintain an internal locus of control; draw from prior knowledge and intuition to guide actions; manage time effectively.

- Self-monitoring: Able to understand oneself in relation to others; able to seek alternative perspectives; aware of gaps in knowledge and able to self-evaluate and correct.

- Self-modifying: Seeks feedback and thoughtfully acts on it; learns from reflecting on experience; can identify appropriate sources of feedback; is a lifelong learner. 
These skills may not be fostered in contexts where teacher-centered learning and hierarchical power dynamics are the norm. Consideration of teachers' readiness to engage in professional development, and the types of learning opportunities they find most effective, are underreported-if they are taken into consideration at all-in international development cooperation. More research on the preconditions and implementation considerations of peer-learning models is needed. Having more such evidence would begin to address the limitations of traditional instructional coaching models and would help introduce sustainable, ongoing professional development for teachers.

In Indonesia, school clusters have long served as a resource for in-service professional development opportunities. Recently, a new model of lesson study and peer learning was used to introduce and disseminate new teaching content and methods. By studying this model, we hope to find key drivers of success and sustainability that can inform other contexts as well.

\section{Methodology}

\section{Study Design and Research Questions}

We used an explanatory case study methodology (Yin, 2003), in which we set out to explore the presumed causal links between peer learning and changes in teaching practice, to document what peer mentoring approaches looked like in this context, and to find what motivated and enabled teachers to participate (or prevented them from participating) in peer-learning events and then use that learning to improve their practice. Data were primarily gathered from in-depth interviews and focus groups with teachers, school administrators, and district leadership. Qualitative research in this context was appropriate because the topic concerned multiple and varied interactions among individuals who were part of a complex system. Describing both how and why the system functioned as it did, and exploring how teachers were influenced in their professional behaviors, required a method that allowed for probing the meaning behind quantifiable survey responses.

More importantly, however, efforts to understand and improve support for teacher behavior change would have been incomplete, at best, and irrelevant, at worst, without including teachers' own voices (Jessop \& Penny, 1998). A quantitative tool-a self-administered questionnaire concerning individual attitudes toward self-directed learning behaviors-was piloted to determine its relevance for gathering more standardized and quantifiable information 
from respondents and to triangulate with interpretations from the qualitative interviews.

In this context, this study set out to answer the following questions:

1. To what extent do teachers see peer learning as an opportunity for improving their professional practice?

2. What motivates teachers to spend time and effort working with other teachers to improve practice?

3. How do cluster/community-of-practice activities among teachers influence teaching practice, generally, and the adoption of new methods, specifically?

The schools and teachers visited made up a convenience sample drawn from two regions on the main island of Java. The sample represented primary and junior secondary schools designated by USAID/PRIORITAS and district officials as high-performing schools that had been demonstrating good practice in teaching and learning, school-based management, and peer learning, such that they were labeled as good-practice schools. These schools were often visited by international researchers or representatives from other schools who were learning about school reform efforts, and as such there was an established expectation of high performance at these schools. Setting the boundaries of the study to encompass effective schools, as defined by these model schools, was expected to help describe functioning peer-learning models and the factors that enabled them to persist.

\section{Background and Context}

\section{Teacher Professional Development in Indonesia}

In Indonesia, the history of peer coaching through school clusters dates back as early as 1979 when the school cluster, known locally as a gugus, was introduced through a project supported by the British Council and the University of London aiming to improve classroom teaching through the sharing of good practices among schools (Jalal et al., 2009). A gugus usually consists of 5-10 schools in the same area. One school, usually designated as the "best" one, serves as a core school and the others are called satellite schools.

Since its introduction, the gugus structure has continued to be an important source of disseminating policy and practice through cascade training and coaching models under projects such as Better Education 
Through Reformed Management and Universal Teacher Upgrading, sponsored by the World Bank, 2007-2013; More Effective Decentralized Education Management and Governance (DBE1 and DBE2), USAID, 2005-2011; and USAID/PRIORITAS, among others. Implemented largely between 1999 and 2001, the decentralization gave local levels of government and schools more resources and authority for education service delivery. One early example of education decentralization was the mandate, now known as the Local Content Curriculum program, to allocate 20 percent of curricular time to topics of local relevance and allow teachers to experiment with designing lesson content within the time block (Bjork, 2003).

Before 2005, individuals were required to have only a high school diploma to become a teacher; however, the 2005 Teacher Law mandated that teachers have a four-year degree and a teaching certificate (Tanang \& Abu, 2014). By 2012, the number of certified teachers had increased to 63 percent, compared with 23 percent in 2005, due to the law and the increased salary allocated to teachers who upgraded their skills accordingly (Chang et al., 2013). The 2005 law articulated high expectations for teachers in what they should bring to the profession (e.g., moral character, integrity) and what they should accomplish in the classroom; in turn, it also articulated strong commitment by the government of Indonesia to support teachers to achieve those ambitious goals, including through continuing professional development as a right and responsibility of the government (Tanang \& Abu, 2014).

Through the pre-service system, teachers are certified after four to five years of study for a bachelor's degree followed by a one-year certification program through a teacher-training college or university. The colleges are usually associated with a "lab school" financed by the college. The laboratory school staff receives training and then supports student teachers and implements new innovations, as needed. The laboratory school becomes a reference school for good practice in certain disciplines. Student teachers conduct lessons through guided and then independent teaching with a mentor teacher, who receives a small allowance from the college. The student teachers also support administration and extracurricular activities. Practicum in the school setting usually lasts two to three months. The university-based pre-service curriculum also includes microteaching (i.e., simulated teaching with "teacher" and 
"student" role-playing), classroom observations, research, and community service.

Although pre-service training is clearly the responsibility of accredited teacher-training institutes and universities, donor projects or the central ministry have traditionally financed in-service continuous professional development (CPD), and, therefore, as decentralization has moved responsibility to districts, these entities have had to assume a greater role in CPD and quality control (Jalal et al., 2009). As such, CPD has traditionally been part of each district's five-year strategic plan and subsequent annual plans, including budgets. However, a study completed under USAID/ PRIORITAS (Healey, 2016) found that per-teacher budgeting for CPD varied widely and was not necessarily based on a sound explanation of how the money would be used to address identified needs. Yet the same report recognized that the model of funding CPD through a mix of district, school, and individual teacher sources was unique and had significant potential to spread innovation. Another study also found that teacher participation in professional development clusters was positively correlated to teacher attendance in school in some districts (Universitas Cenderawasih [UNCEN] et al., 2012).

\section{USAID/PRIORITAS and the Lesson-Study Model}

USAID/PRIORITAS supported teachers' CPD by leveraging the historically embedded gugus mentoring system with a combination of project-, district-, and school-level funding. Across Indonesia, cluster meetings among teachers from different primary schools (generally fewer than 10 schools per cluster) became known by the initials KKG from the Bahasa Indonesian kelompok kerja guru, or "teachers' working group." At the junior secondary and secondary school level, the cluster meetings were called MGMP, from musyawarah guru mata pelajaran, meaning "subject teachers' working group," because there were separate meetings for each subject area. The terms KKG and MGMP also could describe informal school-level (sekolah) meetings of teachers within the same school.

USAID/PRIORITAS operated in 93 districts (known as partner districts made up of partner schools) to support CPD. The project provided master training to trainers-known as district facilitators-who were recruited by the project from among teachers (and sometimes head teachers and school supervisors). The training and mentoring model happened in three parts 
according to a specific curriculum ${ }^{2}$ over four to six weeks, known as "Plan, Do, See." The curriculum content was designed through USAID/PRIORITAS and delivered through the KKG/MGMP system. Through this process, teachers decided upon the lesson content based on the material from the project training and jointly planned a lesson specific to their classroom; the planning activities occurred at the first and sometimes second KKG/MGMP meeting. The "Do" component took place in the classroom, when teachers implemented the lesson and observed fellow teachers.

Finally, for "See," they observed other teachers, reflected on their own teaching, and gave feedback on their observations at the next KKG/MGMP meeting. This model was adapted from the Japanese model of "lesson study" among teachers (Chung Wei, Darling-Hammond, Andree, Richardson, \& Orphanos, 2009; Yoshida, 1999), which also was adopted recently in Zambia, resulting in 12 percent to 20 percent higher pass rates among students in certain subjects in one province that implemented the model (Winthrop et al., 2016).

Generally speaking, although project-led training happened during some scheduled KKG/MGMP meetings, not all meetings were for the purpose of project-sponsored activities. District education officers participated in preparing the KKG/MGMP meeting schedules and attended some meetings, but usually the school principal from the core school within the school cluster served as the organizer. Teachers were expected to participate in continuing professional development events, and each teacher's salary included a stipend for doing so. They were able to use this money or school budgets to contribute to KKG/MGMP meeting organization. The district education office also supported teachers to take the initiative to complete classroom action research. Teachers who published their action research in the district journal were given professional development credits toward promotions. USAID/ PRIORITAS partner schools that demonstrated good teaching practices during lesson observations were labeled as "good-practice schools" by the program, a designation that became a recognized standard. They were invited to district, provincial, and-in some cases-national good-practice showcases, and participants received a stipend and honorarium.

2 In general, there were three parts to a cycle, but sometimes the format varied among districts or even clusters. The first cycle often needed an additional "plan" or "gather" that included establishing a schedule and deciding on lesson content. The cycle also was sometimes referred to as "planning, implementing, improving, reflection." The curriculum covered, for example, active pedagogy, use of leveled reading books, and subject-matter content. 


\section{Methods and Instruments}

\section{Interviews and Focus Groups}

Most data were collected over a period of two weeks (six days of data collection) through individual and focus group interview questions developed along three main lines of inquiry: peer-group functioning, accountability and incentives, and knowledge transfer, as shown in Table 7-1. These lines of inquiry were developed based on key barriers to peer learning as found in the literature. The study aimed to understand how these barriers were overcome in Indonesia.

In total, 12 focus groups were held with 75 individuals (47 female and 28 male) comprising mostly teachers, but also some school principals and district facilitators in separate groups. Separate interviews with key informants included project staff and district education office officials. Most of the interviews were conducted in Bahasa Indonesia, with simultaneous

\section{Table 7-1. Themes of focus group questions}

\begin{tabular}{|c|c|}
\hline Theme & Areas of questions and prompts \\
\hline \multirow[t]{3}{*}{$\begin{array}{l}\text { 1. Peer-group } \\
\text { functioning }\end{array}$} & $\begin{array}{l}\text { How do peer groups function? What do they do (lesson study, viewing } \\
\text { videos, etc.)? How do they approach problem solving if there is a } \\
\text { challenge none of the members has experience with? }\end{array}$ \\
\hline & $\begin{array}{l}\text { How do peer groups [self-]organize? (When, where, how long, who pays } \\
\text { for transport, etc.?) Who leads the activities, and are there characteristics } \\
\text { of teachers who can be instructional leaders? }\end{array}$ \\
\hline & What do teachers perceive as most helpful and why? \\
\hline \multirow[t]{3}{*}{$\begin{array}{l}\text { 2. Accountability } \\
\text { and incentives }\end{array}$} & $\begin{array}{l}\text { What motivates teachers to participate in peer groups? What motivates } \\
\text { them to improve their teaching as a result of peer-group activities? }\end{array}$ \\
\hline & $\begin{array}{l}\text { How often can teachers be reasonably expected to participate in } \\
\text { peer-group activities? What are the trade-offs? }\end{array}$ \\
\hline & $\begin{array}{l}\text { Who is monitoring whether teachers participate in peer-learning activities? } \\
\text { Who is responsible for monitoring quality of teaching in general? }\end{array}$ \\
\hline \multirow{5}{*}{$\begin{array}{l}\text { 3. Transfer of } \\
\text { knowledge in } \\
\text { the classroom }\end{array}$} & $\begin{array}{l}\text { What specific instructional strategies have been transferred or developed } \\
\text { through peer-group activities? }\end{array}$ \\
\hline & $\begin{array}{l}\text { Are there some activities or methods that are communicated better } \\
\text { through traditional training versus those that can be communicated } \\
\text { through peer learning? }\end{array}$ \\
\hline & $\begin{array}{l}\text { Have teachers been able to observe changes in student learning } \\
\text { outcomes as a result of their own changes in behavior? If so, what were } \\
\text { the observable outcomes? }\end{array}$ \\
\hline & What other social benefits emerge from learning from other teachers? \\
\hline & $\begin{array}{l}\text { Do certain teachers/schools benefit more than others from this kind of } \\
\text { approach (e.g., rural schools, women, new teachers)? }\end{array}$ \\
\hline
\end{tabular}


interpretation by an Indonesian staff member of the project (who is also a coauthor of this chapter).

After each focus group, the researcher and interpreter discussed the overall mood and sentiments expressed by the participants, noting any problematic questions that might need reformulating, or surprising answers that might need follow-up or corroboration in subsequent focus group meetings. The meetings were not recorded, but notes were transcribed as directly as possible during interpretation. To the extent possible, the note-taker associated each comment with a particular person. Responses to each question were coded by the lead author, tabulated, and grouped according to the themes presented in Table 7-1 and subthemes that emerged during the interviews. In the end, 38 total individual records were associated with a coded comment. Comments that were not associated with an individual were regrouped by school level only. The next step was analysis, in which we looked for patterns and frequency of responses. Qualitative analysis software was used for this purpose, but, because the notes represented a translation of the focus groups, detailed discourse analysis or text mining was not done.

The lead author conducted the analysis of the focus group notes and prepared the initial draft of the case study; subsequently, preparation of this chapter then involved an additional layer of technical review of the study findings by all the authors, including further verification of local context and application of project knowledge.

Self-administered questionnaire. A self-administered questionnaire was used to gather some standardized data related to teacher characteristics (age, position, experience, etc.) along with the attitudes toward and readiness for self-directed learning. Binary-response questions were developed to determine whether teachers who participated in the focus groups would express attitudes in alignment with Costa and Kallick's (2004) characteristics of self-directed learning readiness. Six questions targeted each of the three categories (i.e., 18 questions in all): self-managing, self-monitoring, and self-modifying. The following adaptations were made to the teacher questionnaire in this regard.

- Self-managing: Asked about who was responsible for deciding whether learning was needed and how/where/when to engage in it.

- Self-monitoring: Probed whether the individual engaged in monitoring learning had confidence in deciding what improvement consisted of, had 
strategies for seeking improvement advice, and knew the role of the mentor.

- Self-modifying: Queried willingness to change throughout one's career, willingness to be mentored and to be a mentor, and belief that learning can be of practical use.

The questionnaire was translated into Bahasa Indonesia, the local language, and teachers filled out this questionnaire on paper before the focus group session. We considered it unlikely that the questionnaire affected the focus group responses as much as the focus group would have "primed" the responses to the questionnaire if it had been administered in the reverse order.

The binary answers to the self-directed questionnaire were recorded on a spreadsheet, and basic descriptive statistics were tabulated by noting whether the response agreed or disagreed with the response expected of someone with a positive attitude toward self-directed learning. Further analysis was done in Stata, including factor analysis to discern whether there were patterns related to age or gender. One item from an opposite-question pair ("I need someone to tell me how to improve," which was paired with "I know how to identify my weaknesses") was eliminated because it had highly unexpected results, and several people did not answer or changed their answer. It is likely that the "how to improve" item was worded unclearly so that the two responses did not seem opposites of the same construct; in fact, this item in an earlier draft of the questionnaire was stated as "I need someone to tell me what to improve."

Although this binary-response questionnaire format has been used with teachers in other contexts, with reliable results (RTI International, 2014), the amount of time allotted was insufficient for a pre-pilot of this particular adaptation before implementation in Indonesia; therefore, this experience was considered the pilot and was used only as an extension of the qualitative findings. Further research needs to be done to determine whether the questionnaire was a reliable and valid measurement of these constructs.

\section{Analytical Framework}

Because teacher professional learning, and particularly peer learning, is a highly social endeavor, Cultural-Historical Activity Theory (most commonly known as Activity Theory) was used for interpreting the results. Activity 
Theory is a framework for analyzing individual and group actions and is often used for understanding participant activity in educational settings (Sullivan \& Lucas, 2001). As a descriptive tool, it emphasizes broader connections and tensions within systems as grounded in the history of that particular practice.

Activity Theory originates from the work of Vygotsky (1978) and Leont'ev (1981), who first concretized the idea that all actions are socially constructed and mediated by cultural artifacts. Leont'ev was responsible for a second generation of the theory, which took into consideration individual activities in relation to collective action. Engeström (2001) subsequently visualized this system with a pyramid diagram (see Figure 7-1) and used it to describe the concept of "expansive learning." Expansive learning applies Activity Theory to complex learning processes, recognizing that the object of learning (for example, learning how to teach) is often a "moving target" (p. 136) for which there is no fully competent teacher.

Beyond functioning as an analytical framework for describing activity systems, Activity Theory also helps identify parts of the system-especially contradictions or structural tensions-that may be a source of the

\section{Figure 7-1. Overview of an activity system}

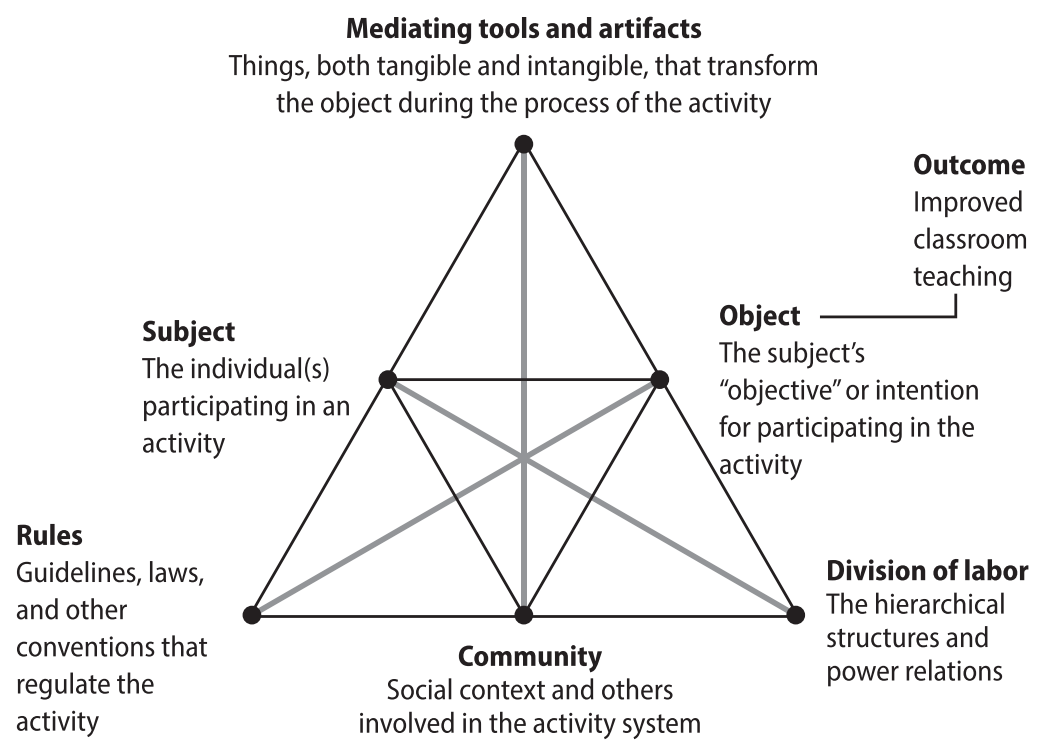


transformation or materialization of the object, as summarized by the following five principles (Engeström, 2001):

1. Individual and group actions are understandable only when interpreted against the background of the entire activity system.

2. Activity systems always consist of multiple points of view and layers of history, rules, and conventions.

3. Activity systems are shaped over time by their own histories, which also need to be analyzed in depth.

4. Contradictions, or "historically accumulating structural tensions," (p. 137) are a source of change-for example, when a new innovation is introduced into the activity system.

5. As a result of contradictions, individuals may deviate from the norms and begin to transform the activity system.

Activity Theory has previously been used to describe teachers' professional learning. For example, Feryok (2009) described an activity system in which teachers in Malaysia used imitation of a teaching process to learn new teaching strategies; the analysis led to a better understanding of learners' conceptual gaps and identification of areas for improvement. Junor Clarke and Fournillier (2012) analyzed multiple intersecting systems (known as "third generation" Cultural-Historical Activity Theory) to analyze a teacher education program for secondary mathematics teachers in the United States, accounting for how various policies and standards affected teaching and learning processes. In this example, pre-service teachers were the subject of one activity system and teacher educators the subject of another system. The objects of the two systems intersected at their shared goal of developing mathematics teachers. Activity Theory enabled Junor Clarke and Fournillier to evaluate their teacher preparation program and identify issues, which resulted in a total curriculum redesign.

Song and Kim (2016) used Activity Theory to describe how the working environment affected motivation of English-language teachers in Singapore and to describe the strategies they used to mediate their own demotivation. One conclusion they reached through the Activity Theory perspective was that teachers' motivation levels changed over time as the internal and external factors that influenced them were also changing. In response, they recommended more ongoing training and opportunities for group discussion with the community about the teachers' role. 
For this chapter, the activity system under investigation was the Indonesian CPD system and, more precisely, the subsystem of KKG and MGMP meetings as they evolved throughout their history of policy formulation and international cooperation, as described previously. Although we inquired about, and teachers discussed, instances of spontaneous and informal meetings among teachers at school level, unless otherwise specified, this chapter reports only on formally scheduled peer-learning opportunities, whether in one school or between schools. The participating teachers were the subjects, and their participation in peer learning was the object, with the intended outcome of participation being improved teaching practice.

\section{Findings}

The findings from the focus group discussions are discussed in this section according to the three primary lines of inquiry described in Table 7-1 (which are aligned with the research questions). This section discusses the findings in terms of the Activity Theory framework and the interplay among various nodes of the system. The descriptions represent recurring themes and common responses to focus group questions across the sample. Because of the sampling strategy, they cannot be considered representative of the attitudes, beliefs, and practices of all teachers in Indonesia; however, they paint a picture of how teachers and other education stakeholders described the process of peer learning and some of the benefits and challenges they experienced.

\section{Peer-Group Functioning}

Most KKGs/MGMPs met at least monthly to discuss the USAID/PRIORITAS content and to engage in the lesson study (i.e., "Plan, Do, See" mentoring program), but some clusters and schools met weekly to discuss issues more specific to their school or subject area. Teachers who were trained by USAID/PRIORITAS were expected to share lessons learned with their peers, for example, on a Saturday. Some teachers explained that Saturdays were also used to discuss issues that the principal brought up as a result of regular classroom observations and school-based quality control. The MGMPs allocated specific weekdays for subject-matter meetings. On this day, subject teachers had no scheduled classes so they could engage in cluster meetings or school-based lesson planning, but the frequency and subject matter were left up to the members of the subdistrict cluster to coordinate. 
Teachers were also able to draw on the school budget to cover transportation to attend the meetings. Funds for the KKG meetings were incorporated into the school budget, and district education officers were often involved in planning the cluster schedule and agendas as part of the KKG subdistrict organizing committee.

The content covered could be related to the USAID/PRIORITAS training topics or topics of interest to the teachers depending on the day-for example, making lesson plans, making teaching media, or learning strategies for preparing students for exams. The choice of meeting facilitator depended on the topic and whether a subject-matter expert had been formally invited. The content that teachers found most valuable in the KKG/MGMP meetings was not specific to a particular subject but was rather any topic of relevance: teachers were motivated to participate in the meetings when they knew the content would be new, relevant to their classroom, and immediately applicable.

Meetings were considered successful if participants were engaged and could practice concepts, and specifically if the facilitator or resource person did not do all the talking. Simulations (microteaching), in which one teacher taught while the others pretended to be students, were considered highly successful; the "teacher" received feedback from the "students" and the mentor on the teaching methods. The process of microteaching and providing feedback was part of the USAID/PRIORITAS training curriculum.

In the focus group sessions, Indonesian teachers expressed that, when they had questions about teaching or needed new ideas, they turned to sources such as the Internet, books, or the community (for example, a museum or local event). They also said they would ask an experienced fellow teacher from the same or a different school-for example, another good-practice school or one with a reputation for excellence. In many instances, district facilitators served this role as the resource person. They trained the teachers; they facilitated the KKG/MGMP meetings; and they, along with other teachers, observed teachers and provided feedback. Teachers noted that they could also occasionally use the budget to invite a guest expert to the KKG or MGMP meetings.

When asked what was the most important characteristic in a mentor or someone from whom they could learn, these teachers answered experience; teachers looked toward other teachers or mentors who had experience and demonstrated evidence of positive classroom outcomes. When they chose to 
turn to a fellow teacher, they explained, they did so because it was someone whose pupils demonstrated positive achievement and engagement. Ideas about who could be a good mentor or resource person were probed specifically because lack of talent or local expertise can be a barrier or risk to implementing school-based approaches, as noted by the literature. Lack of knowledgeable mentors was identified as a barrier to school-based learning, among others, in previous projects in Liberia (Gove et al., 2017), as well as in Ghana and Malawi (as reported in the systematic review by Orr et al., 2013).

\section{Accountability, Incentives, and Motivation}

In the schools visited, the principals and school supervisors were cited as being responsible for monitoring the quality of teaching and learning, suggesting training topics, and ensuring that teachers were participating in CPD. ${ }^{3}$ From school to school, the requirement to attend KKG and MGMP meetings varied; in most cases, however, the meetings were described as voluntary but with strong incentives to participate. For example, some schools provided financial compensation such as transport for their teachers to attend these meetings; as part of USAID/PRIORITAS, teachers were requested and expected to attend KKG/MGMP meetings (and principals to attend their own working group) if they were part of the project-supported schools, but only the district facilitators were given a transport allowance for this task.

Focus group responses that indicated why teachers participated in clusterand school-based peer learning were coded as either intrinsically or extrinsically motivated. The reasons teachers gave that were classified as intrinsically motivated all pointed to the desire to fill an identified need for improving classroom instruction for the benefit of the students. In fact, some teachers said they were responding to demand by students to make teaching more active and engaging, especially if the students had seen other teachers in the same school doing so.

Others mentioned keeping up with other schools in the region and maintaining their status as a good-practice school, so a spirit of friendly

\footnotetext{
3 One of the school principals' standard responsibilities in Indonesia is to help improve teaching and learning quality through teacher observations within their own school. In schools supported by USAID/PRIORITAS, principals were trained to observe classrooms both informally and formally. School supervisors were assigned by the district education officer to "supervise" several schools-10-15 primary schools and 7-15 junior secondary schools per supervisor. Supervisors were responsible for both academic and managerial development of the teachers and principals in the schools within their purview.
} 
competition and school pride were considered intrinsic motivations to participate in the peer-group meetings. One teacher even described social pressure to participate in cluster meetings, saying a teacher who refused could be isolated from the others. Even beyond the learning experience, some teachers expressed that the KKG meetings were a social opportunity to make new friends and to take a break from the routine of teaching and learning. The most common reason given for not participating in peer-group meetings was conflicting events. Some teachers also mentioned that older teachers who were close to retirement were often unwilling to change and therefore unmotivated to participate.

The responses that were coded as extrinsic motivation were fewer than those coded as intrinsic but no less important to understanding the system. These responses included a school or district requirement to participate; sanctions for not participating; immediate monetary incentives (in the form of transportation allowances); and points that could be applied to promotion and later salary increases.

A related question, examined through the self-directed questionnaire described previously, was whether it was necessary for teachers to be selfmotivated to effectively implement a peer-learning model. Most of the respondents expressed positive attitudes toward self-directed learning through this questionnaire and sometimes indirectly during focus group meetings. All respondents (100 percent) answered positively one question out of the 18 total: "I feel comfortable receiving criticism or feedback." For all the other questions, the percentages ranged from 50 percent to 99 percent agreement. The highest average levels of positive attitudes were for the category "self-modifying," and the lowest were for "self-managing," even after the ambiguous item from a question pair was eliminated (as described previously). Learning how to give and receive constructive feedback, and practicing this during observations and microteaching, was always part of the USAID/PRIORITAS mentoring program, which may explain the positive responses from informants on this question.

\section{Transfer of Knowledge in the Classroom}

Participating in training does not automatically mean that the skills taught will be transferred in the classroom (Showers, 1984). An important question explored was whether it was easier to transfer training concepts to classroom teaching when the training happened in the school, or at least very close (in 
time and distance) to when teaching happened, as is the case for peerlearning models. Responses suggested that teachers were eager for new information about teaching, and when cluster meetings provided relevant new knowledge and insights, teachers welcomed transferring that knowledge to the classroom immediately. More importantly, however, Indonesian teachers attributed their motivation to apply learning in the classroom to the observed effect that it had on children's engagement and achievement. If peers in their school or other schools could attest to positive changes in the classroom, other teachers were willing to try the methods; this was the kind of quality and relevance that teachers looked for in peer learning opportunities, as opposed to theoretical lectures only.

Teachers did observe changes in students' levels of engagement and achievement as a result of implementing the new methods from the cluster meetings. Specific changes that they saw were that students were more active, asked more questions, and worked collaboratively more often (all topics covered by USAID/PRIORITAS training modules delivered through cluster meetings). These behaviors were also cited as motivation for the teachers to continue to improve, share their successes with others, and continue engaging in the cluster meetings, despite the time it took.

According to these teachers, the type of content that they applied in the classroom after peer-group meetings tended to be related to general pedagogy rather than specific to subject. For example, teachers mentioned that, as a result of KKG/MGMP meetings, they learned how to be more active (less monotone) in their teaching; manage the classroom better, including group work; and elicit student opinions. The KKG/MGMP meetings also helped align lessons horizontally and vertically across all primary grade-level teachers so that no child would "experience a gap." Some of these specifics could be related to the timing of the study (see the Limitations section).

\section{Discussion}

Activity Theory allowed us to paint an overall picture of all elements of the peer-learning model supported by USAID/PRIORITAS that may have influenced teacher behavior change (i.e., teacher learning and application of learning in the classroom). It also permitted us to explore tensions within that system and to anticipate how change in any one area might have influenced the outcomes. Figure 7-2 shows the elements of this activity system based on 
Figure 7-2. Activity system of peer learning in Indonesia

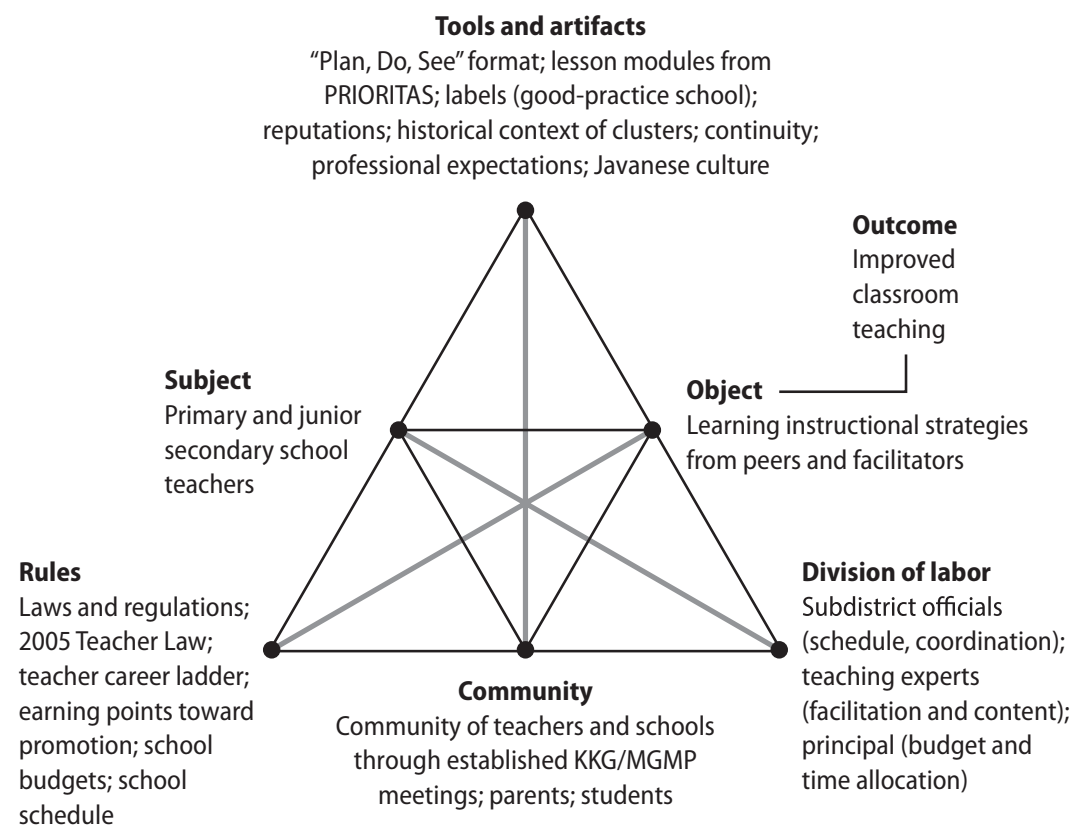

KKG = teachers' working group; MGMP = subject teachers' working group; PRIORITAS = Prioritizing Reform, Innovation, and Opportunities for Reaching Indonesia's Teachers, Administrators, and Students.

the findings from the focus groups. We refer to this figure to answer the three main research questions.

\section{Research Question 1: To What Extent Do Teachers See Peer Learning as an Opportunity for Improving Their Professional Practice?}

First, it is worth pointing out that the focus groups began by asking teachers to describe the different types of professional development opportunities that they engaged in and those they had found most useful for transferring training to the classroom. Although partially an icebreaker activity, it also explored attitudes toward alternatives to peer learning and school-based learning, as a potential counterfactual for comparison.

Although teachers were not specific about naming one single preferred CPD format, they did frequently express that they preferred CPD—whether a traditional workshop or cluster-based peer learning-that was based on practice and experimentation with new methods. The terms teachers used to describe 
their preferred learning approach varied-for example, "theory, practice, observation," "getting training then practice," "first real practice, then feedback, mentoring, and reflection," "contextual teaching and learning"-but the idea of practice with feedback was a strong recurring theme that corroborated much of the adult learning and teacher development literature cited earlier.

If we accept this as true-that learning to teach cannot be done in isolation-what specific format allows for effective practice and feedback? Is there an advantage to peer learning? Comments from two schools illustrated this theme and indicated how peer learning, in particular, was effective for responding to teachers' needs because it was more focused and relevant than training delivered by an external facilitator:

"During the KKG meeting we meet people and get lots of insight. It is a lot of information compared to the Internet. Sometimes there is only one source online, but in KKG there are a lot of people with experiences. Sometimes the Internet only tells about education in urban areas, whereas teacher meetings are more appropriate to the region and better solutions to real problems we face."

"Curriculum changes, so informal learning through peers is more up to date."

The focus groups indicated that teachers intrinsically valued and would participate in a variety of CPD opportunities that matched their needs and interests, but they also looked toward and even depended upon external factors to make it happen successfully. In this context, supportive leadership was critical because the principal set expectations for participation, allocated time, and monitored participation in cluster meetings as well as the quality of classroom teaching. Parents and even students had a role in generating demand for improved teaching that could influence decisions that school leaders made. These findings suggest that motivation was necessary, but not sufficient, for these Indonesian teachers to engage in professional development opportunities.

Other drivers, or factors that made it possible for teachers to participate in peer-learning events, were largely extrinsic. Among them were regulations, expectations from policy makers, and the school budget, but "having time" was the most common answer. Teachers had to have time available or consider that the professional development was more important than other responsibilities.

Where there were weekly meetings, these happened in large part because schedules were conducive to it. For example, standard practice in Indonesian public primary schools is to end the day at 12:30; however, teachers work until 
2:00, so the remainder of the hours can be spent doing joint planning and mentoring or participating in KKG/MGMP meetings, depending on the day. Therefore, the support of the district office and school principal, in the form of time off and budget, were important for maintaining momentum and a culture of peer learning in the two districts visited. Teachers did continue to engage in school-based mentoring at their own initiative and when they had specific teaching problems to solve, but they expressed that it helped to have external innovation and input from a master trainer periodically.

The prospect of being exposed to new and relevant knowledge, by experienced teachers, that could be applied in the classroom was also motivating for teachers. Specific characteristics of the peer-learning events that were satisfying to teachers included getting up-to-date information (about curriculum, methods, materials), learning locally relevant information, meeting new teachers with new insights, and having the opportunity to discuss in practical terms complex theories that they might have learned about in a formal training.

All of these factors combined to influence how teachers experienced professional growth through peer-learning opportunities, as illustrated by the Activity Theory model in Figure 7-2, and specifically the elements of division of labor, tools, community, and rules. In other words, even the most motivated teachers could not participate in a meeting if they did not have time and leadership support (rules, division of labor). Then, it was not enough to influence behavior change for teachers to just show up at a meeting - the meeting also had to include appropriate and supportive content (tools) and the right profile of local teachers who could share common experiences (community, division of labor).

\section{Research Question 2: What Motivates Teachers to Spend Time and Effort Working With Other Teachers to Improve Practice?}

As part of understanding teacher motivation, we wanted to explore whether teacher willingness to participate in peer learning is dependent upon positive attitudes and readiness to engage in self-directed learning (as per the theory of self-directed learning described by Costa and Kallick, 2004). The pilot selfadministered questionnaire for teachers was developed for this purpose; although data showed that teachers all expressed positive attitudes toward self-directed learning, the sample was too small and too heterogeneous to detect differences based on age, gender, grade level of teaching, or years of experience.

Additionally, as noted earlier, the questionnaire did not undergo rigorous piloting, so conclusions based on this questionnaire alone should be made 
with caution. Nonetheless, as additional qualitative data, it supports the notion that teachers in these two regions of Java wanted professional development and had a positive view of lifelong professional learning; however, they did value the presence of a subject-matter expert or other confident and experienced teacher to guide them in that process. Such external expertise was what the USAID/PRIORITAS project supported through the introduction of the district facilitators. These district facilitators were selected because they were good advisors in the first place; then, following their provincial training of trainers and before training teachers, they were expected to implement what they had acquired from training in their classroom, gain experience, and become more confident.

That 100 percent of respondents answered that they felt comfortable receiving criticism and feedback is encouraging, because this aspect was integral to the "Plan, Do, See" model of peer learning and would hardly have been effective if teachers were uncomfortable with it. Although only one pre-service institution was part of the study, the participants in the focus group noted that strategies for ongoing learning, including self-directed learning and peer learning, were not part of the teacher preparation curriculum.

\section{Research Question 3: How Do Cluster/Community-of-Practice Activities Among Teachers Influence Teaching Practice, Generally, and the Adoption of New Methods, Specifically?}

The different terms used by the teachers to describe the types of training they preferred (see research question 1) all reflected the notions of socially situated and experiential learning as being highly valuable. Even one teacher who expressed a preference for five-day training workshops explained that it was because teachers could work intensively together to complete the given curriculum or co-create lesson plans that could be immediately implemented. As with research question 1 , high-quality active training was necessary, but perhaps not sufficient, to improve classroom teaching; teachers could be motivated to attend CPD, and even walk away with new ideas and tools, but still return to their class and continue to teach in the traditional way. So what encouraged teachers to actually change their teaching methods? These focus group interviews elicited ideas from the perspective of these Indonesian teachers.

First, teachers expressed that they looked for mentoring in other teachers who had experience, who had confidence to try new things, or who had a title that implied experience and expertise (including the principal and district 
facilitator, who were either former or current teachers, the senior teacher, or designated model teachers from good-practice schools). This horizontal form of learning through peers was more credible to them than an externally driven training alone because the teachers knew that their peers understood the local environment and had experienced the methods firsthand.

Second, an element of social pressure and social accountability to try the new methods in their classrooms extended even between teachers and students, with several teachers from different schools in different focus group meetings mentioning the importance of responding to students' demands for more active and engaging teaching. In other words, one teacher with the confidence to begin implementing more active, student-centered learning could be the trigger that set in motion demand from students to expect the same from other teachers in the school. In turn, when teachers saw that changes in their teaching influenced the students' achievement, they were motivated to sustain and share those practices.

Finally, the influence of the USAID/PRIORITAS project also was important for providing content, structure, and expectations for continuity between the cluster meetings that were used to disseminate specific training topics. This particular form of peer mentoring, using the lesson-study approach through the KKGs/MGMPs, built in opportunities for implementation of training in the classroom as part of the model. Furthermore, at the end of each training, teachers and principals from partner schools were expected to draw up an action plan for transferring training to the classroom. District facilitators monitored these action plans and organized at least one district meeting in the partner district at which all schools were invited to showcase the results of their implementation. In other words, there was an expectation to perform well.

Again, these elements were present and mutually reinforcing according to the Activity Theory diagram for this case (Figure 7-2), but the "community" element as a force for change at the classroom level emerged during the focus groups as a particularly strong mediator of the transfer of training to the classroom. Focus group and questionnaire responses reflected a proactive approach to learning and a willingness to reach out to others and share new knowledge at the cluster- or school-based peer-learning meetings, which also suggested a strong culture of learning. This culture of learning and professionalism was supported and sustained by the community, but in the activity system it was also a tool or artifact through which the subject's 
Figure 7-3. Analysis of one node of the system
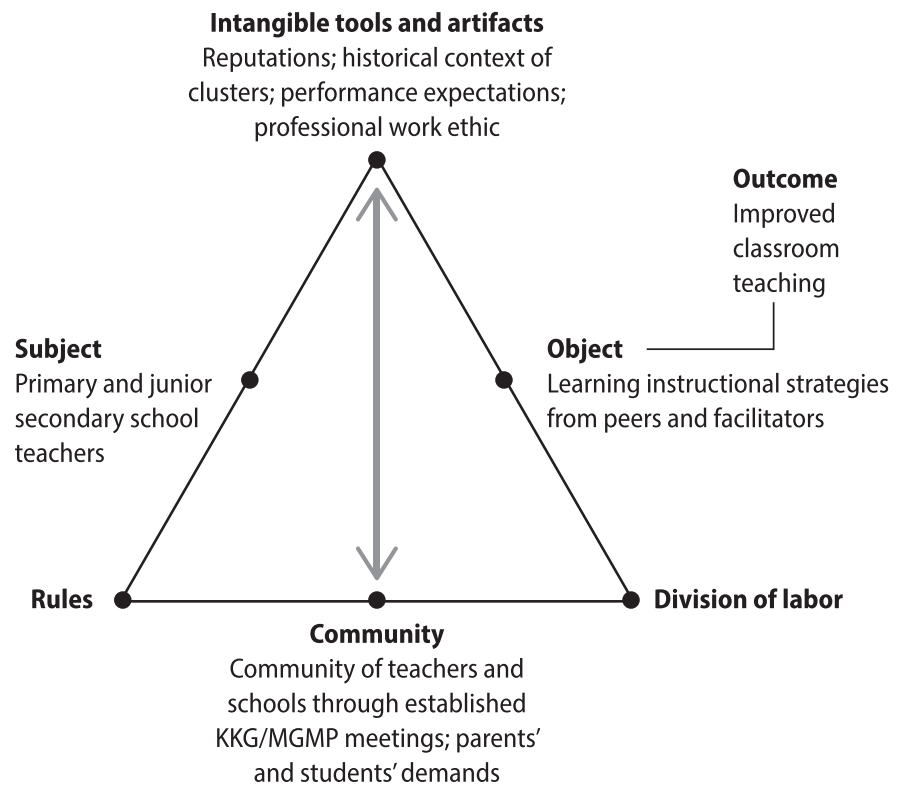

KKG = teachers' working group; MGMP = subject teachers' working group.

(teacher's) engagement with the object (peer learning) was mediated, as illustrated in the system node highlighted in Figure 7-3. High expectations set by students, parents, principals, and all levels of government were shaped over time and established an intangible but potentially powerful reason for teachers to spend time and effort to improve their practices.

This is not the first study in Indonesia to point out the role of government in promoting teacher behavior change. In a study of senior high school subject teachers in the province of South Sulawesi, Tanang and Abu (2014) found that the government's supportive policies toward teachers, especially as articulated in the 2005 Teacher Law, created a sense of security for teachers, which in turn allowed them to innovate and improve. In other words, the government as stakeholder did not just demand high performance but also committed to helping each teacher meet those expectations.

\section{Limitations}

The authors acknowledge the following limitations of the research covered in this chapter. 


\section{Correlation and Causation}

Routine monitoring and evaluation during USAID/PRIORITAS gathered some information about teacher behavior and student outcomes in these schools, and data collection also recorded teacher accounts of changes in student behaviors and achievements. However, we cannot claim that the reported changes in student learning were directly related to the peer-learning model.

\section{Representativeness}

Additionally, the sample was not representative of all Indonesian-or even Javanese-teachers, such that the attitudes and values expressed by this group of teachers might have been an exceptional case. This exceptionality might even be likely because the schools were good-practice schools, and, therefore, the teachers might have been conditioned to speak highly of their professional development opportunities and the KKG meetings, especially for external visitors.

\section{Focus Group Methodology}

A known limitation of all focus groups is that the group format may influence responses, especially when there is a particularly dominant participant (Krueger, 1994). Although 75 individuals participated in these focus groups, the responses recorded may have represented only half of those present at the meetings. As indicated in the Methodology section, individual attribution was not always feasible for every comment captured in the contemporaneous notes.

\section{Project Timeline}

The timing of the study may have limited the views that were shared to what had been most immediately covered by the USAID/PRIORITAS training modules. For example, the content of earlier training modules had been of general pedagogy in active learning. When the study was carried out, the teachers had just finished Module 3 of the project's training curriculum, which focused on using leveled reading books. Subject-matter content was introduced only in Module 4, which may explain why teachers noted that KKG/MGMP meetings usually covered topics related to pedagogy rather than specific subjects.

\section{Program Influence}

Because this effort was not designed as program monitoring, the principal researcher who conducted the focus groups and interviews along with an 
interpreter (both also coauthors of the chapter), did not represent the project in any way and were impartial to indicators of program quality. Interviewees were asked to speak in general about experiences with informal peer learning and structured peer learning through the organized KKG/MGMP meetings but not specifically about the training and mentoring model disseminated with the support of USAID/PRIORITAS. Therefore, at times it was difficult to distinguish how much of the success of the model was due to direct project influence versus locally driven activities. A useful follow-up study would be to compare partner schools to non-partner schools to isolate the relative influence of the project on transfer to the classroom and incentives to continue after the project closed.

\section{Use of Activity Theory}

Finally, this chapter represents an exploratory study that aimed to elicit some of the potential opportunities and obstacles to expanding peerlearning models from the teachers' own perspectives. Activity Theory is not a predictive model, and the study was not designed to establish empirically derived correlations. For that reason, all claims warrant further investigation. Follow-up research in the same or other contexts could use Activity Theory as a methodological framework to design interview questions specifically around the mediating factors of tools, rules, community, and division of labor and as an analytical framework to code qualitative data according to the different elements of Activity Theory. Although Activity Theory has been used with cross-sectional data to describe a system, Jonassen and Rohrer-Murphy (1999) suggested that as a research method, its time frame should be long enough to detect changes in objects (as defined in the model-e.g., peer learning) and in the relations among the various elements. Data for this study, however, were collected at only one point in time. A useful follow-up study might be to more carefully observe changes in teachers' participation in peer groups and to assess how those changes were influenced by the various nodes of the situation (Figure 7-2).

\section{Conclusions}

The data collected and analyzed for this study support many of the lessons learned and documented by the project staff over the five years of implementation. The results suggested that the lesson-study or peer-learning approach was more successful than one-to-one classroom observations 
between teacher and coach (or the district facilitator, in this context). The following reasons were described by program staff who were deeply familiar with the project (and were coauthors of this chapter):

1. The horizontal "mentor" relationship between teachers was less threatening than the vertical, external "facilitator" model of professional development because the lesson-study structure shifted the focus from being on the teacher (in one-to-one classroom observations) to the lesson (because the lesson plan was prepared by a group of teachers). In other words, no one was to blame for bad teaching; instead, the lesson plan was considered to be at fault. This observation from program staff was supported by this study's findings that teachers appreciated opportunities to integrate practice, reflection, and discussion in a structured sequence, and they appreciated learning from experienced teachers familiar with the context.

2. The peer-learning model was suitable for a low-resource context in which facilitators (coaches) were ahead of the teachers by only a few months. In this lesson-study approach, facilitators did not feel the pressure of having to know and implement with fidelity one "right" approach. Instead, they could explore options from the teachers they observed themselves as well as from other facilitators. Although this study did not focus specifically on how facilitators approached the peer-learning process, Activity Theory reminds us of the importance of the community and other participants in the system in mediating teachers' learning transformation.

3. In the context of Indonesia, this peer-learning approach aligned with the Ministry of Education and Culture's reference to teachers as being "lifelong teacher learners." This point, again, illustrates the important mediating role that "rules" and cultural-historical artifacts play in the activity system.

4. The mentoring process used an existing platform of teachers' working groups to develop collective lesson plans and share reflections, rather than the previous approach of one-to-one intensive classroom observations and feedback sessions. The importance of working within an existing system cannot be 
underestimated, as it was further supported by the data from this study. In particular, an important message that teachers emphasized was that they participated in these activities because they were given the time and budget to do so. Schools had a budget to cover coststhat is, funds were not provided by USAID/PRIORITAS but were already existing within the system-and school leaders created time and incentives for teachers to use those resources for professional learning.

\section{This model of improving together and peer sharing aligned well} with existing Indonesian values. Program staff were well familiar with the many ways that the Indonesian (and, specifically, Javanese) collective culture manifests itself day to day, but this ethos also has been established more empirically by, for example, Hofstede (2001). Teachers in this study confirmed that, if they learned a new method in teaching, they were happy to share the new knowledge. It was not unusual for teachers to respond to "demands" from students, which might not be the case in more individualistic cultures with stricter power dynamics.

It was not within the scope of the original research to explore all the potential effects of Indonesian culture on how peer learning functioned as a lever for teacher behavior change, but it would also be remiss not to recognize that observed attitudes like cooperation and openness to criticism may be highly culture-specific. Especially, using the lens of Activity Theory to analyze the system requires some attention to historical factors that shape a system (through, for example, the "tools" that mediate subject and object interaction), and culture is one of these mediators.

Bjork, reporting in 2003 on ethnographic research conducted in Indonesia in 1998-1999, remarked at the time that the teaching profession was characterized by low motivation and a highly bureaucratic civil servant mentality in which "teachers answer to the government, not students, parents, or local school boards" and "loyalty and obedience, not creativity or initiative, bring Indonesian teachers the most tangible rewards" (p. 203). He concluded that the lack of uptake in autonomy provided by decentralization reforms was due to this civil service culture, few incentives and rewards to take on the additional tasks required by the decentralized curriculum development, and traditional power dynamics between central and local levels. He pointed out 
that reforms could not be expected to work the same way from one context to another because school systems were so strongly shaped by culture and values (Bjork, 2003).

Our analyses painted a very different-and more positive-picture of teacher initiative and cooperation than Bjork's study did nearly 20 years ago. If our findings were found to be accurate on a wider scale, it would also be a reminder that behavior change and change in organizational culture take a long time and involve more than any one project alone. Adjusting to the horizontal organization required by decentralization and peer learning from what was previously a very rigid vertical hierarchy was no easier for the government than for the teachers (Bjork, 2003). Bjork's criticism was that policy was not backed up with appropriate enabling support. This observation again contrasts with the more recent picture painted by Tanang and Abu (2014), who described the ways in which the 2005 Teacher Law promoting lifelong learning served not only to change the culture of learning but also to back it up with tangible efforts to enable teachers to achieve the ambitions of the law.

This Indonesia case study also adds to our understanding of teacher professional learning from the adult learning perspective. The attitudes of the teachers toward the processes of experimentation and reflection on action support social and experiential learning theories as described by Kolb (1984) and Guskey (2002). These two researchers emphasized that learning is a process of action and reflection and that behavior changeespecially for teachers-depends upon seeing positive results from implementing a new practice. In this way, training is a beginning, but it is not sufficient to induce behavior change unless the right conditions are in place for teachers to implement the new method in the classroom and reflect upon its added value.

For Indonesian teachers, the motivation to go outside of their comfort zone and try new methods in the classroom resulted from forces both within and outside the school, and both intrinsic and extrinsic to the teacher. As Guskey's (2002) model implies, sometimes teachers change their behavior first, and then the change in attitude follows; the USAID/PRIORITAS project put in place processes that made it possible for teachers to try new methods in a supportive environment and then gradually want to adopt new teaching behaviors after seeing success and encouragement from their peers and their students. 
The cluster meetings were important as a source of information sharing and mutual support, but external input in the form of a guest speaker, a master trainer, or presentation of a project-sponsored topic or training model was also welcome stimulation. This need has been identified in past reports from Indonesia and elsewhere (Evans, Tate, Navarro, \& Nicolls, 2009; Gove et al., 2017). Rather than indicating a limitation of peer-learning models, it suggests the added value of these cluster structures as a means through which to disseminate innovations. This effect was especially true when the KKGs included non-partner schools (schools not directly supported by USAID/ PRIORITAS). The non-partner schools learned of the material from the partner schools, and some tried it out in their own classrooms. Planning for periodic special events or speakers should be considered a core part of the design of peer-learning models in other contexts.

Additionally, a critical distinction to make about the Indonesia peerlearning model is that it was not simply a typical cascade training model, whereby master trainers chose the subject area and trained local trainers, who trained school-based trainers, who trained their peers. Although this type of cascade effect happened at times, the KKG/MGMP system was established as an integral part of the school system, and, over time, peer learning became a norm, not an externally imposed additional burden.

The peer-learning cascade model also involved more than just one expert trainer who trained a school-based resource person. Instead, the master trainer provided content and structure, often on demand, by which a group of teachers began to work together to adopt the methods for their situation. In contrast with some cascade models of training-in which the key resource teacher who was trained may or may not have time or take the initiative to share the learning with peers (see Hardman et al., 2009, for example)-among these high-performing schools in Java, peer learning became an expectation that was supported by leadership, demand-driven, and self-enforced. Although peer learning alone cannot overcome a lack of knowledge about pedagogic improvement at the school level (or even among schools), this study suggests that peers experiencing the same challenges can collectively work together to find solutions.

This chapter also should add to the literature emphasizing that teacher behavior change is not a simple, linear process dependent only on tangible inputs (materials, meetings) that can be supported through development partnerships. Efforts to change pedagogic practices need to take into 
consideration local culture and values and be prepared to deliberately focus on collectively influencing aspects of organizational culture, such as norms, expectations, and accountability, which come from strong leadership at various levels. Although some external financing can help, mobilizing political will ultimately may be more important (adapted from J. DeStefano, personal communication, June 2017).

Using Activity Theory as a framework for discussing the findings from the fieldwork emphasized this more long-term and holistic view of the activity system; it helped to address the distinction between individual and collective actions, and to emphasize the socially mediated nature of the peer-learning model. Furthermore, it helped us realize why we must proceed carefully in attempts to replicate the model elsewhere because embedded within its apparent success in Indonesia was a range of unique and historically established norms of school clusters, collectivism, professional work ethic, parental participation, and other factors that influenced (mediated) the activity of participating in peer-learning opportunities and then translating learning into changed teaching behavior. Some basic principles behind the USAID/PRIORITAS mentoring process using the KKG/MGMP platform with lesson-study and peer-learning approaches can inspire adaptation to other contexts; however, the ways in which these principles interact with other indirect influences and existing norms cannot be overlooked.

Based on these findings, and the authors' other experiences, the following recommendations apply to efforts to achieve successful peer-learning models.

- Ensure compelling learning programs for teachers. Creating a peer- or cluster-based professional learning program for teachers requires addressing two critical questions: (1) What is required to get teachers to the meetings in the first place? (2) What will ensure that they come back? For the first question, teachers must have time and incentives (both financial and personal) to do so. Then, the meetings must cover appropriate and relevant content that is, ideally, derived, managed, and enforced by the teachers themselves. The format should be engaging and active rather than theoretical and lecture-based.

- Bring political leaders on board. Significant effort should be made to mobilize political will so that peer learning becomes an expectation that is tangibly supported by leadership policies, budgets, encouragement, 
and participation. Leaders can set expectations, but they also have to help teachers achieve those expectations.

- Promote self-directed learning skills in pre-service education.

Tangible government support may include integrating expectations and practices of lifelong learning, including self-directed learning and peer learning, into the teacher pre-service curriculum. Provide practical strategies for becoming self-managing, self-monitoring, and self-modifying.

- Create a climate of innovation and dissemination. Allowing teachers more control over the planning and implementation process does not eliminate the need for cluster meetings as a means to introduce new ideas, materials, methods, and innovations. This input can occur through special cluster events and scheduled external facilitators. The topics should, to the extent possible, be made as relevant to the teachers as possible through links to existing school or community practices or teacher experiences and attitudes.

- Find champions. The peer-learning community will benefit from the nurturing presence of a committed champion such as a facilitator, coordinator, experienced teacher, or principal. This champion can push to extend learning and support to the school level so that the peer learning translates into changes in instruction. Engaging the school community as champions seems to be a particularly strong force for ensuring that teachers improve and for creating a culture of learning through high expectations and accountability.

- Use a proven structure for lesson-study feedback. Specific lesson-study models may consider the following five-step approach: (1) A facilitator or other mentor observes a classroom teacher at work. (2) Afterward, the teacher is encouraged to reflect individually on his or her own teaching practice; at that time, issues or challenges encountered during teaching might surface. Otherwise, (3) the observer probes what the teacher thought about how he or she handled a particular issue. (4) The facilitator or other observing teacher provides options for the "problems" encountered during teaching, and (5) the teacher is asked to comment on the options or solutions. Note that for this type of model, master trainers, facilitators, and coaches must first be trained on how to provide constructive and congenial feedback. 


\section{Acknowledgments}

This chapter was made possible through a professional development award to the lead author from RTI International. The original research design and collection also were supported through internal RTI research and development funds implemented with in-kind support of the Indonesia United States Agency for International Development (USAID)/PRIORITAS (Prioritizing Reform, Innovation, and Opportunities for Reaching Indonesia's Teachers, Administrators, and Students) project, which was made possible by the American people through the USAID under Contract No. AID497-C-12-00003. The contents of this chapter are the responsibility of the authors and do not necessarily reflect the views of USAID or the US government.

The authors gratefully acknowledge the support received during the research fieldwork from the USAID/PRIORITAS project team and the district officials, head teachers, and teachers who organized and participated in interviews. Special thanks go to Dr. Matthew Jukes (RTI), who provided helpful comments on an early draft of the chapter, and to Jessica Mejia (RTI), who contributed to the research and instrument design.

\section{References}

Berwick, D. M., James, B., \& Coye, M. J. (2003). Connections between quality measurement and improvement. Medical Care, 41(1, Suppl), I-30-I-38.

Bjork, C. (2003). Local responses to decentralization policy in Indonesia. Comparative Education Review, 47(2), 184-216. https://oi.org/10.1086/ 376540

Chang, M. C., Shaeffer, S., Al-Samarrai, S., Ragatz, A. B., de Ree, J., \& Stevenson, R. (2013). Teacher reform in Indonesia: The role of politics and evidence in policy making. Washington, DC: World Bank. https://doi.org/10.1596/978-0-8213-9829-6

Chung Wei, A. A., Darling-Hammond, L., Andree, A., Richardson, N., \& Orphanos, S. (2009). Professional learning in the learning profession: A status report on teacher development in the United States and abroad (Technical Report). Dallas, TX: National Staff Development Council. Retrieved from https://learningforward.org/docs/pdf/ nsdcstudytechnicalreport2009.pdf?sfvrsn=0 
Costa, A., \& Kallick, B. (2004). Assessment strategies for self-directed learning. Thousand Oaks, CA: Corwin Press/Sage. https://doi.org/10.4135/ 9781483328782

Crouch, L., \& DeStefano, J. (2015). A practical approach to in-country systems research. Background paper prepared for the Research on Improving Systems of Education (RISE) programme. Research Triangle Park, NC: RTI International. Retrieved from http://www.riseprogramme. org/sites/www.riseprogramme.org/files/publications/14_CrouchDeStefano.pdf

Dall, F., Losert, L., Purwadi, A., Bandi, Triatmoko, S., \& Masoken, Y. Y. (2015). Indonesia: USAID/PRIORITAS mid-term evaluation. Prepared for USAID under General Services Administration Federal Supply Schedule No. GS10F0285K, Delivery Order No. AID-497-M-15-00004, “To Assess the Performance of the PRIORITAS Project on the Quality and Relevance of Basic Education in Primary and Junior Secondary Schools in Indonesia," January-April 2015. North Bethesda, MD: JBS International. Retrieved from http://pdf.usaid.gov/pdf_docs/PA00KJXV.pdf

Dubeck, M., Jukes, M., Brooker, S., Drake, T., \& Inyega, H. (2015). Designing a program of teacher professional development to support beginning reading acquisition in coastal Kenya. International Journal of Educational Development, 41, 88-96. https://doi.org/10.1016/j.ijedudev.2014.11.022

Engeström, Y. (2001). Expansive learning at work: Toward an activity theoretical reconceptualization. Journal of Education and Work, 14(1), 133-156. https://doi.org/10.1080/13639080020028747

Evans, D., Tate, S., Navarro, R., \& Nicolls, M. (2009). Teacher education and professional development in Indonesia: A gap analysis. Produced for USAID/Indonesia under Task Order 26 of the Global Evaluation and Monitoring (GEM II) Blanket Purchase Agreement, EDH-E-25-0800003-00. North Bethesda, MD: Aguirre Division of JBS International. Retrieved from http://pdf.usaid.gov/pdf_docs/Pnads282.pdf

Feryok, A. (2009). Activity theory, imitation and their role in teacher development. Language Teaching Research, 13(3), 279-299. https://doi.org/10.1177/1362168809104699

Flaherty, J. (1998). Coaching: Evoking excellence in others. Boston, MA: Butterworth-Heinemann. 
Glewwe, P., \& Muralidharan, K. (2015). Improving school education outcomes in developing countries: Evidence, knowledge gaps, and policy implications (Research on Improving Systems of Education [RISE] Working Paper No. 15/001). Retrieved from http://www.riseprogramme.org/sites/www. riseprogramme.org/files/publications/RISE_WP-001_Glewwe_ Muralidharan.pdf

Gove, A., Korda Poole, M., \& Piper, B. (2017). Designing for scale: Reflections on rolling out reading improvement in Kenya and Liberia. New Directions for Child and Adolescent Development, 2017(155), 77-95. https://doi.org/10.1002/cad.20195

Guskey, T. R. (2002). Professional development and teacher change. Teachers and Teaching, 8(3), 381-391. https://doi.org/10.1080/135406002100000512

Hardman, F., Abd-Kadir, J., Agg, C., Migwi, J., Ndambuku, J., \& Smith, F. (2009). Changing pedagogical practice in Kenyan primary schools: The impact of school-based training. Comparative Education, 45(1), 65-86. https://doi.org/10.1080/03050060802661402

Hardman, F., Hardman, J., Dachi, H., Elliott, L., Ihebuzor, I., Ntekim, M., \& Tibuhinda, A. (2015). Implementing school-based teacher development in Tanzania. Professional Development in Education, 41(4), 602-623. https://doi.org/10.1080/19415257.2015.1026453

Haßler, B., Hennessy, S., Cross, A., Chileshe, E., \& Machiko, B. (2015). School-based professional development in a developing context: Lessons learnt from a case study in Zambia. Professional Development in Education, 41(5), 806-825. https://doi.org/10.1080/ 19415257.2014.938355

Healey, H. (2016). An investigation into the teacher deployment and teacher continuing professional development programs in Indonesia. Report prepared for USAID/PRIORITAS under USAID Contract No. AID-497-C-12-00003. Research Triangle Park, NC: RTI International. Retrieved from https://shared.rti.org/content/investigationteacher-deployment-and-teacher-continuing-professionaldevelopment-programs\#

Hofstede, G. (2001). Culture's consequences: Comparing values, behaviors, institutions, and organizations across nations ( 2 nd ed.). Thousand Oaks, CA: Sage. 
Jalal, F., Samani, M., Chang, M., Stevenson, R., Ragatz, A., \& Negara, S. (2009). Teacher certification in Indonesia: A strategy for teacher quality improvement. Jakarta, Indonesia: Ministry of National Education and The World Bank. Retrieved from http://datatopics.worldbank.org/hnp/files/ edstats/IDNprwp09c.pdf

Jessop, T., \& Penny, A. (1998). A study of teacher voice and vision in the narratives of rural South African and Gambian primary school teachers. International Journal of Educational Development, 18(5), 393-403.

Johnson, K. E., \& Golombek, P. R. (2003). “Seeing” teacher learning. TESOL Quarterly, 37(4), 729-737. https://doi.org/10.2307/3588221

Jonassen, D. H., \& Rohrer-Murphy, L. (1999). Activity theory as a framework for designing constructivist learning environments. Educational Technology Research and Development, 47(1), 61-79. https://doi.org/10.1007/BF02299477

Junor Clarke, P. A., \& Fournillier, J. P. (2012). Action research, pedagogy, and activity theory: Tools facilitating two instructors' interpretations of the professional development of four pre-service teachers. Teaching and Teacher Education, 28(5), 649-660. https://doi.org/10.1016/j.tate.2012.01.013

Knight, C., \& Sutton, R. (2004). Neo-Piagetian theory and research: Enhancing pedagogical practice for educators of adults. London Review of Education, 2(1), 47-60. https://doi.org/10.1080/1474846042000177474

Knight, D. S. (2012). Assessing the cost of instructional coaching. Journal of Education Finance, 38(1), 52-80.

Knight, J. (2009). Coaching: The key to translating research into practice lies in continuous, job-embedded learning with ongoing support. Journal of Staff Development, 30(1), 18-22.

Knowles, M., \& Associates. (1984). Andragogy in action: Applying modern principles of adult learning. San Francisco, CA: Jossey-Bass.

Kolb, D. (1984). Experiential learning. Englewood Cliffs, NJ: Prentice-Hall. Kraft, M. A., Blazar, D., \& Hogan, D. (2017). The effect of teacher coaching on instruction and achievement: A meta-analysis of the causal evidence (Working Paper). Providence, RI: Brown University and Harvard University. Retrieved from https://scholar.harvard.edu/files/mkraft/files/kraft_blazar_ hogan_2016_teacher_coaching_meta-analysis_wp_w_appendix.pdf

Krueger, R. (1994). Focus groups: A practical guide for applied research (2nd ed.). Thousand Oaks, CA: Sage Publications, Inc. 
Lave, J., \& Wenger, E. (1991). Practice, person, social world. In J. Lave \& E. Wenger (Eds.), Situated learning: Legitimate peripheral participation (pp. 45-58). Cambridge, United Kingdom: Cambridge University Press. https://doi.org/10.1017/CBO9780511815355.004

Leont'ev, A. N. (1981). The problem of activity in psychology. In J. V. Wertsch (Ed.), The concept of activity in Soviet psychology (pp. 37-71). Armonk, NY: M. E. Sharpe.

Luigi Giussani Institute of Higher Education (LGIHE). (2016, March). Teacher as continual learner: Case study from Uganda. Paper presented at the Comparative and International Education Society (CIES) annual conference, Vancouver, Canada. Retrieved from http://gihe.org/ wp-content/uploads/2016/04/CIES-Annual-Conference-2016-final.pdf

Nir, A. E., \& Bogler, R. (2008). The antecedents of teacher satisfaction with professional development programs. Teaching and Teacher Education, 24(2), 377-386. https://doi.org/10.1016/j.tate.2007.03.002

Nordstrum, L. E. (2013). A Sisyphean complex? Economic and cost constraints in filling teacher quantity and quality gaps. In B. Moon (Ed.), Teacher education and the challenge of development (pp. 32-49). London, United Kingdom: Routledge.

Nordstrum, L. E. (2015). Effective teaching and education policy in sub-Saharan Africa: A conceptual study of effective teaching and review of educational policies in 11 sub-Saharan African countries. Prepared for USAID under the Education Data for Decision Making (EdData II) project, Task Order No. AID-OAA-12-BC-00004, Data for Education Research and Programming in Africa (RTI Task 19). Research Triangle Park, NC: RTI International. Retrieved from http://pdf.usaid.gov/pdf_docs/PA00KM8X.pdf

Organisation for Economic Co-operation and Development (OECD). (2011). Building a high quality teaching profession: Lessons from around the world. Paris, France: OECD Publishing.

Orr, D., Westbrook, J., Pryor, J., Durrani, N., Sebba, J., \& Adu-Yeboah, C. (2013). What are the impacts and cost-effectiveness of strategies to improve performance of untrained and under-trained teachers in the classroom in developing countries? London, United Kingdom: EPPICentre, Social Science Research Centre, Institute of Education, University of London. Retrieved from http://sro.sussex.ac.uk/43901/1/Undertrained_ teachers_2013_Orr.pdf 
Pflepsen, A., Harden, K., Dubeck, M. M., Sankey, S., \& King, S. (2017). Improving early grade literacy instruction and student outcomes: Findings from a cluster randomized controlled trial in northern Nigeria. Unpublished manuscript.

Piper, B., \& Zuilkowski, S. (2015). Teacher coaching in Kenya: Examining instructional support in public and nonformal schools. Teaching and Teacher Education, 47, 173-183. https://doi.org/10.1016/j.tate.2015.01.001

Popova, A., Evans, D., \& Arancibia, V. (2016). Training teachers on the job: What works and how do we measure it? (Policy Research Working Paper No. WPS 7834; WDR 2018 background paper). Washington, DC: World Bank Group. Retrieved from https://openknowledge.worldbank.org/ handle/10986/25150

Pouezevara, S., \& Khan, R. (2007). Learning communities enabled by mobile technology: A case study of school-based, in-service secondary teacher training in rural Bangladesh (Appendix 11 of Bangladesh country report). ADB TA No. 6278-REG. Research Triangle Park, NC: RTI International. Retrieved from https://shared.rti.org/content/learningcommunities-enabled-mobile-technology-case-study-school-basedservice-secondary

Pouezevara, S., Pflepsen, A. A., Nordstrum, L. E., King, S. J., \& Gove, A. K. (2016). Measures of quality through classroom observation for the Sustainable Development Goals: Lessons from low-and-middle-income countries. Background paper commissioned for the 2016 Global Education Monitoring Report, Education for people and planet: Creating sustainable futures all. Paris, France: UNESCO. Retrieved from http://unesdoc.unesco. org/images/0024/002458/245841e.pdf

RTI International. (2014). Research on reading in Morocco: Analysis of teachers' perceptions and practices (Final report, Component 3). Prepared for USAID under the Education Data for Decision Making (EdData II) project, Task Order No. AID-OAA-BC-11-00001, Data for Education Programming in Asia and the Middle East (RTI Task 15). Research Triangle Park, NC: Author; Rabat, Morocco: Varlyproject. Retrieved from http://pdf.usaid.gov/pdf_docs/PA00M2WN.pdf

Showers, B. (1984). Peer coaching: A strategy for facilitating transfer of training (A CEPM R\&D report). Eugene, OR: Center for Education Policy and Management, College of Education, University of Oregon. 
Showers, B., \& Joyce, B. (1996). The evolution of peer coaching. Educational Leadership, 53(6), 12-16.

Song, B., \& Kim, T. (2016). Teacher (de)motivation from an Activity Theory perspective: Cases of two experienced EFL teachers in South Korea. System, 57, 134-145. https://doi.org/10.1016/j.system.2016.02.006

Sullivan, F., \& Lucas, S. (2001). Student strategies in the online classroom. Association for Educational Communications and Technology (AECT) Annual Conference Proceedings of Selected Instruction Paper Presentations. Bloomington, IN: AECT.

Tanang, H., \& Abu, B. (2014). Teacher professionalism and professional development practices in South Sulawesi, Indonesia. Journal of Curriculum and Teaching, 3(2). https://doi.org/10.5430/jct.v3n2p25

Universitas Cenderawasih (UNCEN: Cenderawasih University, Jayapura); Universitas Negeri Papua (UNIPA); Independent Research Institute of Indonesia, Social Monitoring and Early Response Unit (SMERU); Badan Pusat Statistik (PBS: Statistics Indonesia); \& United Nations Children's Fund (UNICEF). (2012). "We like being taught": A study on teacher absenteeism in Papua and West Papua. Jakarta, Indonesia: UNICEF. Retrieved from https://www.unicef.org/indonesia/Teacher_Absenteeism_ Study_Papua_ENGLISH.pdf

Vygotsky, L. S. (1978). Mind in society: The development of higher psychological processes (M. Cole, V. John-Steiner, S. Scribner, \& E. Souberman, Eds.) (A. R. Luria, M. Lopez-Morillas, \& M. Cole [with J. V. Wertsch], Trans.). Cambridge, MA: Harvard University Press. (Original manuscripts ca. 1930-1934)

Winthrop, R., McGivney, E., Williams, T. P., \& Shankar, P. (2016). Innovation and technology to accelerate progress in education: Report to the International Commission on Financing Global Education Opportunity (Background Paper: The Learning Generation). Washington, DC: Center for Universal Education, Brookings Institution. Retrieved from https://www.brookings.edu/wp-content/uploads/2017/02/global_ 20170223_innovation-and-technology.pdf

Yin, R. K. (2003). Case study research: Design and methods (3rd ed.). Thousand Oaks, CA: Sage.

Yoshida, M. (1999). Lesson study: An ethnographic investigation of schoolbased teacher development in Japan (Doctoral dissertation). Retrieved from ProQuest Dissertations and Theses database, AAT 9951855. 



\section{Teacher Motivation and Behavior Change: Results of the Teacher Motivation Diagnostic Tool in Northern India}

Molly Hamm-Rodríguez, Emily Richardson, and Jarret Guajardo

\section{Introduction}

In education systems around the world, teaching quality has become an emerging policy priority as policy makers and practitioners search for ways to improve student learning outcomes. Numerous studies have shown that the quality of teaching is the single most important in-school factor affecting student learning (Darling-Hammond, 2000; Hanushek, Kain, \& Rivkin, 2004; McKinsey \& Company, 2007). As a result, teaching quality has become a national policy priority in many countries and is embedded within an international context that measures the extent to which countries are making progress toward the United Nations Sustainable Development Goals. The fourth goal (SDG4) seeks to ensure inclusive and equitable quality education and to promote lifelong learning opportunities for all.

In pursuit of this goal, policy makers aim to substantially increase the supply of qualified teachers, including through international cooperation for teacher training in developing countries. Moreover, the United Nations Educational, Scientific and Cultural Organization's (UNESCO's) Education 2030 Framework for Action states that high-quality education requires "relevant teaching and learning methods and content that meet the needs of all learners, taught by well-qualified, trained, adequately remunerated and motivated teachers" (UNESCO, 2015b, p. 7; emphasis added by author).

However, such teachers are in limited supply in many developing nations. International data have shown that 27.3 million primary school teachers must be recruited by 2030 to fill the shortage gap (UNESCO, 2015a). The proliferation of contract teachers, imbalances in teacher distribution within 
countries, difficulty deploying teachers to underserved areas, and low status of the teaching profession (with correspondingly low salaries) pose significant threats to filling available positions with sufficiently qualified teachers (UNESCO, 2015a).

In light of these challenges, education systems and cooperating institutions must respond with policies and programs that fulfill two objectives: (1) satisfy high demand for education professionals by guaranteeing an adequate supply of well-qualified and trained teachers, and (2) ensure that teachers who enter the profession or are currently in service receive the necessary supports to foster motivation in a way that positively influences student learning. A singular focus on meeting the demands of the system through improved recruitment, selection, and deployment of teachers is not enough but rather must be part of a comprehensive strategy that incorporates the multiple stages of a teacher's career progression. If education quality is the end goal, retention and continuous development efforts must also attend to issues of teacher motivation.

For the purposes of this chapter, teacher motivation is defined as "the desire, willingness, and commitment to teach to the best of one's ability in order to ensure equitable and quality instruction for all students. Teacher motivation is derived from a range of intrinsic and extrinsic factors that encourage or inhibit teachers in reaching their full potential" (Teacher Motivation Working Group, n.d.). Motivation is generally understood to be a key factor for producing behavioral change (Fogg, 2009; Ryan \& Deci, 2000). Because improved education quality often requires teachers to change their behaviors in the classroom (e.g., adopting new pedagogical practices based on professional development activities), delving into the motivational factorsboth intrinsic and extrinsic-that influence teacher action or inaction is critical.

This chapter begins by discussing some of the psychological literature on motivation and by summarizing teacher motivation studies in developing countries to demonstrate the unique motivational challenges of teaching in low-income contexts. It then outlines the conceptual framework that Save the Children and World Vision International used to develop an open-source diagnostic tool to learn about factors influencing teacher motivation in specific contexts. Program managers can apply the tool before implementing training or professional development programs. Finally, the chapter presents findings from the tool's administration in India. 
This research has significant implications for policy makers and practitioners looking to understand what motivates or demotivates teachers in particular education systems. It will also inform the design of policies and programs that effectively support teachers to grow professionally, continuously improve upon their teaching strategies, and work hard to improve student learning outcomes.

\section{Literature Review}

\section{Teacher Motivation Theories Grounded in Psychology}

For decades, psychologists have been exploring the concept of motivation, or what makes individuals act toward a specific end. In the field of education, motivational theories have been applied mostly to students and student learning. Researchers, however, have increasingly adapted constructs and processes-originally designed to measure student motivation-and applied them to the task of understanding teacher motivation.

The primary motivational theories applied to teachers are expectancyvalue, achievement goal, and self-determination (Watt \& Richardson, 2015). In "expectancy-value" theory, motivation is influenced by how much value is placed on the end goal and to what extent success is expected in achieving it (Eccles, 1983; Wigfield \& Eccles, 2000). In "achievement goal" theory, individuals are motivated differentially by mastery goals, with a focus on developing their own competence, and by performance goals, with a focus on demonstrating competence by outperforming others (Dweck, 1986; Nicholls, 1984).

In "self-determination" theory, motivation is based on three basic psychological needs: autonomy, competence, and relatedness (Deci \& Ryan, 1985, 2000). Self-determination theory distinguishes between intrinsic motivation, or actions taken due to the inherent interest in or enjoyability of a task, and extrinsic motivation, or actions taken based on their connection to an external outcome, consequence, or result (Deci \& Ryan, 1985). Importantly, research has been conducted to show the universality across cultures of key elements of self-determination theory. This research also demonstrates that, in diverse cultural contexts, the three psychological needs of autonomy, competency, and relatedness are predictably related to different forms of motivation and key work outcomes such as well-being, performance, and commitment (Gagné et al., 2014). 
Key takeaways from these theories are (1) the importance of understanding goal-directed behavior and (2) the extent to which teachers believe in their ability to achieve professional goals, whether the goals are internally or externally imposed. Although in many cases teachers have the opportunity to define their own professional and pedagogical goals for their classrooms and their students, they are increasingly facing external pressures from school leaders, districts, national governments, and international donors to achieve particular, measurable goals in their work. Thus, critically, program implementers and policy makers must know how teacher motivation differs based on types of goals (mastery vs. performance) and where the impetus for goal-directed action is located (extrinsic vs. intrinsic). It is not uncommon for policies and programs to operate with the misguided assumption that all goals have equal value among teachers and that efforts to achieve those goals are based on similar motivational factors.

For example, intrinsic and extrinsic motivational factors exist on a continuum based on the degree of individual autonomy and the type of behavioral regulation involved (Deci \& Ryan, 2000). "Intrinsic motivation" carries the highest level of self-determination and autonomous behavior regulation, as individuals pursue activities based on their inherent interest or satisfaction. "Extrinsic motivation" is influenced by rewards and punishments, with people's behavior control or self-determination depending on the extent to which they have integrated the behavior into their selfconcept. Additional research has shown that the satisfaction of psychological needs is strongly related to both autonomous motivation and well-being in important life domains (Milyavskaya \& Koestner, 2011). Enhancing autonomous motivation (as opposed to controlled motivation) has shown to be more successful in helping individuals achieve personal goals (Koestner, Otis, Powers, Pelletier, \& Gagnon, 2008).

Although differences between intrinsic and extrinsic motivation play an important role in the goal-directed behavior of teachers, behavior change must also be explored through a lens that considers teachers' personal beliefs and interactions with others as key motivational factors. Bandura's (1986) Social Cognitive Theory is a foundational theory in this regard, explaining how individuals use regulation to achieve goal-directed behavior that they can maintain over time. He posited that learning results from dynamic interactions among the individual, the 
environment, and behavior, with learning often occurring through observation of others.

Self-efficacy is a key construct of the theory; it involves measuring people's perceptions of their ability to successfully complete a challenging task. Self-efficacy is derived from four elements: physiological and emotional well-being, verbal encouragement from others, learning from one's own experience, and learning from others' experiences (Bandura, 1986). In particular, experiences of mastery have been found to be among the most effective in building a strong sense of self-efficacy (Bandura, 1994). Studies of self-efficacy among teachers have shown that higher levels of self-efficacy can predict positive attitudes and behaviors for both teachers and students alike (Ashton, 1984; Watt \& Richardson, 2015).

This theory has made an important contribution to the field because it moves beyond cognitive psychological models to introduce social aspects that influence motivation. As we argue in this chapter, satisfying psychological needs is necessary but not sufficient to support the well-being of teachers, particularly those in early career. The next section explores literature that connects teacher motivation with well-being, systemic environmental factors, and issues of job satisfaction, all of which must be viewed through a sociocultural lens.

\section{Teacher Well-Being, Systemic Factors, and Job Satisfaction}

Psychological conceptions of teacher motivation are insufficient to explain the multiple factors that interact with a teacher's ability to set and reach particular professional and pedagogical goals. Beyond motivation, understanding teacher well-being, particularly in developing countries, is a central component of fostering teacher behavior change. To optimize teacher well-being, it is critical to perceive the interactions among "individual, relational and micro-, meso- and macro-environmental factors" (Hobson \& Maxwell, 2017, p. 168). In other words, a focus on internal, cognitive processes only lends itself to partial understanding. Ladyong (2014), for instance, argued that policy makers must pay attention to the connections and relationships between the "private" lives and experiences of teachers and the "public" systems and policy development processes that govern their recruitment, preparation, deployment, conditions of service, working conditions, and professional development. All of these factors influence the extent to which teachers 
feel motivated and/or feel that it is possible to make changes or take on new professional goals.

In the case of teachers in developing countries, Maslow's (1943) hierarchy of needs is particularly relevant for grasping the connection between motivation and well-being. That is, if lower-order needs such as water, housing, and safety are left unfulfilled-as is often the case for teachers working in these contexts-teachers may find it more difficult or unreasonable to focus on pursuing the higher-order needs of belonging and self-actualization in their profession. Thus, adults need certain conditions to be met to effectively learn and integrate new activities into their practice. Instrumental to comprehending this phenomenon is McClusky's (1963) Power Load Margin theory, which advocated for looking at the physical and mental well-being of adults to discern the ways in which various demands interact with their ability to take on new tasks.

The theory posits that to successfully take on a new task, individuals must be able to balance the energy needed-the "load" in their lives-and the energy available. The load is a mix of external factors such as family obligations, work duties, and socioeconomic status, as well as internal factors including selfconcept, goals, and personal expectations. The less personal power one has to handle the load, the less likely a new task can be taken on. Power is affected by both external factors (physical health, social status, economic wealth) and internal factors (skills and life experiences, coping mechanisms). A margin of power, which can be achieved only by reducing the load or increasing power, is what leads to autonomy. Teachers who live and work in low-income contexts often have heavy loads with limited power, leaving low capacity to take on new tasks. In addition, policies and programs promoting teacher behavior change often increase the load without simultaneously increasing power, making implementation success far less likely.

Because teachers are paid professionals embedded within educational systems and schools that shape their experience in the workplace, it is also necessary to look at job satisfaction-one of the most widely researched job attitudes and a frequent measure of teacher motivation. Job satisfaction is defined as a "pleasurable or positive emotional state resulting from the appraisal of one's job or job experiences" (Locke, 1976, p. 1304). Job satisfaction includes multidimensional psychological responses to a job, which can have cognitive (evaluative), affective (emotional), and behavioral components (Hulin \& Judge, 2003). Thus, how teachers think, feel, and 
behave is affected by their levels of job satisfaction. Facets of job satisfaction include a combination of intrinsic and extrinsic factors such as pay, promotions, coworkers, supervision, the work itself, recognition, working conditions, and management (Locke, 1976; Smith, Kendall, \& Hulin, 1969). This research demonstrates the importance of examining systemic workplace factors and how they interact with teacher beliefs, dispositions, and behaviors.

In terms of motivation, Herzberg (1966) found that achievement, recognition, the work itself, responsibility, and advancement were more effective long-run motivators than working conditions or pay (extrinsic factors). Indeed, extrinsic incentives have proven to be weak reinforcers of motivation in the short run and negative reinforcers in the long run (Bénabou \& Tirole, 2000). Thus, although paying attention to the satisfaction of basic needs (such as remuneration) is foundational, doing so exclusively at the expense of other elements will provide only an extrinsic incentive. However, policies and programs often focus on extrinsic incentives (such as increased salaries or pay-for-performance initiatives) rather than influencing other conditions that might sustain change and motivation over the long term.

For teachers, incentives have been found to be related to job satisfaction but not always to teacher classroom practices (Chapman, Snyder, \& Burchfield, 1993). In fact, evidence is mixed on the extent to which external incentives such as performance pay can produce long-lasting, sustainable change in teacher behavior and student learning outcomes (Harvey-Beavis, 2003). An alternative solution is to provide classroom supports for teachers that encourage intrinsic motivation, with a focus on areas such as achievement, recognition, and career development. This approach would have particular value in developing countries where material resources to increase motivation through extrinsic incentives are scarce (Guajardo, 2011). As we argue in this chapter, extrinsic factors certainly influence the extent to which teachers can take up new practices in their classrooms, but far too little attention has been paid to the intrinsic motivators (including supports to implement new practices) that ultimately would help teachers develop the sense of mastery, autonomy, and professional competence that they desire.

\section{Teacher Motivation in Low- and Middle-Income Countries}

Although much research has been done on teacher motivation in developed countries, less information is available to explain how the particular 
challenges of teaching in developing-country contexts differentially interact with motivation, well-being, systemic factors, and job satisfaction. In developing countries, a general belief is that teachers' motivation is fragile and declining and that it is a critically ignored factor in decision-making within education systems (Voluntary Service Overseas, 2012). The existing literature on teacher motivation in developing countries provides important information about the motivating and demotivating factors encountered by teachers in the complex systems within which they work. Several studies have looked at particular country contexts and the factors that correlate with teacher motivation and job satisfaction. A brief survey of those studies follows.

In Iran, a significant correlation was found between the quality of work life and career motivation among teachers (Baleghizadeh \& Gordani, 2012). In Pakistan, recognition of efforts, improved working conditions, promotion, and the work itself were found to be predictive of teacher motivation (Adil \& Fatima, 2013), while factors affecting teachers' motivation included income status, importance in the society, self-confidence, and incentives or rewards for showing good results (Alam \& Farid, 2011). In Ghana, recognition of good work, participation in decision-making, conducive working environments, and wages and salaries were all linked to teacher motivation (Adjei \& Amofa, 2014). In Ethiopia, the two most important factors influencing teacher motivation were salary and a missing link between performance and reward (Gemeda \& Tynjälä, 2015).

Case studies conducted in 12 countries across sub-Saharan Africa and South Asia found that accountability, conflict and security, the policy environment, teacher pay, vocational commitment and occupational status, working and living conditions, and teacher management were linked to low levels of teacher motivation (Bennell \& Akyeampong, 2007). A study in Somalia found significant relationships involving teacher motivation, job satisfaction, and school performance (Sheikh Ali, Dahie, \& Ali, 2016), while another in Ghana found a positive correlation between teacher motivation and job satisfaction (Nyarko, Twumwaa, \& Adentwi, 2014).

This research corroborated some prior studies in developed contexts that linked motivation and job satisfaction with factors including pay, promotions, working conditions, and recognition (Locke, 1976; Smith, Kendall, \& Hulin, 1969) while also demonstrating the broad variation that exists due to diverse social, cultural, political, historical, and economic contexts. Not surprisingly, 
motivating and demotivating factors are thus linked to culture and context. That is, factors that make a difference to motivation in one context may not make a difference in another. Additionally, according to Herzberg's (1966) two-factor model, some factors are simply more likely to cause job satisfaction than others. For example, motivators are mostly intrinsic and tend to produce job satisfaction. They include recognition, responsibility, and personal growth. On the other hand, hygiene factors are mostly extrinsic, and, while their presence does not directly cause job satisfaction, their absence can cause dissatisfaction. Such factors include job security and salary.

The following studies demonstrate the diversity of context-specific factors linked to teacher motivation and well-being in a selection of developing countries. Research in the Maldives found that teachers were motivated to stay in the profession largely due to cultural aspects and specific island-like characteristics (Hasan \& McDonald, 2015). In Nigeria, one study found that teachers believed motivation would increase if salaries were paid regularly, if adequate teaching and learning facilities were made available, and if teachers were encouraged to attend sponsored conferences and workshops (Ofoegbu, 2004). In Sri Lanka, English teachers were motivated by the students themselves, the act of teaching students, and the prestigious social position of teaching English. The main demotivators included limited facilities for teaching and learning in schools, inefficiency of school administration, difficulties in obtaining teacher transfers, and poor relationships among colleagues (Hettiarachchi, 2013).

In Kenya, teacher motivators were mostly work-context factors such as good interpersonal relationships, positive working conditions, and timely salary payment. Teachers were demotivated by low salaries, poor physical working conditions, heavy workloads, unclear terms of service, and poor interpersonal relationships (Ndani \& Kimani, 2010). In Ghana, teachers shared frustrations with their working conditions, including abuse of authority by some principals and nonresponsiveness to teachers' needs, the lack of teacher involvement in decision-making, challenges with the physical environment, and unattractive remuneration (Salifu, 2014). Future teachers in Indonesia perceived that the five most motivating factors in their career would be a good salary, job satisfaction, promotions, recognition, and positive organizational or management styles (Irwandy, 2014).

Motivation levels also may differ by gender, age, education level, and contract type across contexts. In Jamaica, a study found that females were 
more motivated by extrinsic factors whereas males were primarily motivated by intrinsic factors. Males in the sample, however, were found to be significantly less motivated to be teachers than their female counterparts (Bastick, 2000). Higher levels of motivation among female teachers were found in a study conducted in Jordan, where higher levels of education were also predictive of increased motivation (Al-Salameh, 2014). In Madagascar, however, female teachers were found to have lower levels of motivation. Contract teachers also had lower levels of job satisfaction than government teachers, leading to lower levels of commitment and attachment to the work (Gamero Burón \& Lassibille, 2016). Additionally, older and more experienced teachers in Jamaica were significantly more motivated by intrinsic factors, which could point to intrinsic motivation as a key for retention of teachers in the profession over the long term (Bastick, 2000).

Studies have also found a link between teacher motivation and student learning. In Nigeria, teachers who were unhappy with their conditions of service were less motivated, which had a direct result on student academic performance (Adeyinka, Asabi, \& Adedotun, 2013). A study conducted in Ghana found a statistically significant link between teacher motivation and the delivery of quality education (Akuoko, Dwumah, \& Baba, 2012), and the majority of both male and female teachers in a study conducted in Zimbabwe agreed that the challenges faced by teachers were demotivating and thus led to poor academic results among students (Chireshe \& Shumba, 2011). These findings are important because efforts to foster teacher behavior change are typically directly linked to a desire to improve student learning outcomes. However, such efforts often target classroom-based changes without addressing the larger systemic issues that affect teacher job satisfaction and teacher performance, as demonstrated by the multiple studies described previously.

The Sustainable Development Goals are looking to increase the supply of qualified teachers while also focusing on teacher training and professional development, so it is key to view teacher motivation within this context. Research has shown that participation in in-service training programs contributes positively to the job satisfaction of teachers (Gamero Burón \& Lassibille, 2016), and opportunities for development have a significant effect on teacher motivation (Matoke, Okibo, \& Nyamongo, 2015). Teacher engagement in professional learning activities is a strong predictor of teaching practices, with teacher self-efficacy surfacing as one of the most 
important motivational factors that can mediate school conditions and leadership practices (Thoonen, Sleegers, Oort, Peetsma, \& Geijsel, 2011).

In some cases, however, teachers may feel unmotivated to participate in professional development activities or to implement what they have learned in the classroom. A study in Malawi found that poor allowances received during training as well as poor conditions of service contributed to a lack of motivation among teachers to bring new practices into their classrooms (Selemani-Meke, 2013). In contrast, in South Africa, teachers from underperforming schools were motivated to engage in professional development activities based on a passion for working with children from disadvantaged backgrounds, acknowledgment from school leaders, the approach used to inform teachers of development activities, feelings of empowerment after learning new strategies, and the style of the presenters delivering the training (Heystek \& Terhoven, 2014). Properly designed professional development activities, therefore, can increase teacher motivation to participate and use new strategies learned.

The literature described up to this point has addressed some known research gaps. Many studies, however, have divorced psychological and cognitive processes of motivation from the larger systemic factors that influence teacher self-efficacy in vastly different work environments. Our literature review has revealed a need to learn how the following factors intersect and interact to influence teacher motivation:

- the challenges faced by teachers working in particular education systems in low-income contexts

- the perceptions of those teachers regarding their ability to influence key educational processes and reach specific outcomes

- the levels of teacher job satisfaction and well-being within the educational systems in which they work

- the beliefs about teaching and learning held by teachers as well as their current practices connected to those beliefs

To probe and better understand these factors, Save the Children and World Vision International developed the Teacher Motivation Diagnostic Tool through an iterative process of piloting, adaptation, and implementation. Its explicit purpose was to explore how these factors interacted in particular school systems and country contexts and thereby enable the planning of 
professional development programs, training, and other supports that would directly address the identified issues. The conceptual framework-built on the previously reviewed literature and structured to explore new connections between concepts-is explained further in the next section.

\section{Conceptual Framework of the Teacher Motivation Diagnostic Tool}

The conceptual framework underpinning the Teacher Motivation Diagnostic Tool is that teacher well-being influences teacher motivation, which then in turn influences student learning outcomes and student well-being (Guajardo, 2011). Importantly, as highlighted earlier, teacher motivation and well-being are crucial components for a teacher to be willing to change-that is, to continue improving, working hard, and putting forth the best effort to ensure his or her students learn.

The tool design rests on the assumption that basic needs must be met before teachers can be motivated to fulfill their higher-order needs of self-actualization and professional goal attainment. Once basic needs are satisfied and extrinsic (or external) environmental factors are accounted for, a focus on supporting intrinsic motivation will have a more positive long-term effect on teacher effort, performance, and professional conduct.

Developed using Guajardo's (2011) Teacher Motivation Framework of Analysis, the tool can be used to explore and comprehend issues of teacher motivation in developing countries. The framework underpinning Version 1.0-the primary tool of reference in this chapter-includes eight interconnected categories:

1. Workload and challenges

2. Remuneration and incentives

3. Recognition and prestige

4. Accountability

5. Career development

6. Institutional environment

7. Voice

8. Learning materials and facilities

These categories acknowledge and recognize that teachers face increasing demands and challenges in the classroom (category 1), yet the motivational 
supports needed to help teachers confront these demands are often decreasing or stagnant (categories 2-8). Research shows that teacher salaries are generally low and paid irregularly, the teaching profession lacks prestige, there is weak school accountability and little support for teachers, few opportunities for professional development and growth exist within the profession, poor school management is coupled with unclear policies and a constantly changing policy environment, teachers have little opportunity to share concerns or provide input on policy and practice, and teaching facilities and learning materials are of poor quality and in limited supply (Guajardo, 2011).

Overall, Guajardo's (2011) Teacher Motivation Framework of Analysis suggests two basic approaches to improve motivation: (1) ensure teacher workload is commensurate with the seven remaining motivational supports, and (2) balance extrinsic and intrinsic motivational supports while prioritizing intrinsic supports as the most effective motivators over the long term. Heavy workloads and difficult challenges with no support lead to demotivated teachers, whereas a more manageable workload with appropriate supports can significantly increase motivation and thus have a positive effect on student learning (Guajardo, 2011).

\section{Methodology}

\section{Teacher Motivation Diagnostic Tool}

The Teacher Motivation Diagnostic Tool was developed as part of a collaboration called the Save the Children-World Vision "Literacy Boost Partnership." These two organizations wanted to highlight a range of factors that might threaten the implementation quality and impact of teachertraining programs.

The original Teacher Motivation Diagnostic Tool (Version 1.0) used in the 2014 India study presented in this chapter included 180 questions divided into eight sections. The research questions addressed by the tool were as follows:

1. What is the average teacher profile?

2. What is the level of teacher motivation, job satisfaction, commitment, and well-being?

3. What factors do teachers report as most motivating or most demotivating?

4. How do teachers usually spend their time? 
5. What are the major challenges faced by teachers?

6. What extrinsic and intrinsic factors do teachers face that are commonly associated with teacher motivation in low-income contexts?

7. To what degree do teacher self-efficacy, values, practices, and beliefs align with evidence-based best practices?

8. What professional development and support would teachers most value?

9. How does teacher motivation or best effort correlate with other variables?

Table 8-1 provides an overview of the tool used in India in 2014.

Program managers administered the Teacher Motivation Diagnostic Tool to teachers before a planned professional development program began. This program was part of the Promoting Literacy for Children Project (Pro-Lit), which was implemented by World Vision International with technical assistance from Save the Children. In this iteration (i.e., Version 1.0), the tool was thus intended to serve as a needs assessment of teacher motivation levels, allowing the program to take into account the challenges that teachers were currently facing as well as the factors that contributed most to their motivation and job satisfaction. Ultimately, managers also would use this information as the program unfolded to address challenges and opportunities related to teacher motivation and to target their efforts to ensure a more effective, contextualized, and needs-responsive delivery and implementation.

\section{Context}

In 2014 the Teacher Motivation Diagnostic Tool survey was conducted in two northern Indian states: Uttar Pradesh and Jharkhand. Specifically, the tool was piloted at four implementation sites in Agra and Aparajita (Uttar Pradesh) and Borio and Dumka (Jharkhand).

In Uttar Pradesh, even though net enrollment was nearly 100 percent for both boys and girls, the state still confronted several education-related issues that are likely to negatively affect student achievement. Uttar Pradesh had a teaching shortage and required 176,000 additional teachers to fill the 23 percent of posts that were vacant. Another major challenge was teacher absenteeism. In fact, the state had the second highest absenteeism rate among teachers: up to 31 percent of teachers in rural primary schools were 
Table 8-1. Overview of Teacher Motivation Diagnostic Tool for India, 2014

\begin{tabular}{|c|c|c|}
\hline Tool section & $\begin{array}{l}\text { Number of } \\
\text { questions }\end{array}$ & Rationale \\
\hline $\begin{array}{l}\text { 1. Teacher Self- } \\
\text { Defined Motivation, } \\
\text { Challenges, and } \\
\text { Support }\end{array}$ & 25 & $\begin{array}{l}\text { Allow teachers to define their own motivation, } \\
\text { highlight their most pressing challenges, and indicate } \\
\text { what type of support/recognition they most value. }\end{array}$ \\
\hline 2. Self-Efficacy & 15 & $\begin{array}{l}\text { Understand teachers' perceptions of their ability to } \\
\text { influence various processes and outcomes. Where do } \\
\text { teachers feel the most confident/helpless? }\end{array}$ \\
\hline $\begin{array}{l}\text { 3. Self-Reported } \\
\text { Practices }\end{array}$ & 20 & $\begin{array}{l}\text { Understand what practices teachers think are } \\
\text { important, and how frequently teachers engage in } \\
\text { these practices. }\end{array}$ \\
\hline 4. Belief Statements & 60 & $\begin{array}{l}\text { Understand teachers' job satisfaction, commitment, } \\
\text { well-being, common intrinsic and extrinsic factors that } \\
\text { influence teacher motivation, beliefs about the best } \\
\text { way to teach, and enabling factors for adoption of new } \\
\text { techniques. }\end{array}$ \\
\hline $\begin{array}{l}\text { 5. Concerns-Based } \\
\text { Adoption Model }\end{array}$ & 14 & $\begin{array}{l}\text { Understand the nature of teachers' concerns about the } \\
\text { program about to be implemented to better preempt } \\
\text { and address these concerns. }\end{array}$ \\
\hline $\begin{array}{l}\text { 6. Teacher Motivation } \\
\text { Support Ideas }\end{array}$ & 10 & $\begin{array}{l}\text { Understand which suggested interventions for } \\
\text { supporting teacher motivation teachers find most } \\
\text { promising. }\end{array}$ \\
\hline $\begin{array}{l}\text { 7. Professional } \\
\text { Development } \\
\text { Needs }\end{array}$ & 10 & $\begin{array}{l}\text { Understand what teachers want for professional } \\
\text { development. }\end{array}$ \\
\hline $\begin{array}{l}\text { 8. Teacher } \\
\text { Background }\end{array}$ & 25 & $\begin{array}{l}\text { Establish a teacher profile and look at whether } \\
\text { particular types of teachers are demotivated. } \\
\text { Understand common challenges and } \\
\text { counterbalancing supports. }\end{array}$ \\
\hline
\end{tabular}

Note: The table shows Version 1.0 of the Teacher Motivation Diagnostic Tool piloted in India. After this study, a Version 2.0 was created and piloted in diverse country contexts. As of the writing of this chapter in early 2018 , the most recent version of the tool included approximately 90 questions divided into six sections. The conceptual framework underpinning Version 2.0 also had evolved significantly.

Sources that laid the groundwork for Version 1.0 of the tool: Bandura (1962), Deci \& Ryan (1985), Herzberg (1966), Maslow (1943), STIR Education and Columbia Earth Institute's Teacher Survey (Bajaj \& lyengar, 2015), International Rescue Committee's Quantitative Teacher Well-Being Survey (Frisoli, 2013), Education Development Center's Teacher Belief in Mali and Congo studies (Louge, 2014), Teacher Motivation Actionable Framework for Intervention (Richardson, 2014), Concerns-Based Adoption Model (Hall, 1974), Capability Approach/Critical Realism (Tao, 2013).

consistently absent. While more than 84 percent of teachers were technically qualified, such qualifications will have no impact if teachers are not present in school and teaching students. Consequently, half of primary-age children were reported to drop out by grade 5 (Ministry of Human Resource Development, 2012). 
In Jharkhand, where nearly all primary-age children (including girls) were enrolled in school, approximately 30 percent of primary-age children were reported to drop out by grade 5 (Ministry of Human Resource Development, 2012). Up to 45 percent of teachers were regularly absent in Jharkhand, the highest absence rate throughout India (Muralidharan, Das, Holla, \& Mohpal, 2017). High absenteeism coupled with the fact that 46 percent of teachers were unqualified is significant.

\section{Sampling Method}

Chronologically, the project team first carried out a baseline student literacy assessment; then, the tool was administered to 115 government primary school teachers and 299 students throughout 76 schools across the four sites; and, finally, teachers were trained by the Pro-Lit program. An original sample of 80 schools was purposively sampled (Creswell, 2013) based on criteria for inclusion in a randomized controlled trial of Pro-Lit. Specifically, 20 schools were identified and selected because they matched the following selection criteria: government schools as similar as possible to each other in terms of student population, number of teachers, number of grades, and other variables. The final sample, however, contained 76 schools.

At each of the 76 schools where data were collected, the school was contacted in advance to ensure that the teacher(s) would be present for the interview. Interview teams were given instructions to interview up to two teachers per school. For a multitude of reasons, many schools either employed only one teacher, or only one teacher was present on the day that the interview teams visited. Consequently, in 37 schools, the only employed teacher participated, while in 39 schools two teachers were interviewed. Table 8-2 displays the number of schools and teachers interviewed for the Teacher Motivation Diagnostic Tool survey in India.

The Save the Children and World Vision International research team trained enumerators in basic interview techniques. The enumerators then administered the tool across the four research sites. Upon completion of the data collection process, the research team cleaned the quantitative data and entered it into Stata Version 13 for analysis. Data from the open-ended qualitative survey questions were manually coded for key themes. The next section presents the findings from the pilot of the Teacher Motivation Diagnostic Tool in Uttar Pradesh and Jharkhand. 
Table 8-2. Sample for pilot of the Teacher Motivation Diagnostic Tool in northern India

\begin{tabular}{lllllll}
\hline & \multicolumn{2}{c}{ Uttar Pradesh } & & \multicolumn{2}{c}{ Jharkhand } & \\
\cline { 2 - 3 } Sample category & Agra & Aparajita & & Borio & Dumka & Total \\
\hline Number of schools & 20 & 20 & & 18 & 18 & 76 \\
\hline Number of teachers & 31 & 29 & & 24 & 31 & 115 \\
\hline Number of students & 80 & 80 & 63 & 76 & 299 \\
\hline
\end{tabular}

\section{Findings}

\section{Teacher Characteristics}

Slightly less than half of the sampled teachers were female. Fewer than 20 percent of the sampled teachers were permanent civil servant teachers, while approximately half of the sampled teachers were para-teachers, or members of the community hired to teach on a contract basis. In Borio, 71 percent of the sampled teachers were para-teachers. An additional 3 percent of teachers were teachers in training. Table 8-3 summarizes the background information for the sampled teachers in Uttar Pradesh and Jharkhand.

The average age of sampled teachers was 39, while sampled teachers in Agra were slightly older, on average. Not surprisingly, sampled teachers in Agra were also generally more experienced, having taught for an average of 19 years compared with the average 10-13 years of experience among teachers in

Table 8-3. Descriptive statistics of sampled teachers $(N=115)$

\begin{tabular}{lccccccc}
\hline & \multicolumn{2}{c}{ Uttar Pradesh } & & \multicolumn{2}{c}{ Jharkhand } & \\
\cline { 2 - 3 } Characteristic & Agra & Aparajita & & Borio & Dumka & Average \\
\hline Percent female & 90 & 31 & & 16 & 35 & 45 \\
\hline Percent permanent teachers & 13 & 30 & & 13 & 23 & 19 \\
\hline Average age (years) & 43 & 38 & 38 & 36 & 39 \\
\hline Total years of experience & 19 & 10 & 13 & 11 & 13 \\
\hline Taken and passed Teacher Eligibility Test & 10 & 29 & 42 & 29 & 28 \\
\hline Duration of pre-service training (months) & 10 & 9 & & 4 & 2 & 6 \\
\hline Years of experience at current school & 11 & 5 & 10 & 10 & 9 \\
\hline $\begin{array}{l}\text { Total number of schools at which teacher } \\
\text { has taught }\end{array}$ & 3 & 2 & 1 & 1 & 2 \\
\hline
\end{tabular}


the other three areas. Most sampled teachers across all four areas had taught in only one or two schools, which suggests that teacher turnover may not be a serious issue in these two states.

Teachers in the sample were relatively highly educated. While nearly 70 percent of sampled teachers had at least a bachelor's degree, only 28 percent had passed India's Teacher Eligibility Test. Although it is supposedly compulsory for all teachers to pass the exam before they can start teaching, fewer than half of the sampled teachers in Borio and Dumka, and only 10 percent of teachers in Agra, had done so. As such, technically speaking, teachers in this sample were underqualified.

The amount of pre-service training varied across the sample of teachers; however, 41 percent of teachers reported having received no pre-service training at all. The average amount of training for those teachers who did report receiving pre-service preparation was six months. Teachers in Dumka reported receiving about 2 months of training, and teachers in Agra received up to 10 months of training. Additional data show that across all four research sites, teachers likewise reported that they did not frequently attend in-service training.

While teachers' lack of both pre-service and in-service training and professional development may directly (negatively) affect student achievement, it may also hinder teachers' self-efficacy (Bandura, 1986). For example, if teachers have not received adequate training, they may not perceive themselves as capable of fulfilling their responsibilities as teachers-that is, to deliver the best possible instruction for students to learn. Mastery is a key process through which self-efficacy is developed, and mastery experiences are more difficult to achieve without key teacher support and professional development mechanisms in place.

\section{Teachers' Working Conditions and Related Challenges}

To understand teacher motivation, particularly across these four research sites, it is necessary to first know about their working conditions and workrelated challenges. Teachers reported on the time they spent traveling to and from school, preparing lessons, teaching classes, marking exercise books, teaching free remedial lessons, collaborating with colleagues, and meeting with parents. Figure 8-1 summarizes teachers' reported time spent on daily activities and Figure 8-2 their weekly activities. 
Figure 8-1. Sampled teachers' reported time spent on daily tasks in school $(N=115)$

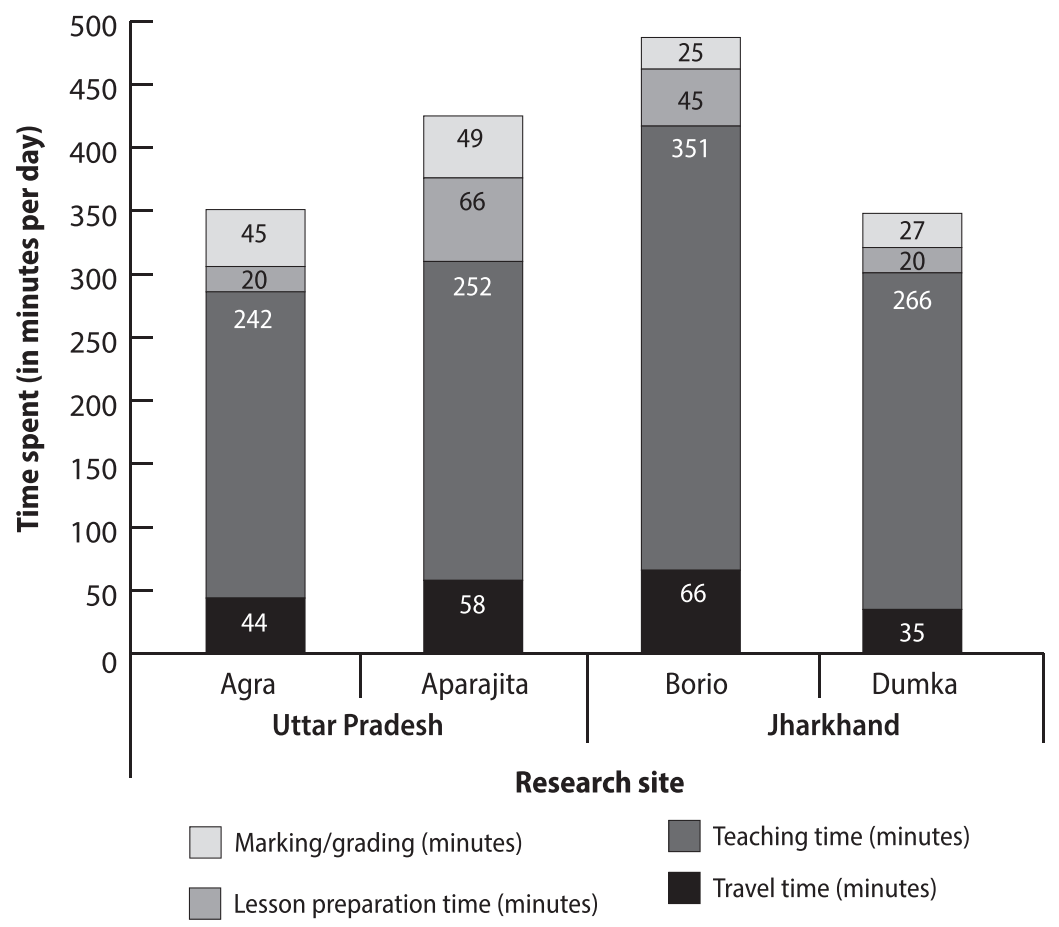

As highlighted in Figure 8-1, teachers said they spent most of their days on instructional time in the classroom, followed by lesson planning and marking exercise books. On average, teachers in Borio traveled for over an hour to and from school each day.

Teachers likewise reported spending several hours each week facilitating extracurricular activities and teaching free remedial lessons. It is important to note that teachers across all four sites also said they took on private tuition tutoring to supplement their incomes. Teachers in Borio spent the least number of hours on extra work-related responsibilities, whereas teachers in both Agra and Aparajita in Uttar Pradesh reported spending the most time on extracurricular activities. Finally, teachers in Agra, Aparajita, and Dumka reported having one or two additional responsibilities, such as assisting with elections (50 percent) or assisting with census-related surveys (44 percent). 
Figure 8-2. Sampled teachers' reported time spent on weekly extra responsibilities $(N=115)$

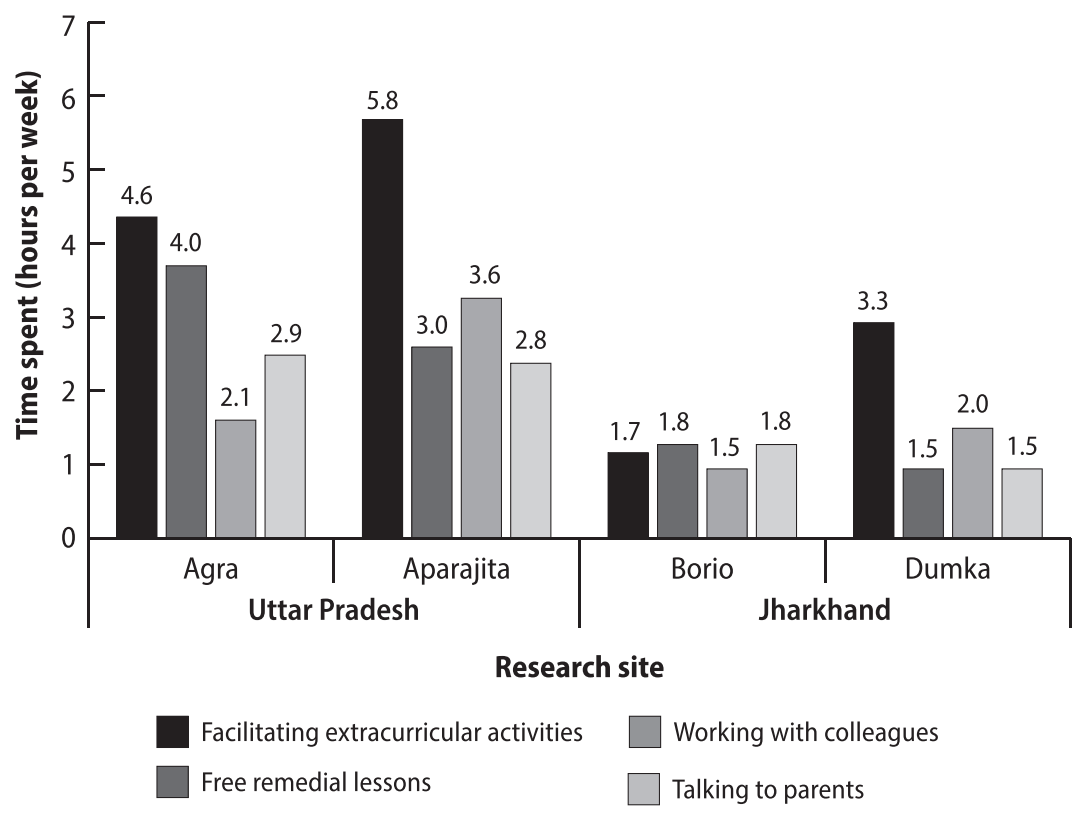

Sampled teachers seemingly had heavy teaching loads. Even so, aside from instruction, they fulfilled several other tasks at the school. In addition, as just mentioned, many teachers supplemented their incomes after school by taking on private tutoring. To what extent their basic needs (Maslow, 1943) were being met was not entirely clear from this data set, but the findings suggested that in many cases, they may not have been. For instance, fewer than half (48 percent) of all sampled teachers reported that they received their salary on time and that it was easily retrievable. In Dumka, only 32 percent of teachers agreed with this statement. Thus, on top of their already heavy workloads, teachers were frequently not paid on time or needed to travel to receive their pay. Moreover, their workloads at school did not accommodate their family obligations or other personal responsibilities, illustrating an example of McClusky's (1963) notion of a heavy 'load' with low power.

Given all their various responsibilities, the question remains as to whether these teachers would have the capacity to take on new learning opportunities, 
Table 8-4. Percentage of sampled teachers reporting classroom challenges $(N=115)$

\begin{tabular}{|c|c|c|c|c|c|}
\hline \multirow[b]{2}{*}{ Challenge } & \multicolumn{2}{|c|}{ Uttar Pradesh } & \multicolumn{2}{|c|}{ Jharkhand } & \multirow[b]{2}{*}{ Average } \\
\hline & Agra & Aparajita & Borio & Dumka & \\
\hline Had assistant or co-teacher & 39 & 63 & 67 & 52 & 55 \\
\hline Taught multigrade class & 43 & 95 & 96 & 7 & 60 \\
\hline Students spoke more than one mother tongue & 7 & 0 & 46 & 84 & 34 \\
\hline Had language communication issues & 0 & 4 & 13 & 39 & 14 \\
\hline Had social caste-related issues & 97 & 96 & 92 & 90 & 93 \\
\hline
\end{tabular}

such as professional development, or to incorporate regular learning into their already busy routines.

In addition to seemingly heavy workloads, teachers also reportedly faced several classroom challenges. Table 8-4 summarizes sampled teachers' reported classroom challenges across the four research sites. Over half (60 percent) of teachers reportedly had at least one multigrade class. In addition, 79 percent of sampled teachers reported that classroom management was a challenge, as was student health and well-being according to 84 percent of sampled teachers. Other frequently mentioned classroom challenges included poor student attendance, poor student attentiveness, and variation in students' skill levels. Interestingly, class size was not reported to be a challenge in this context. However, according to teachers, the average number of children who regularly attended their largest class was 13, and in Borio teachers reported an average number of 8 students who regularly attended their classes.

Language issues posed another challenge, particularly in Jharkhand. For instance, in Borio, 46 percent of teachers reported having classes with students who spoke different mother tongues, compared with 84 percent in Dumka. Consequently, 13 percent of teachers in Borio and 39 percent of teachers in Dumka reported having difficulties communicating with their students. Moreover, on average, 93 percent of teachers reported facing social- and cultural-related challenges, as they taught students from scheduled castes and scheduled tribes.

Again, self-efficacy is less likely to be developed when teachers perceive the challenges they face to be insurmountable. While language and communication issues as well as cultural differences can, of course, be significant challenges, it is even more difficult to ensure that students are 
learning to the best of their abilities when they are frequently late and/or absent. Such challenges can also lead to greater frustration, more stress, lower job satisfaction, and diminished personal well-being, particularly if teachers feel that they are not being adequately supported by their school leaders and students' parents.

\section{Teacher Motivation}

On the Teacher Motivation Diagnostic Tool, teachers were first asked to selfassess their motivation on a four-point scale ranging from "very demotivated" and "somewhat demotivated" to "somewhat motivated" and "very motivated." Figure 8-3 highlights teachers' self-reported level of motivation.

As highlighted earlier, self-report measures are prone to bias and therefore must be interpreted with caution. Nonetheless, most of these teachers reportedly were at least somewhat motivated across the four research sites. Next, we used proxy indicators to explore teacher motivation in greater depth, including teachers' practices and beliefs on a variety of issues.

Figure 8-3. Sampled teachers' reported motivation levels $(N=115)$

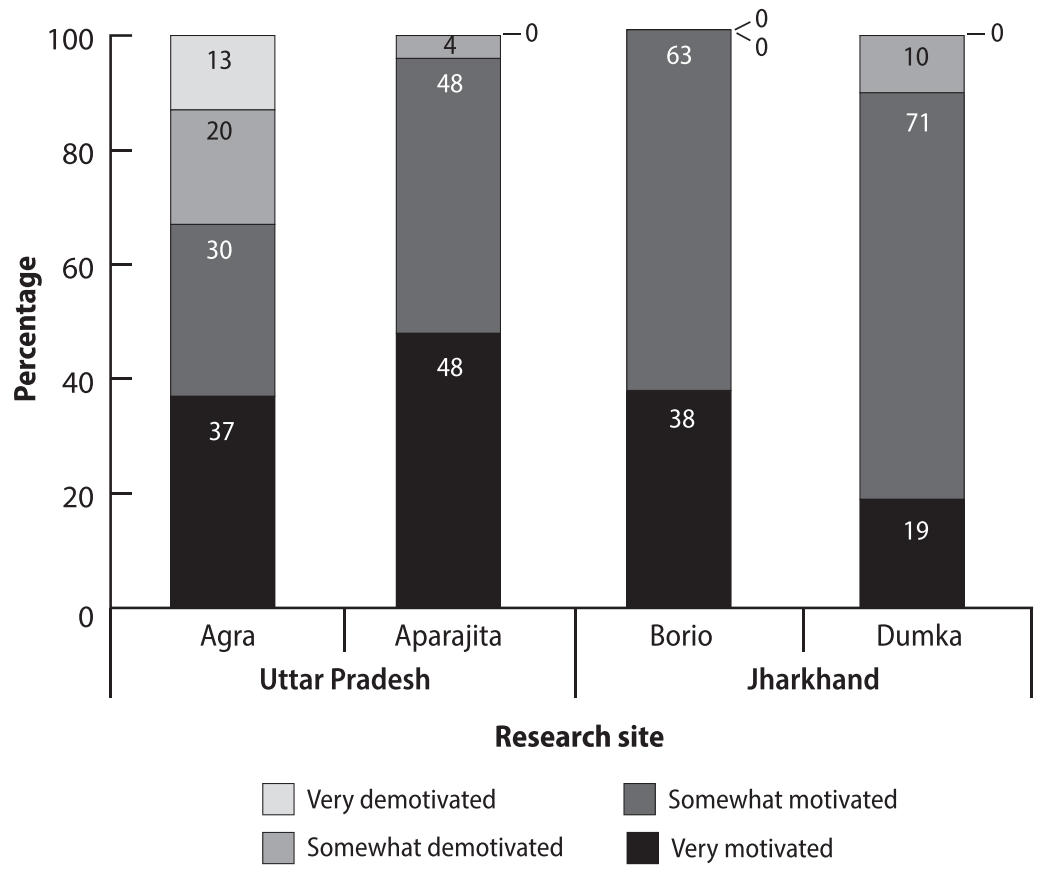


The reasons that teachers said they entered the profession in the first place may indicate, to an extent, their intrinsic motivation for teaching (see Table 8-5). According to 93 percent of sampled teachers, teaching was their first choice of career (not shown in Table 8-5). Specifically, these teachers joined the profession because of their love of working with children (77 percent), their belief in the importance of education (55 percent), and the desire to be like a childhood teacher (39 percent). In addition, 75 percent of sampled teachers said they believed that teaching is a skilled, professional job; and 83 percent were satisfied with their position.

As illustrated, these teachers appeared to be committed to their work, spending their free time working on lesson plans and other activities and responsibilities that might help the school. At the same time, teachers agreed that they did not feel good about wasting time at work and coming to school late.

In addition, teachers were spending several hours each week on nonteaching duties. They met with parents, facilitated extracurricular

Table 8-5. Percentage of sampled teachers who agreed with belief statements $(N=115)$

\begin{tabular}{|c|c|c|c|c|c|}
\hline \multirow[b]{2}{*}{ Belief statement } & \multicolumn{2}{|c|}{ Uttar Pradesh } & \multicolumn{2}{|c|}{ Jharkhand } & \multirow[b]{2}{*}{ Average } \\
\hline & Agra & Aparajita & Borio & Dumka & \\
\hline $\begin{array}{l}\text { Teaching is a highly skilled and } \\
\text { professional job. }\end{array}$ & 84 & 84 & 77 & 58 & 75 \\
\hline I am satisfied with my job. & 87 & 76 & 79 & 89 & 83 \\
\hline $\begin{array}{l}\text { I notice that there is a great deal of } \\
\text { complaining and dissatisfaction among } \\
\text { our staff. }\end{array}$ & 21 & 25 & 23 & 16 & 21 \\
\hline $\begin{array}{l}\text { I would like to remain a teacher but } \\
\text { transfer to another school. }\end{array}$ & 25 & 57 & 39 & 40 & 40 \\
\hline $\begin{array}{l}\text { Teachers should go home at the end of } \\
\text { the day even if they have not finished all } \\
\text { of their work. }\end{array}$ & 37 & 36 & 22 & 54 & 38 \\
\hline $\begin{array}{l}\text { I feel uncomfortable about wasting time } \\
\text { at work. }\end{array}$ & 84 & 69 & 71 & 69 & 73 \\
\hline $\begin{array}{l}\text { Teachers should take on more activities } \\
\text { and responsibilities if it helps the school. }\end{array}$ & 81 & 81 & 75 & 78 & 79 \\
\hline I feel uncomfortable if I come to class late. & 81 & 82 & 75 & 89 & 82 \\
\hline $\begin{array}{l}\text { Teachers should only give extra help to } \\
\text { students after school if students pay. }\end{array}$ & 23 & 27 & 75 & 66 & 47 \\
\hline $\begin{array}{l}\text { I spend my free time working on my } \\
\text { lesson plans. }\end{array}$ & 72 & 78 & 82 & 59 & 72 \\
\hline
\end{tabular}


activities, and marked student assessments such as homework or quizzes. Time spent on lesson planning and marking was positively correlated with teachers' self-reported motivation levels $(p<.05)$, which suggests that it could be a relevant proxy for motivation. While again it should be interpreted cautiously, 87 percent of teachers reported attending school all days, and only 2 percent of teachers reported missing three or more days of work.

Remarkably, 73 percent of teachers reported paying for teaching and learning materials out-of-pocket at least once per week, and 83 percent of teachers reported volunteering for other teachers at least once per week when their colleagues were absent.

Intrinsic motivators, as highlighted earlier (Deci \& Ryan, 2000), are crucial for self-determination and autonomous behaviors, such as participating in professional development trainings or professional learning circles. Indeed, in spite of their heavy workloads and classroom challenges, these teachers' love of working with children and their willingness to spend more time and resources on preparation and instruction are important and positive factors for continuing to promote teachers' skills, willingness to improve, and job satisfaction. These intrinsic motivators can be reinforced through training and in-school support in an effort to continue fostering self-efficacy in teachers.

Moreover, another possible gauge of teacher motivation is teachers' behavior toward students. For instance, motivated teachers ensure that all students - regardless of age, gender, or learning needs-receive attention and support. Approximately 93 percent of teachers agreed or strongly agreed that "although some students may require more attention than others, all students are equally capable of learning." Relatedly, 79 percent of teachers reported that they gave extra help to students whom they noticed struggling at least a few times per week and sometimes every day.

In addition to treating children equitably, it is also important for teachers to ensure that children are safe and protected in their schools and classrooms. Across all four research sites, 94 percent of teachers reported that they agreed with the statement "I am responsible for the students' safety and well-being." The majority of students ( 85 percent) similarly reported that their teachers smiled, laughed, and joked most of the time. In addition, 70 percent of students commented that their teachers advised them on how to learn to read better, and 60 percent of students said they felt their teachers made them want to come to school. 
Furthermore, self-efficacy is an important factor in personal and professional motivation. The diagnostic tool for India included 15 questions related to teachers' perceptions of their self-efficacy. Teachers were asked questions such as, "How capable are you to help the lowest-performing students learn to read?" and "How capable are you to assist parents in helping their children do well in school?” Teachers were asked to indicate how capable they felt to perform the given task, on a scale of 0 to 100 percent. Table 8-6 summarizes teachers' responses to these statements.

In general, teachers rarely reported feeling very capable or incapable of completing various tasks. On average, teachers felt most capable in motivating their learners to show interest in schoolwork, facilitating students to work together in groups or pairs, and assessing students' learning progress. Sampled teachers likewise felt they were able to help other teachers with their teaching skills. Teachers' lack of perceived self-efficacy could indicate that they would benefit from increased professional development and support. Indeed, teachers identified the specific areas they felt they had not yet mastered or were not confident in addressing. This process of identifying needs presents an opportunity to develop tailored professional development that is relevant and contextualized.

\section{Discussion}

As part of the pilot, the field research team constructed a teacher motivation index from the following indicators: whether teaching was the first-choice job for the teacher, the most common intrinsic reasons for becoming a teacher, the amount of time spent lesson planning, reported attendance for the week before the interview, and the sum of teacher practices and beliefs associated with theories and literature on teacher motivation. When the data were processed using the index, the findings suggested that the teacher motivation index as a whole had a moderately positive and statistically significant correlation with teachers' self-reported levels of motivation $(r=0.29 ; p<.01)$.

Overall, sampled teachers in the four districts of Uttar Pradesh and Jharkhand seemingly were motivated. They not only reported feeling motivated themselves but also demonstrated being motivated, as their beliefs about their students, their own self-efficacy, and their behavior toward students suggested. Results from the pilot also revealed a relationship between teacher motivation and teacher background characteristics, as well 
Table 8-6. Teachers' reported perceptions of their self-efficacy: Averages from a scale of 0 to 100 percent $(N=115)$

\begin{tabular}{|c|c|c|c|c|c|}
\hline \multirow[b]{2}{*}{ Self-efficacy questions } & \multicolumn{2}{|c|}{ Uttar Pradesh } & \multicolumn{2}{|c|}{ Jharkhand } & \multirow[b]{2}{*}{ Average } \\
\hline & Agra & Aparajita & Borio & Dumka & \\
\hline \multicolumn{6}{|l|}{ How capable are you... } \\
\hline $\begin{array}{l}\text { 1. To influence the decisions that are } \\
\text { made in the school? }\end{array}$ & 63 & 56 & 53 & 48 & 55 \\
\hline $\begin{array}{l}\text { 2. To obtain the instructional } \\
\text { materials and equipment you } \\
\text { need? }\end{array}$ & 61 & 48 & 63 & 56 & 57 \\
\hline $\begin{array}{l}\text { 3. To help the lowest-performing } \\
\text { students learn to read? }\end{array}$ & 69 & 57 & 74 & 65 & 66 \\
\hline $\begin{array}{l}\text { 4. To motivate students who show } \\
\text { low interest in schoolwork? }\end{array}$ & 78 & 67 & 75 & 63 & 71 \\
\hline $\begin{array}{l}\text { 5. To get students to work together } \\
\text { in groups or pairs? }\end{array}$ & 81 & 67 & 70 & 72 & 73 \\
\hline $\begin{array}{l}\text { 6. To overcome the influence of } \\
\text { adverse community conditions on } \\
\text { students' learning? }\end{array}$ & 58 & 42 & 66 & 32 & 49 \\
\hline $\begin{array}{l}\text { 7. To get students to do their } \\
\text { homework regularly? }\end{array}$ & 68 & 64 & 68 & 64 & 66 \\
\hline $\begin{array}{l}\text { 8. To assess students' learning level } \\
\text { and progress? }\end{array}$ & 76 & 64 & 81 & 60 & 70 \\
\hline $\begin{array}{l}\text { 9. To control disruptive behavior in } \\
\text { the classroom? }\end{array}$ & 72 & 57 & 56 & 68 & 64 \\
\hline $\begin{array}{l}\text { 10. To assist parents in helping their } \\
\text { children do well in school? }\end{array}$ & 64 & 46 & 61 & 54 & 56 \\
\hline $\begin{array}{l}\text { 11. To get community groups involved } \\
\text { in working with the schools? }\end{array}$ & 74 & 67 & 58 & 62 & 66 \\
\hline $\begin{array}{l}\text { 12. To make the school a safe place for } \\
\text { students? }\end{array}$ & 73 & 67 & 57 & 60 & 65 \\
\hline $\begin{array}{l}\text { 13. To make students enjoy coming to } \\
\text { school? }\end{array}$ & 70 & 50 & 52 & 43 & 54 \\
\hline $\begin{array}{l}\text { 14. To help other teachers with their } \\
\text { teaching skills? }\end{array}$ & 76 & 64 & 81 & 60 & 70 \\
\hline $\begin{array}{l}\text { 15. To get students to believe they can } \\
\text { do well in schoolwork? }\end{array}$ & 83 & 63 & 66 & 60 & 68 \\
\hline
\end{tabular}

Note: Average percentage of self-efficacy = how capable a teacher feels to perform a certain task, from 0 percent to 100 percent. 
as work and environmental factors. On the one hand, teacher motivation was negatively correlated with class size and the number of nonteaching responsibilities. On the other hand, teacher motivation was positively correlated with the number of pre-training days and having an assistant or co-teacher. Connections emerged between teachers feeling demotivated by factors that increased their workload but consequently feeling motivated by factors that equipped them to better confront challenges in the classroom, which was the premise of the conceptual framework underlying the tool's development (Guajardo, 2011).

Although these teachers were ostensibly motivated overall, the majority (65 percent) expressed interest in receiving additional professional development, particularly on managing classroom-related challenges. Additionally, most teachers (84 percent) were eager to receive training on curriculum, student assessment, and how to better engage with and relate to students (81 percent). Indeed, teachers were generally interested in having access to more professional development opportunities, particularly because, at the time of the survey administration, significant time had passed since their last in-service training. Teachers in Borio reported that it had been almost 3 years (949 days) since their last in-service training, compared with 19 months for Agra teachers, 1 year for Aparajita teachers, and 6 months for teachers in Dumka. In short, while teachers demonstrated motivation to change-that is, to continue improving and growing professionally as well as gain skills for addressing their work-related challenges-they may have lacked the opportunities to do so.

Teachers also identified various strategies and supports that could be implemented to have a positive effect on their motivation and engagement in the profession. Table 8-7 summarizes teachers' self-reported level of interest (on a scale of 0 to 100 percent) in having access to a menu of options that could be used to support teacher motivation among those already in service.

As can be observed in Table 8-7, teachers were eager for more opportunities for collaboration, mentorship, and learning opportunities from their fellow teachers.

\section{Limitations}

This case study had certain limiting conditions, some of which were inherent to the various methodologies employed in the pilot study, while others were 


\begin{tabular}{|c|c|c|c|c|c|}
\hline \multirow[b]{2}{*}{ Options for motivational support } & \multicolumn{2}{|c|}{ Uttar Pradesh } & \multicolumn{2}{|c|}{ Jharkhand } & \multirow[b]{2}{*}{ Average } \\
\hline & Agra & Aparajita & Borio & Dumka & \\
\hline Training on managing classroom challenges & 70 & 67 & 66 & 58 & 65 \\
\hline Links to further education opportunities & 52 & 53 & 66 & 74 & 61 \\
\hline Video modeling outstanding teachers & 77 & 69 & 93 & 63 & 74 \\
\hline Head teacher and supervisor training & 72 & 71 & 66 & 49 & 64 \\
\hline $\begin{array}{l}\text { Sensitizing and mobilizing community } \\
\text { recognition }\end{array}$ & 69 & 76 & 48 & 57 & 63 \\
\hline Mobilizing community to provide support & 77 & 68 & 53 & 57 & 64 \\
\hline Teacher learning circles & 70 & 58 & 71 & 61 & 65 \\
\hline $\begin{array}{l}\text { Rewards for excellent teachers and teacher } \\
\text { professional development for struggling } \\
\text { teachers }\end{array}$ & 67 & 62 & 55 & 52 & 59 \\
\hline Mentorship program & 70 & 66 & 58 & 55 & 62 \\
\hline $\begin{array}{l}\text { Report card to stimulate community } \\
\text { engagement }\end{array}$ & 77 & 68 & 94 & 81 & 79 \\
\hline
\end{tabular}

Note: Figures here represent average percentage (\%) of interest in each of the strategies.

related to the research design for the pilot, adaptation, and subsequent implementation. First, the tool-development study was small in scope and the findings from this first implementation therefore cannot be generalized to other sites in Jharkhand and Uttar Pradesh, or across India. Relatedly, the four research sites were purposively selected and are not representative of their entire state, or of the country as a whole.

Second, in general, the tool relies heavily on teachers' self-reported data. While it does include a student interview, many of the findings from northern India, especially those pertaining to teacher beliefs and attitudes, could not be properly triangulated. Nevertheless, the findings from this first pilot of the tool can be used not only to refine the tool further but also to better understand teachers, and their attitudes and beliefs, in Uttar Pradesh and Jharkhand.

\section{Conclusions}

Teacher motivation is crucial to sustain a high-quality supply of teachers in any education system, and in low-income contexts in particular. When teachers are motivated, they are more likely to remain in the profession, continue improving their skills, and do all that they can to ensure students 
are learning. Conversely, when teachers are demotivated, they are more likely to be absent from school altogether, arrive late regularly, or leave the profession altogether. As such, decision makers need to promote policies to ensure that teachers are motivated and satisfied.

Most sampled teachers in the pilot study apparently were at least somewhat motivated in their current positions. While they faced no shortage of classroom challenges and undertook heavy workloads, they were generally satisfied with their jobs. As illustrated in the Findings section of this chapter, the teachers were certainly eager for and open to increased professional development opportunities. The challenge will be to ensure that such professional development adequately responds to the needs expressed by the teachers while also ensuring any new demands can be appropriately balanced with existing teacher workload to increase probability of success. In addition to training, teachers demonstrated interest in watching videos of exemplary teachers to observe how they manage similar classrooms, pedagogical strategies, curricula, and assessments in comparable contexts. Thus, teachers were interested and willing to learn from each other. As social cognitive theory (Bandura, 1986) posited, we learn from watching others.

Providing opportunities to observe and share with other teachers could be a key strategy for improving teacher self-efficacy. As such, it is worth exploring how professional learning circles, or teacher learning circles, could be leveraged to provide a platform for continuous professional development in which teachers could share with and learn more from each other. Furthermore, teacher professional development should be based on teachers' emerging needs, interests, and ideas. Teachers should be involved in designing professional development offerings, particularly those that complement in-person trainings and may be more challenging to sustain long term. Programs should also be designed in a way that connects deeply to the intrinsic motivation of teachers, providing ample opportunities to develop autonomy, mastery, and personal growth in the classroom and in the profession.

Sampled teachers also expressed interest in acquiring strategies to better engage community members and parents. For instance, teachers generally supported the issuing of school report cards to stimulate community and parent participation in the education process. As previously noted, teachers perceived student attendance, engagement, behavior, and well-being to be some of their greatest challenges. In other words, as nonschool factors interact with and influence the classroom experience, building stronger 
connections between the school and community is critical. If parent-teacher associations do not exist or if their activity is limited, it may be useful to revive or create similar platforms so that teachers and parents can collaborate on issues of mutual interest. Identifying strategic ways to better engage parents in their children's education not only will benefit student learning but also will have a positive effect on teachers and their motivation to provide the best possible instruction.

Moreover, as highlighted in the literature review, quality of work life is positively associated with teacher motivation (Baleghizadeh \& Gordani, 2012). While working conditions must improve, increased salaries alone are insufficient to compensate teachers for their efforts. Teachers appreciate recognition and positive feedback, and many studies show that teachers want to be recognized for good work, whether it is their own efforts or improved student learning outcomes (Adil \& Fatima, 2013; Adjei \& Amofa, 2014; Alam \& Farid, 2011, Gemeda \& Tynjälä, 2015).

In the Teacher Motivation Diagnostic Tool sample in India, approximately 60 percent of teachers across all sites indicated that rewarding exemplary teachers would have a positive effect on teacher motivation. "Teacher of the Year" campaigns, in-kind rewards such as bicycles, and certificates of appreciation or achievement are highly cost-effective and feasible ways to recognize teachers as they need and deserve to stay motivated. Such recognition can be directly connected to desired behavior changes, such as implementing new pedagogical techniques acquired in a training or professional development course.

Policy makers, donors, and nongovernmental organizations should consider these and other strategies to continue fostering teachers' motivation and to encourage their active pursuit of continuous growth and development as education professionals. Any efforts to address teacher motivation should take into consideration the various demands on teachers (i.e., personal and professional workload), ensure that the teachers' basic needs are met by the system to the extent possible, understand the factors influencing teacher motivation - both positively and negatively - in particular contexts, and adapt policies and programs to address those factors in a way that promotes sustainable change.

Save the Children and World Vision International designed the Teacher Motivation Diagnostic Tool to highlight the various factors that influence teachers' motivation and thus might affect their participation in professional 
development programs. Findings from the initial pilot of the tool (Version 1.0) explored these factors with a sample of 115 teachers in northern India. The two organizations then used the results from the pilot to refine the tool (Version 2.0) and since that time have also collected data in Bangladesh, Vietnam, and Cambodia.

This open-source tool can be used or adapted by researchers and institutions working with teachers in other contexts. The end goal is not only to gain greater understanding of the factors that motivate and demotivate teachers but also to ensure that professional development programs are designed with these factors in mind. Such efforts to link contextualized information on teacher motivation with professional development programs - which often place new demands on teachers-will have a greater likelihood of success. Teachers, students, and education systems globally will see benefits as a result.

We argue that teacher well-being influences teacher motivation, which in turn influences student learning outcomes. In alignment with the Education 2030 Framework for Action, we believe that to achieve increased quality of education and improved learning outcomes, "we [must] ensure that teachers and educators are empowered, adequately recruited, well-trained, professionally qualified, motivated and supported within well-resourced, efficient and effectively governed systems" (UNESCO, 2015b, p. 7). Concerted efforts must ensure that education systems are equipped to respond to the diverse needs of teachers and thus support their well-being and motivation to produce the best outcomes possible for learners.

\section{Acknowledgments}

The authors extend a special thank you to Save the Children US and World Vision International for their financial and technical support for exploring issues of teacher motivation in low-income contexts.

\section{References}

Adeyinka, A., Asabi, O., \& Adedotun, O. (2013). Teachers' motivation on students' performance in mathematics in government secondary schools, Makurdi Lg Area. International Journal of Humanities and Social Science Invention, 2(5), 35-41. Retrieved from http://www.ijhssi.org/papers/v2(5)/ version-2/E253541.pdf 
Adil, M. S., \& Fatima, N. (2013). Impact of rewards system on teacher's motivation: Evidence from the private schools of Karachi. Journal of Education and Social Sciences, 1(1), 1-19. Retrieved from http:/geistscience.com/papers/view/JESS1301101

Adjei, H., \& Amofa, A. K. (2014). Teacher motivation in senior high schools in the Cape Coast Metropolis. European Journal of Education and Development Psychology, 2(1), 18-25. Retrieved from http://www. eajournals.org/journals/european-journal-of-educational-anddevelopment-psychology-ejedp/vol-2issuelmarch-2014/ teacher-motivation-senior-high-schools-cape-coast-metropolis/

Akuoko, K. O., Dwumah, P., \& Baba, W. M. (2012). Teacher motivation and quality education delivery: A study of public basic schools in Tamale Metropolis in Ghana. International Journal of Social Science \& Interdisciplinary Research, 1(12), 29-46. Retrieved from http://www. indianresearchjournals.com/pdf/IJSSIR/2012/December/3.pdf

Alam, M. T., \& Farid, S. (2011). Factors affecting teachers motivation. International Journal of Business and Social Science, 2(1), 298-304. Retrieved from http://www.ijbssnet.com/journals/Vol._2_No._1\%3B_ January_2011/30.pdf

Al-Salameh, E. M. J. (2014). Teacher motivation: A study of work motivation of the primary stage teachers in Jordan. American Journal of Applied Psychology, 3(3), 57-61. https://doi.org/10.11648/ j.ajap.20140303.12

Ashton, P. (1984). Teacher efficacy: A motivational paradigm for effective teacher education. Journal of Teacher Education, 35(5), 28-32. https://doi. org/10.1177/002248718403500507

Bajaj, R., \& Iyengar, R. (2015). Teacher survey. New York, NY: STIR Education and Columbia University Earth Institute.

Baleghizadeh, S., \& Gordani, Y. (2012). Motivation and quality of work life among secondary school EFL teachers. Australian Journal of Teacher Education, 37(7), 30-42. https://doi.org/10.14221/ajte.2012v37n7.8

Bandura, A. (1962). Social learning through imitation. In M. R. Jones \& C. R. Rogers (Eds.), Nebraska symposium on motivation (Vol. 11 of Current theory and research in motivation, pp. 211-269). Lincoln, NE: University of Nebraska Press. 
Bandura, A. (1986). Social foundations of thought and action: A social cognitive theory. Englewood Cliffs, NJ: Prentice-Hall.

Bandura, A. (1994). Self-efficacy. In V. S. Ramachaudran (Ed.), Encyclopedia of human behavior (Vol. 4, pp. 71-81). New York, NY: Academic Press. (Also reprinted in H. Friedman [Ed.], Encyclopedia of mental health, San Diego, CA: Academic Press.)

Bastick, T. (2000, February). The measurement of teacher motivation: Crosscultural and gender comparisons. Paper presented at the 29th Annual Meeting of the Society for Cross-Cultural Research, New Orleans, LA. Retrieved from https://eric.ed.gov/?id=ED451254

Bénabou, R., \& Tirole, J. (2000). Self-confidence and social interactions (Working Paper No. 7585). Cambridge, MA: National Bureau of Economic Research. https://doi.org/10.3386/w7585

Bennell, P., \& Akyeampong, K. (2007). Teacher motivation in sub-Saharan Africa and South Asia (Educational Paper No. 71). London, United Kingdom: UK Department for International Development. Retrieved from https://assets.publishing.service.gov.uk/media/57a08be640f0b652dd000f9a/ ResearchingtheIssuesNo71.pdf

Chapman, D. W., Snyder, C. W., \& Burchfield, S. A. (1993). Teacher incentives in the third world. Teaching and Teacher Education, 9(3), 301-316. https://doi.org/10.1016/0742-051x(93)90045-i

Chireshe, R., \& Shumba, A. (2011). Teaching as a profession in Zimbabwe: Are teachers facing a motivation crisis? Journal of Social Sciences, 28(2), 113-118. Retrieved from http://www.krepublishers.com/02-Journals/JSS/ JSS-28-0-000-11-Web/JSS-28-2-000-2011-Abst-Pdf/JSS-28-2-113-11-1184Chireshe-R/JSS-28-2-113-11-1184-Chireshe-R-Tt.pdf

Creswell, J. W. (2013). Qualitative inquiry and research design: Choosing among five approaches. Thousand Oaks, CA: SAGE Publications.

Darling-Hammond, L. (2000). Teacher quality and student achievement. Education Policy Analysis Archives, 8(1), 1-41. https://doi.org/10.14507/ epaa.v8n 1.2000

Deci, E. L., \& Ryan, R. M. (1985). Intrinsic motivation and self-determination in human behavior. New York, NY: Plenum. https://doi.org/10.1007/ 978-1-4899-2271-7 
Deci, E. L., \& Ryan, R. M. (2000). The "what" and "why" of goal pursuits: Human needs and the self-determination of behavior. Psychological Inquiry, 11(4), 227-268. https://doi.org/10.1207/S15327965PLI1104_01

Dweck, C. S. (1986). Motivational processes affect learning. The American Psychologist, 41(10), 1040-1048. https://doi.org/10.1037/0003-066X.41. 10.1040

Eccles, J. (1983). Expectancies, values, and academic behaviors. In J. T. Spence (Ed.), Achievement and achievement motives: Psychological and sociological approaches (pp. 75-146). San Francisco, CA: W. H. Freeman.

Fogg, B. J. (2009, April). A behavior model for persuasive design. In Proceedings of the 4th International Conference on Persuasive Technology, Claremont, CA. Abstract retrieved from http://dl.acm.org/citation. cfm?id=1541999

Frisoli, P. S. J. (2013). Teachers' experiences of professional development in (post) crisis Katanga province, southeastern Democratic Republic of Congo: A case study of teacher learning circles (Doctoral dissertation). University of Massachusetts, Amherst. Abstract retrieved from https://scholarworks.umass.edu/dissertations_2/82

Gagné, M., Forest, J., Vansteenkiste, M., Crevier-Braud, L., van den Broeck, A., Aspeli, A. K., . . . Westbye, C. (2014). The Multidimensional Work Motivation Scale: Validation evidence in seven languages and nine countries. European Journal of Work and Organizational Psychology, 24(2), 178-196. https://doi.org/10.1080/1359432X.2013.877892

Gamero Burón, C., \& Lassibille, G. (2016). Job satisfaction among primary school personnel in Madagascar. The Journal of Development Studies, 52(11), 1628-1646. https://doi.org/10.1080/00220388.2016.1187726

Gemeda, F. T., \& Tynjälä, P. (2015). Exploring teachers' motivation for teaching and professional development in Ethiopia: Voices from the field. Journal of Studies in Education, 5(2), 169-186. https://doi.org/10.5296/jse. v5i2.7459

Guajardo, J. (2011). Teacher motivation: Theoretical framework, situation analysis of Save the Children country offices and recommended strategies. Washington, DC: Save the Children. Retrieved from https://www. oxfamnovib.nl/Redactie/Downloads/English/SPEF/281-24\%20Teacher\%20 Motivation\%20Report.pdf 
Hall, G. E. (1974, April). The concerns-based adoption model: A developmental conceptualization of the adoption process within educational institutions. Paper presented at the Annual Meeting of the American Educational Research Association, Chicago, IL. Retrieved from https://files.eric.ed.gov/ fulltext/ED111791.pdf

Hanushek, E. A., Kain, J., \& Rivkin, S. (2004). Why public schools lose teachers. The Journal of Human Resources, 39(2), 326-354. https://doi.org/10.2307/3559017

Harvey-Beavis, O. (2003, June). Performance-based rewards for teachers: A literature review. Paper for distribution at the 3rd Workshop of Participating Countries on OECD's Activity Attracting, Developing and Retaining Effective Teachers, Athens, Greece. Retrieved from http://www.oecd.org/education/school/34077553.pdf

Hasan, A. R., \& McDonald, L. (2015). Teachers' motivation in the Maldives: Vital but context-specific. International Journal o Social Science and Humanity, 5(4), 378-383. https://doi.org/10.7763/IJSSH.2015.V5.484

Herzberg, F. I. (1966). Work and the nature of man. Cleveland, OH: World Publishing.

Hettiarachchi, S. (2013). English language teacher motivation in Sri Lankan public schools. Journal of Language Teaching and Research, 4(1), 1-11. https://doi.org/10.4304/jltr.4.1.1-11

Heystek, J., \& Terhoven, R. (2014). Motivation as critical factor for teacher development in contextually challenging underperforming schools in South Africa. Professional Development in Education, 41(4), 624-639. https://doi.org/10.1080/19415257.2014.940628

Hobson, A., \& Maxwell, B. (2017). Supporting and inhibiting the well-being of early career secondary school teachers: Extending self-determination theory. British Educational Research Journal, 43(1), 168-191.

Hulin, C. L., \& Judge, T. A. (2003). Job attitudes. In W. C. Borman, D. R. Ilgen, \& R. J. Klimoski (Eds.), Handbook of Psychology: Industrial and organizational psychology (Vol. 12, pp. 255-276). Hoboken, NJ: Wiley.

Irwandy, D. (2014). Assessing the role of motivation on teacher performance: Case study in Indonesia. International Journal of Education \& Literacy Studies, 2(2), 90-95. https://doi.org/10.7575/aiac. ijels.v.2n.2p.90 
Koestner, R., Otis, N., Powers, T. A., Pelletier, L., \& Gagnon, H. (2008).

Autonomous motivation, controlled motivation, and goal progress. Journal of Personality, 76(5), 1201-1230. https://doi.org/10.1111/j.1467-6494.2008.00519.x

Ladyong, B. L. (2014). Organizational climate and teachers' work motivation: A case study of selected schools in Prachinburi, Thailand. Scholarly Journal of Education, 3(5), 52-57. Retrieved from http://scholarly-journals. com/sje/archive/2014/August/pdf/Ladyong.pdf

Locke, E. A. (1976). The nature and causes of job satisfaction. In M. D. Dunnette (Ed.), Handbook of industrial and organizational psychology (pp. 1297-1343). Chicago, IL: Rand McNally.

Louge, N. (2014). Teachers' literacy knowledge, instructional practices, and their students' reading performance in PAQUED-supported schools in the Democratic Republic of Congo. Boston, MA: EDC. Retrieved from idd.edc.org/sites/idd.edc.org/files/PAQUED\%20Research\%20Report.pdf

Maslow, A. H. (1943). A theory of human motivation. Psychological Review, 50(4), 370-396. https://doi.org/10.1037/h0054346

Matoke, Y. K., Okibo, W. B., \& Nyamongo, D. N. (2015). Determinants of teacher motivation in public secondary schools in Masaba South SubCounty, Kenya. International Journal of Economics, Commerce, and Management, 3(6), 139-160. Retrieved from http://ijecm.co.uk/ wp-content/uploads/2015/06/3611.pdf

McClusky, H. Y. (1963). The course of the adult life span. In W. C. Hallenbeck (Ed.), Psychology of adults (pp. 10-20). Chicago, IL: Adult Education Association of the USA.

McKinsey \& Company. (2007). How the world's best-performing school systems come out on top. Washington, DC: McKinsey \& Company. Retrieved from http://mckinseyonsociety.com/how-the-worldsbest-performing-schools-come-out-on-top/

Milyavskaya, M., \& Koestner, R. (2011). Psychological needs, motivation, and well-being: A test of self-determination theory across multiple domains. Personality and Individual Differences, 50(3), 387-391. https://doi.org/10.1016/j.paid.2010.10.029

Ministry of Human Resource Development, Bureau of Planning, Monitoring \& Statistics [India]. (2012). Statistics of school education 20112012. New Delhi, India: Ministry of Human Resource Development. 
Muralidharan, K., Das, J., Holla, A., \& Mohpal, A. (2017). The fiscal cost of weak governance: Evidence from teacher absence in India. Journal of Public Economics, 145, 116-135. https://doi.org/10.1016/j.jpubeco. 2016.11.005

Ndani, M. N., \& Kimani, E. N. (2010). Factors influencing early childhood development teachers' motivation in Thika District, Kenya. African Journal of Teacher Education, 1(1), 34-47. Retrieved from https://journal. lib.uoguelph.ca/index.php/ajote/article/view/1592

Nicholls, J. G. (1984). Achievement motivation: Conceptions of ability, subjective experience, task choice, and performance. Psychological Review, 91(3), 328-346. https://doi.org/10.1037/0033-295X.91.3.328

Nyarko, K., Twumwaa, D. A., \& Adentwi, K. I. (2014). The influence of motivation on the job satisfaction of junior high school teachers in Ghana. Journal of Education and Practice, 5(5), 202-209. Retrieved from http://www.iiste.org/Journals/index.php/JEP/article/download/10972/11273

Ofoegbu, F. I. (2004). Teacher motivation: A factor for classroom effectiveness and school improvement in Nigeria. College Student Journal, 38(1), 81-89.

Richardson, E. (2014). Teacher motivation in low-income contexts: An actionable framework for intervention (Policy Publication 2). New York, NY: Teacher Motivation Working Group. Retrieved from http://www. teachersforefa.unesco.org/tmwg/blog2/wp-content/uploads/2015/03/ Teacher-Motivation-in-Low-Income-Contexts.pdf

Ryan, R. M., \& Deci, E. L. (2000). Intrinsic and extrinsic motivations: Classic definitions and new directions. Contemporary Educational Psychology, 25(1), 54-67. https://doi.org/10.1006/ceps.1999.1020

Salifu, I. (2014). Barriers to teacher motivation for professional practice in the Ghana Education Service. Policy Futures in Education, 12(5), 718-729. https://doi.org/10.2304/pfie.2014.12.5.718

Selemani-Meke, E. (2013). Teacher motivation and implementation of continuing professional development programmes in Malawi. Anthropologist, 15(1), 107-115. Retrieved from http://www.krepublishers. com/02-Journals/T-Anth/Anth-15-0-000-13-Web/Anth-15-1-000-2013Abst-PDF/T-ANTH-15-1-107-13-767-Selemani-Meke-E/T-ANTH-15-1-10713-767-Selemani-Meke-E-Tx\%5B11\%5D.pmd.pdf 
Sheikh Ali, A. Y., Dahie, A. M., \& Ali, A. A. (2016). Teacher motivation and school performance, the mediating effect of job satisfaction: Survey from secondary schools in Mogadishu. International Journal of Education and Social Science, 3(1), 24-38. Retrieved from http://www.ijessnet.com/ wp-content/uploads/2016/02/4.pdf

Smith, P. C., Kendall, L. M., \& Hulin, C. L. (1969). The measurement of satisfaction in work and retirement. Chicago, IL: Rand McNally.

Tao, S. (2013). Why are teachers absent? Utilising the capability approach and critical realism to explain teacher performance in Tanzania. International Journal of Educational Development, 33(1), 2-14. https:/doi.org/10.1016/ j.ijedudev.2012.01.003

Teacher Motivation Working Group. (n.d.). Teacher Motivation Working Group (TMWG) [Website home page]. Retrieved from http://teachermotivation.org

Thoonen, E. E. J., Sleegers, P. J. C., Oort, F. J., Peetsma, T. T. D., \& Geijsel, F. P. (2011). How to improve teaching practices: The role of teacher motivation, organizational factors, and leadership practices. Educational

Administration Quarterly, 47(3), 496-536. https://oi.org/10.1177/ $0013161 X 11400185$

United Nations Educational, Scientific and Cultural Organization (UNESCO). (2015a). The challenge of teacher shortage and quality: Have we succeeded in getting enough quality teachers into the classrooms? (Policy Paper 19, Education for All Global Monitoring Report). Paris, France: UNESCO. Retrieved from http://unesdoc.unesco.org/images/0023/ 002327/232721E.pdf

UNESCO. (2015b). Education 2030 Incheon Declaration and Framework for Action towards inclusive and equitable quality education and lifelong learning for all (Final draft for adoption). Adopted at the World Education Forum 2015, Incheon, Republic of Korea, May. Paris, France: UNESCO. Retrieved from http://uis.unesco.org/sites/default/files/documents/education-2030incheon-framework-for-action-implementation-of-sdg4-2016-en_2.pdf

Voluntary Service Overseas (VSO). (2012). What makes teachers tick? A policy research report on teachers' motivation in developing countries. London, United Kingdom: Author. Retrieved from http://www.bibalex.org/ Search4Dev/files/288470/119513.pdf 
Watt, H. M. G., \& Richardson, P. W. (2015). Teacher motivation. In J. D. Wright (Ed.), International encyclopedia of the social and behavioral sciences (2nd ed., pp. 64-71). San Francisco, CA: Elsevier. https://doi.org/10.1016/B978-0-08-097086-8.26082-0

Wigfield, A., \& Eccles, J. S. (2000). Expectancy-value theory of achievement motivation. Contemporary Educational Psychology, 25(1), 68-81. https://doi.org/10.1006/ceps.1999.1015 



\title{
Once More Up the Mountain: The Promise of High-Quality Teaching Depends on Behavior Change
}

\author{
Lee E. Nordstrum
}

\section{Quality Teaching and the Problem of Behavior Change}

The subject treated in this book-teacher behavior change-is an important one to address, but not for reasons that are commonly cited. It is true that numerous countries are simultaneously attempting to implement a host of innovative educational reforms, such as mother tongue instruction or direct reading instruction, that require teachers to teach in more ambitious ways. Additionally, societies for which schools attempt to prepare students have themselves drastically evolved and educational reforms have been implemented that carry implications for classroom pedagogy (see the introductory chapter in this volume for a brief discussion of this issue). Substantial societal shifts, such as the ubiquity of technology and dynamism in labor markets, have rendered countries and cities, and to some degree schools and classrooms, different from what they were just a few years earlier.

Perhaps more fundamentally, the problem of teacher behavior change centers on three issues: (1) practitioners in the field of education have become increasingly aware that teaching quality matters; (2) we have also recognized that teaching quality is not homogeneously distributed among schools; and (3) despite many changes in what can be called the mechanics of teaching and learning (such as new curricula, new materials, or pre- and in-service training), teachers' behavior has, for the most part, not changed.

\section{Teaching Quality Matters}

Of any aspect of the educational system, it would make sense that the classroom teacher exerts the most direct influence on student learning. As often proposed, school systems are only as good as the teachers who constitute them, and this notion is not without reason. Research has 
repeatedly demonstrated that teachers and their pedagogical practices within the classroom are indeed important in advancing student learning (Nordstrum, 2015). Study after study has demonstrated links between student learning outcomes and teachers' classroom practices (Bommer, Johnson, Rich, Podsakoff, \& MacKenzie, 1995; Gallagher 2004; Heneman, 1986; Kimball, White, Milanowski, \& Borman, 2004; Milanowski, 2004). Many of the more recent studies, particularly in Western countries, have focused specifically on associating student achievement with "value-added" measurement of teacher effectiveness (the teacher's unique contribution to student achievement when controlling for demographic information, prior achievement, and—often—peer effects [see, for example, Gallagher, 2004; Kimball et al., 2004; Milanowski, 2004]).

The research generally has found positive and significant relationships in this regard. First, for example, Jacob and Lefgren (2008) combined student learning data with principals' ratings of 201 teachers from a US school district (the district chose to remain anonymous in the study) using a value-added model. Principal ratings appeared to match, with relative efficacy, teachers at the low end or at the high end of the value-added scale. A second example comes from Rockoff and Speroni (2010), who examined the relationship between teachers' classroom observation scores and their students' achievement. The authors used two distinct data sets to determine whether the positive association between observational data and achievement would hold for newly recruited teachers. The authors found a significant association between teachers who received higher subjective scores in observational evaluations-conducted either before they were hired or during the initial year of teaching - and their students' achievement gains in subsequent years.

It is worth considering the extent to which these issues have been found in developing countries as well. To this end, at least two recent studies have purposely attempted to determine the types of instructional practices teachers employ in the classroom that are related to student achievement. One of these used a case study approach to review the one-year (2014-2015) Nigeria Reading and Access Research Activity (RARA) (Pflepsen, Harden, Dubeck, Sankey, \& King, 2018), a program that attempted to improve the early grade reading skills of children in formal government schools in the northern Nigeria states of Bauchi and Sokoto. Pflepsen and colleagues found that teachers in RARA treatment schools tended to allocate more time during reading lessons to literacy activities (30 minutes in a 45-minute lesson were 
allocated to literacy) than colleagues in control schools ( 12 minutes in a 45-minute lesson) and had less idle time (5 minutes as compared with 20 minutes in control schools).

The study also scored teachers on their implementation of the RARA program as well as several desired teaching practices. These program implementation scores were compared with student reading fluency (i.e., the number of correct words per minute) on an oral reading assessment. Teachers who received the highest implementation scores (the highest quintile according to their observational score) tended to also have significantly more fluent readers in their classrooms (effect size $=0.38$ standard deviations).

A second study was a baseline assessment for the "3Rs" (i.e., reading, writing, and arithmetic) in Tanzania, a national program that attempts to enhance classroom instruction and student competencies in these content areas. Part of the baseline study included classroom observation: During reading and mathematics lessons, teachers' instructional practices were recorded every three minutes. In their analysis of patterns of classroom instructional techniques, Brombacher, Stern, Nordstrum, Cummiskey, and Mulcahy-Dunn (2014) reported sizable differences in terms of the frequency and nature of teachers' pedagogical moves between teachers in highperforming schools (as measured by average student achievement in that school) and counterparts in low-performing schools. For example, the authors found that most teachers (regardless of school performance) began lessons by direct instruction.

However, more teachers in high-performing schools were able to transition much more quickly from the initial direct instruction to other instructional approaches that allowed for more student engagement (e.g., asking questions). In low-performing classrooms, the transition did not take place until about 10 minutes into the lesson, while in high-performing schools it occurred within 6 minutes. Classroom teachers in high-achieving schools also tended to allocate more time to posing questions to pupils during the middle of the lesson (most of the time, pupils did not pose questions of their own to the teacher). Furthermore, observed teachers in high-performing schools were more likely to interrupt the flow of the lesson to address pupils' misunderstandings regarding the assigned task or lesson content (this behavior was observed in 55 percent of classrooms). In lowerperforming schools, this behavior was observed in only 33 percent of classrooms. 


\section{Teaching Quality Is Not Homogenously Distributed}

Teachers and their pedagogical practices, then, appear to matter greatly in terms of engendering meaningful student experiences in classrooms and advancing learning that we care about. But despite the value that is, probably reasonably, placed on both the practice of teaching and on teachers themselves as inherently instrumental to advancing student learning, it is also true that, at the individual classroom level, substantial variation exists with regard to teachers' effects on student learning. In other words, teachers can be classified as either more or less successful at shepherding students' progress toward agreed-upon learning objectives and therefore fall somewhere along a continuum of teaching "effectiveness" (Nordstrum, 2015).

Traditionally, teachers have been classified by a few quantitative measures of teacher "quality" - seniority, experience, certification status, and education level (Hoxby, 2002; UNESCO, 2005; Vegas \& Umansky, 2005)— but these measures, unfortunately, have been found to be rather weak predictors of high-quality instructional practices (Ballou, Sanders, and Wright, 2004; Boyd, Grossman, Lankford, Loeb, \& Wyckoff, 2006; Goldhaber \& Brewer, 1997; Kane, Rockoff, \& Staiger, 2005; Nordstrum, 2015; Rivkin, Hanushek, \& Kain, 2005; Podgursky \& Springer, 2007). And Aslam and Kingdon (2012) found that traditional characteristics of teacher quality (such as certification or training) in Punjab, Pakistan, had no relationship with students' exam scores. On the other hand, "process" variables relating to teachers' classroom instructional practices were found to affect pupil learning substantially.

Other researchers who have intentionally investigated aspects of instructional practice have found a greater degree of variation in classroom practices than compared with the traditional measures of teacher characteristics mentioned previously. The Measures of Effective Teaching (MET) Project, funded by the Bill \& Melinda Gates Foundation, was one of the largest, and perhaps most well-known (at least within the United States), studies to investigate the relationship between teachers' classroom practices and other measures of teaching. The implementers analyzed a subset $(1,333)$ of teachers who taught mathematics or English in grades 4-8. The project used value-added data from student achievement gains, classroom observational ratings, and student ratings to develop metrics for the quality of classroom instruction. One of the project findings was that teachers varied considerably in terms of the quality of their instruction, regardless of the 
metric used (Archer et al., 2016; Kane, McCaffrey, Miller, \& Staiger, 2013; see also MET Project, 2012).

The 2013-2014 Education for All Global Monitoring Report made clear that, while many nations had made great strides in increasing access to schooling, quality had not always kept pace (UNESCO, 2014). Moreover, disadvantaged students "are most likely to suffer, because of insufficient numbers of trained teachers, overstretched infrastructure and inadequate supply of instructional material" (UNESCO, 2014, p. 191). Evidence of this type of disparity between regions and countries is not unexpected, but it also can manifest within a single country. For example, based on 2012 Annual Status of Education Report data, less than 20 percent of the poorest female students in Uttar Pradesh, India, were able to complete two-digit subtraction problems, as compared with approximately 60 percent of the richest male students (UNESCO, 2014).

While learning outcomes are a rough proxy for teacher instructional competence, it is clear that instructional quality-whether we consider teacher quality to entail traditional measures of ability (e.g., years of experience, training experiences) or classroom pedagogical processes-is differentially distributed among schools and classrooms.

\section{Behavior Is Hard to Change}

Getting teachers to change patterns of behavior to enhance the quality of their instruction inherently assumes that quality is lacking in some regard and needs to be remedied. The natural remedy for low-quality and ineffective instruction is, of course, high-quality instruction. In the field of education, instructional reforms are implemented by individuals, most often teachers, who enact the required more ambitious practices in classrooms. So much is readily obvious. However, and perhaps more importantly, the teachers who are called upon to enact more ambitious instructional techniques-that is, to enhance the quality of their teaching - are the very same individuals who are not capable of enacting high-quality instructional techniques in the first place. In other words, the individuals with the problem (i.e., low-quality teaching) are those expected to implement the solution (i.e., high-quality or more ambitious instruction) (Cohen, Peurach, Glazer, Gates, \& Goldin, 2014).

With this connection in mind, the act of enhancing instructional quality would naturally require educational reformers to design ways for teachers to learn and practice more ambitious pedagogical techniques and to unlearn more familiar, less ambitious practices. Unfortunately, a substantial body of 
research suggests that getting teachers to teach in unfamiliar, more challenging ways is difficult at best, even in settings with a modest amount of professionalism and functional educational systems (see, for example, Cohen, 2011; Labaree, 2010).

Despite decades of attempts to enhance the quality of instruction in schools in the United States, for example, only a very few models of school reform have proven to be successful in systematically altering and sustaining teachers' core practices toward more ambitious instruction (Peurach, Glazer, \& Gates, 2004). This assertion should not be taken to mean that instructional reform cannot be undertaken with fidelity in schools (Berman \& McLaughlin, 1975; Rowan, Camburn, \& Barnes, 2004). Rather, the germane point here is that instructional reform is time-consuming, is complex, and often proceeds with uneven success across schools.

We should also take care to mention that our argument is not that teachers are staunchly conservative agents who eschew all efforts at instructional reform. That is not why instructional change is difficult. Rather, it is because instructional conservatism is a rational response to the rigors and requirements of the teaching profession, and it is an altogether natural response to facing conflicting choices that entail some degree of risk and whose outcomes are uncertain. To this end, the profession of teaching requires that teachers develop a discrete set of instructional practices that allows them to both establish relationships with their pupils and facilitate their learning. This is indeed a delicate balancing act for teachers, for their success in developing an effective and successful teaching persona is bound up with the success of their students. A teacher with failing students is unlikely to be seen as successful in teaching. Teachers, understandably, invest heavily in honing their practices and are unlikely to cast aside their perfected craft for a new and unfamiliar instructional reform. This point was articulated by Labaree (2010):

Once [teachers] have worked out a personal approach for managing the instruction of students within the walls of their classroom, they are likely to resist vigorously any effort by reformers or administrators or any other intruders to transform their approach to teaching. Teacher resistance to fundamental instructional reform is grounded in a deep personal investment in the way they teach and a sense that tinkering with this approach could threaten their very ability to manage a class... . Pedagogical change offers the teacher little apparent benefit and great apparent risk. (pp. 154-155) 
Other research has bolstered such arguments. Cuban (2013) showed in his historical analysis of pedagogical progressivism in the United States that, when confronted with instructional reform, teachers have tended to adopt a few marginal practices rather than substantially alter their classroom practices. The instructional habits and routines that constitute the foundation of most teachers' practice remain unperturbed, as these are intrinsically related to teachers' fundamental beliefs of what good instruction "looks like" and what is familiar.

More recently, neuroscience has helped us understand that habit formation, such as learned teaching routines, is the result of our brains constantly searching for ways to conserve energy (Duhigg, 2012).

"Chunking," or the conversion of a sequence of complex actions into an automatic routine, occurs based on the experience of a cue and the presence of rewards (whether the set of actions is deemed valuable and worth remembering). While chunking can result in the efficient performance of actions, the resulting habit (the set of behaviors that become more and more ingrained over time) can be difficult to break. "When a habit emerges, the brain stops fully participating in decision-making. ... So unless you deliberately fight a habit-unless you find new routines - the pattern will unfold automatically" (Duhigg, 2012, p. 20).

\section{The Contributions of This Book}

The importance, then, of the issue at hand stems from a need to understand how behavior change can be facilitated, encouraged, and guided-not because this is a new need but rather because the need has not been met through tinkering with traditional mechanical changes (e.g., training, materials, and curricula). With that in mind, the chapters in this volume represent a description of seven distinct projects that have, in one way or another, attempted to change teacher behavior in both measurable and meaningful ways.

- The chapter on Ethopia showed how the creation of a module-based mother tongue instruction program in Ethiopian colleges of teacher education influenced teacher educators' and teachers' perceptions of language instruction and, importantly, the practices that teachers employed in the classroom. The introduction of new knowledge on the process of learning to read facilitated teachers' critical appraisals of their prior pedagogical practices. It also led to a recognition that student learning requires more ambitious practices than lecturing. 
- The third chapter discussed school leadership in Zambia and positioned head teachers as facilitators of school improvement. Direct data on teaching practices were not captured as part of addressing the research questions. Even so, the authors could connect the behaviors of school leaders with (1) the provision of opportunities for professional development and peer learning, (2) the amelioration of teacher motivation and commitment, and (3) the establishment of instructional space (i.e., time and opportunity) for teachers to try new strategies. In other words, the authors assert that school leaders have a role in shaping at least some of the environmental conditions in which teachers work, which in turn provides time, space, and (hopefully) motivation for instructional change among practitioners.

- The chapter on the Philippines returned to the topic of teacher training through specific in-service professional development designed to enhance literacy instruction in the Basa Pilipinas program. Two years of focusing on content areas (i.e., the components of literacy) and active learning (reflection, video analysis, and action planning) appeared to lead to changes in instructional practices, notably several literacyspecific strategies (oral language development, reading fluency, and comprehension), the use of classroom materials, classroom management strategies, and reflection opportunities.

- The discussion of Malawi demonstrated that training in content knowledge, which is often ineffective in altering instructional behavior, can be reinforced through follow-up text messages sent to teachers periodically subsequent to the training. Though it was not an intention of the text-message follow-up program, the authors found that teachers routinely shared instructionally relevant messages with their colleagues, which may have facilitated peer learning.

- The context of a literacy intervention in northern Nigeria outlined the relationships between coaching support and teachers' adoption of new instructional practices. Despite a small sample size, the authors found that teachers with more frequent coaching visits were more likely to make changes to their pedagogical practices.

- Peer learning and coaching in the PRIORITAS (Prioritizing Reform, Innovation, and Opportunities for Reaching Indonesia's Teachers, Administrators, and Students) program was the focus of the chapter on 
Indonesia. In the program, teacher working groups used an adapted "lesson study" model (planning activities together, conducting the activities in their own classroom, and observing others teaching the activities and providing feedback) to collaborate, practice new instructional techniques, and learn from them in a nonthreatening context.

- The chapter on India discussed the relationships among teacher wellbeing, motivation, and behavior change: Both well-being and motivation are necessary before behavior change can occur. Using the Teacher Motivation Diagnostic Tool in two states in India, the researchers were able to discern that, while teachers reported feeling motivated and satisfied, they also tended to devote 10 or more hours on "extra" (noninstructional) work per week, 40 percent wanted to transfer schools, and a majority of teachers in Jharkhand would give students extra help only if they were paid to do so. Moreover, there were differences between reported motivation and satisfaction levels, on one hand, and teachers' feelings of self-efficacy (their ability to influence aspects of their working lives) on the other.

\section{A Model of Teacher Behavior}

The preceding chapters have highlighted that pedagogical behavior can be changed in meaningful ways but that instructional change requires more purposeful intervention than simply providing more materials, offering more training, or changing the curricula. While some of the projects in Chapters 2-8 involved altering these traditional mechanics of schooling, they also incorporated "nonmechanical" aspects related to instructional behavior, such as perceptions, motivation, facilitating conditions, and peer learning. From this position, we can turn to an integrative model of teacher behavior that subsumes more than the mechanics of schooling. Such a model should marry background influences to the internal factors (e.g., beliefs, attitudes, and motivation) in explicating an individual's behavior.

Fishbein and Cappella (2006), in their work on health communications, described precisely this kind of model (see Figure 9-1). The model depicts individual behavior as a function of skills, abilities, and environmental factors, which are all mitigated by background influences, beliefs, societal norms, attitudes, and motivation. In other words, behavior is not merely an outcome of individual exertions of skills and abilities within an external 
Figure 9-1. An Integrative model of behavior change

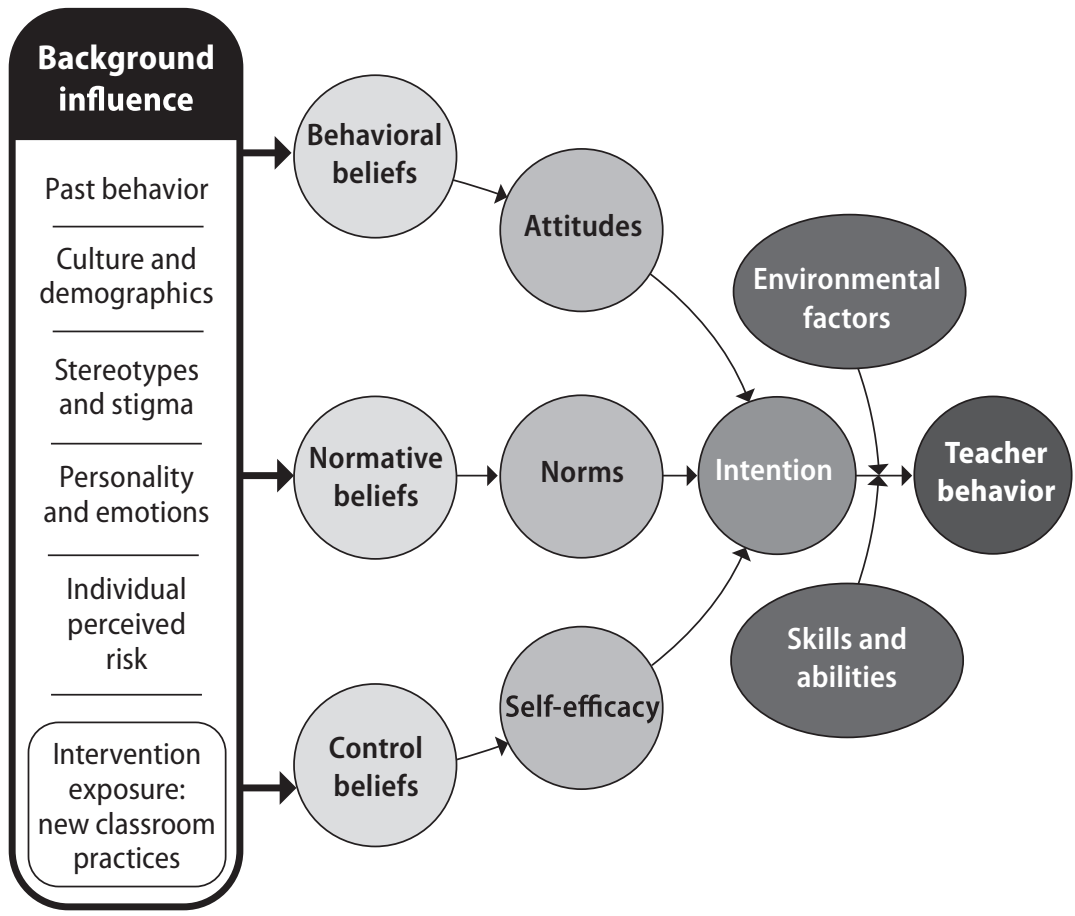

Source: Adapted from Fishbein and Cappella (2006).

environment. Rather, behavior is an instantiation of skills and abilities as they are filtered through background influences, personal beliefs and attitudes, motivation, and social norms, expressed within an environmental context.

While the model's comprehensiveness may be satisfying, it also leads to two sobering conclusions germane to this discussion. First, behavior is complex, and, therefore, any attempt to alter it must of necessity also be complex. This perception is easily seen in the model. Behavior interventions designed to alter teachers' classroom practices (observed behavior) are but one of the background influences depicted in the model, alongside individual differences, personality and emotion, attitudes toward targets, culture and demographics, and prior behavior. All of these background influences are then filtered through beliefs (normative, behavioral, and self-beliefs), social norms, motivation, and attitudes. 
Moreover, some of these background factors and filters-such as social norms, culture and demographics, or an individual's prior behavior-are fundamentally unalterable (at least within the context of a behavioral intervention). This aspect implies that behavioral interventions cannot realistically hope to influence behavior unless the other alterable factors within the model are also attended to. Personality, moods, emotions, attitudes, beliefs, self-perceptions, and motivation, if left unaddressed by the behavioral intervention, are likely to preclude any meaningful change. Interventions will be met with an opposing force favoring behavioral conservatism.

Second, the model highlights the tautology that intention differs from behavior. In other words, behavioral interventions require human actors to enact them, and the behaviors that are exhibited by these actors are not always synonymous with intended actions. In education, teachers often are required to enact behavioral interventions: They are expected to change from a previous way of teaching to embrace new, more ambitious methods. This transition, as described earlier, is far from straightforward for many reasons. Fishbein and Cappella's (2006) model, however, reminds us that teachers may not produce the desired behavior even when background influences are aligned, they believe they can change, and they are motivated to do so. Teachers can and do fail to enact more ambitious instructional practices. But this does not mean that they cannot succeed, either. Rather, intentions are more likely to produce the desired instructional behavior when the other factors in the model are aligned, when teachers are given the opportunity to practice, and when they are given systematic opportunities to improve.

The chapters in this volume take up various factors in the model in Figure 9-1. While none of the chapters discusses all points simultaneously, cumulatively, they present an argument for an integrated consideration of teacher behavior change that moves beyond what we have called the mechanics of instruction (materials, curricula, and training).

Several chapters discuss "internal" factors (i.e., factors that are internal to teachers as they enact behavior changes). These include the introductory chapter, with its emphasis on knowledge and learning. Here, the author discusses Knowles and Associates' (1984) view of adult learning and how it differs from learning in school-aged children: the latter builds a foundation of domain-specific knowledge, and the former emphasizes the utility and applicability of knowledge as well as constructivist designs of learning processes. 
The chapter on India references teacher motivation in relation to pedagogical change and presents three germane theories: expectancy-value theory, achievement goal theory, and self-determination theory (see also Watt \& Richardson, 2015). As presented by the authors, expectancy-value theory describes both the value placed on the end goal that one is seeking to attain and one's expectations of success in attaining it (see also Eccles, 1983; Wigfield \& Eccles, 2000).

In contrast, achievement goal theory asserts that individuals are motivated by achieving mastery (developing competencies) and enhancing performance (demonstrating competence against a standard) (see also Dweck, 1986; Nicholls, 1984). Self-determination theory posits that motivation is based on basic psychological needs of autonomy, competence, and relatedness (see also Deci \& Ryan, 1985; Ryan \& Deci, 2000). These various theories are not mutually exclusive, and the discussion of teacher motivation in India concludes that teachers have a desire to be recognized for their work (i.e., high-quality teaching practices and enhanced student outcomes) through formal and informal mechanisms.

Other chapters highlight "external" factors (i.e., factors relating to background influences as shown in Figure 9-1). The chapter on Ethiopia, for example, centers on teacher training, specifically pre-service training through colleges of teacher education language programs in Ethiopia. The chapter examines the contributions of materials and training on teacher educators' understandings and practices of literacy instruction under the assumption that training (i.e., how one was taught) exerts influence over teachers' eventual classroom practices. Likewise, the chapter on the Philippines discusses pre-service training in the Philippines and demonstrates how content-specific training and active learning (i.e., opportunities to practice) can alter teachers' classroom practices and use of pedagogical materials.

Teacher coaching is an external structural intervention, taken up in the chapters on both Malawi and Nigeria; teacher coaching attempts to enhance internal factors (e.g., knowledge, self-efficacy, motivation). In other words, coaching requires external structures, such as the presence of instructional coaches, designated opportunities to observe teachers' practices, and a professional culture of learning from peers, to influence pedagogical behavior. Head teacher behavior is discussed in the chapter on Zambia, and, while this topic may appear tangential to teachers' pedagogical practices, the authors posit head teachers as instructional leaders in their schools. Teachers' 
practices, therefore, are likely to be affected by interactions with these school-based leaders, through instructional observation and coaching support or managerial authority (compliance with instructional expectations).

The various factors from an integrated behavior model (Figure 9-1) that are covered in the prior chapters, therefore, represent a unique contribution to international literature on teacher behavior change, for at least three reasons. First, the breadth of coverage contained in this volume vis-à-vis the aforementioned model of behavior argues for a holistic conceptualization of classroom instructional practices. That is, teachers' pedagogical practices cannot, in light of these chapters, be seen as merely a linear enactment of the mechanics of instruction, directly and uniquely caused by curriculum change, training, or other inputs. Second, the chapters provide case examples that the behavioral processes of instruction can be changed through interventions on internal or external factors featured in the model. Though the model positions behavior as inherently complex, it does not follow that all factors must be addressed simultaneously to effect change. Third and finally, the chapters demonstrate empirically that instructional behavior cannot be optimized (i.e., teachers cannot eschew lower-quality practices and adopt more ambitious techniques) when only one or two factors in the model are changed.

In other words, although several of the chapters present direct evidence of teachers' behavior and how it changed over the course of an intervention, none of the chapters asserts that the interventions described therein were a panacea. Rather, the chapters clearly suggest in their respective contexts that instructional practices could yet be enhanced, despite the best efforts of the interventionists and the practitioners: More ambitious ways of teaching could still be reached.

The absence of a prescribed panacea should be seen, somewhat ironically, as a strength of the volume. While it does show that classroom pedagogical behavior can be incrementally changed, arguably for the better, through interventions such as those described in the chapters, it simultaneously illustrates that instructional practices are unlikely to be optimized through those same (somewhat limited) interventions. Again, the stated limits of the interventions should not be viewed as weaknesses in the prevailing chapters; all interventions are inherently limited. Instead, this third point demonstrates the necessary complexity in addressing all (or even most) of the factors presented in the integrated behavior model within a single project. 


\section{Other Frames Related to Behavior}

This concluding chapter would be remiss were it not to mention two other ways of framing behavioral patterns that are germane to a discussion on teaching practices. They were alluded to in Chapter 1 but were not featured in the case study chapters: mindsets (about the nature of success and learning) and prospect theory. Both are psychological theories about the drivers of individual behavior. Each is briefly presented here in turn, and their relation to the exercise of teaching is considered.

\section{Attribution and Mindsets}

Recent research on mindset theories points to two related psychological beliefs about the nature of success (attribution theory) and learning (growth mindset theory). Attribution theory centers on how individuals interpret events and attribute causes to behavior (even in the absence of causal relationships). Although Heider (1958) first proposed a theory of attribution related to interpersonal relationships (i.e., the information individuals use to try to determine why others act the way they do), his theory was later adapted by Weiner $(1974,1986)$ to focus on achievement and success.

Weiner $(1974,1986)$ theorized that individuals tended to attribute success (or the lack of it) to four main factors: effort, ability, task difficulty, and luck. Attributions are categorized into these four factors according to three continua that are perceived as causal: locus of control (internal versus external control), stability (static versus dynamic), and controllability (causes under one's control versus those that are not). According to Weiner, behavioral outcomes (success or failure) are observed and are then attributed to either effort (which is internal, unstable, and controllable), ability (internal, stable, and uncontrollable), level of task difficulty (external, unstable, and uncontrollable), or luck (external, unstable, and uncontrollable). These attributions then influence an individual's self-affect: "Causal attributions determine affective reactions to success and failure. For example, one is not likely to experience pride in success, or feelings of competence, when receiving an 'A' from the teacher who gives only that grade. ... On the other hand, an 'A' from a teacher who gives few high grades ... generates great positive affect" (Weiner, 1980, p. 362).

Attribution theory posits that high and low achievers tend to categorize success and failure differently. High achievers generally view success as a product of internal factors (ability or effort), whereas low achievers tend to view success as aided by external, uncontrollable factors (task difficulty or 
luck). These groups take the opposite position with regard to failure: High achievers view it as external and uncontrollable, whereas low achievers view it as internal and, possibly, uncontrollable (they have low ability).

In this respect, teachers are no different; they must attribute success and failure in their profession (e.g., student outcomes, professional advancement) to one of the four factors and along the three continua. High-achieving teachers who often experience success are, according to the theory, likely to attribute their success to internal factors ("I am a good teacher," "Teaching comes naturally to me," or "I have learned a lot from experience"), while chalking up failure to external or uncontrollable factors (e.g., "I had a difficult class this year," "The head teacher just saw a bad lesson," or "My students have a difficult home environment").

The pattern plays out oppositely among low-achieving teachers, and the attributions have implications for behavior. Those who attribute success to internal and controllable factors are more likely to try new tasks (such as teaching a new curriculum) because they are confident in their ability and can control their level of effort. On the other hand, teachers who attribute success to external factors are less likely to engage fully in new, potentially difficult tasks. If a task is difficult, they are likely to succeed only if they are lucky (since they are not confident in their ability or see their effort as insufficient), but luck is external, unstable, and uncontrollable.

Dweck's (2006) work on mindset (growth versus fixed) is related to attribution theory. Dweck posited that individuals, when they reflect on their abilities, intelligence, personalities, and character, hold one of two mindsets. A fixed mindset believes that personal characteristics (e.g., ability, intelligence, personality) are fixed and immutable-they cannot be altered through effort or learning. Individuals with fixed mindsets tend to view success or failure as a direct measure of their internal (and fixed) characteristics. A growth mindset, however, "is based on the belief that your basic qualities are things you can cultivate through your efforts" (Dweck, 2006, p. 7). Individuals with growth mindsets, then, tend to view success or failure as a result of their current ability level but also believe that their potential is greater than whatever their current level and performance indicates. These mindsets, then, relate mostly to the ability and effort factors as well as the locus of control continuum in attribution theory.

Dweck (2006) went on to show how individuals with fixed mindsets tend to avoid difficult tasks. Because success or failure is a direct indication of their 
ability, and ability cannot be changed, it is better to engage in easier tasks and to prove yourself a success than it is to try something difficult and be viewed as a failure. This effect is even seen when individuals who hold fixed mindsets succeed at a task: When asked if they would like to do a task that is slightly harder or one at about the same level of difficulty, they choose the latter. Why risk failure instead of assuring affirmation? Contrarily, individuals with growth mindsets are more likely to put forth effort on challenging tasks because they do not view performance as a critique on their personal characteristics. Moreover, they are more likely to feel that they can learn from failure and are more likely to persist in the face of difficulty.

Mindset theory clearly describes behavioral and thought patterns that are germane for classroom teaching, for at least two reasons. First, if teaching performance (whether measured by student outcomes, classroom observations of practice, or head teacher ratings) is a function of individual characteristics such as ability or personality, and these characteristics are fixed and outside of one's locus of control, then the teacher will likely lean toward instructional conservatism. That is, success (a good measure of one's characteristics) will be more likely when one is teaching in ways that are less difficult and that are familiar.

Even when asked to teach in new and more ambitious ways, teachers who hold a fixed mindset will be unlikely to make an attempt because failure in the classroom means that they are intrinsically (in terms of abilities and personality) a failure. Teachers who hold growth mindsets, on the other hand, will inherently view their ability to teach in the classroom as alterable. Thus, when confronted with an educational reform that requires them to teach in more ambitious ways, they will be more likely to view it as both possible (i.e., they can improve) and an opportunity to learn (even if it is initially difficult).

Whether teachers hold a fixed or growth mindset also will determine their posture toward and interactions with students. Teachers with a fixed mindset will believe that student ability, like their own, is fixed and will therefore classify students along a continuum of intelligence (i.e., some are intelligent, some have average intelligence, and some just are not intelligent). This approach will, of course, carry implications for how they teach the class (e.g., not providing remedial instruction for those who do not get the content) and the feedback they provide to children ("some people are just not good at math"). A growth mindset implies that a teacher will believe that all students are capable of learning and will use assessment results, for example, as an 
indicator of student understanding and misunderstanding, as well as a signal of how to change instructional strategies to enhance student understanding of lesson content.

\section{Risk Aversion and Prospect Theory}

Prospect theory describes a set of predictable behavioral tendencies that have been empirically observed when individuals confront choices whose outcomes are uncertain and which entail some degree of risk. Tversky and Kahneman (1981) introduced this theory around the psychology of choice and, over time, articulated at least three effects or biases at play when individuals make choices (see also Kahneman, 2011; Rabin \& Thaler, 2001).

The first effect is loss aversion: Individuals tend to react more strongly to a loss (or a potential loss) than to a corresponding gain. In other words, most individuals would be much less likely to choose an option in which they had a chance to lose $\$ 100$ even if they had a similar chance to win the same amount. Kahneman (2011) stated: "Loss aversion is a powerful conservative force that favors minimal changes from the status quo in the lives of both institutions and individuals. This conservatism helps keep us stable in our neighborhood, our marriage, and our job; it is the gravitational force that holds our life together near the reference point" (p. 305).

The second effect is the endowment effect: An individual's willingness to engage in certain behavior depends on his or her current position (his or her endowment). In other words, if you possess something, you tend to consider the pain you would experience if you had to give that up. If you do not possess something and face the prospect of obtaining it, you tend to consider the pleasure of getting it. However, the pain of loss and the pleasure of gain tend to be experienced as unequal-individuals tend to be more interested in retaining their endowment than chance gaining a new possession.

The third effect in prospect theory maintains that achievement goals serve as reference points. When an individual considers a goal, whether it is professional or personal, that person views exceeding the goal as a gain but sees failing to meet it as a loss. Due to the first effect (loss aversion), the aversion to failing to reach the goal is much stronger than the desire to exceed it. Kahneman (2011) noted that, as a result, people often adopt short-term goals that they strive to achieve but not necessarily to exceed, and they are also likely to reduce their efforts when they have reached an immediate goal. 
Figure 9-2. The fourfold pattern

\begin{tabular}{|c|c|c|}
\hline & $\begin{array}{l}\text { Low Probability } \\
\text { (possibility effect) }\end{array}$ & $\begin{array}{l}\text { High Probability } \\
\text { (certainty effect) }\end{array}$ \\
\hline ฮั. & $\begin{array}{l}\text { Risk-seeking behavior: } \\
\text { Hope of large gain }\end{array}$ & $\begin{array}{l}\text { Risk-averse behavior: } \\
\text { Fear of disappointment }\end{array}$ \\
\hline ङั 气ू & $\begin{array}{l}\text { Risk-averse behavior: } \\
\text { Fear of large loss }\end{array}$ & $\begin{array}{l}\text { Risk-seeking behavior: } \\
\text { Hope to avoid loss }\end{array}$ \\
\hline
\end{tabular}

Source: Adapted from Kahneman (2011).

According to prospect theory, these effects combine to create a "fourfold pattern" that describes how individuals attach values to gains and losses, as well as how the value weights they assign to outcomes differ from probabilities that those outcomes will occur (Figure 9-2).

It has already been mentioned that instructional conservatism is a natural reaction for teachers under some circumstances. Relatedly, the pattern in Figure 9-2 demonstrates that individuals tend to act in predictable patterns when faced with risk, uncertainty, and unknown probabilities of success (Kahneman, 2011). All of these elements are at play when teachers are asked to adopt new, unfamiliar, and more ambitious methods of teaching. The adoption of new instructional practices is risky for teachers because they are, in essence, being asked to enact new techniques and approaches that they are unlikely to immediately master. With little practice in the new approaches, they are more likely to fail than if they simply stick with more familiar techniques.

In the mind of a classroom teacher, according to Figure 9-2, the employment of an unknown, new approach is likely to be framed as a lossspecifically, the loss of the ability to teach effectively. This loss would certainly be a less attractive option than staying on familiar pedagogical terrain. Instructional conservatism is also likely because the outcomes of the new instructional method (e.g., student learning success) are uncertain, whereas the outcomes of their previous approaches are, more or less, known (i.e., the status quo). Thus, we see that teachers, when confronted with new instructional reform, are being asked to trade a known process and outcome that they have previously experienced (i.e., current teaching practices and 
levels of student success) for an uncertain outcome in the future that they have not yet experienced.

The fourfold pattern (Figure 9-2) suggests that individuals tend to bet on outcomes that are known and certain rather than those that are unknown and uncertain (Kahneman, 2011; Rabin \& Thaler, 2001). Risks and uncertainty, whether real or perceived, are likely to influence teachers to act in risk-averse ways when they confront instructional change (i.e., they will exhibit resistance to change).

An example of this behavioral pattern could be seen in a recent remedial reading and mathematics program implemented by RTI International on behalf of the United States Agency for International Development (USAID) in Jordan. During the intervention, each teacher was required to use the first 15 minutes of every reading and mathematics lesson for "foundational" skills warm-up exercises. Teachers were trained to implement the program, given professional support, and provided with necessary instructional materials developed exclusively for the program.

An evaluation of the program found significant and positive impacts on both reading and mathematics achievement in treatment schools over control schools (Brombacher et al., 2014). Furthermore, teacher interviews revealed widespread agreement that the intervention had led to positive outcomes: The interview respondents mentioned enhanced student reading and mathematics achievement, improved teaching practices, and enjoyment.

Regardless, when teachers were asked directly, most (82 percent) did not believe the program should be continued. That is, even though the teachers had observed and admitted to the positive impacts of the program on student achievement and had learned enhanced instructional techniques that they themselves saw as superior to their previous practices, they nearly unanimously decided that the program was not worth continuing. The report did not ask teachers to elaborate on their judgment. One might infer, however, using the fourfold pattern, that teachers did not perceive that the program's benefits (i.e., enhanced learning, better teaching practices) warranted the extra work required and the pedagogical risk involved in changing their instructional approaches.

\section{Summary}

The subject of teacher behavior change is undoubtedly an important one. This chapter has posited that the instructional practices of teachers 
represent an essential focal point for international education research, for the three reasons named at the opening of the chapter. First, evidence has shown us that teaching quality matters in terms of optimizing schooling experiences and outcomes for students. Second, we have also recognized that teaching quality is not homogeneously distributed among schoolsteachers themselves are distributed differentially along a continuum of effectiveness. Third, despite many changes in what can be called the mechanics of teaching and learning (e.g., new curricula, new materials, or pre- and in-service training), teachers' behavior has, for the most part, not changed.

With this connection in mind, the preceding chapters constitute a unique contribution to international educational literature in at least four ways. First, this volume represents an attempt to understand how instructional behavior change can be facilitated, encouraged, and guided-a need that has not been met through tinkering with traditional mechanical changes. These chapters describe seven distinct projects that have, in one way or another, attempted to change teacher behavior in both measurable and meaningful ways.

Second, the chapters contain a breadth of coverage vis-à-vis an integrated model of teacher behavior that is often unseen in educational literature. These chapters collectively argue that teachers' pedagogical practices cannot be taken as a linear enactment of the mechanics of instruction, directly and uniquely caused by curriculum change, training, or other inputs.

Third, the chapters provide case examples that the behavioral processes of instruction can indeed be changed, if slowly and fitfully. While the practice of teaching is positioned herein as complex and difficult, these chapters present evidence that teachers' practices are indeed dynamic and their ability to enact more ambitious ways of teaching can be enhanced.

Fourth, the chapters demonstrate empirically that instructional behavior cannot be made perfect when only one or two aspects of the instructional system are changed. In other words, although several of the chapters show how teachers' behavior changed over the course of an intervention, none of the chapters asserts that the interventions described were a panacea.

Finally, this concluding chapter briefly presents two psychological frameworks that influence individual behavior patterns. Weiner's attribution theory describes how individuals interpret events, view success and failure, and react to it. Dweck's $(1986,2006)$ theory of fixed versus growth mindset 
implies that teachers who hold the latter perspective are more likely to engage in ambitious and challenging ways of teaching and will adopt a more constructive instructional posture toward students. Tversky and Kahneman's (1981) prospect theory predicts that the presence of pedagogical or professional risks and uncertainty is likely to influence teachers to act in risk-averse ways when they are confronted with instructional change (i.e., teachers will exhibit resistance to change).

Although this chapter and this volume overall provide both arguments and evidence for the importance of focusing on and researching patterns of teacher behavior and its evolution during educational reform, they also make evident that the task teachers face (i.e., to teach in ever more ambitious ways) is daunting. Change-real instructional change that positively affects students' classroom learning experiences-takes time, space, and effort to flourish. And while teachers generally do not lack effort, time and space to implement changes in their pedagogical practices are unfortunately rarely afforded them.

Yet, it is clear that more ambitious ways of teaching are needed: Many students are not learning, even in school, and high-quality teaching practices are not found in equal measure in all classrooms (see, for example, Nordstrum, 2015). This volume does not boast revolutionary practices and silver-bullet policy solutions in that regard, but it does offer a broad discussion of instructional practices and how they might be encouraged and facilitated in low-resource contexts. It assumes that teaching ability is dynamic and can be enhanced, rather than of a fixed quantity; high-quality teaching can be spread, given time, space, and thoughtful effort. It argues, though not simplistically, for a continued push toward the zenith of ambitious instruction in all classrooms - that is, in many ways, a quiet revolution, but one that is certainly worth waging. Enacting more ambitious pedagogical practices is, for teachers, an uphill struggle in less-than-ideal contexts. We are asking them to go once more up the mountain, for little reward or benefit. It is our hope that this volume has yielded some insights that will lighten their load and make easier their path.

\section{References}

Archer, J., Cantrell, S., Holtzman, S. L., Joe, J. N., Tocci, C. M., \& Wood, J. (2016). Better feedback for better teaching: A practical guide to improving classroom observations. San Francisco, CA: Jossey-Bass. 
Aslam, M., \& Kingdon, G. (2012). How teachers' pedagogic practice influences learner achievements: A study from the Punjab, Pakistan. In R. E. Moon (Ed.), Teacher education and the challenge of development: A global analysis (pp. 164-182). New York, NY: Routledge.

Ballou, D., Sanders, W., \& Wright, P. (2004). Controlling for student background in value-added assessment of teachers. Journal of Educational and Behavioral Statistics, 29(1), 37-65. https://doi.org/10.3102/10769986029001037

Berman, P., \& McLaughlin, M. W. (1975). Federal programs supporting educational change: Vol. IV. The findings in review. Santa Monica, CA: RAND.

Bommer, W. H., Johnson, J. L., Rich, G. A., Podsakoff, P. M., \& MacKenzie, S. B. (1995). On the interchangeability of objective and subjective measures of employee performance: A meta-analysis. Personnel Psychology, 48(3), 587-605. https://doi.org/10.1111/j.1744-6570.1995.tb01772.x

Boyd, D., Grossman, P., Lankford, H., Loeb, S., \& Wyckoff, J. (2006). How changes in entry requirements alter the teacher workforce and affect student achievement. Education Finance and Policy, 1(2), 176-216. https://doi.org/10.1162/edfp.2006.1.2.176

Brombacher, A., Stern, J., Nordstrum, L. E., Cummiskey, C., \& MulcahyDunn, A. (2014). Education Data for Decision-Making (EdData II): National early grade literacy and numeracy survey-Jordan (Intervention impact analysis report). Prepared for USAID/Jordan under the Education Data for Decision-Making (EdData II) project, EGRA/EGMA/SSME National Survey in Jordan, Task Order No. AID-278-BC-00019 (RTI Task 16). Research Triangle Park, NC: RTI International. Retrieved from http://pdf.usaid.gov/pdf_docs/PA00KH3M.pdf

Cohen, D. K. (2011). Teaching and its predicaments. Cambridge, MA: Harvard University Press. https://doi.org/10.4159/harvard.9780674062788

Cohen, D. K., Peurach, D. J., Glazer, J. L., Gates, K. E., \& Goldin, S. (2014). Improvement by design: The promise of better schools. Chicago, IL: The University of Chicago Press.

Cuban, L. (2013). Inside the black box of classroom practice: Change without reform in American education. Cambridge, MA: Harvard Education Press. 
Deci, E. L., \& Ryan, R. M. (1985). Intrinsic motivation and self-determination in human behavior. New York, NY: Plenum. https://doi.org/10.1007/ 978-1-4899-2271-7

Duhigg, C. (2012). The power of habit: Why we do what we do in life and business. New York, NY: Random House.

Dweck, C. S. (1986). Motivational processes affect learning. The American Psychologist, 41(10), 1040-1048. https://doi.org/10.1037/0003-066X.41.10.1040

Dweck, C. S. (2006). Mindset: The new psychology of success. New York, NY: Ballantine Books.

Eccles, J. (1983). Expectancies, values, and academic behaviors. In J. T. Spence (Ed.), Achievement and achievement motives: Psychological and sociological approaches (pp. 75-146). San Francisco, CA: W. H. Freeman.

Fishbein, M., \& Cappella, J. N. (2006). The role of theory in developing effective health communications. Journal of Communication, 56(Suppl 1), S1-S17. https://doi.org/10.1111/j.1460-2466.2006.00280.x

Gallagher, H. A. (2004). Vaughan Elementary's innovative teacher evaluation system: Are teacher evaluation scores related to growth in student achievement? Peabody Journal of Education, 79(4), 79-107. https://doi.org/10.1207/s15327930pje7904_5

Goldhaber, D., \& Brewer, D. (1997). Why don't schools and teachers seem to matter? The Journal of Human Resources, 32(3), 505-523. https://doi.org/10.2307/146181

Heider, F. (1958). The psychology of interpersonal relations. New York, NY: Wiley. https://doi.org/10.1037/10628-000

Heneman, R. L. (1986). The relationship between supervisory ratings and results-oriented measures performance: A meta-analysis. Personnel Psychology, 39(4), 811-826. https://doi.org/10.1111/j.1744-6570.1986.tb00596.x

Hoxby, C. M. (2002). Would school choice change the teaching profession? The Journal of Human Resources, 37(4), 846-891. https://doi.org/10.2307/3069619

Jacob, B., \& Lefgren, L. (2008). Can principals identify effective teachers? Evidence on subjective performance evaluation in education. Journal of Labor Economics, 26(1), 101-136. https://doi.org/10.1086/522974

Kahneman, D. (2011). Thinking, fast and slow. New York, NY: Farrar, Straus, and Giroux. 
Kane, T. J., McCaffrey, D. F., Miller, T., \& Staiger, D. O. (2013). Have we identified effective teachers? Validating measures of effective teaching using random assignment (MET Project Research Paper). Seattle, WA: The Bill \& Melinda Gates Foundation. Retrieved from https://files.eric.ed.gov/ fulltext/ED540959.pdf

Kane, T. J., Rockoff, J. E., and Staiger, D. O. (2005). Identifying effective teachers in New York City. Paper presented at the National Bureau of Economic Research (NBER) Summer Institute, Cambridge, MA.

Kimball, S. M., White, B., Milanowski, A. T., \& Borman, G. (2004). Examining the relationship between teacher evaluation and student assessment results in Washoe County. Peabody Journal of Education, 79(4), 54-78. https://doi.org/10.1207/s15327930pje7904_4

Knowles, M., \& Associates. (1984). Andragogy in action: Applying modern principles of adult learning. San Francisco, CA: Jossey-Bass.

Labaree, D. F. (2010). Someone has to fail: The zero-sum game of public schooling. Cambridge, MA: Harvard University Press.

Measures of Effective Teaching (MET) Project. (2012). Gathering feedback for teaching: Combining high-quality observations with student surveys and achievement gains. Seattle, WA: The Bill and Melinda Gates Foundation. Retrieved from https://files.eric.ed.gov/fulltext/ED540960.pdf

Milanowski, A. T. (2004). The relationship between teacher performance evaluation scores and student achievement: Evidence from Cincinnati. Peabody Journal of Education, 79(4), 33-53. https://doi.org/10.1207/ s15327930pje7904_3

Nicholls, J. G. (1984). Achievement motivation: Conceptions of ability, subjective experience, task choice, and performance. Psychological Review, 91(3), 328-346. https://doi.org/10.1037/0033-295X.91.3.328

Nordstrum, L. (2015). Effective teaching and education policy in sub-Saharan Africa: A conceptual study of effective teaching and review of educational policies in 11 sub-Saharan African countries. Prepared for the USAID Bureau for Africa under the Education Data for Decision Making (EdData II) project, Data for Education Research and Programming in Africa, Task Order No. AID-OAA-12-BC-00004 (RTI Task 19). Research Triangle Park, NC: RTI International. Retrieved from http://pdf.usaid.gov/pdf_docs/ PBAAF487.pdf 
Peurach, D. J., Glazer, J. L., \& Gates, K. (2004). Supporting instructional improvement: Teacher learning in Comprehensive School Reform (Consortium for Policy Research in Education [CPRE] Working Paper). Philadelphia, PA: CPRE.

Pflepsen, A., Harden, K., Dubeck, M., Sankey, S., \& King, S. (2018). Improving early grade literacy instruction and student outcomes: Findings from a cluster randomized controlled trial in northern Nigeria. Unpublished manuscript.

Podgursky, M., \& Springer, M. (2007). Credentials versus performance: Review of the teacher performance pay research. Peabody Journal of Education, 82(4), 551-573. https://doi.org/10.1080/01619560701602934

Rabin, M., \& Thaler, R. H. (2001). Anomalies: Risk aversion. The Journal of Economic Perspectives, 15(1), 219-232. https://doi.org/10.1257/ jep.15.1.219

Rivkin, S., Hanushek, E., \& Kain, J. F. (2005). Teachers, schools and academic achievement. Econometrica, 73(2), 417-458. https://doi.org/10.1111/ j.1468-0262.2005.00584.x

Rockoff, J. E., \& Speroni, C. (2010). Subjective and objective evaluations of teacher effectiveness. The American Economic Review, 100(2), 261-266. https://doi.org/10.1257/aer.100.2.261

Rowan, B., Camburn, E., \& Barnes, C. (2004). Benefiting from comprehension school reform: A review of research on CSR implementation. In C. T. Cross (Ed.), Putting the pieces together: Lessons from comprehensive school reform research (pp. 1-52). Washington, DC: National Clearinghouse for Comprehensive School Reform. Retrieved from http://www.uky. edu/ gmswan3/609/Cairncross_Mannion_2001.pdf

Ryan, R. M., \& Deci, E. L. (2000). Intrinsic and extrinsic motivations: Classic definitions and new directions. Contemporary Educational Psychology, 25(1), 54-67. https://doi.org/10.1006/ceps.1999.1020

Tversky, A., \& Kahneman, D. (1981, January 30). The framing of decisions and the psychology of choice. Science, 211, 453-457.

United Nations Educational, Scientific and Cultural Organization (UNESCO). (2005). Education for All global monitoring report 2005: The quality imperative. Paris, France: UNESCO. Retrieved from http://unesdoc.unesco.org/images/0013/001373/137333e.pdf 
UNESCO. (2014). Teaching and learning: Achieving quality for all (Education for All global monitoring report 2013/4). Paris, France: UNESCO. Retrieved from http://unesdoc.unesco.org/images/0022/002256/ 225660e.pdf

Vegas, E., \& Umansky, I. (2005). Improving teaching and learning through effective incentives: What can we learn from education reforms in Latin America? Washington, DC: World Bank. Retrieved from https://openknowledge.worldbank.org/handle/10986/8694

Watt, H. M. G., \& Richardson, P. W. (2015). Teacher motivation. In J. D. Wright (Ed.), International encyclopedia of the social and behavioral sciences (2nd ed., pp. 64-71). San Francisco, CA: Elsevier. https://doi.org/10.1016/B978-0-08-097086-8.26082-0

Weiner, B. (1974). Achievement motivation and attribution theory. Morristown, NJ: General Learning Press.

Weiner, B. (1980). Human motivation. New York, NY: Holt, Rinehart, and Winston.

Weiner, B. (1986). An attributional theory of motivation and emotion. New York, NY: Springer-Verlag. https://doi.org/10.1007/978-1-4612-4948-1

Wigfield, A., \& Eccles, J. S. (2000). Expectancy-value theory of achievement motivation. Contemporary Educational Psychology, 25(1), 68-81. https://doi.org/10.1006/ceps.1999.1015 


\section{About the Contributors}

Tifa Asrianti was a communications specialist for the United States Agency for International Development (USAID)/PRIORITAS (Prioritizing Reform, Innovation, and Opportunities for Reaching Indonesia's Teachers, Administrators, and Students) program during 2012-2017. She supported translation, media monitoring, and web updates for the program. She currently works as communications and reporting officer for an off-grid, community-owned renewable energy project in East Sumba, East Nusa Tenggara province, Indonesia.

Stephen Backman is an educator and African studies specialist with numerous experiences in project management in various countries in Africa. He served as the chief of party for RTI International on the Reading for Ethiopia's Achievement Developed Technical Assistance (READ-TA) project from 2014 to 2017.

Adrienne Barnes is a literacy and pedagogy specialist at Learning Systems Institute at Florida State University (FSU). She received her doctoral degree from FSU in 2015, where she also completed the Pre-Doctoral Interdisciplinary Research Training Program as a fellow with the Florida Center for Reading Research. She has supported literacy initiatives in multiple developing countries.

Guy Bostock is an independent education consultant currently based in Monrovia, Liberia. He was the education leadership and management advisor and RTI team leader on the USAID/Zambia Read to Succeed project.

Bonita Cabiles is currently a PhD candidate at the Melbourne Graduate School of Education, University of Melbourne. She completed her master's degree in lifelong learning: policy and management from the Institute of Education,
University College London. Prior to pursuing graduate school, she worked as a project officer for Basa Pilipinas (Read Philippines) Project. She has over 10 years' experience in the field of education and training, including teaching at the primary level, teacher training, and curriculum development. Her research endeavors and professional experiences are inspired by exploring and responding to spaces of marginalization and disadvantage especially in the context of cultural and linguistic diversity.

Nancy Clark-Chiarelli is a principal international advisor and research scientist with expertise in teacher development and literacy. Her investigative work informs the design and implementation of professional development and literacy programs, including those that promote reading, writing, and mother tongue instruction. Ms. Clark-Chiarelli has led research projects, program evaluations, and teacher professional development initiatives both in the United States and abroad. She specializes in creating research-based literacy programs that improve teaching and learning in resource-lean environments. Currently working in Nigeria and Ethiopia, she has also contributed to multiyear, large-scale, USAID-funded teacher education and literacy programs in the Philippines, Rwanda, South Sudan, and Pakistan.

Stirling Cummings is a research statistician in the International Statistics Program at RTI International. He has worked in the field of reproductive health, infectious disease, vital registration, and monitoring and evaluation of health programs for more than 16 years. He has extensive experience working in Anglophone and Francophone Sub-Saharan Africa and the Caribbean. 
Marion Fesmire is a reading instruction specialist; she is a retired research associate in elementary education at FSU's College of Education, Panama City Campus. She has served as a team member on several projects supporting teacher educators and developing early grade reading materials in the United States, Tuvalu, Indonesia, Nigeria, Haiti, and Ethiopia.

Jarret Guajardo is the cofounder of the Teacher Motivation Working Group. He holds a master's degree in international development and international economics from Johns Hopkins School of Advanced International Studies. He specializes in early grade literacy, impact evaluation, and teacher professional development. He is currently the head of evidence and learning for Save the Children International in Cambodia.

Molly Hamm-Rodriguez is a cochair of the Teacher Motivation Working Group. She holds a master's degree in international educational development from Teachers College, Columbia University, and is pursuing a $\mathrm{PhD}$ in educational equity and cultural diversity from the University of Colorado-Boulder. She specializes in multilingual education, immigration and schooling, language issues, and teacher education and professional development.

Karon Harden is a research education analyst in the International Education Division of the International Development Group at RTI. Coming from a background in linguistics, Ms. Harden has more than 20 years' experience in education (12 years in sub-Saharan Africa), including in teaching, curriculum and materials development, teacher training and support, and student assessment.

Simon King is a senior education research analyst at RTI and holds a master's degree in statistics from Texas A\&M University. He has extensive experience in evaluation of education programs in Asia and Africa. Before joining RTI, Mr. King worked as a school principal and teacher of mathematics and statistics in the
United Kingdom, Switzerland, Zambia, The Channel Islands, and North Carolina.

Scott Kipp is an educational technology specialist who provided technical support for RTI-implemented projects, including the Malawi Early Grade Reading Activity's SMS campaign. $\mathrm{He}$ is currently pursuing a $\mathrm{PhD}$ in curriculum studies and teacher development at the University of Toronto.

Dawit Mekonnen, $\mathrm{PhD}$, is an associate professor of education at the Addis Ababa University in Ethiopia. He has supported numerous educational initiatives in Ethiopia, serving as a consultant to the Ministry of Education, the World Bank, and USAID-funded projects. He also served as the national coordinator for the FSU activities in Ethiopia under the USAID/Ethiopia READ-TA project from 2013 to 2017.

Lee E. Nordstrum, is an independent research consultant with more than 12 years of international experience in the field of social science research and policy, inclusive of education, workforce development, and health. He has served as a consultant for UNESCO, the World Bank Group, RTI International, the International Labour Organization, and Discovery Learning Alliance, specializing in teacher quality, teaching training, education finance, incentives and accountability, and impact evaluation. From 2015 to 2018

Dr. Nordstrum was an Education Research Analyst with RTI International's International Development Group, where he led research projects on next generation of student assessment methods; school-related genderbased violence; and investment in early grade reading in low- and middle-income countries in Asia. Before this, Dr. Nordstrum was the Director of the Advancing Teaching-Improving Learning program at the Carnegie Foundation for the Advancement of Teaching in Stanford, CA, where he led a cooperative program of research with the US Department of Education's Institute for Education Sciences on teacher evaluation and quality teaching. 
Kondwani Nyirongo is the monitoring, evaluation, and learning specialist for the USAID-funded Malawi Early Grade Reading Improvement Activity implemented by RTI, having previously served in the same role for the Malawi Early Grade Reading Activity. He is a development economist and monitoring, evaluation, and learning expert who has led the monitoring and evaluation of a number of projects in the sectors of education, health, agriculture, and livelihoods in Malawi and Zimbabwe for over 12 years. He graduated from the University of Malawi with a bachelor's degree in agricultural economics (2005) and earned a master's degree in development and natural resource economics (2011) from the University of Life Sciences in Norway.

Alison Pflepsen, MS, has more than 15 years of experience designing and managing education programs in sub-Saharan Africa. She served as the technical lead for Nigeria Reading and Access Research Activity (RARA) while working at RTI for six years. Ms. Pflepsen currently works at University Research Co., LLC (URC) supporting the Reading within Reach (REACH) initiative and the Global Reading Network to improve early grade reading programming.

Sarah Pouezevara is a senior education research analyst and e-learning specialist within RTI's International Development Group. She supports research, analysis, training, and evaluation of capacity-building and teachertraining initiatives for RTI projects, especially when the use of technology is being applied to improve access to and quality of ongoing professional development.

Mitch Rakusin is a program development specialist and education management information system (EMIS) advisor within RTI's International Development Group. He is currently based in Zanzibar as the EMIS advisor for the USAID/Tanzania Tusome Pamoja ("Let's Read Together") program. He has previously supported RTI-implemented programs in
Zambia and the Philippines in the areas of management systems, school report cards, research and survey design, partnerships, and monitoring and evaluation.

Flavia Ramos-Mattoussi, EdD, is a senior research associate and associate director of the Learning Systems Institute's Center for International Studies in Educational Research and Development at FSU. She served as the principal investigator and project director for the FSU activities in Ethiopia under the READ-TA project. She is a development education specialist and author of The FotoDialogo Method $^{\odot}$ and several educational materials for multilingual and diverse audiences. She is a playwright as well as the author and illustrator of numerous children's books published in Brazil.

Emily Richardson, EdD, is a cochair of the Teacher Motivation Working Group. She holds a doctor of education in international and comparative education from Teachers College, Columbia University, and she specializes in teacher policies and teacher professional development.

Feiny Sentosa was the deputy chief of party for the USAID/PRIORITAS program in Indonesia from 2012 to 2017. Together with the chief of party, she was responsible for managing this $\$ 88.2$ million (USD) basic education project. Its aims were to elevate the quality of teaching and learning in schools through enhanced pre- and in-service teacher training, to improve education management and governance, and to strengthen coordination among all levels of the Indonesian government and its key education institutions.

Timothy S. Slade is the deputy chief of party for the Kenya Tusome Early Grade Reading Activity implemented by RTI, having previously served in the same role for the Malawi Early Grade Reading Activity. Since joining RTI, his work has focused on the design, delivery, and evaluation of reading interventions in various African contexts. He graduated from Alma 
College with a bachelor of science in exercise and health sciences and a bachelor of arts in French language and earned a master's degree in international studies from North Carolina State University and a graduate certificate in early grade reading from the University of Massachusetts at Amherst. He is currently a candidate in the Master of Information and Data Science program at the University of California, Berkeley. 


\section{Index}

A

Achievement goal theory, teacher motivation, 251,300

Activity Theory (Cultural-Historical Activity

Theory), 219-222

description, 220

as framework for fieldwork, 239

limitations of, 234

overview of, $220 f$

applied to peer learning in Indonesia, $226,227 f, 231,232 f, 235$

third generation, 221

use for describing teachers' professional learning, 221, 234

Adaptive expertise, term, 18

Adult education, 15

Adult learning, 4, 207, 237, 299

Andragogy, 12, 207

see also Adult education

see also Adult learning

Annual Status of Education Report (2012), 293

Attribution theory, 302-305

\section{B}

Balanced coaching model, 171-172, $172 t$

Bangladesh, 279

Bandura, Social cognitive theory

Basa Pilipinas program (Philippines), 13, 107, 296

active learning, use in training, 124

approach to professional development, 108-110, 296

content focus of training, 122-123

duration of teacher training, 125

evaluation design, 113

language and literacy instruction results,

$118 t, 119-122$

oral reading and comprehension skills

(effect on), 114-117

teachers' instructional practices (effect

on), 117-122

video, use in teacher training, 122-123

see also Philippines
Behavior

predictable patterns of, 306f, 306-307

risk aversion and prospect theory, 305-307

see also Teacher behavior change

Better Education Through Reformed

Management and Universal Teacher

Upgrading, 213-214

Bill \& Melinda Gates Foundation, 292

British Council, 213

Brookings Institution, 210

C

Cambodia, 279

Career

continuing professional development, $9 f$ career-wide learning, 3, 10, 11, 15, 17,

ladder, trajectory, career development, 5, 191, 192, 227, 255, 257

teaching career, teaching span, $17,44,219$, 250,253

Certification, 67

Change. See Teacher behavior change

"Chunking", 295

Cluster(s)

in Indonesia, 13, 16, 212, 213, 215, 222-226, 227f,

in the Philippines (see Learning Action Cell)

randomized controlled trial, 181

school-clusters, 206, 208-210

training, cluster meetings, cluster-based professional development, 12, 178, $180,205,215,239,240$

see also Gugus

see also KKG/MGMP

Coach(es)

background characteristics, 172-173, 182

background's influence on performance, 190-192

characteristics of effective support, 172-175

influence of quantity vs. quality on

support, 192-194 
Coach(es) (Continued)

intervention coach training and support, 178-179

relationship between background and quality of coaching, 187, 188t

relationship between background and teacher instructional practices, $188,189 t$

relationship between quality of coaching and teacher instructional practices, 189-190, 190t

relationship between quantity of visits and teacher instructional practices, $188-189,189 t$

\section{Coaching}

addressing teacher performance, 208-209

common model of, 208

data sources, 176-181

definition, 169

effectiveness of, 169-170

findings from research, 186-190

hard, soft and balanced models,

171-172, 172t

intervention model, 177-178, 300

intervention results, $180-181$

items measuring gains in teachers' instructional practices, $186 t$

leadership practice variables, $80,80 t$

limitations of research, 194-195

literacy intervention in Nigeria, 170, 195-196, 296

models of, $170-172$

peer, 209-212

practices for fostering change, 174-175

professional development through, 133-135

quality of, 173-175, 183-185, 191

quantity of, 173, 183

teaching practice, 208, 300-301

term, 209n1

visits by EGRA primary education advisors (PEAs), $134 f$

what coaches do, 170-171

see also Quality coaching

Coherence, 12, 124-125

Collaboration

in coaching, 174, 191, 208

need for, 4

parent and teacher, 278

as professional development, collaborative learning, $13,40,80,98$, 101,210 in professional development in colleges of teacher education, Ethiopia, 33-34, $40-42,46,49,52$

among students, 226

among teachers in school, 266, 275

see also Communities of learners

see also Peer learning

Collaborative leadership

archetype, 74-74

dimensions, 70

practices and practice variable, $69,73-75$,

$74 t, 80,80 t, 90,93$

Communities of learners

communities of practice, $3,7,9 f, 11,13$, $70,112,206$

Ethiopia, 48-49, 51-52

learning communities, 3, 31, 48, 51-52, 70

see also Cluster(s)

see also Learning Action Cells

Community, 9f, 10, 69, 74, 85, 112, 137, 170, $221,227 f, 267,274$

community-school preference variable, $78 f, 85-86$

engagement, mobilization, $68,74,97,131$, 276,277

participation, $9 f, 68$

service, 215

Comparative and International Education

Society, 2016 conference, 5

Continuous professional development

(CPD), $9 f$

in-service, 215, 296

leadership practice variable, $80,80 t$

peer learning for improving, 227-229

policy for, 16

school supervisors, $224 \mathrm{n} 3$

teacher participation, 224, 230

see also Professional development

Corporate social responsibility (CSR), Early

Grade Reading Activity (EGRA), 152

CPD. See Continuous professional development (CPD)

Creative Associates International, 68, 70

Cultural-Historical Activity Theory, 219-222 see also Activity Theory

D

Data, 11, 35

analysis of, 8, 37, 126, 147, 154-155, 170,273

classroom observation data, $35,69,113$, 156,185 
collection tools, $35,47,49,79,113-114$, 141f, 176f, 181f, 194-195, 206, 212, $217 f, 233,234,264,276,290$

for decision making, 69-70, 126-127, 234-236, 292

focus group, 212, 222-232, 233 interview, 7, 16, 35, 36, 79, 81, 88-89, 96-97, 162, 182, 206, 212, 264, 266, 268

leadership, 90-95, 100, 212

performance, $82 f, 115-122$

resource allocation, 45

survey, 11, 36, 78, 79, 98-99, 249

school, 67, 76, 82f, 88, 96f, 206, 224, 264

student assessments, 69, 264, 293

teacher coaching, 133, 161, 170, 175, 178, 180, 183-185, 192, 195

teacher education, $24,35,37,45,47$

Database of school statistics, 83

Direct effects model discussion and limitations from large-scale survey, 97-98 school leadership, 72, 75

Direct effects test, quality of research design, 98

Distributed leadership, description, $74 t$

Diversity, 3, 257

\section{E}

Early Grade Reading Activity (EGRA) distribution of coaching visits, $134 f$ intervention schools receiving coaching, 134t

Learning Gains instrument, 141-142, $142 t$

limitations of intervention design, 154-157

Malawi, 131, 131n1, 141

short message service (SMS) as component of professional development, 135-139

Early Grade Reading Assessment (EGRA), $113,131 n 1$

Ethiopia, 25

Filipino grade 2 results, $115 t, 117 f$

Hausa language in Nigeria, 176-177

whole model effects of changes in, $96 t$, 96-97

Zambia School Gateway, 82, $83 t$

EDOREN (Education Data, Research and Evaluation in Nigeria), 111-112

Education 2030 Framework for Action, UNESCO, 249, 279
Education Development Center, Inc.

(EDC), 107

Education for All Global Monitoring Report (2013-2014), 293

Education leadership archetypes, 73-75

models of, $72-73$

Zambia, 66-70

see also School leadership

Education Sector Development Plan for 2010-2015, Ethiopia, 16

Education Sector Development Program, Ethiopia, 53-56

EGRA Plus, Liberia program, 133

Ethiopia, 1, 2, 3

background and context of primary education in, 25-26

barriers to revised Mother Tongue program, 44-47

Education Sector Development Plan (2010-2015), 16

Education Sector Development Program, 53-56

institutional structure, 34

languages, 24n2, 45, 295

lifelong learning, 16-17

literature review of teacher education, 30-34

modeling and simulations, 32-33

participants' summary, $37 t$

policy implications for teacher education reforms, 53-56

pre-service teacher education in, 26-27

READ-TA program, 24

region states, $25 \mathrm{n} 3$

resource availability, 34

student teachers, 26

target languages of instruction, 25

teacher educator impact on student teachers' preparation, 42-44

teacher educators, 27, 37-44

teacher motivation, 256

teachers in training, 12, 295, 300

see also Mother Tongue Language

Program, Ethiopia

Ethiopian Ministry of Education, 25

Expansive learning, 220

Expectancy-value theory, teacher motivation, 251,300

Expertise, building, 17-19

Extrinsic motivation, 206, 251-252 
F

Fixed mindset, 303, 304

Florida State University (FSU)

Mother Tongue Language Program module development, 27-30

READ-TA program and, 26

\section{G}

Gateway, Zambia School. See Zambia

Ghana, teacher motivation, 256, 257, 258

"Ghost teacher" phenomenon, 132n2

Goal setting, leadership practice variable, $80,80 t$

Growth mindset, 302-305

Guidance and counseling center of excellence, $82,83 t$

Gugus, 13, 213, 215

\section{H}

Hard coaching model, 171-172, $172 t$

Head teacher, head of school, 3, 124, 161, $138 t$

experience as head teacher, in coaching, 188

in the Philippines, 125

responsibilities, in Zambia, 67

training, 276

Health and Literacy Intervention (HALI) project, Kenya, 141, 160

Health sector

interventions for medicinal adherence, 140

model of behavior change, 297, $298 f$

Herzberg's two-factor model, motivating and hygiene factors, 17, 257

Hygiene factors, Herzberg's model, 17, 257

\section{I}

Improvement, definition of, 18

India, 3

Annual Status of Education Report (2012), 293

teacher motivation, 270-273, 273, 275

Teacher Motivation Diagnostic Tool, use in 14, 261-262, 264, 270-273, 278, 297

teacher motivation survey, 11-12

teachers and self-efficacy, 269-270, 273

teachers' ideas for motivational support, $275,276 t$

teachers' reported classroom challenges, $269,269 t$

teachers' reported perceptions of self-efficacy, $274 t$ teachers' reported time on daily tasks, $267 f$

teachers' reported time on weekly extra responsibilities, $268 f$

teachers' working conditions and challenges, 266-270

see also Teacher motivation

Indirect effects model, school leadership, $72-73$

Indonesia, 1, 3

activity system of peer learning, $227 f$

ethnographic research in 1998-1999, 236

function of communities, 7

ongoing learning, 11

peer-learning, 7

PRIORITAS (Prioritizing Reform,

Innovation, and Opportunities for Reaching Indonesia's Teachers, Administrators, and Students), 13, 205-206, 296

school clusters, 212

school supervisors, $224 \mathrm{n} 3$

teacher motivation, 257

teacher professional development in, 12 , 213-215, 237

USAID/PRIORITAS and lesson-study model, 215-216, 231, 239

see also Peer learning

Initial Primary Teacher Education, Malawi, 132

Instructional change see Behavior see Teacher behavior change

In-service training. See Teacher education

Instructional coaching, teachers, 10-11 see also Coaching

Instructional conservatism, 306

Instructional leadership, 66 description, $74 t$

education, 73-75

effectiveness factor, 81

Instructional methods, teacher educators, 39-40

Instructional practices. See Teacher instructional practices

Instructional reform, difficulty of, 293-295

Integrated leadership

effectiveness factor, 81

notion of, 75

Integrated model of behavior change, 297-301, $298 f$

International Education Division, RTI, 4 
International Literacy Association, 172, 192

International Reading Association, 172

Intervention coaching model, 177-178 coach training and support, 178-179 results, 180-181

teacher training and support, 179-180

Intrinsic motivation, 206, 251-252

Iran, teacher motivation, 256

\section{J}

Jamaica, teacher motivation, 257-258

Job satisfaction

definition, 254

teacher motivation, 253-255, 258

Jordan, 258, 307

\section{K}

Kenya, 3

Health and Literacy Intervention (HALI), 141

Primary Math and Reading (PRIMR) initiative, 141

teacher motivation, 257

KKG/MGMP (kelompok kerja guru/ musyawarah guru mata pelajaran)

activity system, 222

lesson-study model, 215-216, 231, 239

meetings, 224-225, 226, 229, 233, 234

peer-group functioning, 222-223

L

Languages

Ethiopia, 24n2, 45

see also Mother Tongue Language

Program, Ethiopia

Leadership effectiveness

correlation between leadership practices and, 89-91, 91f

differences in pilot and large-scale, 81-82

by early grade teachers and head teachers, $92 f$

overall integrated, 93-94

positive behaviors, 99-100, $100 t$

variables, $80-82$

vs. school performance, $94 f$

Leadership practices

correlation between leadership effectiveness and, 89-91, 91f

by early grade teachers and head teachers, $92 f$ positive, 99-100, $100 t$

variables, $80,80 t$

Learner performance improvement plans

(LPIPs), Zambia, 69-70

Learning Action Cells, 13, 108-109, 125, 127

see also Clusters

Learning communities, Ethiopia, 48-49, 51-52

Learning Gains instrument, Malawi features of, $142 t$

respondent scores, $145,146 t$

Learning outcomes, school leadership influencing, 71-72

Lesson-study model, USAID/PRIORITAS and, 215-216, 231, 239, 240, 296-297

Liberia, EGRA Plus, 133

Lifelong learning, 14

concept of, 15

self-directed, 15-17

Literacy, term, 24

Literacy achievement instructional goals and objectives, $109 f$ theory of change, 109-110

Literacy Boost, 261

Literacy intervention or program

Nigeria, 170, 195-196, 296

Philippines, 108-110, 117-122

Literature review

coaching, 170-175

influence of leadership on learning outcomes, 70-76

literacy professional development, 111-113

messaging technologies for training, 139-141

peer coaching, 209-212

professional development of teacher educators, 31-32

teacher education, 30-34

teacher effectiveness and student achievement, 110

teacher motivation, 251-261

teacher preparation, 206-209

Zambia and school leadership, 70-76

Load, 254, 268

Local Content Curriculum program, 214

\section{M}

Margin, McClusky's theory of, 13-14, 254

Malawi, 2, 3

addressing professional development through coaching, 133-135 
Malawi (Continued)

currency, 152n5

Early Grade Reading Activity (EGRA),

131, 131n1, 141

early reading outcomes in, 132

introducing short message service (SMS),

131, 135-136, 296

Ministry of Education, Science, and

Technology (MOEST), 131, 133

program implementation, 7

teacher motivation, 259, 300

teacher-training workshops, 10-11

see also Short message service (SMS)

Maldives, teacher motivation, 257

Margin of power, 254

Maslow's hierarchy of needs, 13-14, 254

McClusky's Power Load Margin theory, 254

Measures of Effective Teaching (MET)

Project, Bill \& Melinda Gates

Foundation, 292-293

Mentoring, term, 209n1

Mindset theory

behavior change, 302-305, 308-309

fixed mindset, 303, 304

growth mindset, 303, 304

Ministry of Education, Ethiopia, 27, 28, 45, $46,52,55,56$

Ministry of Education, Science and Technology (MOEST)

Malawi, 131, 133

primary education advisors (PEAs), 131, $134 f, 136$

Ministry of Education and Culture, Indonesia, 235

Ministry of General Education, Zambia, 67-68

Modeling and simulations, Ethiopia, 32-33

Module development, Mother Tongue Language Program, 27-30, 295

More Effective Decentralized Education Management and Governance (MBE1 and MBE2), 214

Mother Tongue Language Program, Ethiopia barriers to implementation and sustainability of revised, 44-47

collaboration, 46-47

course scheduling, 46

external funding, 47

fieldwork, 46

FSU team revising, 26, 49-50

impact on student teacher quality, 43-44

institutional obstacles, 44 limited resources of, 44-45

process of module development, 27-30, 295

steps for materials development, 29-30

teaching practices in, $41 f$

technology challenges, 45-46

see also Ethiopia

Motivating factors, Herzberg's two-factor model, 17, 257

Motivation. See Teacher motivation

\section{$\mathrm{N}$}

National Adult Education Strategy, Ethiopia, 16

National Certificate of Education, Nigeria, 182

Nigeria, 3, 6

Early Grade Reading Assessments

(EGRAs) in Hausa language, 176-177

instructional coaches, 11

literacy intervention in, 170, 195-196, 296

Reading and Access Research Activity

(RARA), 176-177, 290, 290-291

teacher motivation, 257, 258, 300

see also Coaching

O

Occupational learning, 17-19

On the job, training programs, 13

Organisation for Economic Co-Operation and Development (OECD), 207, 210

P

Pakistan, teacher motivation, 256

Peer coaching, literature review, 209-212

Peer learning, 205

activity system in Indonesia, $227 f$

cascade model, 238

cluster/community-of-practice activities, $230-232$

cluster meetings, 238

knowledge transfer in classroom, 225-226

Learning Action Cells, 13, 108-109, 125, 127 mentoring through USAID/PRIORITAS, 205-206

motivating teachers to engage in, 229-230

opportunity for improving professional practice, 227-229

peer coaching model, 209-212

peer-group functioning, Indonesia, 222-224 
recommendations for successful models, 239-240

Tanzania, 210, 211

USAID/PRIORITAS and lesson-study model, 215-216, 231, 239, 296-297

Philippines, 1, 3

Basa approach to professional development, 108-110, 122-126

Basa intervention after two years, 114-117

Basa Pilipinas program, 13, 107, 296

Filipino oral reading fluency by school year, $116 f$

grade 2 reading comprehension by school year, $117 f$

introduction of Filipino and English by grade, $123 t$

teachers in training, 12, 296, 300

teachers' practices in teaching students to read, 117-122

teacher-training model, 7

teacher-training workshops, 10-11

see also Basa Pilipinas program (Philippines)

Power Load Margin theory, McClusky, 254

Primary education, background and context in Ethiopia, 25-26

Primary Literary Program (PLP), Zambia, 66, $68,81-82,100 t, 101$

Primary Math and Reading (PRIMR) initiative, Kenya, 141, 160

PRIORITAS (Prioritizing Reform, Innovation and Opportunities for Reaching Indonesia's Teachers, Administrators, and Students), 13, 205-206

USAID/PRIORITAS and lesson-study model, 215-216, 231, 239, 240, 296-297

Prioritization of needs, concept of, 14

Professional development addressing through coaching, 133-135 Basa approach, 108-110, 122-126, 296 continuing (CPD), if evaluations, 36 facilitator model of, 235 impact on teacher educators' belief and practices, 37-42

influencing, 8-9

key features of literacy, 112-113 motivating teachers engagement in peer learning, 229-230 promoting ongoing, 50

short message service (SMS) as component of, 135-139

teacher, in Indonesia, 213-215

teacher motivation, 259

teachers as adult learners, 12-14

see also Continuous professional development (CPD)

Progressivism, 295

Project MIND (Mobile Technology Initiatives for Nonformal Distance Education), 141

Promoting Literacy for Children Project (Pro-Lit), 262, 264

Prospect theory

achievement goals as reference points, 305

behavior change, 305-307, 309

endowment effect, 305

loss aversion, 305

predictable behavior patterns, $306 f$, 306-307

Pupil learning, conceptual theory of change, 109-110

Q

Qualitative assessment tool, Zambia data, 230, 234

Qualitative research method, 212, 213, 218,264

Quality coaching data for, 183-185

definition, 173

influence of quantity versus, 192-194

limitations of measurement, 194-195

measuring, 191-192

observation items of coach-teacher visits measuring, $184 t$

relationship between coach background and, $187,188 t$

Quality teaching

behavior change and, 293-295

distribution of, 292-293

importance of, 289-291

model of teacher behavior, 297-301

supply in developing nations, 249-250, 276-277

Qualtrics, 37

R

Reading and Access Research Activity

(RARA), Nigeria, 176-177, 290-291 
Reading for Ethiopia's Achievement Developed Technical Assistance (READ-TA) program, 24 aligning pre-service teacher education with country-based policies, 53 approach, 25-26, 34, 56 module development and training, 38-39 participation in, 41 professional development, 48-50 student teachers' perceptions, 43-44 teacher educators' perceptions, 42-43 technical assistance, 54 technology challenges, 45-46

READ-TA. See Reading for Ethiopia's Achievement Developed Technical Assistance (READ-TA) program

Read to Succeed (RTS) Project, Zambia, 66, 68-70, 81-84

Regional State Education Bureaus, Ethiopia, $27,45,52$

Routine expertise, term, 18

RTI International, 4, 5, 26, 307

Gooseberry software system, 156n6

Tangerine:Tutor ${ }^{\circledR}$ platform, 162

\section{$S$}

Save the Children, 5, 250, 259, 262, 264, 278-279

Save the Children-World Vision "Literacy

Boost Partnership", 261-262

School leadership

assessment of, 75-76

collaborative leadership, 73-75

direct effects model, 72

direct effects test, 76-77, $77 f$

hypothesis, 76

impact on instructional change, 65

indirect effects model, 72-73

influence on learning outcomes, 71-72

instructional leadership, 73-75

large-scale survey, 79

leadership effectiveness variables, $80-82$

leadership practices variables, $80,80 t$

learning outcome measures, $84,85 t$

literature review, 70-76

methodology for research, 76-87

mixed-methods research design, 78-79

models of effective, 72-73

pilot qualitative assessment, 78-79

purpose of studying effects from Zambia, 65-66

research questions, 76 sampling plans, $87,88 t$

school performance measures, $82-84,83 t$

transformational leadership, 73-75

whole model test, 77, 78f, 84-87

Zambia, 11, 17, 296

School performance, measures of, $82-84,83 t$

School support officers (SSOs) intervention coaching model, 177-178 literacy intervention sample, 181-186

SCOPE-Literacy. See Standard Classroom Observation Protocol for EducationLiteracy (SCOPE-Literacy)

Self-assessment, teacher educators, 40

Self-determination theory, teacher motivation, 251, 300

Self-directed, lifelong learning, 15-17, 211

Self-efficacy

teacher motivation, 253, 258

teachers and, 269-270, 273

teachers' reported perceptions of, $274 t$

Self-reflection, building sustainability, 33-34

Shared leadership, description, $74 t$

Short message service (SMS)

as component of professional development, 135-136

costs of SMS intervention, 151-154, $152 \mathrm{n} 5,152 t, 153 t$

design of SMS intervention, 136, 138-139

EGRA SMS traffic during campaign, 150, $152 t$

as entry point for changing teacher practice, 159-160

exploration of teachers' SMS-sharing behaviors, 158, 158-160

integrating SMS interventions into teacher coaching processes, 161-163

intervention, 131

limitations of intervention design, 154-157

literature review, 139-141

message themes, counts and examples, $137 t-138 t$

regression models controlling nonintervention factors, 150, 151t

role in design of teacher-training strategies, 160-161

self-reported SMS receipt and sharing, $149 t$

sharing among teachers, 147, 149t, 150-151

social learning and, 158-160 
teacher knowledge retention and, 145, $146 t, 147$

see also Malawi

Social Cognitive Theory, Bandura's, 252-253

Soft coaching model, 171-172, 172t

Somalia, teacher motivation, 256

South Africa, teacher motivation, 259

South Asia, teacher motivation, 256

Sri Lanka, teacher motivation, 257

Standard Classroom Observation Protocol for Education-Literacy (SCOPE-

Literacy), 113-114

classroom structure results, 119

graphic depiction of changes, $119 f$

language and literacy instruction results, $118 t, 119-122$

ratings of classroom instruction, $118 t$

Stanford University, 140

Student achievement, teacher effectiveness and, 110, 289-290

Student teachers

Ethiopia, 26

focus group discussions, 36

perceptions, 43-44

term, 24

Sustainability revised Mother Tongue Language

Program, 44-47

self-reflection and collaboration building, 33-34

Sustainable Development Goals (SDGs), 4 education, 23-24

goal, 4

global objective of, 14

release of 2016, 2

SDG 4 target, 14, 23n1, 249

supplying qualified teachers, 258

\section{$\mathrm{T}$}

Tangerine:Tutor ${ }^{\circledast}$ platform, RTI's, 162

Tanzania, 1, 2

assessment of "3Rs", 291

peer learning program, 210, 211

Technology, 4, 18, 30, 38, 43, 44, 45-46, 55, $56,139,157,158,194,289$

Teacher(s)

as adult learners, $12-14$

continuing professional development, $9 f$

learning over the course of career, 9-12

pedagogical content knowledge, 111

short message service (SMS) sharing among, 147, 150-151
SMS and knowledge retention, 145, 147 supply in developing nations, 249-250, 276-277

Teacher behavior change

attribution theory, 302-305, 308

coaching, 208

descriptive studies, 6-7

difficulty of, 293-295

experimental studies, 7-8

influencing professional development, 8-14

integrated model of, $298 \mathrm{f}$

international contributions to research, 307-308

mindset theory, 302-305, 309

model of, 297-301, $298 f$

occupational learning and building expertise, 17-19

prospect theory, 305-307, 309

researching, 6-14

risk aversion, 305-307

secondary analysis of data, 8

survey research, 6-7

teachers as adult learners, 12-14

term, 19

understanding how to influence, 6-8

Teacher Development Center, 133

Teacher education

aligning pre-service, with country-based policies, 53

learning over the course of career, 9-12

pre-service, in Ethiopia, 26-27

pre-service reforms in Ethiopia, 53-56

in-service, 68

teaching practices of Mother Tongue classrooms, $41 f$

Teacher educators

changing teaching practices of, 48-50

collaboration, 40-42

communities of learners, 51-52

conducting further research on, 52-53

in Ethiopia, 27

impact of professional development on

beliefs and practices, 37-42

instructional change of, 10

instructional methods, $39-40$

modeling and simulations, 32-33

module development and training, 38-39

observation and support, 51

perceptions, $42-43$

preparing for "unlearning and relearning", 50 
Teacher educators (Continued)

professional development of, 31-32

recommendations for, 50-53

self-assessment of, 40

self-reflection and collaboration for

sustainability, 33-34

semi-structured interviews with, 36

surveys, 36

term, 24

Teacher effectiveness, student achievement and, 110

Teacher instructional practices

data for teachers' gains in, 185-186

influence of quantity vs. quality of coaching support, 192-194

observation items measuring gains in, $186 t$

percentage of teachers implementing, $187 f$

relationship between coach background and, $188,189 t$

relationship between coaching quality and, 189-190, $190 t$

relationship between quantity of coach visits and, 188-189, 189t

see also Coaching

Teacher Law (2005), 232, 237

Teacher motivation

achievement goal theory, 251

definition, 250

engaging community and parents,

277-278

expectancy-value theory, 251

ideas for motivational support, $275,276 t$

India, 270-273

intrinsic and extrinsic motivation, 251-252, 254-255

job satisfaction, 253-255, 258

literature review, 251-261

in low- and middle-income countries, 255-260

research gaps, 259

self-determination theory, 251

self-efficacy, 253, 258, 277

self-efficacy perceptions, $274 t$

Social Cognitive Theory, 252-253

supply of quality teachers in education, 276-277

systemic factors, 253-255

teacher well-being, 253-255

theories grounded in psychology, 251-253

Teacher Motivation Diagnostic Tool, 14, 17, 259

behavior towards students, 272 characteristics of sampled teachers, $265 t$, 265-266

conceptual framework of, 260-261

conducting in two Indian states, 262, 264

context of, 262,264

India, 270-273, 278, 297

Indian teachers' working conditions challenges, 266-270

limitations of, 275-276

methodology, 261-262

overview of, for India, $263 t$

sampled teachers agreement with belief statements, $271 t$

sampling method for India, 264, $265 t$

Save the Children and World Vision

International, 278-279

see also India

Teacher Motivation Framework of Analysis, 260-261

Teacher Motivation Working Group, 5, 250

Teacher preparation

addressing through coaching, 208-209

challenge of, 206-208

literature review, 206-209

Teacher quality, 249. See also Quality teaching

Teacher well-being, teacher motivation, 253-255

Training, teacher. See Teacher education

Transformational leadership

description, $74 t$

education, 73-75

effectiveness factor, 81

Tusome literacy program, Kenya, 3

U

Uganda, 1, 2, 208

United Kingdom, Department for International Development, 66

United Nations Educational, Scientific and Cultural Organization (UNESCO), Education 2030 Framework for Action, 249, 279

United Nations Sustainable Development Goals, 23, 249. See also Sustainable Development Goals (SDGs)

United States Agency for International Development (USAID)

Basa funded by, 107

Early Grade Reading Activity, 7

Education Strategy Progress Report (2010-2015), 2 
funding Nigeria Reading and Access

Research Activity (RARA), 176

funding READ-TA program, 24

Malawi Early Grade Reading Activity

(EGRA), 131

programs, 5, 6, 66, 134

USAID/PRIORITAS and, 13, 205-206,

215-216, 222-223, 233-234, 296-297

Zambia's Primary Literacy Program

(PLP), 66, 68

University of London, 213

University of Pittsburgh, 70

USAID. See United States Agency for International Development

(USAID)

\section{V}

Vanderbilt Assessment for Leadership in Education, 79

Vietnam, 279

Vision, leadership practice variable, $80,80 t$

\section{W}

Whole model test antecedent variables, $85-86$ changes in grade 2 and grade 3 oral reading fluency (ORF), 95, $95 t$ curricular knowledge, 86-87 discussion and limitations of, from large-scale survey, 98-99 learning outcome measures for, $84,85 t$

mediating-condition variables, 86

meta-analysis of, changes in EGRA ORF, 96t, 96-97

methodology, 94-95

Workshops, teacher-training, 10-11, 207

World Bank, 66, 214

World Vision International, 250, 259, 262, 264, 278-279

\section{Z}

Zambia, 3, 296

education leadership, 66-70

learner performance improvement plans (LPIPs), 69-70, 100-101

literature review, 70-76

ongoing learning, 11

Primary Literacy Program (PLP), 66, 68, 81-82

Read to Succeed (RTS) project, 66, 68-70, 81-82

research design, 7

school leadership, 11, 17, 296

studying leadership effects from, 65-66 see also School leadership

Zambia School Gateway, 68-69, 82 performance data, 97 school performance rating criteria, $83 t$ Zimbabwe, teacher motivation, 258

Zonal Education Bureaus, Ethiopia, 27, 52 


"Helping teachers to improve their practice is at the center of improving learning outcomes. This volume brings together insights from researchers who have gotten their hands dirty with implementation and sheds light on topics ranging from school leadership to text messages, from Zambia to the Philippines. This is a great resource for how countries are innovating around the world in supporting their teachers, with lots of ideas for systems that are seeking to improve."

—David K. Evans, Lead Economist, Office of the Chief Economist for Africa, World Bank

"These compelling and comprehensive case studies of teacher behaviour change in such different contexts make invaluable reading for practitioners in our space. The emphasis on the gaining of mastery and achieving lifelong learning for teachers, added to a behavioural approach, adds enormous and exciting new ground."

—Sharath Jeevan, Founder \& CEO, STIR Education

"SDG4 notes the key role of teachers in the achievement of education for all. This book is based on the kind of analysis and understanding that comes from experience. on Insights on teachers' practice, motivation and behaviour provide unique inspiration and guidance for practitioners supporting teaching and learning."

\section{RTI Press}

